\title{
IMPROVING POLICY CAPABILITY AND \\ THE QUALITY OF POLICY ADVICE WITH INITIATIVES: \\ LESSONS FROM NEW ZEALAND PUBLIC SECTOR AGENCIES
}

by

Khandaker Aftab Jahan

\begin{abstract}
A thesis
submitted to the Victoria University of Wellington in fulfilment of the requirements for the degree of Doctor of Philosophy
\end{abstract}

Victoria University of Wellington 2019 


\section{Acknowledgements}

In this roller coaster journey to the end, I realised motivation and perseverance played essential roles. My supervisors, Professor Claudia Scott and Dr Amanda Wolf, motivated me the most. Their interest to my research, critical views on my arguments, guidance by asking relevant and intriguing questions, supply of more information about the topic, careful reading of my drafts and suggestions and overall, challenge and support of my work motivated me to learn. It was indeed a pleasant and proud one. I am sincerely grateful to them.

I persevered with my research because obtaining the prestigious $\mathrm{PhD}$ degree has been, along with mine, a dream of my parents who had left this mundane world. They wanted their son to become the first PhD degree achiever in the family. The companionship of my daughter and wife kept me inspired during this journey. Notably, my daughter Ahneta Aftab for who I wanted to set examples by studying from home in the evening.

My research is indebted to the contributions of Rob Laking, John Martin, and Dr Roderic Alley who showed their sincere interest to this research and encouraged me. They pointed out the relevant and important issues for the New Zealand public sector that the research required to address.

I am grateful to my all PhD colleagues, especially to Endah Setyaningsih, with who I shared my research and the unavoidable stresses that came along. I thank them for hearing me patiently, sharing their stories and showing way-outs. I like to convey my gratitude to Ali Azwar, my best friend and a PhD Candidate, whose extended support, be technical or mental or personal, cannot be compensated. I am thankful to Mpaphi Tsholofelo, PhD candidate, to keep me cheered. He read some of the crap drafts but always, not often, identified them as 'wonderful'. Had there been no support from my colleagues and friends, I wonder if it was at all possible to complete such a big task. I cannot emphasis more on their support. 
Some Ministers' claim of I am just as good as the advice I receive from my policy staff, can almost be resonated here: my research is as good as the contributions of my interviewees. The credit for any richness from diverse views, in this thesis, entirely, goes to the interviewees who were extremely kind to allocate sufficient time for the interviews, despite being busy in their work.

I like to thank Professor Claudia Scott to help identify the potential interviewees and connect me with them. I am also indebted to her for gradually drawing my attention to this research topic which is, undoubtedly, an exciting and timely for the New Zealand public sector.

I like to sincerely acknowledge the support I have received from Dr Amanda Wolf. She has honestly been a supervisor, guide, mentor, research expert, quick responder, friendin-need, an editor and what not. I sincerely thank her.

I like to thank Victoria University of Wellington to support me financially through Victoria Doctoral Scholarship and PhD Submission Scholarship. 


\begin{abstract}
There continues to be discourse about declining policy capability at high government levels in Australia, the United Kingdom and New Zealand. Over the past 25 years, New Zealand public sector agencies have taken various initiatives intended to change policy practices with a view to professionalising policy analysis and advice. Policy practice refers to the activities of policy staff and agencies to contribute to policy analysis and policy advice. The initiatives indicate an ongoing resolve to improve policy capability and the quality policy advice to the satisfaction of advice clients.
\end{abstract}

This thesis examines the initiatives developed by the central government agencies and three agencies (two policy ministries and one council, a local government, which are collectively referred to as 'agencies') in New Zealand. The central government initiatives developed between 1990 and 2015 are examined to identify the concepts and ideas used to improve policy capability and the quality of policy advice and explain the contexts that influenced the initiators' choice and use of initiatives. The initiatives developed between 2008 and 2015 by the Ministry of Transport, the Ministry for the Environment and the Auckland Council are examined in depth to identify and explain the initiators' choice and use of initiatives. 'Initiatives' are used as a means to study organisational choices and activities, centred on the development, use and consequences of initiatives to build, improve or maintain policy capability and ensure high-quality policy advice. The research question addresses what initiatives are developed, why and with what consequences.

A qualitative inquiry draws on evidence from the literature on policy analysis, policy advice and policy capability, focusing on the knowledge, skills, competencies and behaviours required to produce policy analysis and advice. Similarities and differences in the drivers, designs and approaches of the initiatives across three cases are analysed using data from documents and interviews with policy staff and experts outside the case-study agencies.

The findings relating to central agency initiatives suggest that the focus of policy capability initiatives sought to standardise policy practices, ensure the quality of policy 
inputs with special attention to the use of evidence, tools and frameworks, bring a future focus to policy analysis, and promote collaborative policy analysis. Overall, these initiatives respond to the contextual conditions emanating from state sector reforms.

The findings relating to agency initiatives suggest that policy capability initiatives are driven, approached and designed by the circumstances specific to the organisations (internal influences) and the expectation-response relation between the producers of and clients for policy advice at different levels (external influences). The similarities of the forms of the initiatives with slight modifications in their design but differences in their approaches across the organizations, imply that the initiators are influenced by the contextual conditions.

The initiators' used their insights and experiences to contextualise initiatives and mixed several ingredients for policy capability to ensure both policy analytical and management capability of policy staff. In some instances, they followed local and international practices considered 'effective' in other public-sector organisations. At other times, they responded to the circumstances specific to the agency and external influences on policy capability, and focused on meeting the clients' quality expectations from policy advice.

The findings confirm that improving policy capability is strongly reliant on the senior leaders' and policy managers' ability to identify and apply an appropriate analytical style to policy analysis and bring practical and contextual considerations to bear on policy advice. The appropriateness of the analytical style is determined by a range of factors such as the nature of clients, nature of the problem, political views on the problem, and the demand and supply of policy skills.

The significant influences of contextual variables suggest that policy capability discourse can also be framed as the ability of the policy managers and senior leaders of the organisations to choose policy analytical styles that are fit-for-purpose. This conclusion reveals that the conventional understanding of declining policy capability as due to analytical deficiency is limited in its ability to account for the innovative efforts in New 
Zealand to improve both policy analytical and management capability at individual and organisational levels. 


\section{Table of Contents}

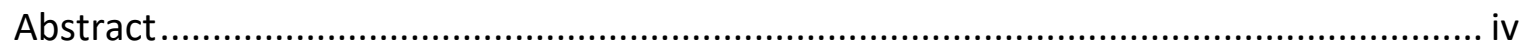

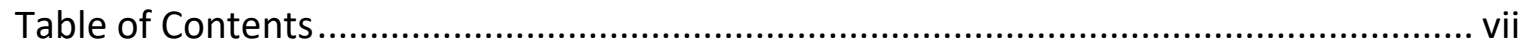

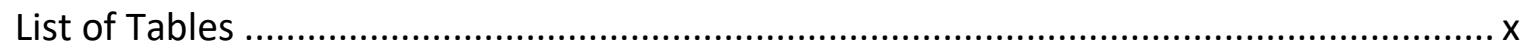

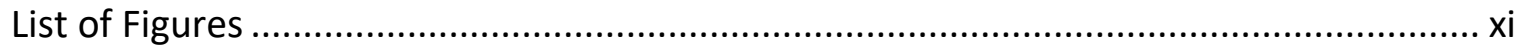

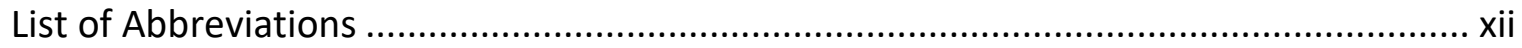

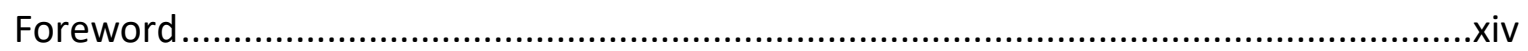

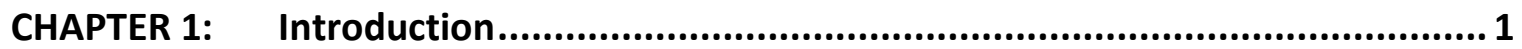

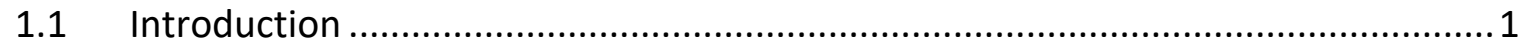

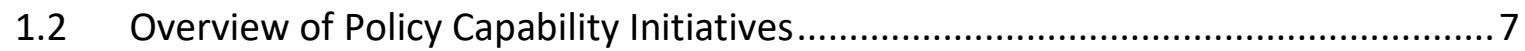

1.2.1 Policy Capability Initiatives from 1990 to 2009 .............................................. 8

1.2.2 Recent Policy Capability Initiatives 2009-2014 ….......................................... 11

1.2.3 On-going Policy Capability Initiatives......................................................... 14

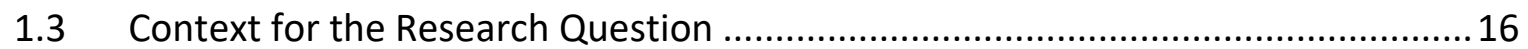

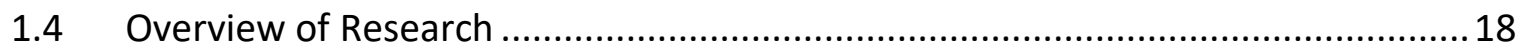

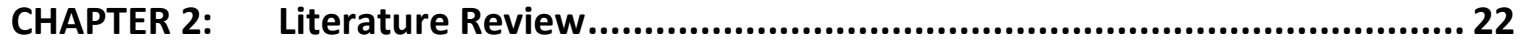

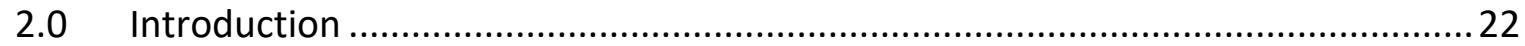

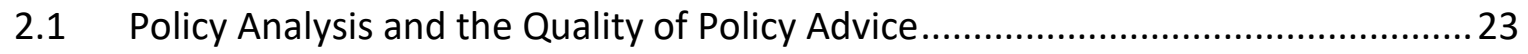

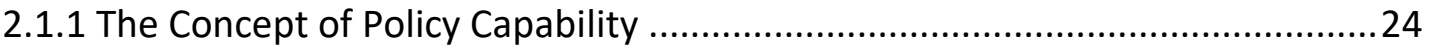

2.1.2 A Modified Conceptual Framework for Understanding Policy Capability........28

2.1.3 Policy Capabilities of Different Types at Different Levels...............................31

2.1.4 Multiple Views on High-Quality Policy Advice .................................................35

2.1.5 The Relation between 'Policy capability' and 'High-quality Policy Advice' ......41

2.2 Policy Analysis: Evolution, Comparative Perspectives and Influences .................. 44

2.3 Evolution of Policy Practices/Professionalising Policy Analysis and Advice ............55

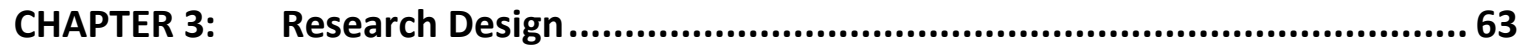

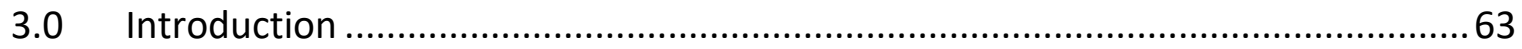

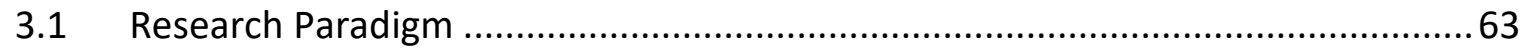

3.2 Methods to Examine Central Agency Initiatives.......................................................65 


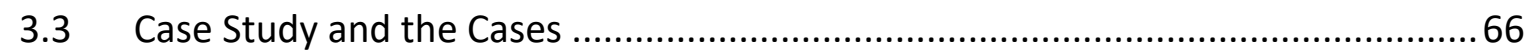

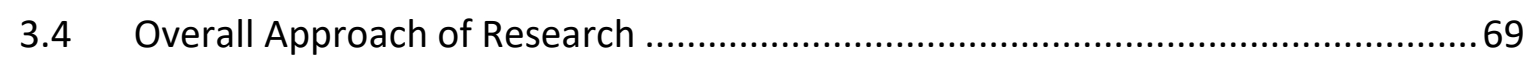

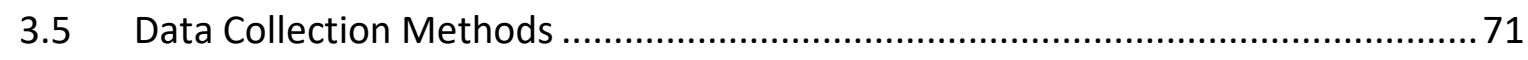

3.6 Data Analysis, Interpretation and Reporting of Data ......................................... 77

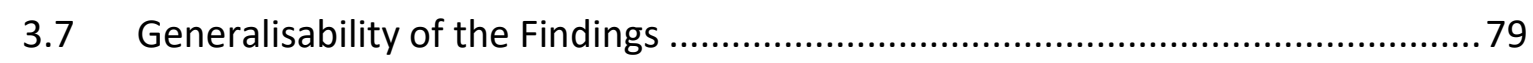

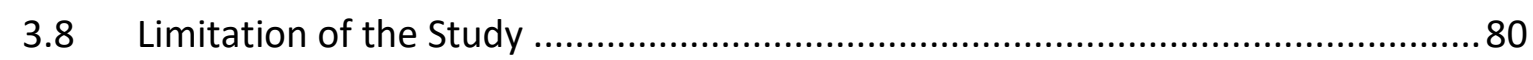

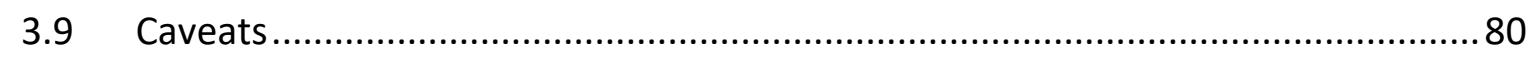

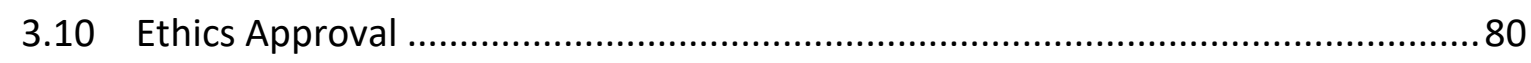

CHAPTER 4: The Choice and Use of Central Agency Initiatives ..............................82

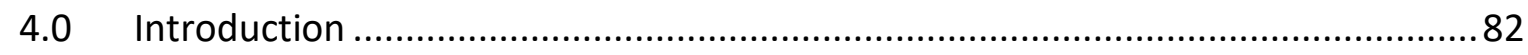

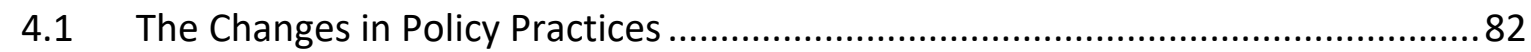

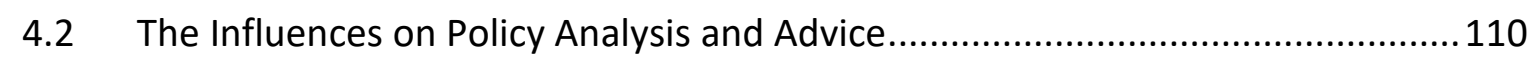

4.3 Summary Assessment of Central Agency Initiatives.......................................... 118

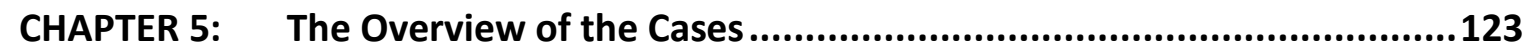

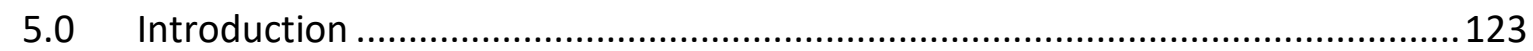

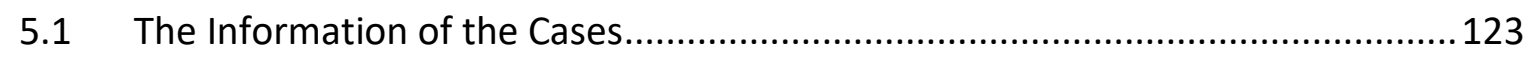

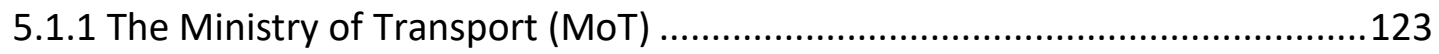

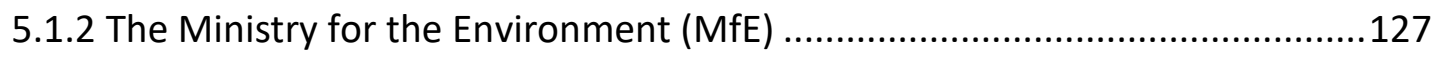

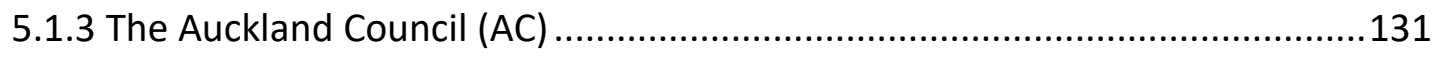

5.2 Key Information on Policy Analysis and Advice across the Cases .......................133

5.3 Similarities and Differences across the Cases..................................................136

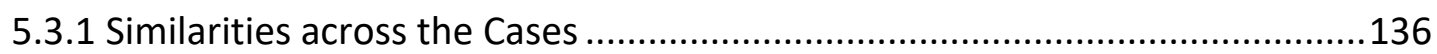

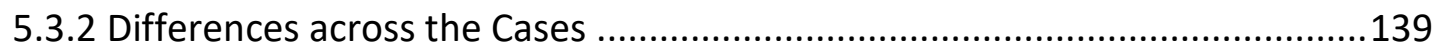

CHAPTER 6: The Agency Driven Initiatives.........................................................141

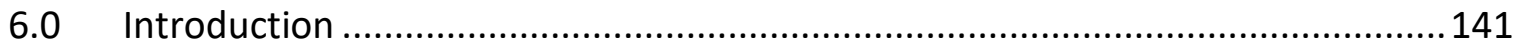

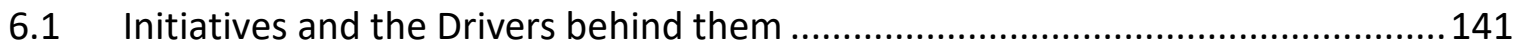

6.2 Agencies' Initiatives for Policy Capability and Quality Assurance ........................147

6.2.1 The MoT's Initiatives for Policy Capability and Quality Assurance.................147

6.2.2 The MfE's Initiatives for Policy Capability and Quality Assurance .................164

6.2.3 The AC's Initiatives for Policy Capability and Quality Assurance.....................180 


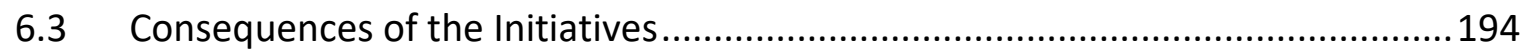

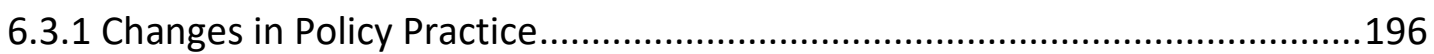

6.3.2 Contribution of Changes to Policy Capability ..............................................199

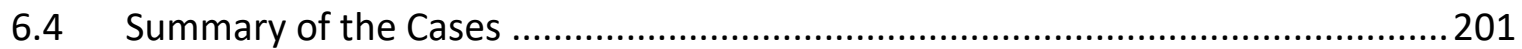

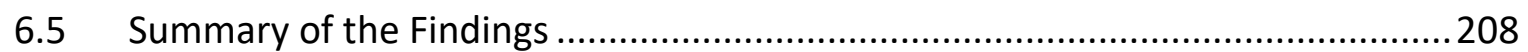

CHAPTER 7: The Choice and Use of Agency Driven Initiatives ............................. 210

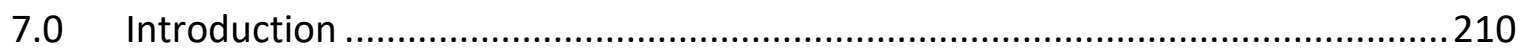

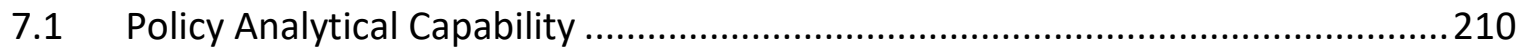

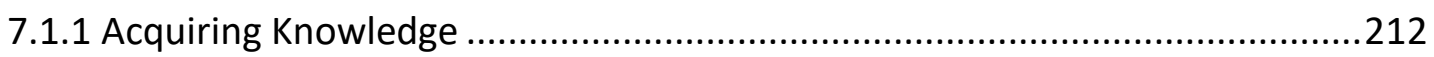

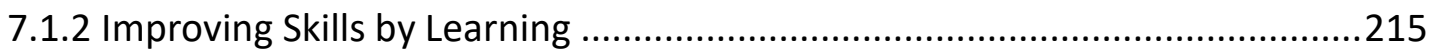

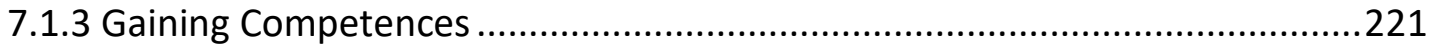

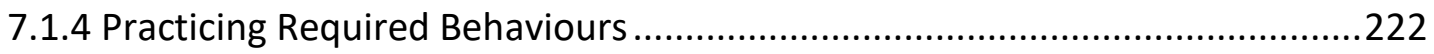

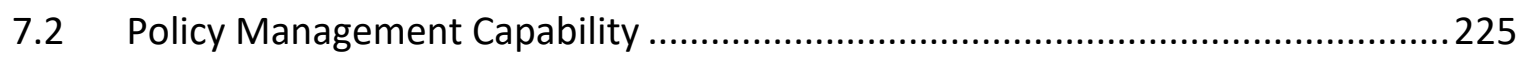

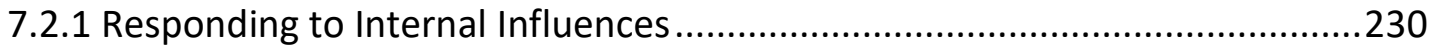

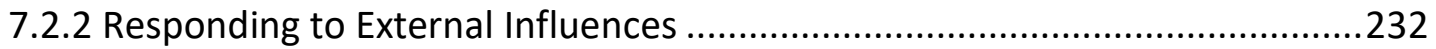

7.2.3 Meeting the Client's Quality Expectations from Policy Advice ......................234

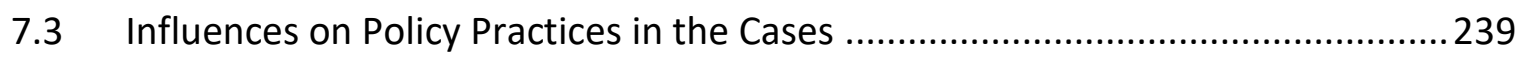

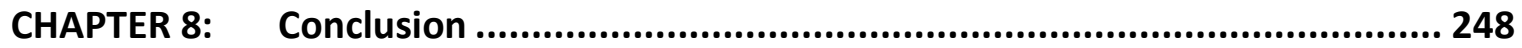

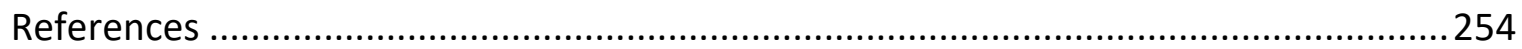

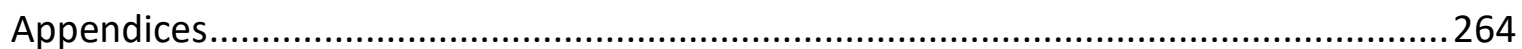

Appendix 1 The New Zealand Government's Other Principal Economic Reforms..264 Appendix 2 Interview Consent Form, Information Sheet and Guide .....................265 


\section{List of Tables}

Table 1.1: Implications of Recent Initiatives to Build Policy Capability .............................14

Table 2.1: Overall Framework of Policy Capacity ...........................................................29

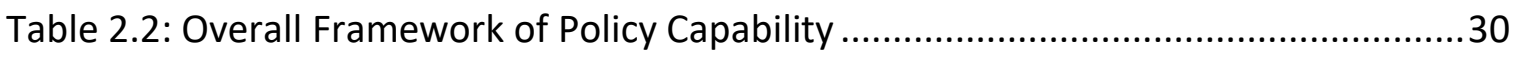

Table 2.3: Different Types of Policy Capacity at Different Levels ....................................33

Table 2.4: The Treasury Quality Standards for Policy Advice .........................................37

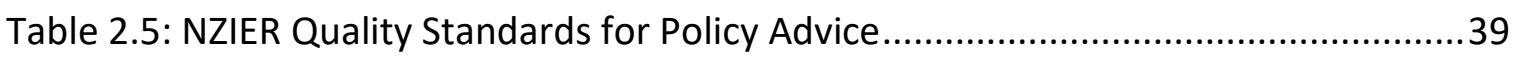

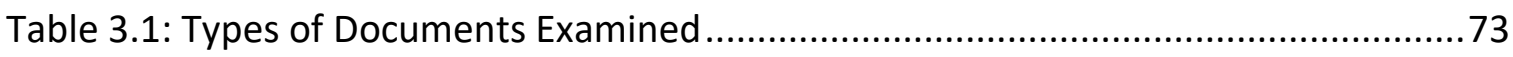

Table 3.2: Three-stage Process for Data Analysis, Interpretation and Reporting of Data 77

Table 4.1: Five Key Characteristics in People Practising the Craft of Policy Analysis ........83

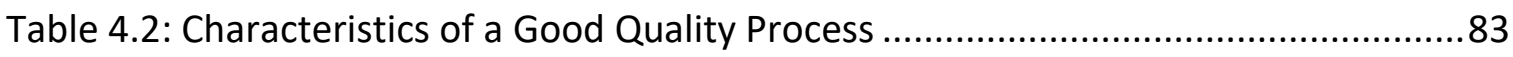

Table 4.3: Identification of Core Competences in People Who Develop Policy Advice ....84

Table 4.4: Suggestions on Human Resources Management by the PAI 1991-1995.........85

Table 4.5: Five Measures of Performance for Suppliers of Policy Advice .........................90

Table 4.6: A Checklist to Assess the Quality of Policy Advice .........................................91

Table 4.7: Quality Management Process by the PAI, 1991-1995 ..................................91

Table 4.8: Key Messages on the Quality of Policy Inputs, IQPA Initiative 1997-99........101

Table 4.9: The REPA 2010 Recommendations in Four Main Areas ...............................106

Table 4.10: A Comparison of Central-agency Driven Policy Capability Initiatives............109

Table 5.1: The Strategic Plan in Action of the MfE ....................................................128

Table 5.2: A Selection of Typical Job Titles for Policy Staff...........................................135

Table 6.1: Selected Initiatives Developed by the MoT, MfE and AC .............................142

Table 6.2: Goals and Strategies of the MoT towards a Professional Services Ministry ..149

Table 6.3: MoT Interviewees' Views on Policy Skills and Attributes in Policy Staff ........154

Table 6.4: Interviewers' Views on Policy Skills and Attributes in Policy Staff .................172

Table 6.5: COBRA Quality Standards for Policy Advice ...............................................178

Table 6.6: The AC's Quality Standards for Policy Analysis and Advice ...........................189

Table 6.7: Mapping of Different Issues across the Cases .............................................206

Table 7.1: Policy Analytical Capability Efforts in the Three Cases ...............................212

Table 7.2: Policy Management Capability Efforts in the Three Cases .............................229

Table 7.3: The Quality of Policy Advice Assurance Efforts in the Three Cases................234

Table 7.4: Different Types of Policy Capabilities at Different Levels ..............................237 


\section{List of Figures}

Figure 1.1: Recent Initiatives to Build Policy Capability................................................. 13

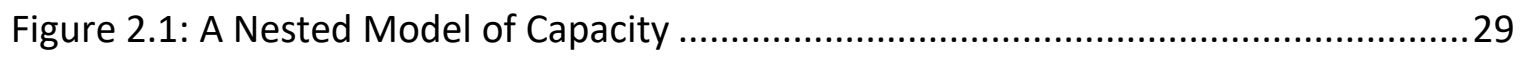

Figure 2.2: A Nested model of Capability …................................................................. 31

Figure 3.1: The Overall Approach of Research Design ................................................. 70

Figure 3.2: Approach Used within Each Case .............................................................. 71

Figure 3.3: The Composition of the Interviewees ........................................................ 75

Figure 4.1: Ministry of Commerce Framework for Policy Making ...................................89

Figure 4.2: The Relationships within Strategic Result Areas Networks ...........................94

Figure 4.3: The Relationships within Strategic Result Areas Cycle ..................................95

Figure 4.4: The High-Performance Model ...................................................................97

Figure 4.5: The Value Chain for Training and Development in Policy Advice ...................99

Figure 4.6: New Zealand's High-Level PIF Agency Model ...............................................104

Figure 4.7: Policy Improvement Frameworks of the Policy Project ..............................107

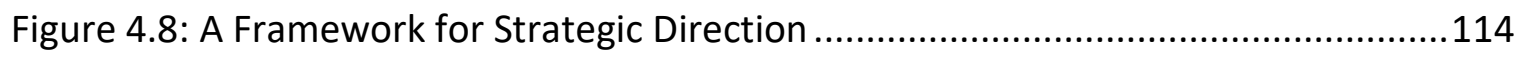

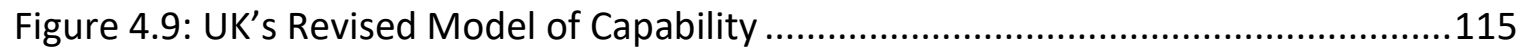

Figure 5.1: The Responsibilities of the MoT's Leadership Team ...................................126

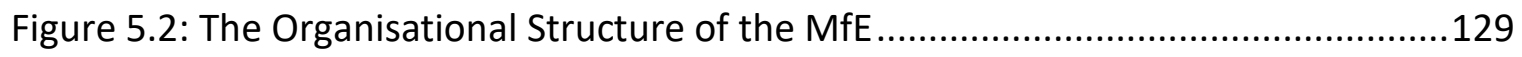

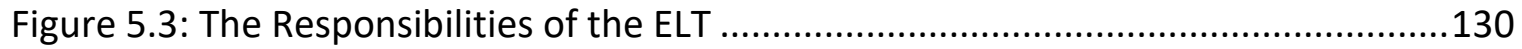

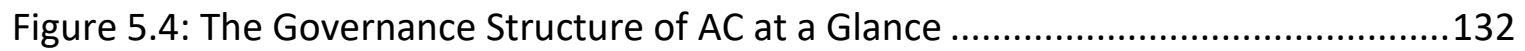

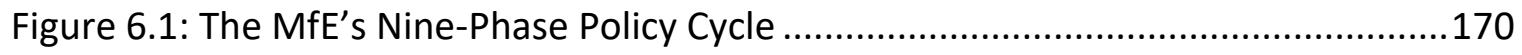

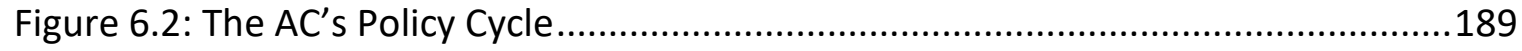

Figure 6.3: The AC's Eight-Steps Commissioning Process ............................................191 


\section{List of Abbreviations}

AC

AGRAGA

ANZSOG

a-PAD

CAF

cCOs

CE

COBRA

CSIRO

DOC

DPMC

EEO

ELT

EMPA

HEC

HoPP

HPGIS

HPGS

HPOs

IGPS

IQPA

IPA

IPANZ

MAF

MBIE

MDC

MfE

MMP

MoT
Auckland Council

Australian Government Reform of Australian Government

Administration

Australia and New Zealand School of Government

Applied Policy Adviser Development

Common Assessment Framework

Council-controlled organisations

Chief Executive

Cost Opportunity Benefit Risk Analysis

Commonwealth Scientific and Industrial Research Organisation

Department of Conservation

Department of Prime Minister and Cabinet

Equal Employment Opportunities

Environment Leadership Team

Executive Master of Public Administration

Human Ethics Committee

Head of the Policy Profession

High Performance Groups and Individuals

High Performance Governance System

High Performance Organisations

Institute of Governance and Policy Studies

Improving the Quality of Policy Advice

Institute of Public Administration

Institute of Public Administration New Zealand

Management Accountability Framework

Ministry of Business, Innovation and Employment

Management Development Centre

Ministry for the Environment

Mixed Member Proportional

Ministry of Transport 


\begin{tabular}{|c|c|}
\hline NRF & Natural Resources Framework \\
\hline NRS & Natural Resources Sector \\
\hline NZIER & New Zealand Institute of Economic Research \\
\hline NZTA & New Zealand Transport Agency \\
\hline OIA & Official Information Act \\
\hline PAl & Policy Advice Initiative \\
\hline PPBS & Planning, Programming and Budgeting System \\
\hline PC & Performance Contracting \\
\hline PCDF & Policy Capability and Development Framework \\
\hline PIF & Performance Improvement Framework \\
\hline PMES & Performance Monitoring and Evaluation System \\
\hline PMN & Policy Managers Network \\
\hline PQs & Parliamentary Questions \\
\hline PSC & Public Service Commission \\
\hline PSTO & Public Sector Training Organisation \\
\hline QPAl & Quality of Policy Advice Initiative \\
\hline REPA & Review of Expenditure on Policy Advice \\
\hline RIS & Regulatory Impact Statement \\
\hline SOEs & State Owned Enterprises \\
\hline SOG & School of Government \\
\hline SOI & Statement of Intent \\
\hline SOSR & State of the Services Report \\
\hline SSC & State Services Commission \\
\hline TINZ & Transparency International New Zealand \\
\hline US & United States \\
\hline VUW & Victoria University of Wellington \\
\hline
\end{tabular}




\section{Foreword}

This thesis is about how central government and agency initiatives have served to improve policy and management capability and the quality of policy analysis and advice in New Zealand, which is a parliamentary democracy. The many reforms to the New Zealand economy and its public sector in the 1980s and 1990s received world-wide attention. New Zealand was one of a number of governments which developed a policy, management and governance reform movement which became known as 'new public management'.

Australia, Canada, New Zealand and the United Kingdom, introduced similar reforms which influenced the development of the multidisciplinary fields of public policy and later public management. These reform initiatives contributed to increasing the policy capability of individuals, organisations and other influences which lifted policy capability and public-sector performance.

Similar initiatives to build and improve policy and management capability in the public sector were developed by other countries. The introduction of such reforms involved a different approach to the work of policy analysts, policy advisors or policy managers from what I had been familiar with in my role as a public officer in the Internal Resources Division of Bangladesh, which is also a parliamentary democracy.

Public policy problems and issues are often 'complex' and 'wicked', with many variables affecting each other in multiple ways and directions. Policy solutions require multidisciplinary interventions, different perspectives, diverse views, and the use of a range of methods, policy instruments, tools and approaches. An objective solution then requires support from the policy advisors, politicians and political processes. Further influences and variables make the production of policy advice ever more challenging.

These challenges and novelties attracted me to do a Master's of Science in Public Policy and Management in 2008 at Carnegie Mellon University (CMU) in Adelaide with the support of a CMU-AusAid scholarship. Until I went to CMU, I was quite an objective 
technician with a view that a scientific approach, facts and evidence would drive the solutions for the problem and other influences were there just to corrupt the derived solutions. My view was partly influenced by my study of Economics from 2005 to 2006 at the Australian National University where I completed a Master's of International and Development Economics, following study in pure science at school.

When I was offered a PhD scholarship to undertake research in Public Policy at Victoria University of Wellington, I began with my 'positivist' view of policy issues and designed a proposal on evidence-based policy practice. I tried to develop a framework of a comprehensive nature as a device to find empirical solutions for policy problems.

My views began to change when I started exploring the numerous initiatives developed by central and line government departments and ministries or units in New Zealand over the period 1990 to 2015. The Westminster advisory system, culture, way of doing business and many other such factors were completely different from the practices of the public service in Bangladesh. I explored some major central government department initiatives which were launched between 1990 and 2015. Looking at these New Zealand policy capability initiatives created renewed interest in conducting research on this topic for my PhD.

Two things struck me while examining the initiatives. First, the list of initiatives since state sector reforms began in the late 1980s indicated policy advice clients' continued dissatisfaction with the quality of policy advice produced in the New Zealand public sector. Second, not all these initiatives were meant only to lift the policy analytical capability of policy staff. Some initiatives were also developed to meet the challenges of managing policy development in a policy unit, government department or policy ministry.

I realised that developing policy solutions with a positivist approach might not be a perfect fit, at least in New Zealand. I also realised that achieving policy capability relied on many influences and considerations. I wondered why, after so many initiatives were taken, the goal of improving policy capability remained under constant challenges. This 
curiosity motivated me to examine the initiatives developed in New Zealand more closely.

I decided to explore both the macro and micro levels of improving policy capability by undertaking some in-depth case studies of specific public-sector organisations so as to look at both policy and management issues as they contribute to building policy capability and raising overall organisational performance. I selected three New Zealand public sector organisations to research: two policy ministries (the Ministry for the Environment and the Ministry of Transport) and the Auckland Council, which provides planning, infrastructure and regional and local services. This topic allowed me to explore the policy capability initiatives and their policy and management capability consequences and to consider the role of systemic capability influences which have featured in academic and practitioner literature over recent years. 


\section{CHAPTER 1: Introduction}

\subsection{Introduction}

Public policy advisors in government agencies are continuously changing their policy practices to improve policy capability with a view to producing high-quality policy advice for their clients. I use 'policy practices' to refer to the activities of policy staff and organisations (or a policy unit of an organisation) in government departments or ministries that contribute to policy analysis and policy advice. These practices, however, cannot be described in common terms. Ideas about how to professionalise policy practices have evolved over time, in variations, across different countries, types of governments, and tiers of government, and at different levels of government including individual, organisation and system levels. How the professionalisation of policy practices has evolved and been supported at organisational level is ripe for detailed investigation.

Efforts to professionalise policy practices, which I refer to collectively as 'initiatives', take many forms. These efforts are consistent with the breadth of ideas about improving practice. Public sector departments, ministries or government units (collectively, 'agencies') adopt initiatives to provide guidance or instructions. Initiatives include frameworks, guides, models, coaching, training, mentoring, or feedback: anything that aids policy professionals with developing policy analysis and advice. Initiatives include, for example, changes in selection and recruitment processes of a department or ministry or government unit; changes in the process for developing policy analysis and advice; and introducing or changing policy advice quality assurance processes.

The public sectors across the world have used initiatives as a means to improve policy practices. Such initiatives have been taken over a long period of time in various countries. By way of recent example, in 2010, the Advisory Group on the Reform of Australian Government Administration (AGRAGA) produced a report on the development and implementation of forward-thinking, creative and innovative policy making for the Australian Public Service (AGRAGA, 2010). In 2013, the Policy Profession 
Board of Civil Service of the United Kingdom introduced 'Twelve actions to professionalise policy making' (Civil Service, 2013).

In 2016, the Department of Prime Minister and Cabinet (DPMC) of New Zealand developed the Policy Project initiative to improve the policy system and thus government decision-making (Department of Prime Minister and Cabinet [DPMC], 2017). Very recently, in 2018, the Policy Profession Board of the UK Civil Service, United Kingdom (UK), has introduced the Policy Profession Standards, a 'framework for professional development', that describe the skills and knowledge required by policy professionals at all stages of their career (Civil Service UK, 2018). These examples indicate that the governments adopt initiatives with some specific objectives to achieve, be that an effective policy system or a well-performing group of policy professionals.

Despite many such initiatives being developed, their objective has been unsatisfied for over two decades. There continues to be discourse about declining policy capability at high government levels in Australia, the United Kingdom and New Zealand. Concerns about policy capability have been expressed by a wide range of policy actors, including political leaders, policy practitioners, policy experts, stakeholders, interest groups, and the public in general. Political leaders have publicly expressed disappointment with the ability of bureaucratic advisors to produce policy advice that meets their purpose and expectations. The former prime ministers of Australia, New Zealand and the United Kingdom publicly criticised the 'lack of vision and analytical skills of their bureaucratic advisers' (Tiernan \& Wanna, 2006, p. 2). The New Zealand ministers, in general, asked 'why a large and costly policy advice system apparently [did] not provide Ministers with the information they need[ed] to make sound decisions' (State Services Commission [SSC], 1999a, p. 5) and indicated that the quality of policy advice was not high.

A similar sentiment but from a somewhat different viewpoint was expressed by lain Rennie, then Head of State Services and State Services Commissioner of New Zealand, in a speech in 2013. Rennie mentioned that the Performance Improvement Framework (PIF), a State Services Commission of New Zealand review of government agencies' strengths and weaknesses, said that the New Zealand public sector was 'much less good 
at thinking about the long term than the short term' although he acclaimed it for achieving its highest rating, at 5th in terms of government effectiveness ahead of Australia at 10th and UK at 15th, according to the World Bank report (SSC, 2013).

An interesting comment came from Rt Hon. Prime Minister John Key, the former prime minister of New Zealand, when he inaugurated The Policy Project ${ }^{1}$ in 2016 . He said:

I initially wondered why we needed the Policy Project - I was pretty happy with the service I was getting. But there is always room for continuous improvement and innovation. I am delighted that my department took a leadership role in collaboration with policy leaders from other departments, to improve the quality of policy advice across government. (DPMC, 2016a)

These comments from state and policy leaders of different countries and jurisdictions over time indicate that improving policy capability is not a one-time affair. Efforts to achieve improved policy capability and the appreciation of improved policy capability are likely to be influenced by country -and context-specific dynamic conditions, factors and influences and the views of multiple clients of different types. Also, what seems good today may not remain good in future with respect to achieving improved policy capability because opinions change and/or circumstances require changes in approach to improving policy capability. Comments from political leaders and state organisations' senior policy practitioners have drawn my attention as a researcher. They have, in conjunction with initial observations of initiatives to improve policy capability, led me to several observations about the context of these efforts. These are set out here.

My first observation concerns who has the right to judge policy capability and the quality of policy advice because there are multiple clients for policy advice: the immediate client/minister, the cabinet, the public sector and the public. Different clients appreciate policy capability and the quality of policy advice from their own standpoints. The clients' appreciation of the quality of policy advice, potentially, cannot be unanimously or

\footnotetext{
${ }^{1}$ An initiative by the Department of Prime Minister and Cabinet (DPMC) to promote collaboration across departments and ministries in the New Zealand public sector to work as a 'policy system'.
} 
uniquely outlined. The clients' quality expectations from policy advice involve their own views on the rigorousness of policy analysis that underpins policy advice and the ability of the policy advice to solve or address the policy issue/problems/opportunities. Therefore, who hold the views and conveys the ideas about policy capability and the quality of policy advice has a more prominent expression in how policy capability and the quality of policy advice is finally determined. A consequent question arises as to who is expected to judge the quality of policy advice: the immediate client/minister, the cabinet, the public sector or the public in general.

Policy producers, generally, consider political leaders to be their clients for policy advice and political leaders correspondingly position themselves as the clients for policy advice. In such a client-producer relation, other important policy actors, institutions and clients for policy advice seem to be disregarded. In documents and statements by governments about policy advice, it is rare to find mention of other important policy actors. Among the discounted in this depiction of the policy advice client-producer relation are independent policy consultants, producers of policy advice in the private sector, think tanks, academics, and not-for-profit organisations. The actors and institutions contribute to policy by producing policy analysis and advice or generating knowledge supportive of policy practices or informing policy directions. The other important and ultimate client, the public, has a relatively unspecified role within this traditional view on policy advice client-producer relation.

Another observation concerns how to judge policy capability of government agencies and the quality of policy advice they produce. Should these be judged by the ability of the policy advice producers to produce policy advice based on the rigor of policy analysis? Or, by the ability to meet the clients' expectations with regard to the quality of policy advice? Or by both? A consequential question arises as to how to measure policy capability and the quality of policy advice and how to meet multiple clients' expectations which potentially can be different. Besides, the clients' expectations regarding the quality of policy advice and the policy capability of the government agencies are likely to change when government priorities change and when the government decides to adjust different portfolios. 
Policy analysis generates and underpins policy advice but there is no single and agreed view on what counts as policy analysis. One of the main dichotomies has been expressed as analysis of policy process vs analysis in and for policy process (Parsons, 1995, p. xvi). Other different views arise from how policy analysis is approached, and whether it is treated as scientific versus technical, for example, or an art versus a craft. Policy analysis is affected by several dynamic factors, and which can ultimately affect the quality of policy advice. It differs, sometimes strikingly, across countries, sectors, political structures, institutions and inside and outside of government (Radin, 2017; C. Scott, 2017, p. 44).

Furthermore, policy analysis, irrespective of views on policy analysis and the quality of policy advice, is strongly influenced by the producer and consumer of policy advice; the institutions where policy analysis is produced; the processes through which it is produced; and in which form and with what effects the outputs are produced. Developing policy advice each time is a fresh enterprise and policy analysis is significantly influenced by the nature and magnitude of policy problems (or opportunities), skills repertoire, orientation and styles such that the type, nature and magnitude of the policy problems can determine the nature and combination of policy skills required to produce policy advice. The political leaders' disappointments, briefly sketched above, may not converge to a common view of the reasons for poor policy analysis capability of policy advice producers in the public sector.

Political leaders' comments about declining policy capability in some countries point out the lack of vision and analytical ability in bureaucratic policy advisors on the quality of policy advice. This implies that the clients for policy advice implicitly assume a kind of relation or association between policy capability and the quality of policy advice. It seems that a policy-capable individual or team or organisation is perceived to be the one that produces high-quality policy advice that meets the clients' quality expectations, however the connection is never made completely explicit.

While there is no common view regarding who has the right to and how to judge policy capability and the quality of policy advice, it is unclear why the declining policy capability 
is so consistently identified by a range of policy actors and institutions. And while there is no all-satisfying view on the improved policy capability and the quality of policy advice, it is also unclear what drives the choice and use of the initiatives in the government agencies.

These curiosities have encouraged me to learn more about policy-improvement initiatives. A brief overview of the initiatives is provided in the following section. First, to orient the New Zealand initiative discussion, a few words about the form of New Zealand's government are given.

\section{Westminster-based Government System}

Westminster government systems, including New Zealand, have at least five, common components: the concentration of political power in a cabinet; the accountability of ministers to parliament; the constitutional bureaucracy with a non-partisan and expert civil service; an opposition acting as a recognised executive-in-waiting as part of the regime; and parliamentary sovereignty with its unity of the executive and legislature ( $R$. A. W. Rhodes \& Weller, 2005, p. 7). But New Zealand departed from Westminster by adopting Mixed Member Proportional (MMP) electoral system. MMP was promoted as a catalyst for 'extending citizen rights; heralding multi-party coalition government; and giving a greater electoral influence over the legislature, the executive and policy settings (including split voting for candidates and party lists)' (Wanna, 2005, p. 155).

\section{Westminster-based Advisory System}

New Zealand transplanted a Westminster-based advisory system that shared a British heritage where 'settler societies without prior local traditions other than indigenous cultures developed the structures, but then began to adjust them to local conditions' ( $R$. A. W. Rhodes \& Weller, 2005, pp. 2-3). New Zealand is a Westminster model of democracy which some regard as more Westminster than Westminster itself (Lijphart, 1984; R. G. Mulgan, 1997, p. 63). Wanna (2005, p. 153) commented, 'the transplanted seed apparently produced purer strain than the original stock'. The Westminster system in New Zealand requires that policy advice producers in government agencies develop free and frank expert opinion based on evidence. 


\subsection{Overview of Policy Capability Initiatives}

Public-sector organisations across the world, including in New Zealand, have developed many and various initiatives to improve policy capability and produce high-quality policy advice. These initiatives are developed even when there is no common understanding of what counts as policy analysis, no single viewpoint on the quality expectations from policy advice which is also a shifting goal, making it difficult for policy advice producers to meet the clients' quality expectations and the dynamic influences on policy analysis and advice that come from how policy analysis is done, who does it, where it is produced, the nature and magnitude of problems, and so on.

\section{Some Initiatives across the World}

Governments around the world are giving attention to how to improve policy analysis which is a key input to developing policy advice, so that policy choices can effectively address the policy issues. There have been many initiatives by different governments at different levels. Some of these initiatives have come from the central governments and have been directed at building the capability of government agencies. For instance, Australia, Canada, the European Union, New Zealand and the United Kingdom have developed frameworks or models such as: Dynamic Four-tier Model for High Performance and the Australian Public Service Capability wheel (Australia); Management Accountability Framework (Canada); Common Assessment Framework (EU); Performance Improvement Framework (New Zealand) and Capability Model (UK). Some initiatives are developed at a level other than central government. The Policy Capability and Development Framework (PCDF) of the Queensland Government in Australia is such an example.

It is evident that the efforts to achieve improved policy capability are based on different considerations across countries and the discourse about declining policy capability is global. A detailed inquiry into the initiatives developed worldwide is timely. The New Zealand public sector offers an excellent case in point because it has developed many initiatives of different types. The following section presents an overview of some of the initiatives developed in the New Zealand public sector. 


\section{Policy Capability Initiatives in the New Zealand Public Sector}

The New Zealand public sector has, since 1990, introduced many initiatives intended to improve the policy capability of its departments and ministries. The research focuses on policy capability initiatives developed in the New Zealand public sector between 1990 and 2015 which allows a discussion that is sufficiently current to discern trends of purpose, drivers and ideas shaping developing policy capability initiatives over this time. Given the speed of change involved, discussion about conditions before 1990 are less relevant for current public policy activity. What follows is a brief discussion of some of the key initiatives developed between 1990 and 2015, identifying the concepts and ideas that drove them.

\subsubsection{Policy Capability Initiatives from 1990 to 2009}

\section{Review of State Sector Reforms 1991}

The New Zealand Government appointed a steering committee in 1991 convened by Basil Logan, the former Chief Executive of IBM New Zealand, to review progress under major state sector reforms instituted from 1988 to 1990. The objective of the Logan Review was to assess the effectiveness of two instrumental pieces of legislation, the State Sector Act 1988 and the Public Finance Act 1989, designed to improve the efficiency and effectiveness of the Public Service. The Logan Review gathered evidence from a written survey, supported by interviews with key interested and affected parties including ministers, departmental chief executives and senior management, central agency executives and senior management. It also used historical documentation, selected case studies, and existing statistical information to comment on the expected benefits of these reforms. The review addressed key issues of decision-making, asset management, human resource management, the role of the central government departments, and provided 40 recommendations to the New Zealand Government (SSC, 1991).

The relevance of these reforms for my research lies in the impetus they generated and their recommendations. They were instituted for two reasons: first, there was a general concern about the quality of performance in the public service and, second, the 
government wanted to bring public service labour practices into line with the private sector labour market (SSC, 1991). Because of these reforms, a traditional system of 'permanent heads' of departments was replaced by a contractual system that placed accountability for resource management and departmental outputs firmly in the hands of a chief executive directly accountable to a minister. The Logan Review's recommendations called for a retention of financial, managerial, performance and planning responsibilities by the chief executives (recommendations 10 to 32 and especially recommendation 39) (SSC, 1991).

The New Zealand Government accepted the recommendations of the Logan Review. It then engaged departments and ministries in a self-review of current performance, with central departments overseeing the quality of these self-reviews and advising based on the results. The Chief Executives (CEs) were then given wider functions, greater accountability responsibilities, and competitive challenges in the hope that ministries and departments would perform better. To improve performance, the departments and ministries focused on how to produce high-quality policy advice.

\section{Policy Advice Initiative (PAI) 1991-1995}

Despite the reforms, some ministers remained unsure about the value they were getting from public expenditure on policy advice. Besides, the distinction between the output category of policy advice in the public accounts, and the kind of activity that ministers considered to be policy advice needed clarification (Hawke, 1993, p. 1). Accordingly, the SSC convened an interdepartmental group in 1991 which formed a Policy Advice Initiative (PAI) committee. This committee, also known as the Policy Advice Review Team, was mandated to achieve a permanent improvement in the cost-effectiveness of advice. To begin, it developed a booklet named The Policy Advice Initiative about opportunities for managers to foster improvement by drawing on the practices and views of policy managers in 24 government departments, internal documents and reports, and overseas literature on public policy analysis and organisational management. The Policy Advice Initiative set out what was expected from policy managers, and the quality characteristics of policy advice. It further discussed the skills 
needed for policy managers, core competencies for human resource management, and the efficient use of organising resources (SSC, 1992).

The PAI Committee then collaborated with the State Services Commission and the Institute of Policy Studies to organise seminars in 1993. They were titled Policy Advice Reforms, Expecting the Best, Working with Others, Project Management of Policy Advice, and Gender Analysis. They covered topics such as identification of policy issues; identification of key players, both internal and external; understanding customers' needs; and the relationship between implementation and research design.

\section{Improving the Quality of Policy Advice (IQPA) 1997-1999}

The State Services Commission initiated a project in 1997 in response to the concerns of the Minister of State Services who had expressed concern about the inability of the public service to define clearly the outcomes the government seeks to achieve and to put forward sound policy solutions; inadequate human resource capability; lack of attention to policy implementation issues; and the counter-productive and debilitating consequences of departmental patch-protection (SSC, 1999a, p. 5). The project issued a report named Essential Ingredients: Improving the Quality of Policy Advice in June 1999. The project investigated the ways in which structures, systems, human resources and management practices impact on the quality of policy advice and how it could be improved. It discussed the quality of policy inputs: the information, research evaluation and consultation required, and the need to enhance central coordination mechanisms to improve the quality of policy advice (SSC, 1999a).

\section{Policy Managers Network (PMN) 2000-2009}

The next stage saw the SSC convene a Policy Managers Network (PMN) focusing on policy capability development at a senior level. The network developed a shared workspace, ran policy manager meetings, and held biannual policy leaders' workshops, policy forums and a policy conference. This network started in 2001 in response to the interest of some policy general managers in opportunities to network on matters of common interest. The network focused on building the capability of the policy workforce and addressing areas of shared concern. It provided information to support 
collaboration, reduce duplication, build policy capability and ultimately improve the quality of policy advice. The policy managers' meetings also shared information on developing and managing policy teams or staff. They were held periodically from 2000 to 2009.

\subsubsection{Recent Policy Capability Initiatives 2009-2014}

Inquiry into recent initiatives designed to improve policy capability in the New Zealand public sector is timely. The commitment of the New Zealand public sector to improving policy capability has been reflected in several recent initiatives. They have been introduced in response to changing conditions experienced in New Zealand in recent years. Better use of public funds has been required by increasing fiscal constraint. Concern about the declining quality of policy advice and policy capability have required attention. A need for trying new approaches to develop policy analysis and advice has been acknowledged as the policy problems have become increasingly complex and contestable. Initiatives to improve policy capability have been devised by central government departments (the State Services Commission, the Treasury, and the Department of Prime Minister and Cabinet) as well as agencies.

\section{Performance Improvement Framework 2009}

The State Services Commissioner expressed concern about declining policy capability, noting that the New Zealand public sector was not good at addressing medium-term to long-term policy issues (SSC, 2013). The SSC declared its ambition to have the New Zealand public sector achieve world-best practice in assessing public service performance and capability, and fitness-for-purpose now and into the future (Rennie, 2012).

New Zealand has introduced the Performance Improvement Framework (PIF) in 2009. The PIF is developed in order to achieve the best value for money under the fiscal constraint of the time. Citizens' expectations regarding access to services and value from their tax dollar are rising and the interaction between citizens and government are changing too. It also reflects the aspiration stated in the Better Public Services 
programme to become a great public service in the medium term (Rennie, 2012). This is the context of the perceived need for State Services to do things differently, and the PIF remains as a key tool.

The PIF is a tool for quick review of an agency's capability and performance. Unlike performance management tools developed elsewhere, the PIF review is claimed not just to audit an agency's performance, but to offer uniquely forward-looking perspectives. Under the PIF model, reviewed ministries or departments are asked two critical questions and then invited to respond: first, what is your future performance challenge? Second, how will you address this challenge after four years? This was designed to make an agency focus on achieving better policy capability for the future. The PIF, thus, is a review of an agency's fitness-for-purpose and its preparation for fitness-for-the-future.

\section{The Review of Expenditure on Policy Advice 2010}

In 2010, the Treasury appointed a high-profile committee. The committee produced a report, Review of Expenditure on Policy Advice: Improving the Quality and Value of Policy Advice. This report was also known as the Scott Review as its committee was chaired by former Secretary to the Treasury, Dr Graham Scott. It presented a thorough analysis of issues of capability, quality assurance and getting value for money from policy advice. It considered how existing incentives, structures and processes could be improved, and recommended further professionalising policy advice and policy capability (G. Scott, Duignan, \& Faulkner, 2010)

\section{Department of Prime Minister and Cabinet (DPMC) 2011-2014}

The Office of the Prime Minister's Chief Science Advisor under the auspices of the DPMC has produced two reports. The first, in 2011, proposed better ways that evidence could be used in the policy process (Gluckman, 2011). Another report in 2013 provided a stocktake of evidence-based policy practice in the New Zealand public sector. This stocktake indicated scope for improvement in policy analysis and advice (Gluckman, 2013). More recently, the Chief Science Adviser set out ten principles for developing policy advice (Gluckman, 2014). The recent employment of science advisors in some 
ministries and departments, on the recommendation of the Chief Science Advisor, has reflected the need for scientific approach in developing policy advice.

\section{Initiatives at Agency Level 2011}

While the initiatives to improve policy capability described so far in this section came from central government departments, initiatives have also been taken at agency level, including the development of policy guides and frameworks. For example, in an attempt to improve its policy capability, the Ministry for the Environment (MfE) developed two policy guides, the Cost Opportunity Benefit Risk Analysis (COBRA) (Ministry for the Environment [MfE], 2011) and Professionalising Policy: A guide for developing the craft of policy analysis (MfE, 2011). See Figure 1.1 for the initiatives by the New Zealand Public Sector along a time line.

Figure 1.1: Recent Initiatives to Build Policy Capability

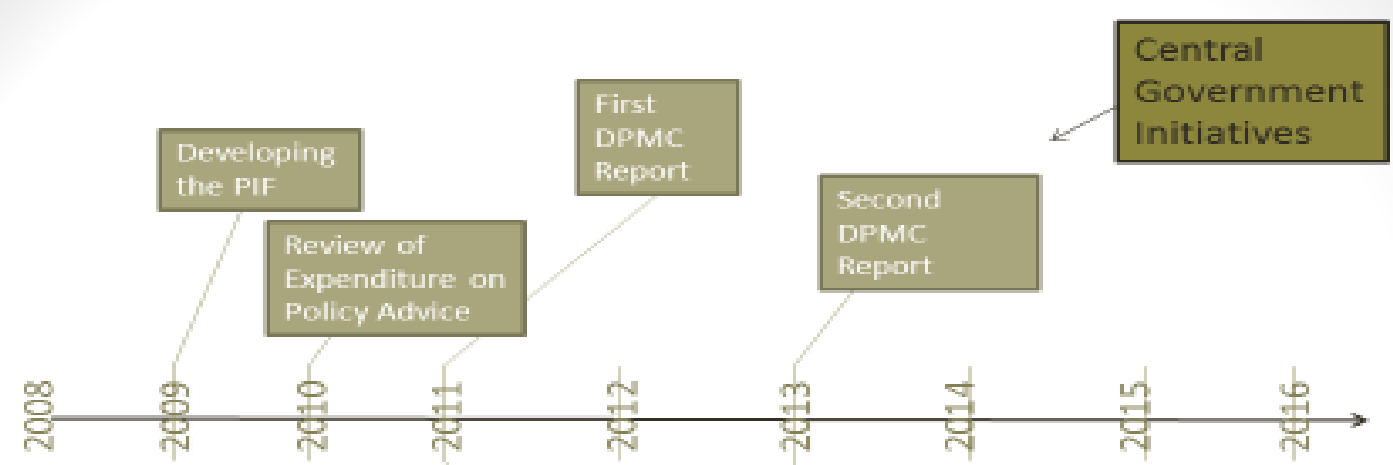

Department Initiatives

Developing Policy Guides by the MfE

Table 1.1 summarises a few recent initiatives in the New Zealand public sector to achieve improved policy capability and high-quality policy advice. The introduction of a relatively recent new position at DPMC, the 'Head of the Policy Profession', with a 
specific role of improving the quality of policy advice further indicates that the New Zealand public sector is increasingly emphasising producing high-quality policy advice.

Table 1.1: Implications of Recent Initiatives to Build Policy Capability

\begin{tabular}{|l|l|}
\hline Developing the PIF in 2009. & $\begin{array}{l}\text { Draws attention of an agency to need to achieve } \\
\text { improved policy capability for medium-term. }\end{array}$ \\
\hline $\begin{array}{l}\text { The Review of Expenditure on } \\
\text { Policy Advice, 2010. }\end{array}$ & $\begin{array}{l}\text { Recommends professionalising policy advice and } \\
\text { policy capability. }\end{array}$ \\
\hline $\begin{array}{l}\text { The DPMC initiatives since 2011 } \\
\text { to date. }\end{array}$ & $\begin{array}{l}\text { Indicates that there is scope for improvement in } \\
\text { policy analysis and advice using evidence in policy } \\
\text { process. }\end{array}$ \\
\hline $\begin{array}{l}\text { Developing policy guides and } \\
\text { frameworks by an agency in } 2011 \\
\text { and 2013. }\end{array}$ & $\begin{array}{l}\text { Examples of agency initiatives to enhance policy } \\
\text { capability. }\end{array}$ \\
\hline $\begin{array}{l}\text { The State Service Commissioner's } \\
\text { Speech on 30th July 2013. }\end{array}$ & $\begin{array}{l}\text { Emphasises a shift for public agencies from short } \\
\text { term focus to enhance capability in five to ten } \\
\text { years. }\end{array}$ \\
\hline $\begin{array}{l}\text { New appointment at DPMC in } \\
\text { 2014 with specific role of } \\
\text { improving the quality of policy } \\
\text { advice. }\end{array}$ & $\begin{array}{l}\text { Indicates the degree of involvement of the } \\
\text { central agency in improving the quality of policy } \\
\text { advice. }\end{array}$ \\
\hline
\end{tabular}

\subsubsection{On-going Policy Capability Initiatives}

\section{The Policy Project (Initiated in 2014)}

The seriousness with which the New Zealand public sector continues to take improving policy advice is reflected in current initiatives. The DPMC initiated The Policy Project in 2014 in collaboration with public service policy leaders. It produced a document, Policy Project-Responsive Today, Shaping Tomorrow, setting out its aim of driving excellence in the policy system by improving policy capability, standards, design and delivery. This project was co-developed with the Policy Leaders Network of deputy chief executives with policy responsibilities. Its key areas of focus include system leadership, people capability, policy products and services, and policy leadership.

The Policy Project has diagnosed and commented on the overall quality of policy advice which has remained relatively static despite decades of inquiries and initiatives by 
central agencies. The policy problem as diagnosed by the project entails, according to its website (DPMC, 2017):

- Policy that is of variable quality within agencies and across the system;

- A shortage of skilled senior policy advisors who agencies compete for;

- Policy advice sometimes short on evidence, and poorly informed by the needs of users and by evaluation or feedback on what has worked (or not);

- Meeting Ministers immediate demands but not investing in policy capability for the future; and

- Evidence of weak cross-government systems for collaboration, alignment and prioritisation.

The project proposes professionalising policy services by introducing a value-adding model. It also provides directions for the future via a framework designed to reflect the key components of the policy system: people, products and services, and leadership.

The Policy Project has developed three policy improvement frameworks: The Policy Capability Framework, Policy Skills Framework, and Policy Quality Framework. They are co-designed for and by the policy community to help government agencies deliver good policy advice. The frameworks were endorsed for use by the Head of the Policy Profession and the Tier 2 Policy Leaders Network (DPMC, 2017).

The Policy Project has also provided a policy-methods 'toolbox' for policy staff to use as applicable. This emphasises the behavioural aspect of policy, recognising that it is generally about bringing about changes in human behaviour around an issue. The codesign approach is distinctive for emphasising co-production of policy so that the likelihood of the policy community embracing the message of the project is increased. Another feature: it has taken a holistic view on how to develop 'great' advice. It demonstrates the necessity of establishing links between policy skills, tools, capability and quality. 


\section{The Natural Resources Sector Framework 2014}

Another on-going unique initiative is the Natural Resources Sector Framework (NRF) that deals with long term and complex natural resources issues. The government has recognised that environmental policy issues often involve cross portfolios and diverse community interests. Addressing these policy issues therefore go beyond one agency's jurisdiction. The Natural Resources Sector (NRS) is formed with a group of seven agencies led by the Ministry for the Environment (MfE). The NRF is responsible for building a coherent and integrated approach to sector-wide natural resources issues while providing joined-up, high quality advice to government ministers (Ministry for the Environment [MfE], 2013a).

\subsection{Context for the Research Question}

The above discussion of the initiatives developed between 1990 and 2015 by the New Zealand public sector shows that the efforts to improve policy capability and the quality of policy advice have not diminished, but rather increased, since the state sector reform of the late 1980s. The recent initiatives seem relatively more comprehensive than the previous initiatives in their design and approach. To illustrate, the initiators' earlier focus was on setting and clarifying the clients' expectations from policy advice, identifying policy skills in staff and suggesting ways to hone those skills to satisfy the clients' quality expectations.

The later focus shifted to how to improve the 'quality' of inputs, with the use of evidence, developing policy tools and frameworks to guide policy advice producers in government departments and ministries or units. The most recent initiative, the Policy Project, pulls together policy skills, tools, capability and quality with a co-design approach, with a view to influencing policy analysis and advice throughout the policy system instead of limiting it to the level of individual or organisation. The question arises why, after so many initiatives have been developed, the desired outcomes are yet to be attained. It seems the discourse about declining policy capability has continued over a reasonably long period, and has drawn further attention very recently. 
The overview of initiatives also shows that the initiatives to achieve improved policy capability and high-quality policy advice were largely driven by central government departments and ministries or units. The initiatives' purposes were broadly, to:

- Clarify understanding of what policy advice is;

- Clarify the expectations from policy analysis and advice;

- Identify the characteristics of quality policy advice;

- Identify the skills needed in policy managers, the core competencies for human resource management, and the efficient use of organising resources;

- Measure performance;

- Take a forward-looking view of the agency's policy work;

- Guide policy analysis and advice by providing policy guides;

- Apply more data and evidence to policy analysis;

- Keep an eye on the cost of developing policy advice;

- Promote collaboration by bringing agencies together under a lead agency; and

- Make use of the available policy capability, skills and quality frameworks.

The policy capability initiatives developed in the New Zealand public sector seem to have relied on efforts to increase the ability of policy advice producers in the government departments and ministries so that they are likely to produce better policy advice.

The overview of policy capability initiatives shows that improvement in the policy capability of an individual or an organisation is assumed to be reflected in the quality of policy advice they produce. It is also understood from the overview that policy capability is not reliant only on the analytical ability or vision or any single specific attribute of the policy advice producers, but on other considerations such as the cost of producing policy advice, collaboration with other agencies, and links between policy outputs and targeted policy outcomes by the government of the day. Achieving improved policy capability involves changing policy practices, which may include the process of developing policy analysis, the quality of policy inputs including people skills, evidence, and methods, and the way policy advice is presented. Government agencies' need for better policy 
capability to produce high-quality policy advice remains under constant challenge, despite the many and various initiatives developed.

This preliminary understanding from the overview of the policy capability initiatives developed in the New Zealand public sector between 1990 and 2015 increases my curiosity about what exactly policy capability is, how policy capability is perceived by policy staff, organisations and systems, how the quality of policy advice is understood by various actors, and what efforts organisations make to improve policy capability and thus advice. Overall, I wonder what influences the policy actors, the initiators and the users of the initiatives, and the choice and use of initiatives in government departments and ministries and other government units in the New Zealand public sector.

\subsection{Overview of Research}

\section{Research Question}

This thesis examines some initiatives in the New Zealand public sector which were developed to improve policy capability and the quality of policy advice. The purpose is to identify the changes in policy practices because of the developed initiatives and influences on the initiators' choice and use of initiatives. It uses initiatives as a focus for examining changes in policy practices with the following research question: What central government and agency-led initiatives have been developed to achieve improved policy capability and high-quality policy advice, why, and with what consequences?

\section{Scope of Research}

The scope of this study is limited to the effects of initiatives on the policy capability of the agencies, their policy analysis practices and production of policy advice, and the quality of that policy advice from 1990 to 2015 in New Zealand. The study considers three agencies in the New Zealand public sector: The Ministry for the Environment (MfE), the Ministry of Transport (MoT) and the Auckland Council (AC). The timeline considered is between 2008 and 2015 


\section{Overview of Research Design}

This study is a qualitative inquiry. It uses the case-study method to understand the influences on and implications of various initiatives in terms of changes in policy practices. To appreciate the initiators' choice and use of initiatives to improve policy capability and policy advice, I sought to observe similarities and difference between their activities and the approaches with the initiatives. I observed how similarly and/or differently the initiators designed and approached their initiatives, then developed explanations for why they do what they do. Finally, I analysed their choice and use of initiatives. The approach required the selection of different types of cases with some similarities.

The three organisations from the New Zealand public sector, the MoT, MfE and AC have been chosen purposefully. The MoT and MfE are both overseen by the central government, while the AC is a local government body. The MoT is a small policy-focused ministry, which has only one minister and two associate ministers as its immediate clients. In contrast, the MfE is a ministry that needs to serve two ministers, one for the environment and one for climate change, among its immediate clients for policy advice, which also include two associate ministers for the environment. However, as the lead organisation of the natural resources sector, which is a grouping of several government agencies, it serves a pool of several ministers. The AC has its mayor and the councillors, who are elected, as its immediate clients. A preliminary study based on publicly accessible information suggested the time-frame for the cases, 2008 to 2015, because all these organisations developed various initiatives within this time.

The study involved document analysis and face-to-face semi-structured interviews with professionals occupying various roles in the policy analysis and advisory process. Each interview lasted for approximately one hour and the interviews took place where the interviewees felt comfortable. Further information on the research design is presented in Chapter 3. 


\section{Structure of Thesis}

This thesis consists of eight chapters. In Chapter 2, the literature is reviewed covering the multiple views and approaches through which policy analysis is understood, because policy analytical capability strongly supports policy capability. The understanding of policy analysis, for the purposes of this thesis, is the activities of policy advice producers for analysis in and for policy processes and limited to the policy formulation stage of a policy process only, rather than analysis of the policy process.

The literature on policy capability is then reviewed, identifying three different kinds of policy capabilities, namely policy analytical, management and political capability at three levels, individual, organisation and system.

The qualitative research design used for this study is set out in detail in Chapter 3. Central-government initiatives are examined in Chapter 4 to identify changes in policy practices and the influences on policy analysis and advice, and to determine which types of policy capability became more or less important under which conditions and influences.

The basic information about the three case organisations is given in Chapter 5 , which includes information about their organisational history in brief, their structure, policy leaders and staff, policy clients, mission, and challenges. It briefly compares their challenges.

What initiatives were developed, why they were developed, and the consequences are covered in Chapter 6. The initiatives developed between 2008 and 2015 in three cases are discussed, classifying them into two groups: initiatives to improve policy capability and initiatives to achieve high-quality policy advice. The drivers, forms and design of the initiatives, the actors' use of different approaches, and the perceived consequences are reported first. The similarities and differences in the actors' working with the various initiatives are described, and the cases are summarised at the end. The overall purpose of this chapter is to identify the changes in policy practices, using initiatives as a framework to examine policy practices. 
The findings are explained in Chapter 7 by considering the findings, set out in Chapter 6 , in light of the theoretical understanding gained from the review of literature, in Chapter 2. Specifically, the chapter looks across the cases in the New Zealand context to identify the influences that drove changes in policy practices in the three cases. Generalisations are made only across the cases, recognising the limitations of the case study method. The conclusion is drawn in Chapter 8. 


\section{CHAPTER 2: Literature Review}

\subsection{Introduction}

Policy advice clients' continued concern with policy capability and policy advice producers $^{\prime 2}$ continued responses to the identified concern by developing initiatives, overviewed in Chapter 1, seem to show an implicitly assumed deterministic relation between 'initiatives' and 'policy capability'. It appears that if policy capability improving initiatives are successful in achieving their objectives, then policy advice producers' policy capability is likely to be improved. Policy clients' mention of producers' poor policy analysis as an obstacle to producing high-quality policy advice also apparently indicates that the rigour of policy analysis is expected to produce high-quality policy advice. Thus, a relation between 'initiatives', 'policy capability', 'policy analysis' and 'policy advice' is implied, such that 'successful' initiatives are assumed to improve producers' policy capability to generate high-quality policy analysis which then yields high-quality policy advice. In this chapter, I first scrutinise this view in light of current knowledge on 'policy capability', 'policy analysis' and 'high-quality policy advice'. 'Improved policy capability' and 'high-quality policy advice' are found to be interrelated. The dynamic influences on policy analysis and advice and the interaction of many variables in multiple ways together make the interrelationship between capability and advice complicated. Second, I present how 'policy practice' is evolving to respond to these dynamic influences. This chapter provides the basis for explaining the choice and use of initiatives developed and adopted in the New Zealand public sector.

\section{The Organisation of the Chapter}

The literature review has three sections. First, the relation between 'policy capability' and 'high-quality policy advice' is examined. The concept of 'policy capability' and multiple views on 'high-quality' policy advice are presented before showing the relation between them. In theory, policy capability is understood as comprising four constituents: policy knowledge, skills, competencies, and behaviours. Policy capabilities can be of three types: analytical, management and political and these types of capability

\footnotetext{
${ }^{2}$ According to the definition by (Bromell, 2010a)
} 
are each found at different levels: individual, organisational and system. Thus, 'policy capability' refers to intellectual processes and abilities that are aided by policy-specific knowledge, skills, competencies, and behaviours at individual, organisational and system levels in undertaking policy analysis to develop policy options for the clients for policy advice.

With respect to the quality of policy advice, there are multiple clients who perceive 'high-quality' from their standpoints and there are multiple measures available which do not converge to a single view of 'high-quality'. A perceived assessment of policy capability by some measures for the quality of policy advice, therefore, seems problematic.

The concept of policy analysis is considered in the second section. Policy analysis is understood here simply as the activities that policy advice producers in government organisations undertake to develop policy advice for the clients. The discussion on the evolution and comparative perspectives of policy analysis shows how the field is developing to accommodate dynamic influences on policy analysis.

The third section focuses on how policy practices are evolving to respond to everchanging dynamic influences with a focus on 'professionalising' policy analysis and advice.

\subsection{Policy Analysis and the Quality of Policy Advice}

The overview of the initiatives developed by the central government agencies and three New Zealand government organisations (the two government ministries and one local council, collectively referred to as 'agencies'), presented in Chapter 1, indicates that initiatives were developed to improve policy capability and produce high-quality policy advice. How the literature considers the relation between 'policy capability' and 'highquality policy advice' is the subject of this section. The concept of 'policy capability' and multiple views on 'high-quality policy advice' are explored first and then the relation between them is presented. 


\subsubsection{The Concept of Policy Capability}

'Policy capability' and 'policy capacity' are often used interchangeably in the literature. However, some scholars define them differently. The objectives of this section are to show how 'policy capability' is assessed in theory; how 'policy capability' and 'policy capacity' are closely related and used interchangeably; and how a conceptual framework for understanding policy capability is developed.

Since the fields of policy, management, and leadership are converging, it is not easy to separate policy capability from other kinds of pertinent capabilities (C. Scott, 2008b). This section, nevertheless, is aimed at identifying the distinctive features of policy capability and separating it from the other terms. Before clarifying the meaning of 'policy capability', some capability terminology is outlined here to demonstrate common elements. Terms such as 'capabilities', 'capacity', 'strategic capabilities', 'service delivery capabilities', 'core capabilities', 'dynamic capabilities' and 'capability management' are closely associated but can be distinguished.

\section{Capability}

'Capability', in its simplest form, refers to the ability of a worker/professional to execute a specified course of action. It answers the simple question: 'Can the worker do the task at the point of work?' which simply refers to the ability of the worker to meet the purpose of the given task. Expanding, 'capability' entails whether a worker has the necessary knowledge, skill, mind-set/behaviour and physiology necessary to do a task (Matthews, 2013, p. 36). These components of capability attach to the worker. But components in the working environment of the worker also affect whether or not workers are capable of a task. These components include performance-support aids and information such as tools, culture, management style, mandated systems and processes, incentives and feedback (Matthews, 2013, pp. 39-40). 'Capabilities' are also defined by Barney (1991) as bundles of assets developed within an organisation which is different from Matthews (2013) definition in terms of the ability to perform.

There are other associated capability terms such as 'core capabilities' and 'strategic capabilities'. 'Core capabilities' are about how to enable the delivery of the products and 
services that an organisation offers (Pratt \& Horn, 2014, p. 49), also termed as 'service delivery capabilities'. 'Strategic capabilities' are related to how best an organisation prepares itself for future challenges and delivers on results (Pratt \& Horn, 2014, p. 49). The discussion of strategic capabilities, therefore, focuses on an organisation's planning for the future and strategies to achieve results, along with how to align and integrate the various resources of the organisation.

'Capability management' refers to the branch of knowledge that deals with the highlevel integrative function of aligning systems, people, policies, and information and physical resources towards the strategic intent of an organisation (Pratt \& Horn, 2014, p. 49). Another recent concept is that of 'dynamic capabilities' which scholars define as 'the routines, structures and processes which support the productive activity of organisations, and/or enable them to adapt and change...[building] on competences and capabilities' (Eisenhardt \& Martin, 2000; Teece, Pisano, \& Shuen, 1997). 'Competences' is a term that has been used to refer to individual skills, attributes, and knowledge (Blackman, Buick, O'Donnell, O'Flynn, \& West, 2012, p. 45).

\section{Capacity}

'Capacity' is sometimes used interchangeably with 'capability' while some scholars define them differently. According to Franks (1999, p. 52),

Capability refers to the knowledge, skills and attitudes of the individuals, separately or as a group, and their competence to undertake the responsibility assigned to them. Capacity, on the other hand, refers [to] the overall ability of individuals or groups and the organisations combined to actually perform the responsibilities.

'Capacity', as a concept, was originally developed in Economics, in the context of 'relative ratios of inputs to outputs and the degree to which capital investment augmented productive capacity (fixed capital, physical infrastructure)' (Tiernan \& Wanna, 2006). 
TMP Worldwide is an international recruiting agency (TMP Worldwide, 2018). In TMP'S Worldwide's Job index, 'human capability' is seen as the sum of 'capacity' and 'opportunities'. People's skills, knowledge, and attitudes are referred to collectively as 'capacity' whereas 'human capability' is seen as matching capacity with opportunities (the utilisation of capacity) from the recruiter's point of view (TMP Worldwide, 2018).

\section{Policy Capability}

'Policy capability' has been defined as having four constituents: the knowledge, skills, competencies and behaviours required for policy analysis (C. Scott, 2008b, p. 11). These constituents are attributable at individual, organisational and system levels. Policy capability is also understood as something that can be improved by recruitment, training, agency alignment and performance (Teasey \& Forword, 2012, p. 3). The term is also used to mean the necessary generic skills, professional knowledge and subjectspecific knowledge of policy professionals (The Treasury of New Zealand, 2012-2013). Defining policy capability, Tiernan and Wanna (2006, p. 8) say: 'capability is the effective power, ability and volition to make decisions or take actions. It is partly innate and partly learned'.

Policy makers in the Australian Commonwealth Scientific and Industrial Research Organisation (CSIRO) define policy capability, in a scientific context, as:

An enduring, multidisciplinary, synergistic combination of relationships, knowledge, understanding, expertise, equipment and facilities that can be applied to a range of scientific research problems to achieve national and/or international impact. Cited in Tiernan and Wanna (2006, p. 8)

The definition by Painter and Pierre $(2005$, p. 2 ) as 'the ability to marshal necessary resources to make intelligent collective choices about setting strategic directions for the allocation of scarce resources to public ends' suggests that improving policy capability involves including strategic considerations in policy analysis.

Policy capability is a concept that encompasses the attributes, behaviours, and environment necessary for professionals to complete a task using their skills and 
knowledge. Policy capability involves not only the knowledge, skills, competencies, and behaviours required to perform policy tasks but also how they can be acquired. The discussion of 'policy capability' includes how to sharpen the constituent knowledge, skills, competencies, and behaviours by further learning, which in turn involves organisational arrangements for training, coaching, and mentoring. The issue also includes how to recruit the best professionals from the job market and retain them, as well as the tools or frameworks that support the work of policy professionals. The boundaries of policy capability, hence, cannot be defined neatly.

Policy knowledge, skills, competencies, and behaviours, the four constituents of policy capability, are equally applicable at the levels of organisations and systems. According to C. Scott (2008a, p. 7),

While such attributes and behaviours are often specified with respect to individuals, competency and capability issues can equally be analysed in terms of groups, agencies and departments, the whole of government, and even the nation.

Any discussion of declining policy capability, therefore, needs to be specified in terms of shortcomings in those constituents at the individual, organisational and sector levels.

\section{Policy Capacity}

There is no dearth of literature on defining policy capacity and describing its nature and composition, and there are many 'different definitions of policy capacity that highlight different dimensions of the subject' (Wu, Ramesh, \& Howlett, 2015, p. 166). Painter and Pierre $(2005$, p. 2$)$ describe policy capacity as the ability of policy makers to make 'intelligent collective choices about and set strategic directions for the allocation of scarce resources to public ends'. Policy capacity is also defined as a process of exploring genuine policy options relatively free from vested interests and ideologies (Tiernan \& Wanna, 2006, p. 7).

After surveying the field, Tiernan and Wanna (2006, p. 6) arrive at an understanding of 'capacity' (specific to the context of 'policy capacity') as follows: 
Capacity refers to the extrinsic resources available to institutions - a utility paradigm including the policy skills mix, the instruments and tools, infrastructure and organisational resources necessary to perform their tasks or intended goals. It concerns their wherewithal to respond to changing circumstances; with capacity building involving the skilling and equipping organisations.

The definitions of policy capacity by Tiernan and Wanna (2006) and Painter and Pierre (2005) suggest that the distinction between 'policy capability' and 'policy capacity' is rather thin. The definition of 'capacity' offered by the Australian Commonwealth Scientific and Industrial Research Organisation (CSIRO) highlights the difference between 'policy capability' and 'policy capacity': it defines capacity as 'the organisation having the potential ability 'but not the resources' to undertake something' as cited in Tiernan and Wanna (2006, p. 8).

'Policy capability' and 'policy capacity' are different in that 'the latter tends to imply structural and organisational (physical) capacities while the former refers to intellectual processes and abilities to decide and/or perform' (Tiernan \& Wanna, 2006, p. 9). 'Policy capability' refers to intellectual processes and abilities that are aided by policy skills, knowledge, competencies and behaviours at individual, organisational and system levels. New Zealand and the United Kingdom tend to use 'policy capability' whereas 'policy capacity' is used in Australia government reports and the literature that originates from Australia to refer often to the same concept. Thus, in the context of this thesis, 'policy capability' and 'policy capacity' are interchangeable.

\subsubsection{A Modified Conceptual Framework for Understanding Policy Capability}

The conceptual framework for understanding policy capacity by Wu et al. (2015) is modified here, with the understanding that 'policy capability' and 'policy capacity' are interchangeable, to develop a conceptual framework for policy capability. The purpose is to position this thesis research within a conceptual framework for understanding policy capability. The framework by Wu et al. (2015) is discussed first, before showing its modifications. 


\section{A Conceptual Framework for Understanding Policy Capacity}

Wu et al. (2015) define policy capacity, similarly to Gleeson, Legge, and O'Neill (2009) and Gleeson, Legge, O'Neill, and Pfeffer (2011), as 'the set of skills and resources - or competences and capabilities - necessary to perform policy functions' (Wu et al., 2015, p. 166). Using this definition, they have developed an overall framework of policy capacity (see Table 2.1). The nested logic of this model is shown in Figure 2.1.

Table 2.1: Overall Framework of Policy Capacity

\begin{tabular}{|l|l|l|l|}
\hline \multicolumn{2}{|l|}{ Policy Capacity: Skills and Resources } \\
\hline \multirow{2}{*}{$\begin{array}{l}\text { Levels of Resources } \\
\text { and Capabilities }\end{array}$} & \multicolumn{4}{l|}{ Skills and Competences } & Political \\
\cline { 2 - 4 } & Analytical & Operational & $\begin{array}{l}\text { Individual } \\
\text { Political } \\
\text { Capacity }\end{array}$ \\
\hline Individual & $\begin{array}{l}\text { Individual } \\
\text { Analytical } \\
\text { Capacity }\end{array}$ & $\begin{array}{l}\text { Individual } \\
\text { Operational } \\
\text { Capacity }\end{array}$ & $\begin{array}{l}\text { Organisational } \\
\text { Political } \\
\text { Capacity }\end{array}$ \\
\hline Organisational & $\begin{array}{l}\text { Organisational } \\
\text { Analytical } \\
\text { Capacity }\end{array}$ & $\begin{array}{l}\text { Organisational } \\
\text { Operational } \\
\text { Capacity }\end{array}$ & $\begin{array}{l}\text { Systemic } \\
\text { Political } \\
\text { Capacity }\end{array}$ \\
\hline Systemic & $\begin{array}{l}\text { Systemic } \\
\text { Analytical } \\
\text { Capacity }\end{array}$ & $\begin{array}{l}\text { Systemic } \\
\text { Operational } \\
\text { Capacity }\end{array}$ &
\end{tabular}

Source: Wu et al. (2015, p. 167)

Figure 2.1: A Nested Model of Capacity

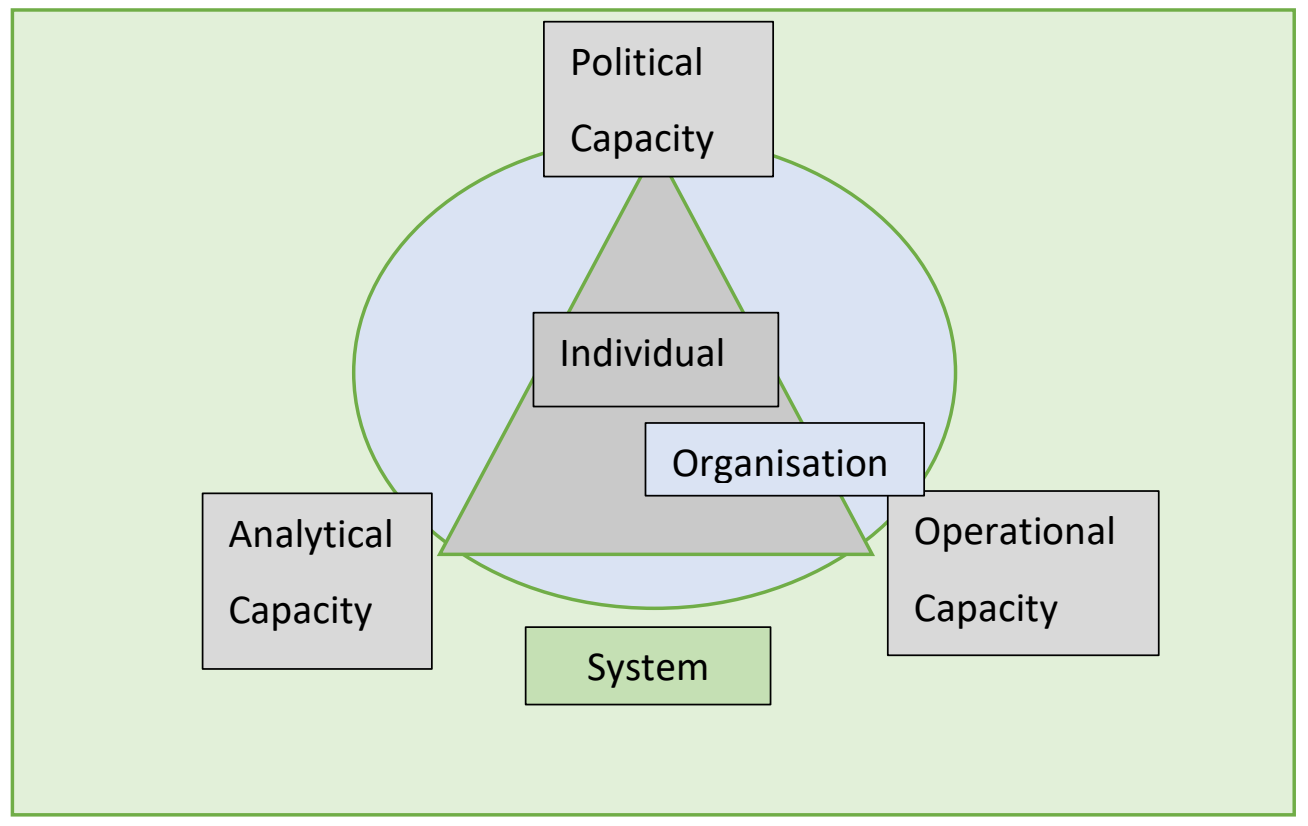

Source: Wu et al. (2015, p. 168) 


\section{A Modified Conceptual Framework for Understanding Policy Capability}

The modified conceptual framework for policy capability (see Table 2.2 and its logic in Figure 2.2) retains Wu et al.s' (2015) view of the interconnectedness of three types of capabilities and at three levels. The modified conceptual framework, as does that of Wu et al. (2015), relies on Moore's (1995) analysis from a policy management perspective and comprises three sets of skills and three levels of capabilities.

The modification addresses the distinction in the literature between 'policy capability' and 'policy capacity'. In place of policy capacity, consisting of both skills and resources, policy capability within the modified conceptual framework is viewed as intellectual processes and abilities to decide on and/or perform the application of knowledge, skills, competencies and behaviours. In addition, the term 'management' replaces 'operational', as more pertinent for the aims of this thesis.

Table 2.2: Overall Framework of Policy Capability

\begin{tabular}{|l|l|l|l|}
\hline Policy Capability: Knowledge, skills, competencies, and behaviours \\
\hline \multirow{2}{*}{$\begin{array}{l}\text { Levels of } \\
\text { Capabilities }\end{array}$} & \multicolumn{3}{|l|}{ Types of Capabilities } \\
\cline { 2 - 4 } & Analytical & Management & Political \\
\hline Individual & $\begin{array}{l}\text { Individual } \\
\text { Analytical } \\
\text { Capability }\end{array}$ & $\begin{array}{l}\text { Individual } \\
\text { Management } \\
\text { Capability }\end{array}$ & $\begin{array}{l}\text { Individual } \\
\text { Political } \\
\text { Capability }\end{array}$ \\
\hline Organisational & $\begin{array}{l}\text { Organisational } \\
\text { Analytical } \\
\text { Capability }\end{array}$ & $\begin{array}{l}\text { Organisational } \\
\text { Management } \\
\text { Capability }\end{array}$ & $\begin{array}{l}\text { Organisational } \\
\text { Political } \\
\text { Capability }\end{array}$ \\
\hline Systemic & $\begin{array}{l}\text { Systemic } \\
\text { Analytical } \\
\text { Capability }\end{array}$ & $\begin{array}{l}\text { Systemic } \\
\text { Management } \\
\text { Capability }\end{array}$ & $\begin{array}{l}\text { Systemic } \\
\text { Political } \\
\text { Capability }\end{array}$ \\
\hline
\end{tabular}

Source: Adapted from Wu et al. $(2015$, p. 167) 
Figure 2.2: A Nested model of Capability

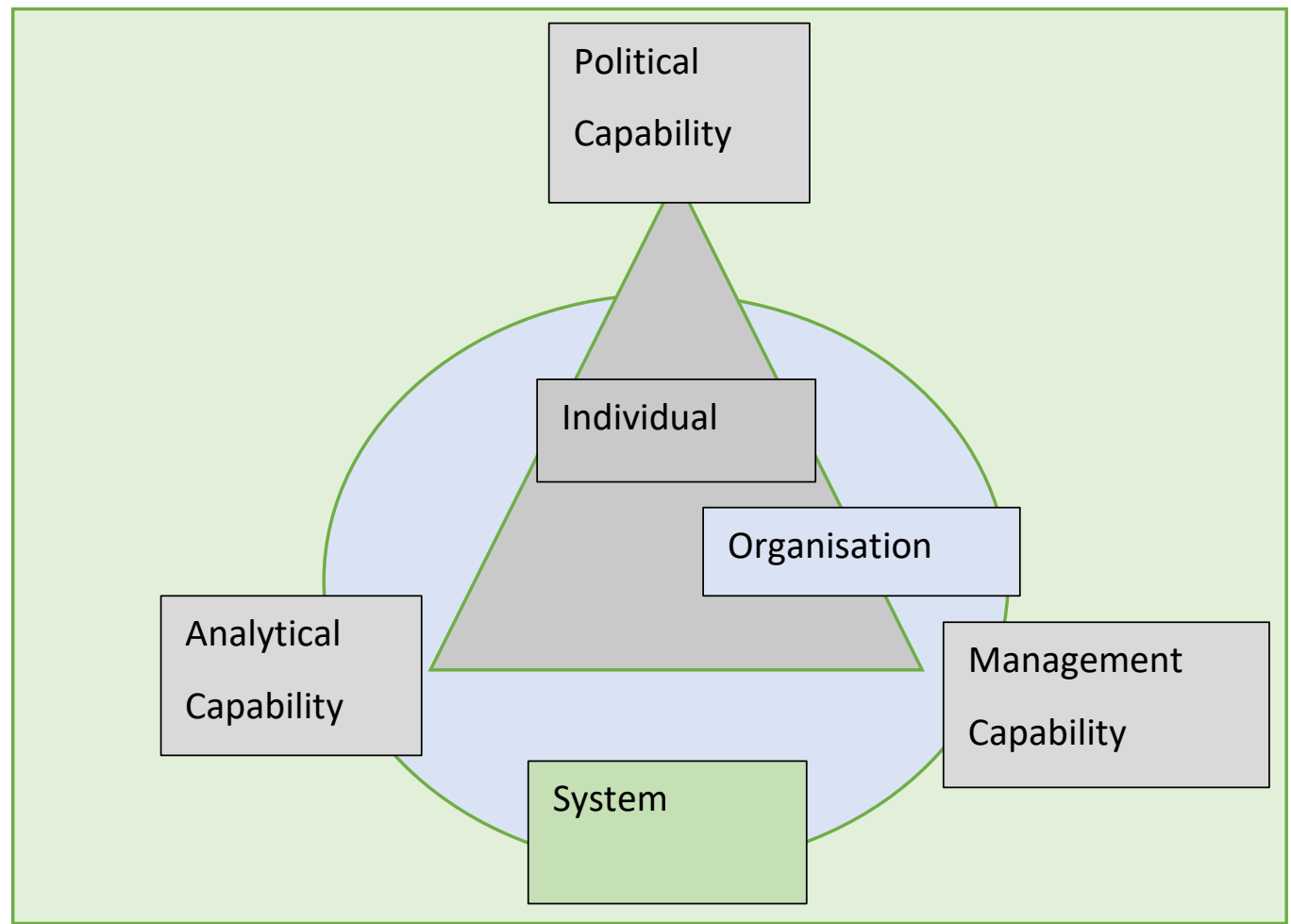

Source: Adapted from Wu et al. (2015, p. 168)

\subsubsection{Policy Capabilities of Different Types at Different Levels}

Wu et al. (2015, p. 168) wrote: 'Although these analytical, operational and political-level capacities are inter-connected, they are governed by different considerations and their contributions to policy process are separable and irreplaceable', leading to them to call for specified policy capacities at different levels, as shown in Table 2.3. These specifications for different capacities are equally applied to understand policy capabilities at different levels and types while examining the initiatives.

Policy individual analytical capability refers to the ability of individuals in a policyrelevant organisation to produce valuable research and analysis on topics asked of them, following Howlett (2009), to deliver policy advice for the clients for policy advice, which is influenced by the capability of other policy staff (Colebatch, 2006) and the quality of policy inputs. Policy organisational analytical capability refers to the ability of the organisation in utilising individual analytical capability of its policy staff. 
Howlett (2015) and Wu, Ramesh, and Howlett (2018, pp. 4-14) similarly identified: expertise in planning, staffing, budgeting, delegating, directing and coordinating as policy individual operation capabilities. The organisational commitment to achieving goals, availability of fiscal and personnel resources, coordination of internal processes, performance management, and administrative accountability were considered as policy organisational operational capabilities.

Policy individual management capability here refers to the activities of the senior policy staff who seldom are directly involved, but bring further inputs into policy analysis and advice, such as client considerations, political feasibility, cost, timeliness and other such relevant issues; provide guidance and feedback to other policy staff; and manage developing policy advice in a team. Policy organisational management capability refers to the availability of organisational support services and resources with which the leaders of the organisation develop plans, make strategies and execute them not only to achieve but also to maintain policy capability for now and future.

The difference with the definition of Howlett (2015) and Wu et al. (2018) here is how 'policy capacity' and 'policy capability' are defined: 'capacity' by the availability of resources and skills whereas 'capabilities' by the accomplishment of skills, knowledge, competencies and behaviours with respect to policy analysis. 'Operation' and 'management' are used interchangeably without referring to any differences in their meaning. 
Table 2.3: Different Types of Policy Capacity at Different Levels

\begin{tabular}{|c|c|c|c|}
\hline 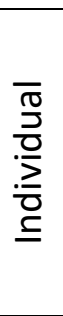 & $\begin{array}{l}\text { Individual } \\
\text { Analytical Capacity } \\
\text {-knowledge and skills } \\
\text { in policy analysis and } \\
\text { evaluation }\end{array}$ & $\begin{array}{l}\text { Individual } \\
\text { Operational Capacity } \\
\text {-expertise in planning, } \\
\text { staffing, budgeting, } \\
\text { delegating, directing and } \\
\text { coordinating }\end{array}$ & $\begin{array}{l}\text { Individual } \\
\text { Political Capacity } \\
\text {-knowledge about } \\
\text { policy process and } \\
\text { stakeholders' positions }\end{array}$ \\
\hline & $\begin{array}{l}\text { Organisational } \\
\text { Analytical Capacity } \\
\text {-availability of } \\
\text { individuals with } \\
\text { analytical capability } \\
\text {-machinery and } \\
\text { processes for } \\
\text { collecting and } \\
\text { analysing data } \\
\text {-organisational } \\
\text { commitment to } \\
\text { evidence-based policy }\end{array}$ & $\begin{array}{l}\text { Organisational } \\
\text { Operational Capacity } \\
\text {-organisational } \\
\text { commitment to achieving } \\
\text { goals } \\
\text {-availability of fiscal and } \\
\text { personnel resources } \\
\text {-coordination of internal } \\
\text { processes } \\
\text {-performance } \\
\text { management } \\
\text {-administrative } \\
\text { accountability }\end{array}$ & $\begin{array}{l}\text { Organisational } \\
\text { Political Capacity } \\
\text {-legitimacy of the policy } \\
\text { process } \\
\text {-processes for } \\
\text { stakeholder } \\
\text { engagement } \\
\text {-access to key } \\
\text { policymakers }\end{array}$ \\
\hline & $\begin{array}{l}\text { Systemic } \\
\text { Analytical Capacity } \\
\text {-systems for } \\
\text { collecting and } \\
\text { disseminating } \\
\text { information } \\
\text {-access to } \\
\text { competitive policy } \\
\text { advisory systems } \\
\text {-political support for } \\
\text { rigorous policy } \\
\text { analysis and } \\
\text { evaluation }\end{array}$ & $\begin{array}{l}\text { Systemic } \\
\text { Operational Capacity } \\
\text {-inter-governmental and } \\
\text { inter-agency coordination } \\
\text {-coherence of policy } \\
\text { communities and } \\
\text { networks } \\
\text {-clarity in agencies' roles } \\
\text { and responsibilities }\end{array}$ & $\begin{array}{l}\text { Systemic } \\
\text { Political Capacity } \\
\text {-political accountability } \\
\text { for policies } \\
\text {-trust in government } \\
\text {-participation of non- } \\
\text { state actors in policy } \\
\text { process } \\
\text {-presence of policy } \\
\text { entrepreneur }\end{array}$ \\
\hline
\end{tabular}

Source: Adapted from Wu et al. (2018, pp. 1-2)

There is a vast literature on policy analysis, both academic and practitioner, that outlines taxonomies and frameworks for policy work as an activity and process, the role and values of policy analysts and advisers and associated policy analysis styles, for example, Bardach (2012), Weimer and Vining (2017), Colebatch (2006), Hill (2005), John (2012), Sabatier (2007), Considine (1994). The scholarship of Michael Howlett, M Ramesh, and A Perl (2009) on policy cycles and subsystems has shown how an analyst can identify the policy actors and institutions and thus wider policy environment in which the analyst 
performs. There is also literature on policy methods that suggests how to do policy analysis considering the constraints of policy analysts in practice, for example, Winer (1983). Scholars such as C. Scott and Baehler (2010), Cairney and Geyer (2015), and Geyer and Rihani (2010) have sketched the complexity with public policy. Laking (2000) has considered advice as an input into policy decision processes and depicted the role of advisors in different perspectives of the policy process, specifically under open and learning system (as views of the process). How to understand the success of policy work is captured in McConnell (2010) and Nagel (2002).

While policy knowledge refers to what an analyst needs to know to do policy analysis, policy skill is the ability of the analyst to make use of policy knowledge. Competencies refer to a nuanced set of attributes, which scholars have expressed in various ways. These attributes refer to 'the abilities that people are expected to demonstrate on the job' (The Treasury of New Zealand, 2008); the abilities and skills-sets the public sector does or should possess (Lodge \& Hood, 2003); individual skills and accomplishments or group/organisational expertise (Tiernan \& Wanna, 2006, p. 5). Traditionally, competency refers to the ability to perform specific functions or tasks or set of tasks reliably and proficiently (Tiernan \& Wanna, 2006).

While competency has more than one meaning, these different definitions broadly agree that competence refers to actions or accomplishments which are obtained drawing on policy knowledge and skills. Further, competencies are not generic. Different government problems may require different competencies (Lodge \& Hood, 2003, p. 139) as such that 'the salience of particular competencies... is context and situation dependent' (Tiernan and Wanna, 2006, p.5). The agencies, therefore, tend to identify the competencies relevant for and specific to their work and to display these in their choice of competency framework. As an example, the Treasury outlined a required competencies framework comprising communication; external relationship management; intellectual leadership; people leadership; expertise; analysis skills; internal management; and work practice (The Treasury of New Zealand, 2008). 
In sum, 'policy capability', as envisaged by C. Scott (2008b) and Tiernan and Wanna (2006), refers to the policy knowledge, skills, competencies, and behaviours required for policy analysis, which can be partly learned and partly innate, and can be analysed in terms of individuals, organisations and systems. 'Policy capability' also covers the environment necessary for policy professionals to complete their tasks, using their skills and knowledge which can be sharpened by training, on-the-job learning, using tools or frameworks, or coaching, or by recruiting and retaining the best. There is a scope for analysis in terms of individuals, groups, agencies, and departments.

The discussion until this point has concerned policy knowledge, skills, competencies, and behaviours at different levels, as needed to achieve policy capability. The following section shows who and what determines the quality of policy advice, and how it is judged, measured or assessed in order to better reveal the critical relation between policy capability and the quality of policy advice. The subsequent sections outline the influences and show how the policy practices are gradually changing and responding to meet the policy advice producers' challenges to produce 'high-quality' policy advice.

\subsubsection{Multiple Views on High-Quality Policy Advice}

Policy advice is the output of policy analysis and is also a service delivered to clients. The quality of policy advice can, therefore, be judged both by the 'rigour' of policy analysis and the satisfaction of clients that the advice met their demands. But clients are multiple and 'quality', it is to be expected, appeals diversely. Customers or clients at different levels assess and appreciate quality differently. The determinants of the quality of policy advice, therefore, vary depending on who judges it.

Central agencies have their views on the overall quality of policy advice produced by the agencies (The Treasury of New Zealand, 2012-2013). Some agencies have their measures or understandings for assessing the quality of policy advice. Immediate recipients of policy advice appreciate quality by comparing it with their expectations. For example, ministers consider how policy advice produced by the public sector helps achieve Government's objectives. The ultimate stakeholders, the target population of the policy 
advice, assess the impact of the resultant policy on their life, generally, as the basis of judging the quality of the policy.

Thus, the quality of policy advice seems to need to meet the expectations of multiple customers to be universally classed as high-quality advice. The diverse views among customers with their subjectivity and dissimilar interests, the different kinds of clients, and differing views about the process of ensuring quality are just some challenging factors in meeting 'quality' expectations.

Furthermore, the assessment of the quality of policy advice is continuous rather than a one-point affair. The immediate client assesses the advice when it is presented. Then, organisations judge quality in part by the acceptance of the advice by the client/s. Various other stakeholders reflect their understandings of 'quality' by their satisfaction or dissatisfaction when the policy instrument is introduced. They also keep assessing the impact of policies over time. An appointed evaluator of policy advice may judge the quality of the advice by assessing the impact of policy after a reasonably long time. New considerations inevitably arise after the policy advice is promulgated and they, too, influence the assessment of the quality of policy advice.

Just as there are multiple views as to what constitutes 'quality', there are various standards to measure the quality of policy advice. For instance, the New Zealand Treasury (Table 2.4) and the New Zealand Institute of Economic Research ${ }^{3}$ (NZIER) (Table 2.5) have different criteria (New Zealand Institute of Economic Research [NZIER], 2012). The Treasury quality standard is indicative of the New Zealand central government agencies' view on what policy advice producers should follow to produce high-quality policy analysis and advice. The NZIER quality standard is a measure for determining the quality of policy advice produced in government agencies, if they seek an external review of the quality of the policy papers they produce. In addition to depicting divergent views on 'quality', these measures show that the quality of policy advice is

\footnotetext{
${ }^{3}$ An independent consultancy in New Zealand
} 
influenced by the quality of policy analysis - the rigor of the analysis, how the customer considerations are taken into account and how the advice is communicated to the clients.

Table 2.4: The Treasury Quality Standards for Policy Advice

\begin{tabular}{|c|c|c|}
\hline $\begin{array}{l}\text { Analytically rigorous } \\
\text { (analysis) }\end{array}$ & $\begin{array}{l}\text { Set in a wider strategic } \\
\text { context } \\
\text { (applied analysis) }\end{array}$ & $\begin{array}{l}\text { Customer focused and } \\
\text { persuasive (advice) }\end{array}$ \\
\hline $\begin{array}{l}\text { Relevant Frameworks } \\
\text { - Knowledge is up to date and } \\
\text { informed by recent thinking } \\
\text { and literature in the field } \\
\text { - Assumptions behind the } \\
\text { frameworks used are } \\
\text { explicit and consideration } \\
\text { has been given to how they } \\
\text { will be expected to play out } \\
\text { in the real world (a world } \\
\text { which includes information } \\
\text { and transaction costs, } \\
\text { market failure, government } \\
\text { failure, etc.), and } \\
\text { - Consideration has been } \\
\text { given to less traditional and } \\
\text { whether they would add } \\
\text { innovative or useful } \\
\text { perspectives. }\end{array}$ & $\begin{array}{l}\text { Strategic } \\
\text { - Advice is set in the } \\
\text { context of the Treasury's } \\
\text { results and informed by a } \\
\text { strategic view about what } \\
\text { is important. } \\
\text { - We are explicit about the } \\
\text { relative importance and } \\
\text { materiality of the issue, in } \\
\text { fiscal, economic and } \\
\text { strategic terms. } \\
\text { - Connections across policy } \\
\text { issues are made, ensuring } \\
\text { that Ministers receive a } \\
\text { whole-of-government } \\
\text { perspective. } \\
\text { - Advice considers the } \\
\text { long-term implications of } \\
\text { decisions and provides a } \\
\text { perspective that goes } \\
\text { beyond immediate } \\
\text { impacts } \\
\text { - We frame issues and help } \\
\text { set the agenda. }\end{array}$ & $\begin{array}{l}\text { Clear } \\
\text { Advice is compellingly } \\
\text { presented. It is: } \\
\text { - Brief and concise-key } \\
\text { messages should be readily } \\
\text { apparent to the reader } \\
\text { - Easy to read-has a clear } \\
\text { and logical structure, } \\
\text { avoids technical jargon and } \\
\text { uses visual devices such as } \\
\text { charts and tables where } \\
\text { possible. } \\
\text { - Pitched to suit the target } \\
\text { audience-uses appropriate } \\
\text { language, style and level of } \\
\text { detail, and } \\
\text { - Framed in terms of how it } \\
\text { fits with previous advice } \\
\text { and communications with } \\
\text { the Minister. }\end{array}$ \\
\hline $\begin{array}{l}\text { Robust reasoning and logic } \\
\text { - Advice has a clear purpose, } \\
\text { problem definition, } \\
\text { evaluation of options, } \\
\text { against criteria, and } \\
\text { assessment of risks and } \\
\text { opportunities. We come to } \\
\text { a conclusion and give } \\
\text { action-oriented } \\
\text { recommendations. }\end{array}$ & $\begin{array}{l}\text { Practical } \\
\text { - Issues of implementation, } \\
\text { technical feasibility, } \\
\text { practicality and timing are } \\
\text { considered and advice } \\
\text { accurately identifies } \\
\text { compliance, transitional, } \\
\text { legislative, revenue and } \\
\text { administrative } \\
\text { implications and costs. }\end{array}$ & $\begin{array}{l}\text { Timely } \\
\text { - Reports should meet } \\
\text { Ministers' need for advice } \\
\text { that helps in the decision- } \\
\text { making process (even if it } \\
\text { means, at times, that } \\
\text { advice is not fully } \\
\text { developed) and indicate } \\
\text { when a decision is } \\
\text { required. }\end{array}$ \\
\hline
\end{tabular}




\begin{tabular}{|c|c|c|}
\hline $\begin{array}{l}\text { Analytically rigorous } \\
\text { (analysis) }\end{array}$ & $\begin{array}{l}\text { Set in a wider strategic } \\
\text { context } \\
\text { (applied analysis) }\end{array}$ & $\begin{array}{l}\text { Customer focused and } \\
\text { persuasive (advice) }\end{array}$ \\
\hline $\begin{array}{l}\text { Evidence-based } \\
\text { Analysis is supported by } \\
\text { relevant evidence: } \\
\text { - Empirical methods are } \\
\text { sound, data gaps are } \\
\text { identified and the level of } \\
\text { confidence/certainty in } \\
\text { our empirical base is } \\
\text { explicit. } \\
\text { - New Zealand experience } \\
\text { of current and past policy } \\
\text { interventions are drawn } \\
\text { and, where relevant, the } \\
\text { experience of other } \\
\text { countries. } \\
\text { - Best judgement is done } \\
\text { despite data } \\
\text { imperfections; } \\
\text { information limitations are } \\
\text { acknowledged and } \\
\text { advised within them. }\end{array}$ & $\begin{array}{l}\text { Public sector consultation } \\
\text { Ministers receive advice that } \\
\text { enables them to engage with } \\
\text { their colleagues on a fully } \\
\text { informed basis because: } \\
\text { - Thorough and timely } \\
\text { consultation with other } \\
\text { government departments } \\
\text { has occurred and points } \\
\text { of difference, and the } \\
\text { reasons for these, are set } \\
\text { out, and } \\
\text { - Where possible, advice is } \\
\text { developed in conjunction } \\
\text { with relevant government } \\
\text { agencies. }\end{array}$ & $\begin{array}{l}\text { - Demonstrates awareness } \\
\text { of the wider environment } \\
\text { and political situation } \\
\text { - is based on a clear } \\
\text { understanding of the } \\
\text { desired outcomes of the } \\
\text { Minister/Government } \\
\text { - Relates to the perspectives } \\
\text { of Ministers, even if } \\
\text { suggesting something that } \\
\text { tests those perspectives, } \\
\text { and } \\
\text { - Recognises choices and } \\
\text { constraints Ministers face, } \\
\text { and includes a range of } \\
\text { option to address these. }\end{array}$ \\
\hline $\begin{array}{l}\text { Free and Frank } \\
\text { Our advice is honest, } \\
\text { impartial and politically } \\
\text { neutral-we have a duty to } \\
\text { alert Ministers to the possible } \\
\text { consequences of following } \\
\text { particular policies, whether } \\
\text { or not such advice accords } \\
\text { with Ministers' views. Good } \\
\text { free and frank advice is } \\
\text { offered with an } \\
\text { understanding of its political } \\
\text { context and the constraints } \\
\text { within which the Minister is } \\
\text { operating. }\end{array}$ & $\begin{array}{l}\text { Perspectives of wider } \\
\text { stakeholders } \\
\text { We understand and advise } \\
\text { Ministers on the perspective } \\
\text { of groups outside the public } \\
\text { sector consult with key } \\
\text { stakeholders and provide } \\
\text { advice on communications } \\
\text { where appropriate. }\end{array}$ & $\begin{array}{l}\text { Solution focused } \\
\text { We are proactive, } \\
\text { anticipating, as well as } \\
\text { responding to, Ministers' } \\
\text { needs. Advice suggests a clear } \\
\text { way forward ("Here is what } \\
\text { you can do" as well as "Here } \\
\text { is a problem") and includes a } \\
\text { range of practical options } \\
\text { (first best advice, but also } \\
\text { second and third) }\end{array}$ \\
\hline
\end{tabular}

Source: The Treasury Quality Standard (The Treasury of New Zealand, 2012-2013, pp. 62, 129) 
Table 2.5: NZIER Quality Standards for Policy Advice

\begin{tabular}{|c|c|}
\hline Rating & $\begin{array}{l}\text { Overview, key qualities and issues, and how it could have been } \\
\text { better }\end{array}$ \\
\hline \multicolumn{2}{|l|}{ Customer focus } \\
\hline Anticipation & $\begin{array}{l}\text { Addresses likely next steps and timeframes } \\
\text { Has all the necessary content to support next steps, and to pre- } \\
\text { empt unnecessary follow-up } \\
\text { Provides talking points, a ' } 25 \text { words or less' argument, or other } \\
\text { aids }\end{array}$ \\
\hline Risk and mitigation & $\begin{array}{l}\text { Identifies risks (acceptability, cost, effectiveness, implementation } \\
\text { etc.) } \\
\text { Indicates how risks would be managed (communication, } \\
\text { monitoring, trials, evaluation, exit etc.) }\end{array}$ \\
\hline Purpose \& context & $\begin{array}{l}\text { States the objective of the briefing clearly and early } \\
\text { Gives enough background to shape the discussion and resolution } \\
\text { Makes linkages to wider matters, such as strategy, long term } \\
\text { drivers, or other parts of the system }\end{array}$ \\
\hline \multicolumn{2}{|l|}{ Credible analysis } \\
\hline Problem definition & $\begin{array}{l}\text { Has a clear problem definition } \\
\text { Indicates the scale and scope of the issue }\end{array}$ \\
\hline Framework \& Options & $\begin{array}{l}\text { Shows evidence of an appropriate theory or logical approach to } \\
\text { support the analysis } \\
\text { Has logical assessment criteria and a clear explanation of how } \\
\text { the analysis applies } \\
\text { Shows evidence of appropriate consultation/engagement } \\
\text { Has clear recommendations that flow from the discussion } \\
\text { Is clear about who and how the recommendations would be } \\
\text { implemented }\end{array}$ \\
\hline Date \& Evidence & $\begin{array}{l}\text { Uses evidence and is clear about its strengths, sensitivities, and } \\
\text { limitations } \\
\text { Presents accurate numbers and calculations } \\
\text { Uses examples or international comparisons to make points }\end{array}$ \\
\hline \multicolumn{2}{|l|}{ Clear \& Concise } \\
\hline Language & $\begin{array}{l}\text { Uses plain English and minimises jargon } \\
\text { Uses short sentences and paragraphs to make the reading task } \\
\text { easier } \\
\text { Is uncluttered, and has no typos, grammatical errors, or other } \\
\text { slips }\end{array}$ \\
\hline Structure & $\begin{array}{l}\text { Is concise, and avoids duplication or unnecessary clutter } \\
\text { Uses meaningful subheadings as sign-posts and to tell a logical } \\
\text { story } \\
\text { Summarises the key points, preferably in well under a page }\end{array}$ \\
\hline Format & $\begin{array}{l}\text { Selects the medium (report, poster, presentation, one-pager) } \\
\text { that best fits the situation } \\
\text { Uses tables and charts that are easy to understand and read }\end{array}$ \\
\hline
\end{tabular}

Source: NZIER report-Review of quality of advice 2012 (NZIER, 2012, p. 10 Appendix B)

The above two measures show some similarities and differences between them. Both measures put importance on components such as analytical rigorousness; smooth and 
clear communication to the clients; and clients' needs. However, the Treasury measure focuses on the whole-of-government approach through strategic priorities, whereas the NZIER measure emphasises on the presentation of advice because it assesses policy advice as policy output.

From the point of view of the producer of policy advice, the quality of policy advice may be judged by two yardsticks. The first measures to what extent the policy advice has met the expectations of multiple clients. A second yardstick of the quality of policy advice is the rigour of the policy analysis undertaken. Although it is obvious that the rigour of the analysis will influence the development of policy advice, it remains open to question whether the quality of policy advice should be judged by the efforts of the policy analysts to demonstrate its basis in the persuasive evidence and reasonable arguments, or by the correctness of their conclusions.

By the 'correctness' of policy advice, I mean the extent to which the policy advice has addressed the issue or the problem in question. This can be assessed after the policy advice is implemented, and also at the evaluation stage of a policy process. Ignoring the common concerns about methods of evaluation, and assuming there is an agreed and acceptable way to evaluate policy advice, it seems logical to assess the quality of policy advice from its ability to proffer effective solutions for the problem under scrutiny. While this measure of the quality of policy advice may be interesting, it is less significant for this research because the evaluation stage of a policy process is not within the purview of this research.

The discussion until this point has presented the concept of 'policy capability' and multiple views on 'high-quality policy advice'. 'Policy capability' refers to policy knowledge, skills, competencies and behaviours that can be of three types: analytical, management and political, and it can be recognised at three levels: individual, organisational and system. With respect to the quality of policy advice, multiple clients judge the quality of policy advice from their standpoints that may not converge to reflect, overall, a single view of 'high-quality' policy advice. There are different measures 
to assess the quality of policy advice. Moreover, there is a question of who, among the clients, has the right to judge and value the quality of policy advice.

The following section presents the relation between 'policy capability' and 'high-quality policy advice'.

\subsubsection{The Relation between 'Policy capability' and 'High-quality Policy Advice'}

When there is no single standpoint on 'high-quality policy advice', what guides the work of policy? While policy analytical capability is only one type of policy capabilities among others such as policy management and political capabilities, it appears that the emphasis is on the rigour of policy analysis and why the focus is more on how the producers of policy advice produce policy advice and less on how the consumers/clients use the produced policy advice? ${ }^{4}$

The concept of 'policy capability', discussed above, has shown that improving 'policy capability' involves more than improving the policy capability of policy advice producers. It appears that 'improved policy capability' cannot be specified either by the rigour of analysis or policy advice producers' acquisition of constituents of policy capability alone. Improved policy capability seems, rather, contingent upon how different types of policy capability at different levels are utilised with a 'right mix' rather than just acquiring them to produce 'high-quality policy advice'.

Policy advice producers face many challenges to produce high-quality policy advice. First, they must know the types of policy capabilities required to apply in doing policy analysis because each type of policy capability is needed in varying degree to produce policy advice. Not all policy problems require the same set of policy capabilities. Second, there is a challenge in determining the 'right mix' of constituents of policy capabilities,

\footnotetext{
${ }^{4}$ See Parkhurst (2017) who provides new insights into the nature of political bias with regards to evidence and critically considers what an 'improved' use of evidence would look like from a policymaking perspective.
} 
while there are no predefined or prescribed single formulae available. Third, satisfying multiple clients who perceive 'high-quality' from their standpoints presents a challenge, as does maintaining professional standards, work ethics and ensuring the rigour of policy analysis.

I investigate, in this thesis, what influences the 'right mix' of policy capability constituents; what influences the work of policy in the public sector; and how policy practice changes and responds to try to achieve 'high-quality policy advice'. The investigation overall reflects on the relation between 'policy capability' and 'high-quality policy advice', and therefore the existing views on the relationship is highly pertinent.

In one clear strand of the literature, and despite the challenges sketched above, policy analysts are said to attempt to apply a scientific approach. A closer look shows that what is meant by 'science' is variously conceived. Nevertheless, while rocket science is different from social science, the commonality in different kinds of scientific research is manifested in the systematic efforts that organise knowledge in the form of verifiable explanations and predictions.

Demonstrating the 'science' strand, the New Zealand Prime Minister's Chief Science Advisor has advised policy analysts about the features of scientific research. They include high-quality and accessible data; robust and accessible data collection and analytical instruments; critical awareness of analytical assumptions and choices and of theoretical perspectives that underpin the research methodology; understanding of the limitations of even the most robust evidence; and adjusting expectations of certainty and managing uncertainty (Gluckman, 2013, p. 11). Policy analysis is, according to Gluckman (2013), a scientific or technical undertaking where a policy analyst applies a systematic approach to using evidence scientifically and wisely to develop high-quality policy advice.

Although a few scientists and philosophers believe that scientific knowledge is proven knowledge, all schools of thought agree that scientific knowledge is always tentative and open to refutation (Majone, 1989). In a statement that continues relevant today, 
Majone (1989) argued that the process of scientific research is craft than a purely logical activity:

the scientist utilizes knowledge and skills that are not themselves scientific but are acquired by practice and imitation..., the process of scientific research depends more on "knowing how" rather than "knowing that"; it is craft, a social process, rather than a purely logical activity.

'Craft knowledge' in this sense is positioned between subjective and objective knowledge. It is defined by Majone as 'less general and explicit than theoretical knowledge, but not as idiosyncratic as pure intention' (1989, p. 43-44).

Scholars argue that such craft knowledge is essential for the work of policy analysts (Majone, 1989; C. Scott \& Baehler, 2010). According to this view of policy work, a policy analyst acts as a craftsperson. The policy analyst collects data, information and evidence; uses different tools from the toolbox and methods as they deem appropriate; and understands the pitfalls and fallacies, to find solutions for a policy problem. The policy analyst then blends factual suggestions, logical inferences, mathematical and logical arguments, statistical inferences, expert opinion, local and international scholarship and anything else that seems relevant. If a blending technique is not a pure scientific method, what influences the blending style of a particular policy analyst? And when there are varying views of 'quality' from multiple clients, how does a policy analyst meet the client's quality expectations? The answers to these questions are sought in this study.

The discussion so far has shown that the 'rigour' of policy analysis is not a guarantor for producing 'high-quality' policy advice and 'high-quality policy advice' is not a complete reflection of 'improved policy capability'. A policy analyst acts as a craftsman in which the analyst is involved in a social proces which is neither a purely logical activity nor a pure intuitive activity. How a policy analyst balances between the two and what influences the work of policy development is the focus of the following section.

The review next moves to outline the dynamic influences on policy analysis with a discussion of evolution and comparative perspective of policy analysis. It is shown that 
trying to understand 'improved policy capability' without taking into considerations of the contextual influences is likely to generate an overly simplified view.

\subsection{Policy Analysis: Evolution, Comparative Perspectives and Influences}

This section discusses policy analysis as an ever-changing field with multiple views. Then it considers the way policy analysis is subject to evolution and dynamic influences from many sources. The discussion here, therefore, covers multiple views and comparative perspectives.

Policy analysis is multidisciplinary, and its boundaries cannot be determined by any single discipline. Many scholars from different disciplines have entered the discussion of policy analysis and created a rich diversity of opinion, possibly at the cost of clarity (Hogwood \& Gunn, 1984, p. 12). While Hogwood and Gunn (1984) find that the term 'policy analysis' is used interchangeably with 'policy sciences' and 'policy studies', these terms are also used by other scholars to represent different paradigms. (Weimer $\&$ Vining, 2017, p. 26) represent policy analysis as different from others policy research, social science research or classical planning.

There are various approaches to the analysis of public policy, such as the studies of the policy-content origins, intentions and operation of specific policies; studies of the policy process by which policies are made; studies of policy outputs; evaluation studies; studies seeking information on the implications of policy alternatives; process advocacy; and policy advocacy (Hogwood \& Gunn, 1984, pp. 26-27). Ideas on understanding policy analysis fall into two main streams: analysis of policy process and analysis in and for policy process (Parsons, 1995, p. xvi).

Analysis of policy process deals with how problems are defined, agendas set, policy formulated, decisions made, and policies evaluated and implemented. Analysis in and for the policy process is about the use of analytical research and advocacy in problem definition, decision making, evaluation and implementation (Parsons, 1995, p. xvi). The difference between the two is clearly visible in the Australian policy cycle, where 'policy 
analysis' is understood as one of eight stages of the policy cycle. The other seven stages are identifying issues, choosing policy instruments, consultation, coordination, decision, implementation and evaluation (Althaus, Bridgman, \& Davis, 2007).

Analysis in and for the policy process involves identifying a policy problem to yield policy alternatives, which are stated in a memorandum, issues paper or draft legislation, for which there is a specific client. It typically has a short time horizon and an openly political setting (C. Patton \& Sawicki, 1993, p. 20). It draws on theories, methods, and substantive findings from multiple disciplines and a process of multidisciplinary inquiry to create, assess, and communicate information to understand and improve policies (Dunn, 2004, pp. 1-2).

For this thesis, the alternate understanding of policy analysis as analysis in and for policy process is preferred. This understanding systematically separates a whole policy issue or public problem into its component parts to understand them fully and determine the underlying problem; and policy advice entails stitching the parts together to design and recommend the appropriate response to the problem (C. Scott \& Baehler, 2010, p. 22). The policy formulation stage of a policy process is the focus in this thesis.

Policy analysis, then, refers in this thesis to the activities of public-sector policy advice producers and their work to produce policy advice for clients. The producers of and clients for/consumers of policy advice are important actors who contribute to policy analysis and advice. This client-centric view accords with the view of Weimer and Vining, that 'Policy analysis is client-oriented advice relevant to public decisions and informed by social values' (Weimer \& Vining, 2005, pp. 23-24) and Moore's (1995) view of social value. The clients are multiple, and include ministers as immediate clients; sectors such as transport or natural resources; the cabinet; the public sector; and a very important client, the public. A policy manager is also a client for a policy analyst, and the analyst is expected to deliver policy outputs to the manager within the agreed terms of references or roles. 
Policy analysis has evolved over time differently in different jurisdictions, such that the field of policy analysis that exists in the $21^{\text {st }}$ century is quite different from that found in the field's earlier phases' (Radin, 2017, p. 85). The changes in policy analysis are reflective of dynamic changes in the sphere of public life over time and in diverse political, institutional, governmental, organisational and cultural settings. The field of policy analysis cannot control how public problems should be managed for solutions. Rather, the nature, type and magnitude of policy problems, the client-producer relations for policy advice in different countries, political structures, and levels and types of governments, have all influenced the way policy analysis is appreciated by the policy actors and scholars.

The significant development of policy analysis dates to the early 1960s, with its emergence as a profession in the USA, which has a lot of bearing on policy analysis today, although 'the profession of policy advising can be traced, in principle, to Plato's idealised republic' (C. Scott \& Baehler, 2010, p. 21). In 1961, the Planning, Programming and Budgeting System (PPBS), a decision allocation process, was established by the US Department of Defence, with a view to the rational analysis of programme choice and to removing politics from policymaking. PPBS was identified by Radin (2013) as the possible inception of policy analysis as a profession. The PPBS process relied on confidence that 'an increased use of knowledge and information would produce better decisions' (Radin, 2013, p. 16).

Policy analysis has continued to evolve in a way that is distinguished by Dror (1967) from systems analysis. Dror delineates the characteristics of policy analysts as government staff members, and advocates the creation of policy analysis as a profession as a means to improve policy decision-making. This has led to the creation of a 'technician' type of policy analyst in the USA who rely exclusively on the use of their technical skills rather than also using political skills (Rennie, 2013). But Meltsner (1979) distinguishes four different types of policy analysts: the technician; the entrepreneur; the politician; and the pretender and shows that better decision-making is not reliant only on technical skills of policy analysts. 
Policy analysis took on a new form in 1970s in the USA. Political leaders started taking interest in what analysis could offer in making better decisions. Analysis of data and evidence became a part of the decision-making process which encouraged different policy actors to seek to influence analysis to derive the desired policy decision. Consequently, it becomes 'a field with many voices, approaches and interests' (Radin, 2000, p. 74). Policy analysts are no longer only government staff members. Think tanks, private firms, policy research organisations, academic institutions and interest groups participate and contribute to policy analysis. Policy analysis has significantly changed from the technocratic model of the 1960s. As it is perceived in this century in the USA, it involves participatory processes, networking and a wide range of approaches. It is a field with multiple clients, languages, values, forms, and vested interests, an unclear sense of professional standards, and no clear definition of policy success; policy analysts perform a balancing act between analytical rigour and responsiveness to the clients (Radin, 2000, pp. 73-77).

Policy analysis has also developed in various countries and jurisdictions beyond the USA. The form of its evolution in different countries has been influenced by the government structure (whether it is a centralised or federal system), political structure (whether it is a parliamentary democratic system or a Westminster democratic parliamentary system) and institutional design (Radin, 2017). It is also influenced by the presence of local or regional governments alongside central government with variations across countries. Veselý (2013) has shown the differences, similarities and trends of policy analysis in central governments of Australia, Canada, Germany and the Netherlands, while a study by Lundin and Öberg (2017) has explained four stages of policy formulation at the local level to show how policy analysis took a different approach from that of central governments.

The government and political structures and institutional design determine the nature of the client-analyst relationships and the analytical integrity of policy analysts. In a Westminster system, such as in New Zealand, policy advising relies on the working relationships between departmental policy advisors, ministers and members of parliament. Working relationships are based on defined guidelines and 'ministerial 
relationships' through which policy advisors are expected to produce impartial, full, accurate, and 'free and frank advice' to an elected official who is a part of government. These elected officials are accountable to the parliament and public through the ballot box. The information remains open for scrutiny under the official information act. Free and frank advice ('frank and fearless' in Australia) is a 'hallowed tradition under which officials are obliged to speak their minds openly and honestly and to tell ministers things that they may not wish to hear' (J. R. Martin, 2012, p. 11).

In New Zealand, the two potentially competing good principles for government are free and frank advice to ministers and the opportunities for the public to participate in decision-making and hold the government accountable (Kibblewhite \& Boshier, 2018). While R. Mulgan (2012) considers the New Zealand public service has retained elements of free and frank advice, Eichbaum (2017) has shown a concern that free and frank advice is fast disappearing. Despite concerns, the requirement to produce 'free and frank advice' by policy advice producers is prominent and it is surviving, as Voyce (1997) predicted. The government's serious intention to retain the elements of free and frank advice is reflected in outlining the features of a free and frank advice guideline by the Policy Project for policy advice producers to follow (DPMC, 2016b). New Zealand has also maintained 'high-profile' working groups of varying independence which serve to recommend policy options while keeping some distance from governments (Craft \& Halligan, 2017; Shaw \& Eichbaum, 2011).

A policy 'market' has been said to existed in New Zealand since the state sector reforms of the late 1980s to mid-1990s. The New Zealand public sector went through radical bureaucratic and managerial reforms during this period (see Appendix 1 for New Zealand government's principal economic reforms) ${ }^{5}$, transforming the conventional public sector into a public sector driven by the incentives found in well-functioning

\footnotetext{
${ }^{5}$ The reforms between the mid-1980s and the early 1990s were profound, with changes taking place in every significant area of public policy. The public policies in economic, social, environmental and administrative were reengineered and refashioned (Boston \& Eichbaum, 2014, p. 373).
} 
private sectors (Bale \& Dale, 1998a, p. 104) with two laws enacted, the State Sector Act of 1988 and the Public Finance Act of 1989, to effect these changes.

Overall, the New Zealand core public sector transformed the traditional New Zealand public service with the reforms of the late 1980s to mid-1990s into a policy market, in principle and structure. Policy advice is an output of the advisory agencies (G. Scott, Bushnell, \& Sallee, 1990, p. 158) which is produced similarly to the way that consulting advice is produced by a consulting firm (Bale \& Dale, 1998a, p. 109). Separating policy advice from service delivery was considered necessary to reduce the potential for policyadvice bias. If a ministry only provides the advice but does not deliver services, 'its advice about appropriate interventions can be independent of the business implications for the department' (Bale \& Dale, 1998a, p. 109). A related reason for separating these functions was to avoid rent-seeking behaviour (Bale \& Dale, 1998a, p. 109) by ensuring that policy is regulated by one agency and enforced by another (G. Scott et al., 1990, pp. 158-159).

Policy analysis is influenced by the client-supplier relationship. As policy scholars such as G. Scott et al. (1990), Bale and Dale (1998b) have shown, the changes in the bureaucracy due to reforms in New Zealand have resulted in new relationships being built within the bureaucracy: between owner and purchaser; between customer or client and supplier; and between the government and the department. Under the new system, the government is free to purchase outputs and obtain services for any particular policy purpose from one or many of the departments it owns. It can also buy similar products and services from the private sector. When buying outputs and obtaining services, the government attempts to achieve the best product or services at a low price and acts in a way that is seen in a buyer in a free market economy. The minister is not required to buy outputs only from the departments it is responsible for. The minister can purchase non-departmental outputs. This should promote pricecompetition among buyers too. The government, thus, has the dual role of being the owner of the departments and the purchaser of the services. 
Similarly, ministers and departments have moved into a client-supplier relationship. Departments consider the ministers as their clients. The chief executives act as buyers of resources such as people, expertise, and information and decide on the appropriate work style. The chief executives, thus, behave like buyers that can be observed in an open market. On the other hand, they also act as suppliers when providing advice and delivering services to the minister as per the contracts between the ministers and the chief executives. Thus, ideally, the features of a well-functioning market can be expected to be observed in the New Zealand bureaucracy; and policy advice is a product in a policy market where buyers and sellers both compete for products and resources.

Generally, all these new relationships are based on contracts between the parties: the government and ministers; the ministers and chief executives; the chief executives and managers. The reforms in the bureaucracy have replaced the implicit or relational contracts that were found in traditional administration with the explicit contract-like relationships which Schick (1998b, p. 124) termed 'new contractualism'. Ministers are considered to be 'clients' for policy advice, and meeting the expectation of the clients has been traditionally an important indicator of the quality of policy advice. The reforms have given the CEs "space' or 'voice' to articulate innovative ways of combining past traditions with new organising principles of economic governance' (R. A. Rhodes, Wanna, \& Weller, 2008, p. 461) and created a new style of public management, (Kettl, 2005), termed New Public Management. The lessons from the reforms and the management challenges ahead for the New Zealand public sector are comprehensively captured in G. Scott (2001).

Policy analysis is also influenced by institutional design. For example, the institutional design of government in the USA (where the power of government is shared between the legislative, executive and judicial systems) and the recent development of networks as decision-makers have created a complex client-analyst relation. The clients were usually the cabinet officials/high-level political figures, but the proliferation of policy analysis both inside and outside of government in recent times has modified the original model, so that analysts now are more concerned with competing views (Radin, 2017). 
Different political and government structures see different types of policy advisors producing policy analysis. Policy advisors in a parliamentary system are experienced officials within a career public service, often called the administrative generalists, who are expected to remain politically neutral and serve successive governments. But in the USA, at the more senior levels, policy advisors are not career public servants. Their roles typically end with the change of government. They can come from think tanks or academia, and may be highly trained in analytical skills. In a Westminster system, policy advisors are mostly generalists. However, they need to work with the specialists and scientists in policy teams in departments and other agencies.

Following the state sector reforms in the late 1980s, a two-tier public service has developed in the New Zealand public service, as envisioned by J. Martin (1996). 'Ministerial' advisors support ministers in decision-making and provide political inputs to policy analysis and 'policy advice producers' in public service fulfil at least three distinct functions - analysis, advising and advocacy (regardless of their job titles) (Bromell, 2010b). 'Ministerial' advisors are important players who can influence, and sometimes impede, the production of policy analysis as they work with public-service policy advisors. This is reflected in C. Scott and Baehler (2010, p. 52):

At times analysis and politics appear to be on a veritable collision course, with the former interested in clarifying issues, and the latter preferring to obscure them and to pursue immediate political advantage irrespective of probable outcomes in the longer term.

The roles of political advisors and think tanks and their influence on policy analysis vary across countries. Their roles and influence seem limited, if measured by the number of ministerial advisors, in New Zealand's Westminster system compared with that of the governmental systems of the USA and Australia. Although a high number of ministerial advisors does not indicate the relative strength of analysis and politics in a system; the lower number of ministerial advisors in New Zealand (51) in 2006 relative to Australia (469), Canada (201) and the United Kingdom (78)(C. Scott \& Baehler, 2010, p. 52) indicates that the role and influence of ministerial advisors was limited in New Zealand. 
An increased number of ministerial advisors can be reflective of the low confidence of political advisors in public-service policy advisors, or a bypassing of analysis.

The nature of policy analysis in central governments is also diverse across countries. The comparative study of policy analysis in central governments across countries by Veselý (2013) has explained the differences partly by the professionalisation of policy analysis (that is, to what extent public policy and policy analysis is taught in higher education), and the preparation and recruitment of central government personnel:

As for the context, the nature of policy analysis is clearly influenced by a country's level of centralization or decentralization...... While there is no doubt that federalism influences the nature of policy analysis, it does not determine it. Australia, Canada and Germany are federal states, yet the form of policy analysis in central government is substantially different. (Veselý, 2013, p. 113)

Veselýs arguments reinforce the importance of contextual conditions, and influences that do not come from one source but from many which are not easily discerned. Interestingly, the core issues identified for Australia in Veselý (2013) study were declining policy capacity, politicisation and the need for whole-of-government working, which are not very different from those observed in New Zealand (shown in the subsequent sections) but with less similarities with respect to politicisation.

Policy scholars have shown a trend across countries of increased attention to efforts to achieve improved policy capability. Mendez and Laguna-Dussauge (2017) have recently compared policy analytical capacity in Australia, Canada, Germany, Brazil and Mexico, to illustrate how these different governments have tried to build their own policy analytical capacity. They also showed the challenges to building policy analytical capacity and identified the influencing variables. In a comparative overview, they found that these five countries have all readjusted bureaucratic structures after important administrative reforms, and seem to be regularly engaged in adjusting their central government's policy analytical capacity (Mendez \& Laguna-Dussauge, 2017, p. 80). A very similar trend is seen in the New Zealand public sector when the New Zealand public sector went through radical reforms between the late 1980s and mid-1990s. 
Mendez and Laguna-Dussauge (2017) further detail how the demand and supply of policy analysis are important factors in achieving policy analytical capacity. They have developed a two-by-two supply-demand matrix for governmental policy analysis distinguishing four demand-side elements: type of political regime; level of bureaucratic development; work culture; and professionalism and two supply-side elements: the availability of quality data and information; and the existence of study programmes on public policy. They argue that high levels of analysis is associated with both high levels of demand and supply for policy analysis and low standards of analysis are associated with lower levels of both demand and supply. Their cross-national examination has classified Australia, Canada and Germany as having high levels of both demand and supply, whereas Brazil and Mexico have high levels of supply but a low level of demand ${ }^{6}$.

Policy scholars have criticised the usefulness of a supply-demand perspective because the market can be imperfect, and may need to be connected by policy networks for it to be functional (S. M. Nutley, Walter, \& Davies, 2007). Criticising the market approach, Craft and Howlett (2012) identified three locational components: the supply of policy advice (the knowledge producers from academia, statistical agencies, research institutes etc.); demand on the part of decision-makers (proximate decision makers who consume policy analysis and advice); and brokers, who match supply and demand (knowledge brokers who serves as the intermediaries). They argue that the locational model may no longer be completely applicable because the shifts in governance arrangements have blurred both the technical and political dimension and the inside-government and outside-government policy formulation environments.

Boston (1994) has explored issues in purchasing policy advice, assessing whether internal and external markets could be created to compete for the policy work of departments in New Zealand. Other elements of the market that feature in the New Zealand public sector include ensuring contestability of supply where it is applicable,

\footnotetext{
${ }^{6}$ They have identified New Zealand, although it was not included in their detailed analysis, with high standards of policy analysis
} 
limiting outputs in the extent of the departments' operations, avoiding capture by the rent-seeking behaviour of pressure groups, and promoting monitoring. Another very important criterion for a public sector to qualify as a market is contestability. A contestable policy market is the one in which there are no barriers for both policy advice producers and consumers to entry or exit. Ignoring the debate on whether ministers in the New Zealand public sector often purchase policy advice from the ministries or departments and less from the think tanks and private consultants, the New Zealand public sector is a policy market in principle and structure.

Policy analysis is also influenced by the nature of policy problems. The increasing complexity and wickedness of policy problems over time have influenced the methods and approaches used in doing policy analysis. Solutions for so-called tame problems are replicable, as the policy problem is clearly defined and solutions are agreed by the stakeholders. But for complex policy problems, stakeholders may agree about the nature of policy problem but not the solutions. Wicked problems are more wayward. A wicked problem is tentatively defined only when solutions are proposed; has no precise stopping point for when the problem is solved; does not have 'right' or 'wrong' solutions but only has 'better' or 'worse' ones; is unique and specific to context; may affect an infinite set of related problems; and is unstable and resistant to policy solutions insofar as interventions involve stakeholders (Morrison, 2013, pp. 1-3). Both the nature of and solutions for wicked problems remain obscure (Roberts, 2000). Yet, policy solutions for both wicked and complex problems are sought. Head and Alford (2015, p. 711) argue that provisional solutions can be developed 'despite the difficulties of reforming governance processes to address wicked problems more effectively'.

Policy analysis, then, is subject to enormous dynamic influences. These influences come from different sources, as comprehensively captured in Radin's words (2017, p. 87):

There are many ways to sort out the developments in the field. One can easily list the range of these developments. They include types of policy issues, the diverse relationships between analysts and clients, the types of analysis required, its time frame, the stage of the policy process where it occurs, where in the system it occurs (e.g., whether it takes place inside government or outside government), 
the impact of the structure of the government involved, the placement of analysis in central agencies vs programme agencies, whether analysts and clients are career or political actors, the appropriate skill set found in analysts, and the boundaries between policy analysis and management.

The review so far has shown that policy analysis is subject to dynamic influences. These influences affect the way policy analysis is continuously evolving as a field. The political structure, type of government, clients' expectations or demand for policy analysis, the supply of policy analysis, the nature of the problems encountered, and the client-analyst relations are some factors that influence the production of policy analysis and advice. These influences vary significantly between jurisdictions and over time.

Policy leaders in the public sector take efforts to respond to these influences by developing 'initiatives'. In their efforts, they intervene to change 'policy practices' and mostly under the tag of 'professionalising' policy analysis and advice. The following section focuses on the literature that shows how policy practices are continuously evolving to respond to the dynamic influences.

\subsection{Evolution of Policy Practices/Professionalising Policy Analysis and Advice}

This section discusses first how policy skills, methods and approaches have changed with the changes in policy analysis as a field, under the dynamic influences sketched above and second, what can be said about professionalising policy analysis and advice. Third, it presents the design-approach to policy analysis as an innovative approach that places significant weight on the people-centric skills and coproduction of policy development.

Different types of policy skills and analytical styles have emerged with the evolution of policy analysis. Weimer and Vining (2005) have described three different types of policy analysts - objective technician, client's advocate, and issue advocate - with three distinct corresponding styles of analytical integrity. An objective technician, will let analysis speak for itself, keep a distance from the clients and consider political leaders 
secondary, and leave the responsibility for the values attached to the policy options entirely in the hand of the clients. A client's advocate will take advantage of ambiguity to advice clients' position and rarely produce definitive conclusions. In contrast, an issue advocate will emphasise ambiguity and exclude values when analysis does not support advocacy (Weimer \& Vining, 2005).

The analyst in the public sector is expected to practice their 'craft' (Tiernan, 2015) in which the analyst is, first, an objective technician and then partly a client's advocate, but only to the extent that the advice is 'fit-for-purpose' for the clients. The extent to which the analyst will lean towards becoming a client's advocate (rather than taking the client's needs as an 'objective' constraint) will be determined by various influences such as the client-analyst relationship, demand for policy analysis from clients and so on, which collectively make up the contextual conditions in which the advice is offered. The policy analyst pays attention to politics, institutional arrangements, bureaucracy, and the views of multiple actors and stakeholders, and develops policy advice based on his or her own judgment, experience and intuition about the context and situation characteristics (Thissen \& Walker, 2013).

In crafting 'fit-for-purpose' policy advice, the analyst not only relies on the scientific or technical approach to the issue of interest with a variety of tools, techniques, methods, and approaches that seem appropriate, but also applies intuition, wisdom, experience and judgment so that policy advice is based on facts, analysis and intuitions. The success for a policy analyst in producing 'fit-for-purpose' policy advice lies in how the analyst balances between a rational and normative approach.

The dynamic influences, such as the political structure, client-analyst relation, way of doing business in the public sector, culture, level and type of government, identified in the previous section, affect the analytical integrity of a policy analyst and influence the 'crafting' work of an analyst.

Different policy methods, approaches and orientations/styles have emerged, associated with the craft view, a collaborative approach to practice and an appreciation of policy 
'wickedness'. Scholars such as Bromell (2017), Weimer (1998), C. Scott and Baehler (2010), Amanda Wolf (2000) have shown the significance of considering policy analysis as 'craft' rather than 'scientific undertaking' or 'arts' implying the need for wisdom, experience, and judgement rather than the reliance on more mechanistic techniques in developing solutions to policy problems. Huxham (2003) has developed five themes in the concept of collaboration practice: common aims, power, trust, membership structures and leadership. It is argued that the real advantage out of collaboration can be achieved when 'something has to be achieved that could not have been attained by any of the organizations alone'. As solutions to wicked problems are defined to be impossible to achieve by the simple intervention of one organisation, Huxham's argument indicates that collaboration practice is relevant to public sector organisations while dealing with wicked problems. It is strongly relevant when the public sector organisations have some common policy outcomes to achieve.

Viewing policy analysis as a problem-solving discipline gained popularity in the last decade of $20^{\text {th }}$ century and continued to be appreciated by policy scholars in the first decade of the $21^{\text {st }}$ century, the 'craft' view retains the attention of policy scholars. In these periods, policy scholars have advised attempting to solve public problems using a steps-based approach, which starts with identifying and defining a problem, and then proceeds to producing policy options, linking them with their possible consequences, then leaving clients to make a final call to accept/reject/choose particular policy option/s.

For example, Bardach (2012, p. xiii) presents an eight-step approach to policy analysis. The eight steps are: define the problem, assemble some evidence, construct the alternatives, select the criteria, project the outcomes, confront the trade-offs, decide and tell your story. Jenkins-Smith (1990) considers that evaluation of public policy options and selecting from them with a set of techniques and criteria are at the core of policy analysis, which involves the exercise of judgment to choose policy options, using both subjective and objective criteria. 
Many scholars approach policy analysis framed as positivist or post-positivist. Michael Howlett et al. (2009) capture this long-standing distinction. A positivist approach relies on rigorous scientific or technical reasoning. In contrast, post-positivist approaches rely on a normative analytical base and the application of subjective judgment. While the positivist or rationalist approach relies on ideas and techniques, quantifiable facts and rational reasoning, the post-positivist approach postulates subjective reflection, normative analysis, and argumentation as more rewarding tools for understanding public policies and policy-making (M Howlett, M Ramesh, \& A Perl, 2009, pp. 21-27).

Mayer, van Daalen, and Bots (2013) use a hexagon diagram to show six major clusters of activities that policy analysts perform to conduct policy analysis: research and analyse; design and recommend; clarify arguments and values; provide strategic advice; democratise. The model also distinguishes six policy analysis styles: rational style; argumentative style; client advice style; participatory style; process style; interactive style. Associated values and criteria (which guide the clients for choosing between policy options) make one policy style more relevant than the other policy styles. This model reflects a view that policy analysis is not reliant only on analytical, technical and political skills only, but also on understanding the influences that bear on policy analysis and then adopting an appropriate style to develop policy advice for the clients.

An emerging view sees policy analysis as a profession, like fields such as medicine, psychology or law. This view highlights the intellectual processes involved in policy analysis, involving the adaptation of intellectual cognitive performance to the political and social realities of the policy-making process. Like a clinical practitioner who faces a patient and a health problem, policy practitioners face a client and a policy problem (Geva-May, 2005, pp. 16-19). However, unlike that of the clinical professions, the training of policy professionals is less systematic, is not overseen by the profession (as through medical boards, for example) and there are no requirements to attain a license or similar to practice or to maintain practice standards through regular professional development. 
Drawing on the earlier scholarship on 'profession' by Millerson (1964), Adachi (2017, pp. 38-39 ) argues that policy analysis satisfies four conditions to qualify as a profession. The conditions outlined in the study are: a specific mode of thinking that consists of the capacity for systemic thinking - an ability to exercise a special type of thoughtexperiment for the analyst by putting on the shoe of a decision maker; a body of knowledge that can be systematised to a high level of abstraction - that is theoretical and methodological knowledge; an analytic tool-kit or 'tricks of trade' (Geva-May, 2005); and a minimum level of professional ethics - the analyst should demonstrate the attributes of honesty, candour, competence, diligence, loyalty and discretion as components of trustworthiness (Tong, 1986, p. 92).

Recently interest has grown in an approach to policy analysis characterised by 'design thinking', the origins of which is attributed to Simon's (1996) Sciences of the Artificial. 'Design' in public policy theory is seen as a component of policy development (Howlett, 2010) and policy implementation depends on the design of products and services. Policy professionals are cast as 'designers' in design-thinking approach. The work of the role still referred to as 'policy analyst' is seen to rely on individuals' own talents and efforts to differentiate between the given preconditions and constraints and on their planning to devise solutions of a problem/design activity (Adachi, 2017, p. 33).

Since evidence-based policy practice cannot fully, or even partially, inform the policy development (Wesselink, Colebatch, \& Pearce, 2014), Mintrom and Thomas (2018) argue that 'design thinking can contribute to improved use of evidence in policymaking and in program implementation' in which '[p]olicy designers must be socially perceptive when gathering evidence and politically savvy when deploying it'. Brown (2008, p. 87) identifies a policy designer's most important skill as the ability to 'imagine the world from multiple perspectives - those of colleagues, clients, end-users and customers (current and prospective)'.

In the exercise of policy design, the resolution of policy challenges is seen to emerge through the activities themselves. Mintrom and Luetjens $(2016$, p. 394) have described five phases in design thinking: empathetically observe target group, explore the 
problem, canvas possible solutions, develop a prototype solution and test the prototype with the target group. In their words:

Design thinkers empathetically observe groups to define problems and canvas possible solutions. Prototype development and testing are done iteratively in collaboration with the target group to ensure the devised solution is fit for purpose.

Design thinking is considered a convenient way to make use of contexts in developing policy advice or strategies, where the designer's talents play a significant role.

The design-thinking approach to policy development places a greater value on the deep knowledge of the contexts and clients. Mintrom and Thomas (2018) write:

With respect to public policy, gaps often exist between policy design, the services governments deliver, and the needs and expectations of citizens. To remedy this, good policy should be informed by deep knowledge of the contexts and clients for which that policy is being made.

The design-thinking approach, overall, supports and encourages collaborative practice of end-users, policy designers, central departments, and line agencies to work in a collaborative and iterative manner (Mintrom \& Luetjens, 2016).

The public sectors in United Kingdom and New Zealand have recently started using collaborative and innovative policy practice where the elements of the design-thinking are being applied. The Policy Lab in United Kingdom brings people-centred design approaches to policy-making in which policy teams co-design new solutions with the people they try to reach with policy. It is a creative space where policy teams improve its capability by using new tools and techniques and in a more open, data-driven, digital and user-centred way (Civil Service, 2019). The Policy Project, ${ }^{7}$ a recent initiative in the New Zealand public sector to improve policy capability, was also co-designed to provide a platform in which policy teams practice people-centric and innovative tools and frameworks.

\footnotetext{
${ }^{7}$ The Policy Project is presented in chapter 4 as a central agency initiative.
} 
Due to variation in influences, professionalising policy analysis and advice has not taken an identical form. 'Professionalising policy analysis and advice' is sometimes taken to pertain to who does what, why and how (Baimyrzaeva, 2013). For others, the term applies to the 'effective' delivery of three functions of policy advice producers analysing, advising and advocating (Bromell, 2010a) or to increasing policy capability in order to produce high-quality policy advice (G. Scott et al., 2010). Meltsner (1979) is often identified as a pioneering treatment of policy analysis as a profession. Further, the formalisation of study in policy formulation was considered by Meltsner a step towards professionalising policy analysis and advice. This view has strengthened over time as Public Policy has emerged as a discipline taught in universities. Of particular relevance to New Zealand, in 2002, the Australia and New Zealand School of Government (ANZSOG) was created to train public officials from Australia and New Zealand. Graduates earned an Executive Master of Public Administration (EMPA) (ANZSOG, 2002). In New Zealand, the Victoria University of Wellington (VUW) has been involved over many decades in designing programmes to develop public policy and administration skills for the New Zealand public sector. Although Meltsner (1979, p. 46) considered formal study programmes to be important, he also pointed out that 'policy analysis-whether it is used and how it is used-depends heavily on the organisational context' which implied that professionalising policy analysis and advice needed to take organisational context into account.

Different governments have developed a range of ways to professionalise policy analysis and advice. The Policy Profession Board of United Kingdom civil service, in 2013, developed 12 actions to professionalise policy making. The actions concentrated on six areas to professionalise: clear responsibility for professionalisation; building improvement capacity; communicating to policy officials; Heads of Policy Profession leading change within departments; improving skills, expertise and talent management; improving knowledge management; and assessing progress (Civil Service, 2013). The same Policy Profession Board, very recently, in 2017, has developed a Policy Profession Standards which is a framework for professional development. The framework has shown that 'professionalising' is about attaining knowledge, applying skills and leading the way, and thus emphasises evidence, politics and delivery as three crucial 
components (Civil Service, 2017). In New Zealand, in 2016, the Policy Project draws on the necessity of establishing links between policy skills, tools, capability and quality to professionalise policy analysis and advice (Washington \& Mintrom, 2018).

Consideration of policy analysis and advice as a profession gives the clients for policy advice appropriate weight, but also looks beyond client-centric considerations to develop policy analysis and advice that is strategic and future-focused.

'Professionalising' policy analysis and advice, thus, encompasses building and maintaining individual, organisational and systemic policy capability. This recognises that professional policy analysis and advice also takes different forms in different jurisdictions. In this thesis, the New Zealand public sector's efforts to professionalise policy analysis and advice is explored by examining initiatives to improve policy capability and the quality of policy advice.

The literature reviewed has shown that the relation between 'policy capability' and 'high-quality policy advice' is complex. Improved policy capability is not limited to the ability of policy advice producers to ensure the rigour of policy analysis. Improved policy capability is affected by policy capability at different levels - individual, organisation and system, and of different types - policy analytical, management and political. Clients at different levels view 'high-quality policy advice' differently and there are different measures to assess the quality of policy advice. The discussions on the evolution of policy analysis and comparative perspectives have shown how policy analysis as a field is evolving due to the influences of dynamic nature. Finally, how policy practice is responding to different influences is presented to argue that professionalising policy analysis and advice, consequentially, did not take any identical form across public sectors and over time. To cope up with the dynamic influences to policy analysis and advice, the approach to policy analysis is also changing. The emergence of the designapproach justifies that. This chapter has set out the theoretical framework for an examination of policy capability initiatives developed in New Zealand between 1990 and 2015 by central agencies and between 2008 and 2015 by three agencies. The next chapter presents the research design used in this thesis. 


\section{CHAPTER 3: Research Design}

\subsection{Introduction}

This chapter describes the research design used for this study. It explains and justifies the approach used to find answers to the research question. Why some methods were chosen over the others, and how the data were collected, analysed and interpreted are discussed in this chapter. It begins with a discussion of the research paradigm used in this study. The method to examine central agencies' initiatives is shown in section two. A discussion of the choice to use cases and the overall rationale for choosing methods is explained in sections three and four. The data collection methods and analysis and interpretation of data are set out in section five and six respectively. The chapter concludes with the discussions of generalisability of the findings, limitations, caveats and ethical issues.

\subsection{Research Paradigm}

There are different ways of knowing and there are different competing methodologies for coming to know. What we want to know is often referred to as 'truth'. Typically, views on finding 'truth' are presented as ideals, or extremes. One ideal view holds that 'truth' can be found, as it is 'out there' waiting for the researchers to find. This is usually termed 'positivism' or 'naturalism'. But the terms and their uses remain at times contradictory. Some researchers prefer other terms for the same ideas. The other extreme view is that 'truth' can be constructed by the individuals' perceptions. Thus, how 'truth' is perceived to be constructed will vary among researchers, and their perceptions about the 'truth' may also be different depending on the influences under which the study is done. In this way, multiple realities constructed by the researchers are said to arise. This extreme view is termed as 'constructivism' or 'post-positivism' among other terms, again with no common agreement. My own view is strongly influenced by the arguments of Moses and Knutsen (2012), who see research paradigms, not as ways of knowing positioned by extreme views but rather as a spectrum.

Accordingly, I have sought to cautiously avoid the broad categorisation of research paradigms as 'naturalism' or 'constructivism', on the understanding that is one approach 
best fits the real world and the world can be perceived in different and contrasting ways (Moses \& Knutsen, 2012). I believe, however, that the thing being studied is the same for all the viewers. What varies is the lens for viewing the thing (Krauss, 2005).

The closest label for my perspective is 'scientific realism'. This research paradigm, as described by (Moses \& Knutsen, 2012), is compatible with a relatively wide range of research methods and allows a researcher to use a variety of epistemic devices. It straddles the ontological positions of 'naturalism' and 'constructivism' (Moses \& Knutsen, 2012). I resorted to 'scientific realism' only as a convenient way to avoid the problem of two incompatible ontologies; because its focus was on necessity and contingency rather than regularity; and because it purported that research questions and not methods drove good science; and because it called for methodological pluralism, not methodological conformity (Moses \& Knutsen, 2012).

\section{A Qualitative Inquiry}

This study could not be done objectively, as I aimed to learn about the choices of initiatives by actors in three public-sector organisations and how they used them, in conjunction with an examination of initiatives developed by, or on behalf of, New Zealand's central government departments, namely the Department of Prime Minister and Cabinet (DPMC), the State Services Commission (SSC) and the Treasury. The examination of the actors' working with the initiatives involved finding out why some initiatives were developed, what the forms and types of initiatives were, why the initiators chose them, and the perceived consequences, as reflected in the research question:

What central government and agency-led initiatives have been developed to improve policy capability and the quality of policy advice, why and with what consequences?

Overall, I aimed to explore the influences on the actors' choice and use of initiatives. A qualitative inquiry was applied to find the answers to the research question. The study of initiatives generally and three in-depth cases rejected positivist 'rules' and assumed 
that actors did not see one single 'reality' (Z. O'Leary, 2017, p. 105) in their experience of the object of the study in its real-world context.

The research examined initiatives developed by New Zealand's central government departments, and three agencies, namely the Ministry of the Transport (MoT), the Ministry for the Environment (MfE) and the Auckland Council (AC) in the New Zealand public sector. The purpose was to explore and understand what influenced the initiators' choice and use of policy capability initiatives in both central and line agencies and interpret those influences to draw conclusions.

Data analysis and reporting comprised two main strands: a general investigation of New Zealand government initiative in the period 1990 to 2015 and three case studies covering the period 2008 to 2015.

\subsection{Methods to Examine Central Agency Initiatives}

Only secondary data was used to examine central agency initiatives and explain the actors' choice and use of initiatives to improve policy capability and the quality of policy advice. Initiatives that were publicly accessible and available in document forms were examined. It was not possible to do interviews of the initiators of the central agency initiatives while this could provide rich information that was not possible to obtain from documents. The initiators were the high-profile senior leaders of the New Zealand public sector, who head the three central agencies, the Department of Prime Minister and Cabinet (DPMC), the State Services Commission (SSC) and the Treasury.

The consequences of the initiatives, however, were examined in terms of the suggested resultant changes, but not their actual effects, and of the commentary found in the practitioners' literature. The scope of the research was limited and did not include all the actual changes in policy practices in all the ministries and departments in the New Zealand public sector following the initiatives. This was not possible for practical reasons such as time and cost. 


\subsection{Case Study and the Cases}

A case study approach was a good fit according to Yin's (2014) widely used criteria for selecting case study as a method. The research involved answering a 'why' question. Moreover, all the initiatives studied were contemporary and the researcher had no control over the actual events. The study needed to capture the experiences of the initiators and users of initiatives in a holistic way, as it was expected that the unique features of each case context would be important to understanding actors' choices, reasoning, and influences. I wanted to concentrate on collecting data about why the initiators did what they did, interpreting the findings against the existing literature and drawing conclusions. The study aimed to obtain a rich understanding of policy capability initiatives intended to produce high-quality policy advice. These considerations together justified the case study as an appropriate method for this research.

Before deciding to use the case study approach, I also considered the merits of a broader approach, a survey. Such an approach would have allowed me to collect data from a large, and perhaps even representative, sample of New Zealand organisations. Nevertheless, it was rejected for three reasons. First, the context for each organisation is rich and varied. With multiple variables potentially influencing actors' choices in using initiatives, the survey method is unsuitable. Second, a significant aim of my research was to understand why actors designed initiatives in a specific way to improve policy capability and the quality of policy advice. A survey might have given me some indications of the reasons, but without the context and an opportunity to explore in depth, I would have lacked the full understanding I aimed for. Finally, I was also interested in exploring initiatives in a local context, hence the selection of Auckland Council. Extending a survey to all the councils in the country would have introduced even more complexity to the task of discerning any influences on the use of initiatives.

\section{Unit of analysis}

My cases were located in three chosen organisations, the Ministry of Transport, the Ministry for the Environment and the Auckland Council. Within the organisations, I focused on the policy teams and the senior leaders as the subject of the study. The object of the study was to understand the actors' uses of initiatives, the reasons they 
offered for doing so, and the influences on their decisions. In this regard, I follow the distinction made by (Thomas, 2011, p. 511) between '(1) the subject of the study, which is the case itself, and (2) the object, which is the analytical frame or theory through which the subject is viewed and which the subject explicates'. The subjects of this study were the key cases or instances of the phenomenon, which was seeking to improve policy capability by means of initiatives. Again, following Thomas (2011), I aimed to provide 'exemplary knowledge' about the use of initiatives, using three organisational examples.

By 'policy teams', I mean the policy staff assigned to producing policy analysis and advice on behalf of the organisations, regardless of whether they were organisationally identified as a 'team'. The senior leaders of the organisations are the professionals who were responsible for leading the organisation to deliver its responsibilities, including policy responsibilities.

\section{Type, Approach and Process of Case Studies}

The cases were exploratory in nature. I did not have any prior perceptions or seek any pre-determined outcomes. Rather, my intention was to approach the three cases as illustrations, in the sense of overall pictures of the initiatives, I therefore elected to use multiple case studies with cross-case analysis. The cases were studies in parallel, since the 'cases were all happening and being studied concurrently' (Thomas, 2011, p. 515).

\section{Purposive Selection}

Purposive sampling was applied to select three cases: the Ministry of Transport (MoT), Ministry for the Environment (MfE) and Auckland Council (AC). The timeframe considered was from 2008 to 2015 . The boundaries on the cases, thus, were set by time and place (Creswell, 2009).

There were four reasons for choosing the cases and the boundaries. First, selection concerned the place of the organisation in policy governance. All three organisations are in the New Zealand public sector, and have significant potential to affect public life with their policy advice. The DPMC, the SSC and the Treasury are the 'central' New Zealand 
public sector agencies, responsible for overseeing 36 agencies, two of which are the MoT and the MfE. In contrast, the AC is an organisation under local government authority.

Second, variation in size and lines of authority was sought in the case selection. The MoT is a small policy-focussed ministry with just one immediate client to respond to, whereas the MfE is a relatively big policy ministry which needs to co-produce policy advice with other departments in the natural resources sector, and to respond to multiple ministers.

In contrast, the $\mathrm{AC}$ is a large organisation overseeing the governance of Auckland, the most populous city of New Zealand where more than 1.57 million people or about $34 \%$ of total population of New Zealand live (World Population Review, 2018). The immediate client for the AC is the Mayor of Auckland and the City Councillors. The different nature of the clients for the AC's policy analysis and advice brings different considerations from those of the MoT and MfE.

Third, the difference between the organisations in terms of their roles were taken into consideration in choosing them as the cases. Both the MoT and MfE have very limited operational responsibilities, whereas the $\mathrm{AC}$ has extensive operational roles. The AC, unlike the MoT and MfE, is a service-delivery organisation. The focus of the AC has been on developing small policies and undertaking traditional urban planning, guided by engineers and other technical professionals. In contrast, the MoT deals with policies for meeting the current and future needs of the transport sector; and the MfE deals with many challenging problems relating to environment.

Fourth, a similarity across the three case organisations was that all were challenged to improve their policy capabilities. The challenges for the MoT originated in 2008 from its immediate client, those to the MfE originated from its clients at sector level, and those to the AC originated in 2009 from public expectations following the formation of the AC from the amalgamation of eight previous city councils including Auckland City Council, completed in 2010. All three were challenged to improve their policy capability and to 
produce high-quality policy advice. To some degree, they all acquired a poor reputation when external assessments of their capability and performance were made public. ${ }^{8}$

The cases were chosen to facilitate comparing and analysing their similarities and differences as organisations, and interpreting them to explain the rationale for their efforts to improve their policy capability and thus policy advice.

The period from 2008 to 2015 was chosen as the timeframe for the cases because the case organisations developed many initiatives within this period to improve policy capability and policy advice. This allowed such initiatives to be used as a means of understanding these agencies' efforts to improve policy capability and policy advice.

\subsection{Overall Approach of Research}

\section{The overall approach of this research is depicted in}

Figure 3.1. To contribute to the current stock of knowledge, this research carefully employed several stages. Although the different stages appear discretely in the figure below, the boundaries between them were fluid in practice. The overall research design was flexible. For example, the figure does not imply that, at the stage of data collection, the spontaneous understandings of the researcher needed to be suspended until the next stage of the research was reached.

\footnotetext{
${ }^{8}$ These assessments included the PIF, which assesses overall performance and the ratings done by the New Zealand Institute of Economic Research (NZIER), using their own quality measures.
} 


\section{Figure 3.1: The Overall Approach of Research Design}

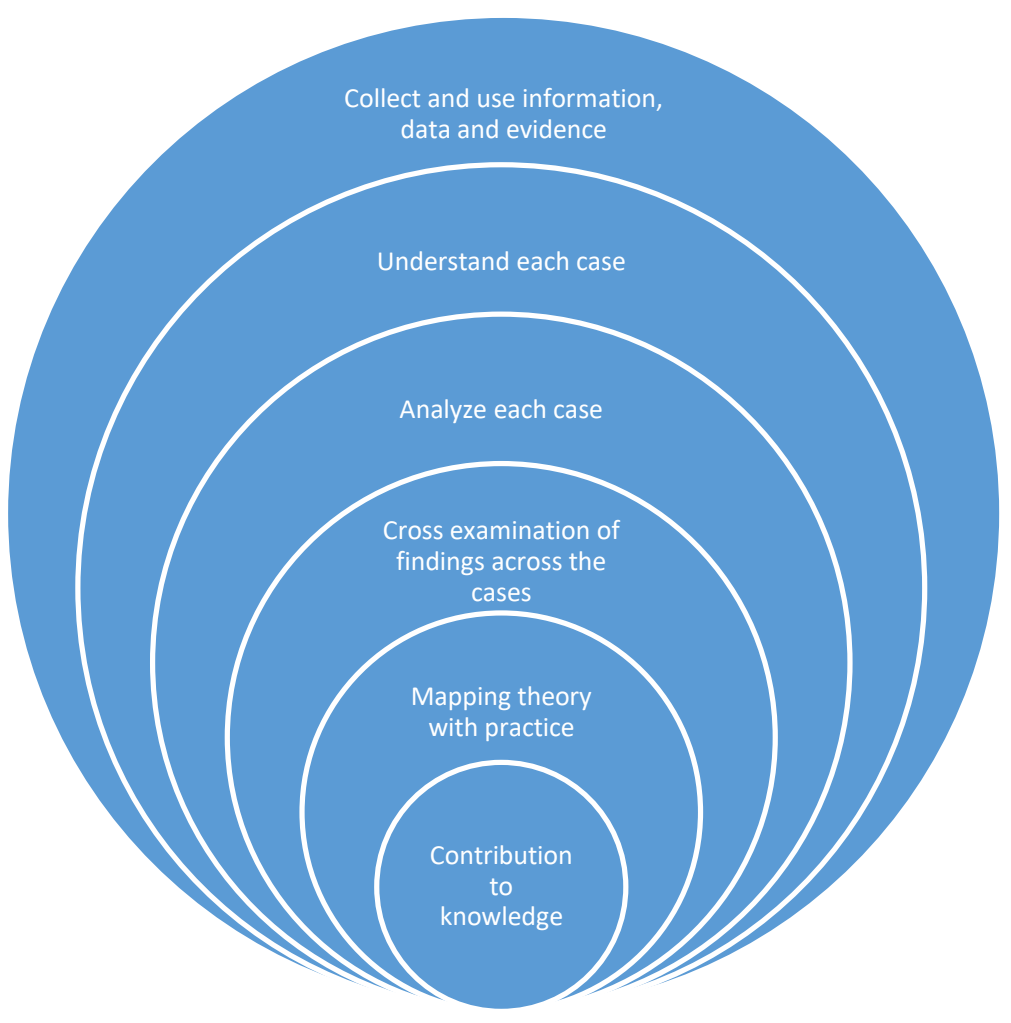

I, as a researcher, maintained a distance from the object of the study while collecting and using information, data and evidence. For example, during the interviews, I did not try to influence and guide the conversations in any direction but sought to ensure spontaneous responses from the informants by making them comfortable. For instance, one strategy was to read the interviewees' right to confidentiality at the very beginning of the interviews, which encouraged them to open in sharing their views and experiences. This helped me understand the cases objectively.

But at the stage of analysis, I played a more central role, explaining what I found from the cases. In the process of exploration, I tested, refined, altered, accepted, verified and where applicable refuted the views I formed from reviewing current knowledge, as outlined in the literature review chapter, against the views of the informants. The 
overall research design remained open and flexible to the emergent findings as I observed internal and external influences on the actors' work with the initiatives to improve policy capability and advice.

This approach facilitated me finding some similarities and differences about the object of the study across the cases, explaining them and relating them to existing theory. This qualitative study, however, did not allow me to confirm that all the possible influences on the initiatives were considered.

\section{Approach within Each Case}

I took a systematic, but not stringent, approach to each case. The analytical framework used to study the cases is represented in Figure 3.2. Within this analytical framework, various pertinent details of the organisations beyond their policy functions were explored, and then the policy capability initiatives were examined in depth.

Figure 3.2: Approach Used within Each Case

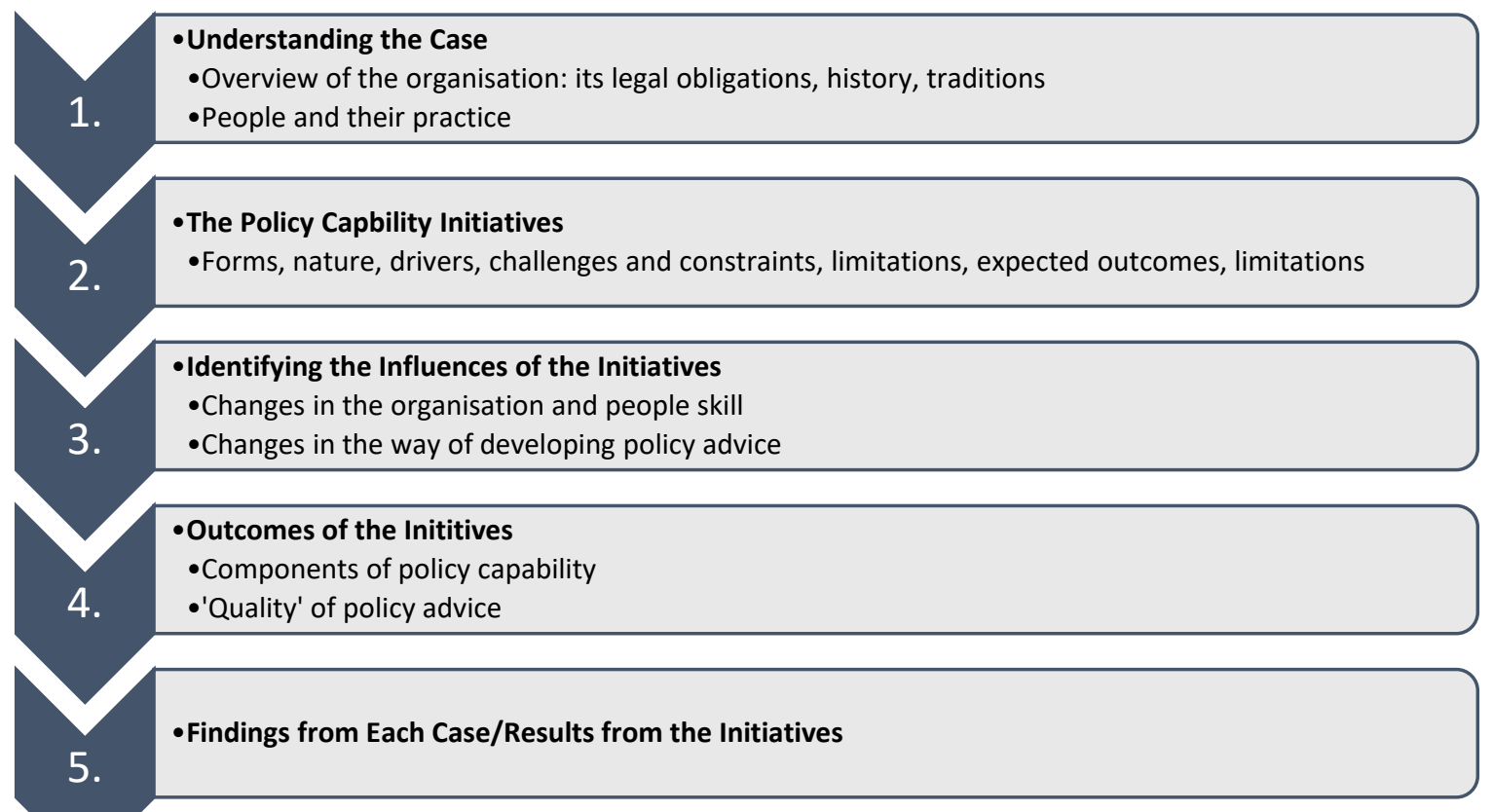

\subsection{Data Collection Methods}


The data for the case studies were collected using various sources and methods, mainly document analysis and interviews. The process started with collecting documents from the agencies and external sources and analysing them to gain preliminary understandings about the agencies and their policy work. Then, I collected further information by interviewing senior leaders and policy personnel at different tiers of the three agencies, and policy experts external to the organisations. The policy experts were former public officials with many years of work experience in different departments of the New Zealand public sector, who closely observed some of the many initiatives developed by central agencies between 1990 and 2015. Policy experts also included some performance improvement framework (PIF) reviewers.

\section{Documents}

Document analysis was the first stage of collecting information about an agency and its policy work. The documents analysed were mainly web-based documents, with a few paper documents such as policy advice documents, policy briefs, government reports, policy project papers, strategic papers, and organisational resource materials.

Documents obtained from the websites of the three agencies include annual reports, PIF reviews, Statements of Intent, Regulatory Impact Statements, organisational charts, accounts of organisational strategic direction, policy guides, protocols and guidelines, and other similar documents. These sources provided background and contextual information on the agencies relating to their purpose, structure, human resources, planning, policy work, policy capability initiatives and strategic direction. The reviews also gave an indication of the overall strengths, weaknesses, challenges and constraints on policy capability in the organisations. The documents from the websites of the central government departments (the DPMC, the SSC and the Treasury) were also used as sources of information on the three case organisations, such as turnover, the quality of the policy advice they produced by the two ministries; whereas AC is beyond the jurisdiction of the central government departments.

Document analysis provided rich information on the processes used to produce policy analysis and advice, the agencies' policy capability initiatives, and both internal and 
external assessments of the quality of the policy advice and policy capability of the agencies. The types of documents that were accessed and analysed are set out in Table 3.1. The list indicates the types of documents examined; some of these types of documents, such as annual reports and statements of intent, were examined for each year from 2008 to 2015.

Table 3.1: Types of Documents Examined

\begin{tabular}{|c|c|c|c|}
\hline \multirow{8}{*}{ 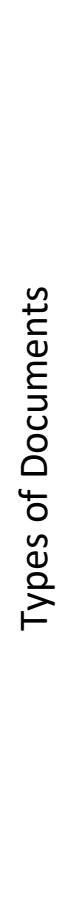 } & The MfE & The MoT & The AC \\
\hline & Annual Reports & Annual Reports & $\begin{array}{l}\text { Royal Commission } \\
\text { Report on Auckland's } \\
\text { Governance }\end{array}$ \\
\hline & Statement of Intent & Statement of Intent & $\begin{array}{l}\text { The Government's } \\
\text { response to the Royal } \\
\text { Commission Report }\end{array}$ \\
\hline & PIF Reviews & PIF Reviews & \multirow{3}{*}{$\begin{array}{l}\text { The Governance of } \\
\text { Auckland }\end{array}$} \\
\hline & PIF Follow-up Reviews & PIF Follow-up Reviews & \\
\hline & $\begin{array}{l}\text { Legislation and } \\
\text { Regulations }\end{array}$ & $\begin{array}{l}\text { Legislation and } \\
\text { Regulations }\end{array}$ & \\
\hline & $\begin{array}{l}\text { Policy advice (RISs), } \\
\text { Policy briefs, } \\
\text { Guidelines; } \\
\text { Strategic papers }\end{array}$ & $\begin{array}{l}\text { Policy advice (RISs), } \\
\text { Policy briefs, } \\
\text { Guidelines; } \\
\text { Strategic papers }\end{array}$ & \multirow[t]{2}{*}{$\begin{array}{l}\text { Documents related to } \\
\text { Policy Capability } \\
\text { Initiatives }\end{array}$} \\
\hline & $\begin{array}{l}\text { Documents related to } \\
\text { policy Capability } \\
\text { Initiatives }\end{array}$ & $\begin{array}{l}\text { Documents related to } \\
\text { Policy Capability } \\
\text { Initiatives }\end{array}$ & \\
\hline
\end{tabular}

Several objectives were achieved by the document analysis. First, it helped gain a preliminary idea of how policy advice was developed in these agencies. Second, it provided an idea of the agencies' policy capability initiatives and helped create an understanding of the agencies' efforts to build policy capability. Third, it captured external impressions of the policy capability of the agencies as expressed in the PIF reviews. Fourth, it gave an idea of the quality of their policy advice as assessed by internal panels and external reviews. Document analysis helped determine the dimensions of the questions to be used in the interviews.

\section{Introductory Visit to the Agencies}

I visited two of the case study organisations, the MoT and the AC, early in the research process. The visits were intended to establish communication and liaison, and to be 
introduced to the policy team and its work. The visits facilitated meetings with policy staff who were directly involved in developing policy advice. The visits were important to me, as I undertook to achieve a thorough understanding of the way of doing business in the New Zealand public sector and to appreciate the differences from my experiences in the public sector in Bangladesh, where I worked as a practitioner for 12 years. During the visits, the information gathered covered:

- Organisational functions, responsibilities and strategic directions

- Areas where recent policy advice had been developed

- Policy processes involved in developing policy advice

- Standards used for the quality of policy advice.

\section{Interviews}

The data collection for the case studies included both open-ended and semi-structured face-to-face interviews with policy staff at different levels occupying different roles in the policy analysis and advisory process. The interviews involved the chief executives, deputy secretary, policy managers and the senior leaders of the agencies who were responsible for leading their policy work. The other informants were the personnel who were directly involved in developing policy advice. The interviewees also included the lead reviewers who had reviewed the agencies' overall capability and performance using the PIF model, and who were responsible for evaluating policy documents prepared by the agencies. The composition of the interviewees is represented in Figure 3.3 below. An attempt was made to cover different perspectives by interviewing personnel occupying different roles, capacities and policy personnel at different tiers of the policy function.

\section{Interview Strategy}

I asked the interviewees either open-ended questions or semi-structured questions depending on their roles, capacity and occupation. In the style of élite interviewing, (Gillham, 2000), I asked just a few key open questions of senior leaders of the case organisations, policy experts, policy consultants, lead PIF reviewers, and former public officials at the beginning of the interviews. The subsequent questions were guided by the relevance of the conversations and the opinions shared by the informants; the 
overall purpose was to encourage flexibility so as to learn as much as possible from their experiences. The chief executives and/or senior leaders of each agency, both current and previous, were interviewed to gain their views on the specific responses of their agencies to the central government-led initiatives such as the PIF; how they tried to improve policy capability and policy advice; and the consequences that they observed or experienced from the agency's own initiatives.

\section{Figure 3.3: The Composition of the Interviewees}

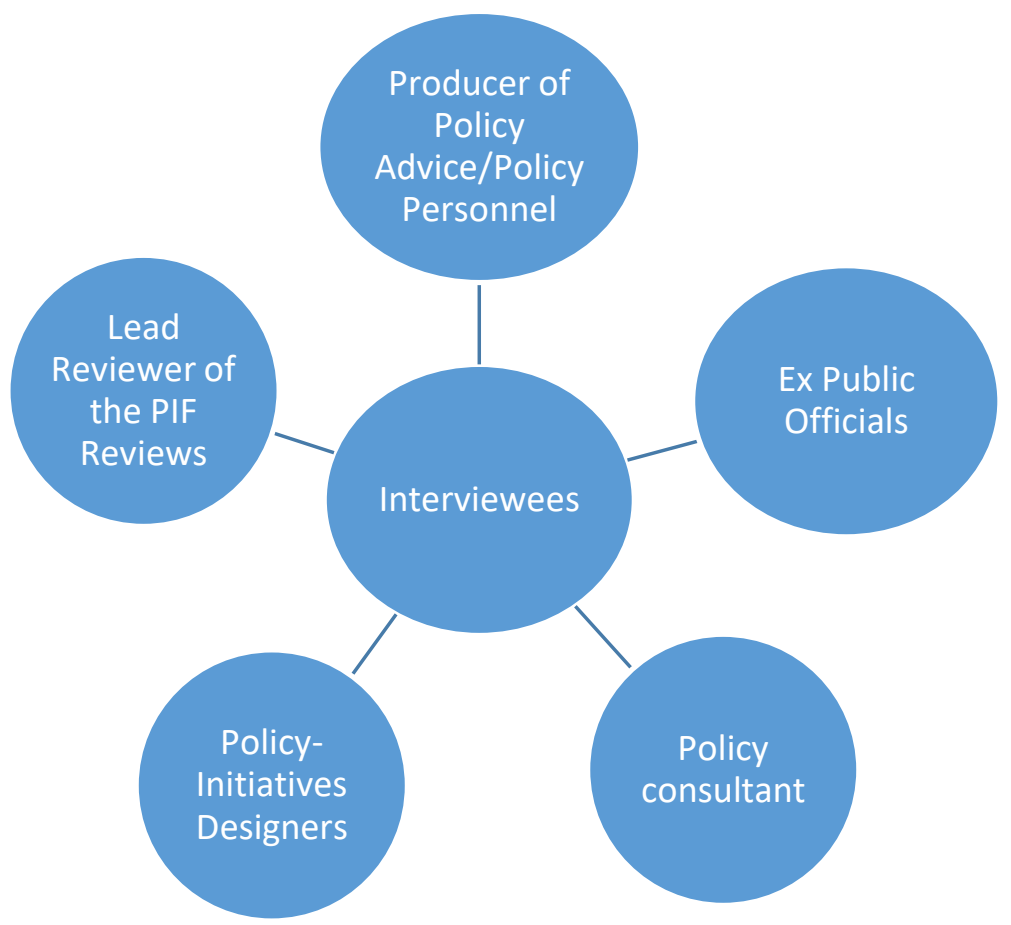

These interviews were also based on an interview guide, which means that all the chief executives and the senior leaders were asked similar questions to start with, although the open-ended format allowed the discussion to cover the dimensions important to the chief executives/senior leaders.

The interview guide was also used to interview the policy professionals directly involved in developing policy advice, to elicit their experiences and opinions of working under the guidance or instructions articulated in central government policy capability initiatives such as the PIF or in the agency's own initiatives. 
I asked semi-structured questions to the policy managers or policy staff directly involved in the production of policy analysis and advice, who I referred to as the 'users' of the developed initiatives. Interviewing policy staff at different levels and in different roles, I avoided asking an identical or even similar question. For example, I asked the senior leaders of the organisations about the drivers behind the initiatives, to learn about their choice to adopt an initiative but I did not ask such a question to policy staff as they were the users of the initiatives only.

Similarly, the senior leaders were not asked about the use of policy guides because they were seldom directly involved in the production of policy analysis. The independent reviewers had the roles of assessing the agencies and providing expert opinion and so were asked different open questions. The chief executives of agencies were asked questions framed according to this role.

Therefore, key open questions of different kinds were asked during the interviews: one set for the policy professionals who were engaged directly in developing policy advice for agencies; one set for the independent lead reviewers and the policy experts; and another set for the Chief Executives and senior leaders.

The total number of interviews was 20 , which included interviews with the independent reviewers and some policy experts external to the organisations. The interviews took place where the interviewees felt comfortable. The interviews were audio-recorded, and each interview lasted for approximately one hour. The overall objective of the interviews was to obtain a full picture of the experiences and impressions of participants in different roles regarding their efforts to improve policy capability and advice, to gain an understanding of their choice and use of initiatives.

\section{Strength of the Data Collection Methods}

The strength of the data collection methods applied in this research arose from applying a systematic approach to finding comprehensive answers to the research question. First, a preliminary understanding of the agencies' functions and responsibilities, people, 
policy capability initiatives and policy work was gained from internal reports and external reviews and publications. This helped select interviewees and decide the number of interviews and the dimensions of interview questions. Then different styles of questions for participants at different roles and levels were used to capture their experience from their own points of view, which finally helped develop a comprehensive picture.

Third, the quality of data was ensured by collecting information from multiple sources, to provide multiple measures of the same phenomenon (Robert K Yin, 1994, p. 92). For example, an impression of the quality of policy advice produced by the agencies was gained from different internal and external measures and views from different standpoints, rather than relying on only one measure or view. Similarly, the conclusions about the findings were also drawn from multiple information sources.

\subsection{Data Analysis, Interpretation and Reporting of Data}

After collecting information from case documentary data and interview transcripts, I then analysed the data, interpreted them, and produced a report for each case. For data analysis, interpretation and reporting, I followed an adapted three-stage process recommended by (Patton, 2001) as shown in Table 3.2.

Table 3.2: Three-stage Process for Data Analysis, Interpretation and Reporting of Data

\begin{tabular}{|l|l|}
\hline $\begin{array}{l}\text { Assemble the raw case } \\
\text { data }\end{array}$ & Case documentary data and interview transcripts. \\
\hline Construct a case record & $\begin{array}{l}\text { Make raw case data into manageable and accessible case files by } \\
\text { organising, classifying and editing. Summarise each interview. } \\
\text { Identify the similarities and differences in the interview } \\
\text { information. Cross-verify with information from other interviews } \\
\text { and documents. Do cross-case analysis by considering each case } \\
\text { as unique. Use the approach of explore, confirm and synthesise. } \\
\text { Thus, ensure creative synthesis. }\end{array}$ \\
\hline $\begin{array}{l}\text { Produce a final case } \\
\text { study narrative }\end{array}$ & $\begin{array}{l}\text { Ensure each case study is easily understandable with details and } \\
\text { specifics. Present each case holistically by incorporating different } \\
\text { views and perspectives. Convey with credible voice assuring } \\
\text { authenticity and trustworthiness, and give a balanced view by } \\
\text { understanding and depicting the phenomenon genuinely in all its } \\
\text { complexity. }\end{array}$ \\
\hline
\end{tabular}

Source: Adapted from Patton (2001) 
Specific policy initiatives were used as a means to examine policy practices in these case organisations. The initiatives developed by these case organisations to maintain, improve or build policy capability, were examined holistically by asking questions such as what the initiatives were, why they were developed, how they were designed, and what happened after the initiatives were developed. The answers to what question showed the types, forms and details of the initiatives, answers to why questions showed the aspirations of the initiators and the expected consequences of the initiatives. Answers to how question indicated not only the design of the initiatives but also the actors' use of different concepts and ideas in adopting the initiatives, and what happened questions showed the effects of adopting those initiatives on policy capability and advice.

While examining the information from documents and interviews the similarities and differences in the choice and use of initiatives were analysed. The similarities and differences across the cases were then interpreted with the contextual information relevant to each case to determine the factors that influenced the choice and use of policy capability initiatives.

The interviews with the lead reviewers and the policy experts helped gain the understanding from the experts' point of view and provided a source of external impressions on the agencies which were used as rival explanations as suggested by R.K. Yin (2014).

The research design provided an opportunity to give an overview of policy capability initiatives in the New Zealand public sector. It employed three parallel case studies, in conjunction with a broader review of initiatives in New Zealand, to find answers to the research question, using multiple methods such as interview, document analysis and observation. The data collected were analysed, interpreted and reported as per Patton (2001) three-stage process, with the help of observation and evidence gathered by using different methods and from different sources and the available literature. 


\subsection{Generalisability of the Findings}

A general view of case studies is that they generate context-dependent knowledge, meaning that the findings are applicable under certain conditions, such as a particular country context or time frame. Therefore, findings from case studies are considered not generalisable to other times and places, whereas analytical generalisation of the case study is important to contribute to theory (Rowley, 2002, p. 20).

This study neither claims to generalise the findings from these three cases, nor completely accepts the conventional view that a case and a case study cannot be of value in and of themselves and that they need to be linked to hypotheses, following the hypothetico-deductive model of explanation (Flyvbjerg, 2006a). This study takes a softer view of the matter, consistent with Flyvbjerg's argument:

'Social science has not succeeded in producing general, context-independent theory and, thus, has in the final instance nothing else to offer than concrete, context-dependent knowledge. And the case study is especially well suited to produce this knowledge' (Flyvbjerg, 2006b, p. 223).

Maclntyre (1985, p. 91) shares a similar view in his argument that while generalisation is possible in natural sciences, generalisation in social sciences is no better than that of a layperson.

My research, however, has not aimed at the production of hypotheses through induction. Except at a very general level, I will not make arguments in the form of 'if ' $x$ ' is seen to take place under certain conditions it will take place again under those same conditions. Such induction is unlikely from the findings of the three cases I have studied, as policy analysis and advising are done under ever-changing dynamic condition. The research rather aims for more limited generalisations, underpinned by the argument of Thomas (2010, p. 576):

..the goal of social scientific endeavor, particularly in the study of cases, should be exemplary knowledge unselfconsciously based on abduction gained and offered through phronesis rather than through theory......If my argument has validity then there are forms of interpretation that can come from case study that owe their 
legitimacy and power to the exemplary knowledge of case study, rather than to its generalisability.

Accordingly, the objective of the study of three cases is to generate exemplary knowledge.

\subsection{Limitation of the Study}

There were three limitations. First, the immediate clients (such as ministers) for policy advice were not interviewed. Their views were captured by secondary data only. Second, the case studies were limited to three cases by practical considerations such as cost and time. Therefore, it remains unknown whether the findings from the three cases would have been different if there were more than three, or more diverse or more similar cases. Third, while these cases were time-bounded between 2008 and 2015, several initiatives were developed after 2015 and were not examined. The timeframe limited the research to exploring whether the examination of these new initiatives might alter the findings of the cases.

\subsection{Caveats}

The thesis neither attempted to establish a causal relation between the initiatives and the improvement of policy capability and advice, nor tried to establish the relative importance of the initiatives by their contribution to policy capability and the quality of policy advice. Rather, it focused on identifying the factors and conditions that were influential in efforts to improve policy capability and the quality of policy advice, and their complementarity. At a level higher than this, the thesis identified the factors that influenced the actors' choice and use of the initiatives. This research was not designed to evaluate, comment on, rank or rate any initiative, individually or collectively, or any organisation. Any such impression gained from this research is solely the reader's interpretation and not the researcher's intention by any means.

\subsection{Ethics Approval}

This research gained ethics approval from the Human Ethics Committee of Victoria University of Wellington. Permission to conduct interviews was also obtained from the 
case organisations. Three ethical issues were addressed: voluntary participation in interviews; confidentiality in terms of participant identification; and confidentiality in terms of the information discussed during interviews.

Voluntary participation in interviews was addressed by asking individuals in the policy team if they wanted to participate in face-to-face interviews. Senior managers of the agencies also suggested potential participants in individual interviews. Each participant was provided an information sheet about the purpose and theme of the study. Each participant was also given a consent form to sign before the interview. It was communicated to the participants in writing that participation in an interview was voluntary and the participants could stop the interview or withdraw information before the final analysis was completed. The participants were also reminded of these matters prior to the interviews. A standardised consent form, an information sheet and an approved interview guide used for this research are included in Appendix 2.

The confidentiality of participants' identities was ensured by not disclosing their names or personal characteristics (age, gender etc.) in this thesis. It was also communicated to the participants that some information might be attached to their roles; and where their roles were unique, care was taken in reporting to make it unlikely to identify them, though some informed readers might be able to guess their identities. The issue of the confidentiality of interview information was addressed by the careful and responsible use of information by the researcher. In reporting findings, the researcher ensured the confidentiality of participants by removing identifying details from quotations and examples. In drawing conclusions, mention of specific departments/agencies, programmes or services, was avoided where possible. 


\section{CHAPTER 4: The Choice and Use of Central Agency Initiatives}

\subsection{Introduction}

The initiators' choice and use of the central agencies' initiatives are explained in this chapter. The initiators in the three case organisations include both the senior leaders of the organisations and the New Zealand public sector. The central agencies' initiatives, why they were developed and what their consequences have been are examined. The initiatives developed between 1990 and 2015 in the New Zealand public sector to improve policy capability and the quality of policy advice are covered. The changes in policy practices over time in the public sector are shown first to demonstrate how the New Zealand public sector has been professionalising policy analysis and advice since the start of public sector reforms. Second, what influenced the changes in policy practices is identified.

The initiatives examined are: Policy Advice Initiative (PAI) 1991-1995, Improving the Quality of Policy Advice (IQPA) Initiative 1997-1999, Policy Managers Network (PMN) 2000-2009, Performance Improvement Framework (PIF) 2009, Review of Expenditure on Policy Advice (REPA) 2010, the Natural Resources Sector Framework (NRF) 2014 and the Policy Project 2016 (initiated in 2014).

The changes in the policy practices are captured in the following section. The subsequent section shows the influences on policy analysis and advice. The changes in policy practices are reflected in the purpose, design, and form of the initiatives. The changes in the policy practices and the influences on policy analysis and advice together explain the initiators' choice and use of the initiatives.

\subsection{The Changes in Policy Practices}

The New Zealand public sector has been professionalising policy analysis and advice since the public sector reforms begun in the late 1980s by promoting continuous changes in policy practices in the New Zealand public sector. The changes in policy practices were suggested by adopting initiatives. 


\section{The Policy Advice Initiative (PAI) 1991-1995}

The PAI 1991-1995 was the first significant initiative following the core public sector reforms. This showed that professionalising policy analysis and advice was about standardising policy practices to ensure less variation with regards to the quality of policy analysis and advice across public sector agencies. Its emphasis was on providing guidance to achieve policy analytical capability. It, however, also suggested how to manage developing policy analysis and advice.

The PAI was a comprehensive initiative that provided guidance with regards to policy inputs, output and process to show how to craft in policy analysis. In addition to defining 'policy advice', the designers of the PAI set out five key characteristics in people who develop policy advice (see Table 4.1) to demonstrate the importance of both policy analytical and political capability at the individual level. The PAI showed the characteristics of a good quality process (see Table 4.2). This conveyed that good quality policy process was likely to produce high-quality policy advice.

Table 4.1: Five Key Characteristics in People Practising the Craft of Policy Analysis

\begin{tabular}{|l|l|}
\hline 1 & Knowing how to gather, organise and communicate information \\
\hline 2 & Applying a method for putting perceived social problems in context \\
\hline 3 & Having technical skills to be able to predict and evaluate the policy options \\
\hline 4 & Understanding of political and organisational behaviour \\
\hline 5 & $\begin{array}{l}\text { Having an ethical framework that takes account of the relationship of policy analysts } \\
\text { and to their minister and the government }\end{array}$ \\
\hline
\end{tabular}

Source: Adapted from Weimer and Vining (1989) and the PAI Report 'Opportunities for Management', (SSC, 1992, pp. 16-18)

\section{Table 4.2: Characteristics of a Good Quality Process}

\begin{tabular}{|l|l|}
\hline 1 & The task is well-defined at outset \\
\hline 2 & Departments are asked to identify the contribution they wish to make \\
\hline 3 & Interests of the departments are acknowledged \\
\hline 4 & $\begin{array}{l}\text { The process is well managed towards achieving clear and agreed directions for each } \\
\text { stage of the work }\end{array}$ \\
\hline 5 & Participants are well informed of what is being attempted \\
\hline 6 & The group has a stable membership that includes senior officials \\
\hline
\end{tabular}

Source: Hawke (1993, p. 32) 
The core competences of policy staff (see Table 4.3) showed that policy advice producers at different levels required different types of skills and competencies. The roles of policy analysts were depicted as different from the roles of policy managers. It meant to show that each policy advice producer provided different nature of contributions to the development of policy advice. A policy analyst mainly analysed the policy problem and developed policy advice with analytical and innovative thinking as an objective technician, whereas a policy manager set and managed the expectation from policy advice and applied political awareness and judgement as a client's advocate. The different nature of contributions from policy analysts and managers to the production of policy advice implies that developing policy advice is based on team-work in which the policy advice producers applied their policy analytical, management and political capability to produce advice for clients.

Table 4.3: Identification of Core Competences in People Who Develop Policy Advice

\begin{tabular}{|c|c|c|}
\hline Policy Analysts & Policy Managers & Policy Technician \\
\hline $\begin{array}{l}\text { The policy staff without } \\
\text { management } \\
\text { responsibilities who } \\
\text { write most policy } \\
\text { papers }\end{array}$ & $\begin{array}{l}\text { The policy staff } \\
\text { immediately below the } \\
\text { chief executive, middle } \\
\text { level policy managers, } \\
\text { section managers } \\
\text { immediately above the } \\
\text { policy analysts who set } \\
\text { expectations and } \\
\text { manage the policy unit }\end{array}$ & $\begin{array}{l}\text { The policy staff with scientific or } \\
\text { technical knowledge who are } \\
\text { responsible for investigating on setting } \\
\text { standards and regulations and providing } \\
\text { information to the policy analysts or } \\
\text { managers but }\end{array}$ \\
\hline \multicolumn{3}{|l|}{ Core Competences } \\
\hline \multirow[b]{2}{*}{$\begin{array}{l}\text { Analytical thinking } \\
\text { Innovative thinking } \\
\text { Political awareness } \\
\text { Effective writing } \\
\text { Oral communication } \\
\text { Group skills }\end{array}$} & \multirow[b]{2}{*}{$\begin{array}{l}\text { Leadership } \\
\text { Group skills } \\
\text { Ability to delegate } \\
\text { Ability to organise } \\
\text { Political awareness and } \\
\text { judgement }\end{array}$} & Strongly Technical Skills: \\
\hline & & $\begin{array}{l}\text { Tertiary qualifications at post graduate } \\
\text { level (in the specified area often in } \\
\text { natural sciences or engineering) } \\
\text { Knowledge of operational areas } \\
\text { Research skills and experience } \\
\text { Understanding of regulations and } \\
\text { technical standards }\end{array}$ \\
\hline \multicolumn{3}{|c|}{$\begin{array}{l}\text { Clerical Support Staff: The staff who are responsible for providing support with the skills of } \\
\text { word-processing, filing, mailing etc. The critical skills are those allowing final policy papers to } \\
\text { be presented in appropriate formats and with graphs. }\end{array}$} \\
\hline
\end{tabular}

Source: Adapted from the PAI Report 'Opportunities for Management' (SSC, 1992, pp. 29-35) 
Professionalising policy analysis and advice also involved human resources management. The initiators specified how the 'right' people with identified core competences could be selected, developed, motivated, remunerated and sanctioned (see Table 4.4). The constant development of policy advice producers and the organisational commitment to training and development were identified as crucial to maintain policy capability at both individual and organisational levels. The reputation of policy capability was reflected not by the quality of policy work of an individual policy analyst but by the reputation of the policy team or agency the analyst was working for. This implies that improving policy capability is reliant not only on the policy analyst's state-of-the-art policy analysis but also the policy manager's managerial role to understand wider policy contexts.

Table 4.4: Suggestions on Human Resources Management by the PAI 1991-1995

\begin{tabular}{|c|c|c|}
\hline & Diagnosis & Endorsements \\
\hline $\begin{array}{l}\text { Selection } \\
\text { (Policy Analyst only) }\end{array}$ & \multicolumn{2}{|c|}{$\begin{array}{l}\text { It involves identifying and hiring people with the core competences required in policy } \\
\text { staff. }\end{array}$} \\
\hline Testing Procedures & $\begin{array}{l}\text { Inadequate testing } \\
\text { procedures to determine } \\
\text { whether applicants have } \\
\text { the skills of analytical } \\
\text { thinking, effective } \\
\text { writing, oral } \\
\text { communication and } \\
\text { group skills. }\end{array}$ & $\begin{array}{l}\text {-In addition to using a panel interview, examination of } \\
\text { curriculum vitae and references, use written assignments, } \\
\text { group exercise that includes presentation and group skills, } \\
\text { appropriate practical tests that can include personality or } \\
\text { psychological testing which asks critical questions to } \\
\text { concern the applicant's reliability and both content and } \\
\text { predictive ability. } \\
\text {-Make aware of the department's expectations for } \\
\text { performance. }\end{array}$ \\
\hline Filling Vacancies & $\begin{array}{l}\text { Pressure to fill positions } \\
\text { even with the applicants } \\
\text { do not meet the } \\
\text { requirement. }\end{array}$ & $\begin{array}{l}\text { Policy managers should maintain high expectations by } \\
\text { recognising the right trade-off between the consequences } \\
\text { of rejecting second-rate appointment (pressure of extra } \\
\text { work in short term) and hiring right skills at the right level } \\
\text { (outweigh the short-term pressure). }\end{array}$ \\
\hline $\begin{array}{l}\text { Development } \\
\text { (for both Policy } \\
\text { Analysts and Policy } \\
\text { Managers) }\end{array}$ & $\begin{array}{l}\text { Constant development is } \\
\text { necessary. } \\
\text { Organisational } \\
\text { commitment to training } \\
\text { and development. }\end{array}$ & $\begin{array}{l}\text {-Run short basic courses on effective writing, oral } \\
\text { communication, basic computer skills, time management, } \\
\text { project management, speed reading, group skills, and bi- } \\
\text { cultural awareness within the first 12-24 months of their } \\
\text { appointment. } \\
\text {-Acquire extended and formal training in policy analysis to } \\
\text { address skill gap (Master of Public Policy degree at Victoria } \\
\text { University, for example). } \\
\text { Run short courses on policy analysis. } \\
\text {-Ensure development of senior policy staff at overseas } \\
\text { institutions. } \\
\text {-Second policy staff to an overseas public service or a } \\
\text { relevant international organisation. } \\
\text {-Raise investment in training and development. }\end{array}$ \\
\hline $\begin{array}{l}\text { Motivation } \\
\text { (for policy staff) }\end{array}$ & \multicolumn{2}{|c|}{$\begin{array}{l}\text { It involves an interaction between the policy staff and their environment. The } \\
\text { environment includes the relationships to their tasks, colleagues, and managers; the } \\
\text { system of performance assessment, reward and sanction; development opportunities; } \\
\text { and the physical work place. }\end{array}$} \\
\hline
\end{tabular}




\begin{tabular}{|c|c|c|}
\hline & Diagnosis & Endorsements \\
\hline $\begin{array}{l}\text { Arousing } \\
\text { Motivation9 }\end{array}$ & $\begin{array}{l}\text {-The idea of arousal/the } \\
\text { mechanism that gets } \\
\text { staff energised is not the } \\
\text { same thing as either } \\
\text { behaviour or } \\
\text { performance. } \\
\text {-Motivation alone is not } \\
\text { sufficient, the ability to } \\
\text { do well and the } \\
\text { supportive environment } \\
\text { enhance capacity of } \\
\text { people. }\end{array}$ & $\begin{array}{l}\text {-Arousal focuses on need-deficiencies and need for varied } \\
\text { reward systems to match individual reward systems to } \\
\text { individual employees (traditional theories). } \\
\text {-Arousal is also caused by the presence of others (such as } \\
\text { superiors). } \\
\text {-People should be given explicit goals to strive for and be } \\
\text { frequently rewarded for appropriate behaviour }{ }^{10} \text {. } \\
\text {-Enlarged and enriched jobs have positive motivational } \\
\text { properties in the form of autonomy, variety, significance. }\end{array}$ \\
\hline $\begin{array}{l}\text { Recognition and } \\
\text { Reputation } \\
\text { (especially for policy } \\
\text { analysts) }\end{array}$ & $\begin{array}{l}\text { Typically, the core of the } \\
\text { motivation for a policy } \\
\text { analyst is a wish for } \\
\text { her/his idea to prevail } \\
\text { and influence. }\end{array}$ & $\begin{array}{l}\text {-Motivation enhances with the opportunity for intellectual } \\
\text { stimulation and the work environment that is linked to } \\
\text { power (having a senior influential minister). } \\
\text {-Winning the debate over an idea through having policy } \\
\text { advice accepted is a stronger motivation and a mean for } \\
\text { recognition too. } \\
\text {-Recognition can come from having an opportunity to deal } \\
\text { directly with a minister, or work on significant policy } \\
\text { matters, or have one's name attached to a piece of advice. } \\
\text {-Reputation assumes differing values depending on where } \\
\text { the recognition comes from: internal within the analyst's } \\
\text { department, external from other departmental policy } \\
\text { analysts, professional or interest groups in the community. } \\
\text {-An analyst's reputation may not derive from the quality of } \\
\text { work rather the policy company s/he keeps. The credibility } \\
\text { of the analyst can be tied up with the credibility of the } \\
\text { policy unit s/he works for. As a consequence, a policy unit } \\
\text { with low credibility may find it difficult to attract, hire, } \\
\text { motivate and retain high quality staff. }\end{array}$ \\
\hline $\begin{array}{l}\text { Ethics } \\
\text { (for policy analysts) }\end{array}$ & $\begin{array}{l}\text {-Need a common } \\
\text { language of policy } \\
\text { analysis across } \\
\text { departments. }\end{array}$ & $\begin{array}{l}\text {-Increase dialogue among policy analysts. } \\
\text {-Develop common understanding of the rules of behaviour. } \\
\text {-The Public Service Code of Conduct, } 1990 \text { is an important } \\
\text { element in reinforcing appropriate professional ethics. }\end{array}$ \\
\hline \multicolumn{3}{|l|}{$\begin{array}{l}\text { Remuneration and } \\
\text { Sanctions }\end{array}$} \\
\hline The system & $\begin{array}{l}\text {-The state sector reform } \\
\text { facilitates managers to } \\
\text { reward performers } \\
\text { differently to recognise } \\
\text { the differences in } \\
\text { performance. }\end{array}$ & $\begin{array}{l}\text {-The capacity for this flexibility need to be widely and fully } \\
\text { utilised }\end{array}$ \\
\hline $\begin{array}{l}\text { Effects of } \\
\text { remuneration }\end{array}$ & $\begin{array}{l}\text {-Equity theory (relative } \\
\text { remuneration rather } \\
\text { than absolute sums tend } \\
\text { to have greater impact } \\
\text { on performance) is } \\
\text { found to be more } \\
\text { applicable than } \\
\text { Herzberg's approach } \\
\text { (people consider money } \\
\text { and job security as } \\
\text { 'hygienes' rather than }\end{array}$ & $\begin{array}{l}\text {-Policy analysts/managers look at their inputs (for example, } \\
\text { how hard the worker is working) and outcome (that is pay) } \\
\text { and compare these to the inputs and outcomes of other } \\
\text { people doing a similar job. If the difference is significant } \\
\text { then they find it dissatisfying and they tend to reduce the } \\
\text { difference mostly by (a) reducing their inputs, rather than } \\
\text { (b) trying to increase their outcomes or (c) changing their } \\
\text { comparison level/finding a more acceptable job } \\
\text { comparison. The labour market and the tight departmental } \\
\text { budget suggest that (a) is more likely to occur when people } \\
\text { experience inequity under salaried conditions. If such }\end{array}$ \\
\hline
\end{tabular}

${ }_{9}^{9}$ Mitchell T. R., et al., People In Organisations, McGraw-Hill Book Company, 1988.

${ }^{10}$ Expectancy theory, goal-setting theory and Equity theory purports the idea 


\begin{tabular}{|l|l|l|}
\hline & Diagnosis & Endorsements \\
\hline Performance of & $\begin{array}{l}\text { 'motivators') for policy } \\
\text { analysts/managers. }\end{array}$ & $\begin{array}{l}\text { feeling is widespread in a policy unit than the quality of the } \\
\text { service will be impaired. }\end{array}$ \\
\hline Assessment & $\begin{array}{l}\text {-The element of } \\
\text { subjectivity needs to be } \\
\text { reduced } \\
\text {-The attitude towards } \\
\text { rewards and sanctions is } \\
\text { likely to change slowly. }\end{array}$ & $\begin{array}{l}\text {-A sound system of annual performance assessment is } \\
\text { needed but needs to address the question how well the } \\
\text { quality of policy advice work be assessed. } \\
\text {-A clear set of criteria for assessment is used by some } \\
\text { policy units. }\end{array}$ \\
\hline Salary Levels & $\begin{array}{l}\text {-There is budget } \\
\text { constraint to reward } \\
\text { high performers. }\end{array}$ & $\begin{array}{l}\text {-The more appropriate point of reference for remuneration } \\
\text { of policy analysts is primarily the overall rates for policy } \\
\text { analysts. } \\
\text {-Use options of regression, one-off bonuses, and transfers } \\
\text { from operating expenses. }\end{array}$ \\
\hline Sanctions & $\begin{array}{l}\text {-Managers are reluctant } \\
\text { to dismissal. } \\
\text {-The failure to sanction, } \\
\text { after redeployment and } \\
\text { retraining, lowers the } \\
\text { overall quality of the } \\
\text { policy unit by setting } \\
\text { demoralising example to } \\
\text { better performers. }\end{array}$ & $\begin{array}{l}\text {-Regression can be an important option. } \\
\text {-A deadline can be set to allow the performance to rise to } \\
\text { an acceptable level which also provides signalling the } \\
\text { consequences of poor performance. }\end{array}$ \\
\hline
\end{tabular}

Source: Adapted from the PAI Report 'Opportunities for Management', (SSC, 1992, pp. 35-51)

Since policy advice is, essentially, a result of team work in which policy advice producers apply their policy analytical, management and political capability, it is not easy to segregate the contribution of each type of policy capability from the sum of the contributions to the production of policy advice. In conveying the declining policy capability, the clients for policy advice, therefore, seldom point out the types of policy capability (analytical, management or political) that fall short.

The initiators of the PAI also endorsed the framework (see Figure 4.1) developed by the then Ministry of Commerce, and promoted the idea that a 'policy framework' was supportive of a systematic approach to solve policy problems. The use of framework and different policy tools such as cost-benefit Analysis was shown by the initiators as means to translate policy capabilities into results or, in other words, to translate policy analysis into advice. Consultation was considered to be a separate activity, but required to take place in all the three stages (shown in Figure 4.1). This involved seeking peer review by colleagues in the agencies and/or by outside experts. The use of peer review indicated that producing policy analysis and advice was not solely an isolated activity of a policy 
team or organisation for the use of its minister/immediate client only rather for the entire public sector.

However, with respect to 'quality' expectations of policy advice, the initiators stressed meeting the expectations of the ministers/clients. The understanding of policy development was client-centric and considered the minister to be the most important client. To clarify the expectations of ministers from policy advice service, five measures of performance were established as the common guidelines for purchasing policy advice; the satisfaction of the minister was given as an indicator of performance against two of the five measures of performance (see Table 4.5).

The PAI, thus, suggested a significant amount of changes in policy practices to improve both policy analytical and management capability at individual and organisation levels, with special attention to policy inputs, process, framework and tools and human resources management. It focused on ensuring rigorous policy analysis and managing the development of policy analysis and advice with new policy practices. 


\section{Figure 4.1: Ministry of Commerce Framework for Policy Making}

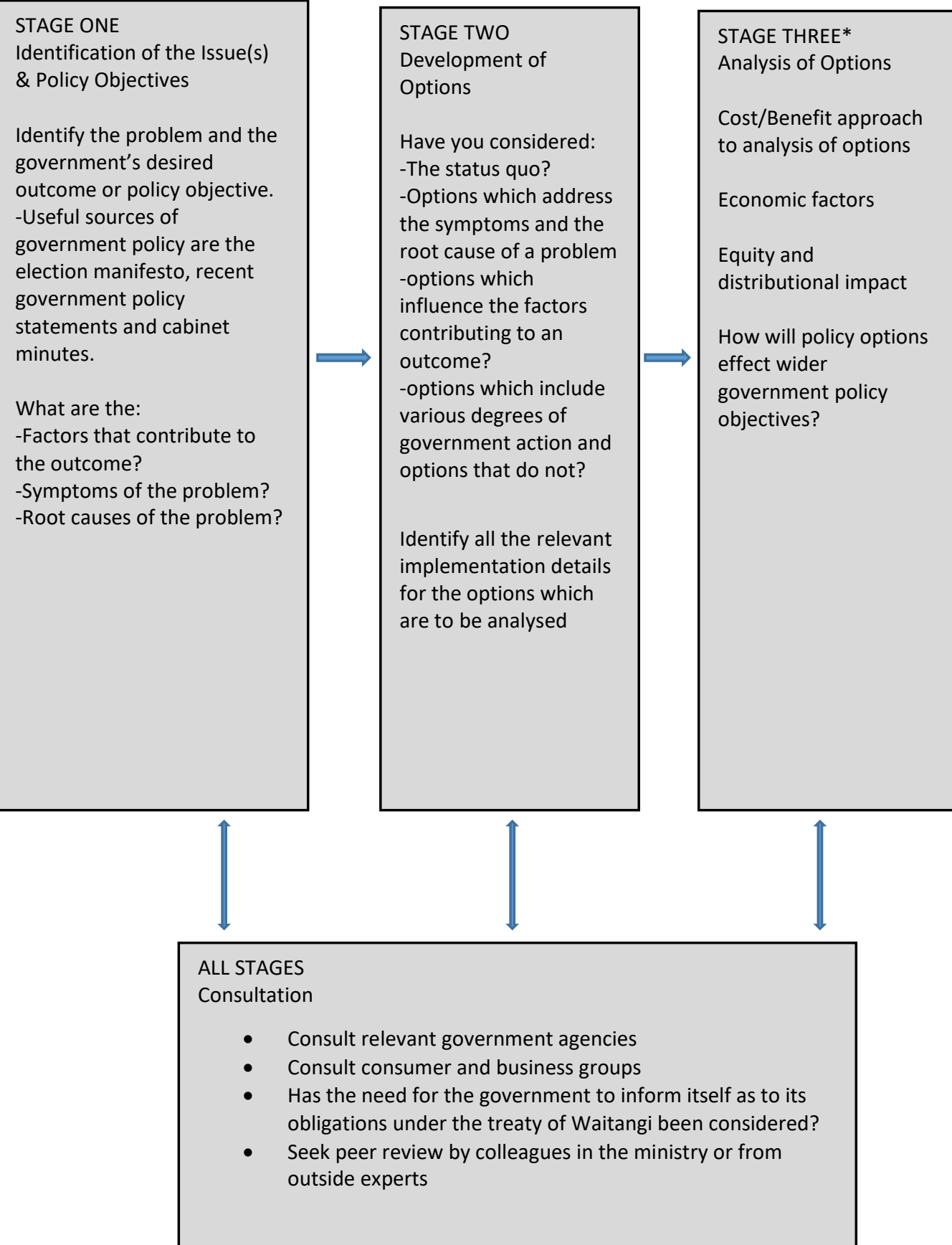

Source: Hawke (1993, p. 40)

*The figure above provides information for stage three briefly than in the source. 
Table 4.5: Five Measures of Performance for Suppliers of Policy Advice

\begin{tabular}{|l|l|l|}
\hline Measures & Clarification & Assessed by \\
\hline Quantity & $\begin{array}{l}\text { Completing all the priority policy } \\
\text { advice projects }\end{array}$ & $\begin{array}{l}\text { Comparison against written } \\
\text { programme and subsequent } \\
\text { amendments }\end{array}$ \\
\hline Coverage & $\begin{array}{l}\text { Providing a comprehensive service } \\
\text { that includes capacity to react } \\
\text { urgently, regular evaluation of } \\
\text { government spending and } \\
\text { confidential briefings }\end{array}$ & $\begin{array}{l}\text { Satisfaction of the minister as } \\
\text { expressed in the ministerial six- } \\
\text { monthly or quarterly response } \\
\text { sheet. }\end{array}$ \\
\hline Quality & $\begin{array}{l}\text { Supplying individual products (policy } \\
\text { advice) of high quality as defined in } \\
\text { a checklist for the minister to use }\end{array}$ & $\begin{array}{l}\text { Satisfaction of the minister as } \\
\text { expressed in the ministerial six- } \\
\text { monthly or quarterly response } \\
\text { sheet. }\end{array}$ \\
\hline Time & $\begin{array}{l}\text { Meeting the reporting deadlines of } \\
\text { projects }\end{array}$ & $\begin{array}{l}\text { Comparison against deadlines set in } \\
\text { the written policy work programme, } \\
\text { subsequent amendments, and } \\
\text { specific instructions }\end{array}$ \\
\hline Cost & Performing within the budget & $\begin{array}{l}\text { Comparison of outturn with } \\
\text { estimates }\end{array}$ \\
\hline
\end{tabular}

Source: Adapted from the PAI Report 'Opportunities for Management' (SSC, 1992, pp. 10-11) and Hawke (1993, p. 19)

With respect to policy output, a checklist was developed for Ministers to use to assess the quality of policy advice and specifically whether the policy advice met the expectations of ministers. The checklist identified policy advice as a 'product', which was required to meet seven product quality characteristics (see Table 4.6). The satisfaction of ministers was explicitly specified as vital for policy advice to qualify as high-quality. The PAI also promulgated a quality management process for overseeing quality throughout the process of developing policy advice (see Table 4.7) and not only after it was produced. Emphasis was also placed on the cost component in assessing the quality of policy advice. 
Table 4.6: A Checklist to Assess the Quality of Policy Advice

\begin{tabular}{|l|l|}
\hline Measures & Clarification \\
\hline Purpose & $\begin{array}{l}\text { The advice is clearly stated and it answers the questions set by the } \\
\text { minister }\end{array}$ \\
\hline Logic & $\begin{array}{l}\text { The assumptions behind the advice are explicit and clear. The argument } \\
\text { follows logically from the assumptions }\end{array}$ \\
\hline Accuracy & The argument is clearly and accurately supported by facts \\
\hline Options & $\begin{array}{l}\text { An adequate range of options are presented and the benefits, costs and } \\
\text { consequences of each option are spelled out }\end{array}$ \\
\hline Consultation & $\begin{array}{l}\text { Adequate consultation with other government agencies and affected } \\
\text { parties }\end{array}$ \\
\hline Practicality & $\begin{array}{l}\text { The feasibility, timing and consistency of recommended actions have } \\
\text { been considered. }\end{array}$ \\
\hline Presentation & $\begin{array}{l}\text { The advice is concisely and clearly presented in simple sentence and plain } \\
\text { English without spelling or grammatical errors }\end{array}$ \\
\hline
\end{tabular}

Source: Adapted from the PAI Report 'Opportunities for Management' (SSC, 1992, p. 11) and Hawke (1993, pp. 22-23)

Table 4.7: Quality Management Process by the PAI, 1991-1995

\begin{tabular}{|l|l|}
\hline \multicolumn{2}{|l|}{ Product quality will be supported by a quality management process that includes: } \\
\hline 1 & External review of scope and methodology for major analytical work \\
\hline 2 & Circulation of drafts for critiquing by other government agencies \\
\hline 3 & Internal peer review and checking procedures \\
\hline 4 & Sign-off of reports by senior managers \\
\hline
\end{tabular}

Source: Hawke (1993, p. 23)

Ministers' satisfaction and cost-effectiveness were considered significant in gauging the quality of policy advice. The initiators understood policy development as a 'process' and policy advice as a 'product' (SSC, 1992, p. 11) which resulted from a process built on 'policy analysis'. As Hawke (1993, pp. 27-29) acknowledges, 'Policy advice is inherently a difficult process;' and 'It is possible to get good policy advice from a muddle, but it is rare for the best advice to emerge without careful management'.

The designers, therefore, showed a systematic approach to the production of policy analysis and advice. They showed how to improve policy process, inputs and output and how to meet clients' quality expectations. However, when the need for costeffectiveness in developing policy advice is over-emphasised and the satisfaction of ministers determines the 'quality' of policy advice (see Table 4.5), the question remains 
to what extent developing policy advice will be guided by 'analysis'. It is plausible that the work of policy analysts and managers might rather be guided, either out of caution or inadvertently, by checklist, standards, instructions, or measures out of mere conformance to requirements.

Furthermore, instead of exploring a policy problem comprehensively and systematically (which may incur higher and unpredictable costs) and tendering advice reasoned from a logical approach, policy options proffered may be the ones that ministers expect to hear. Trying to keep the cost to a minimum and achieve the clients' satisfaction might lead to at least two undesirable outcomes: poor quality policy analysis because of limited exploration of policy problems; and unproductive rent-seeking behaviour by policy analysts or managers seeking to give ministers what they would like to hear as solutions to policy problems. This may encourage ministers to take part in counter-productive activities too. It may become more prominent since the introduction of Mixed Member Proportional Representation (MMP) to New Zealand's parliament, since the Westminster advisory style that emphasises the need for negotiation issue by issue.

\section{Improving the Quality of Policy Advice (IQPA) Initiative 1997-1999}

Despite the PAI 1991-1995, the concern with the quality of policy advice did not fade. Rather, more concerns were noticed. The specific concerns expressed by the then Minister of State Services as set out in the IQPA Initiative 1997-1999 were the inability of the public service to define clearly the outcomes the government seeks to achieve and develop sound policy solutions for achieving them; inadequate human resource capability; lack of attention to implementation issues; and the counter-productive and debilitating consequences of departmental patch-protection (SSC, 1999a, p. 5).

Five main contributing factors were specified in the SSC's report on the IQPA initiative:

a) lack of clarity in ministers' statements about some desired outcomes and policy directions

b) insufficient incentives for active co-operation by departmental chief executives on cross-cutting policy issues 
c) significant variations in leadership and performance of departmental policy units

d) substantial under-investment in capability development resulting in shortages of highly capable policy managers and advisors and

e) significantly inadequate and/or ineffective use of information, research, evaluation and consultation techniques as inputs to policy development. (SSC, 1999a, p. 5)

All these points were addressed by the IQPA initiative project papers and suggestions were put forward. A Better Focus on Outcomes through SRA Networks by the SSC in 1998 partly addressed the concerns (a) and (b) expressed above. The paper suggested developing a system of Strategic Result Areas (SRAs) and Key Result Areas (KRAs) 'to support progress toward strategic goals with better alignment between government priorities, departmental work, and chief executive performance' (SSC, 1998, p. 2).

This proposed system relied on the analysis of the Schick (1998a) report and the Logan report (SSC, 1991) that the state of New Zealand's public-sector management system was geared more to the short-term production of outputs than to planning for the long haul. The SSC argued that only if there is certainty that the production of the outputs leads to the achievement of the outcomes, and if the outcomes can be broken down into measurable parts and distributed among the various departments as outputs, the government is likely to achieve its strategic goals (SSC, 1998). The relationships within SRA networks and the SRA cycle are shown in Figure 4.2 and Figure 4.3 respectively.

The IQPA initiative showed the importance of gaining policy capabilities at system level and pointed out several broad factors in improving the quality of policy advice. One was establishing the link between policy output and outcome to ensure the output contributed to realising the strategic priorities of the government. Another was to establish ministerial teams to enhance the effectiveness of the public service in putting into effect key government priorities. The SSC also identified management development, 
strategic policy development, research and analysis, evaluation and leadership as factors crucial to improving policy capability and the quality of policy advice (SSC, 1998).

Figure 4.2: The Relationships within Strategic Result Areas Networks

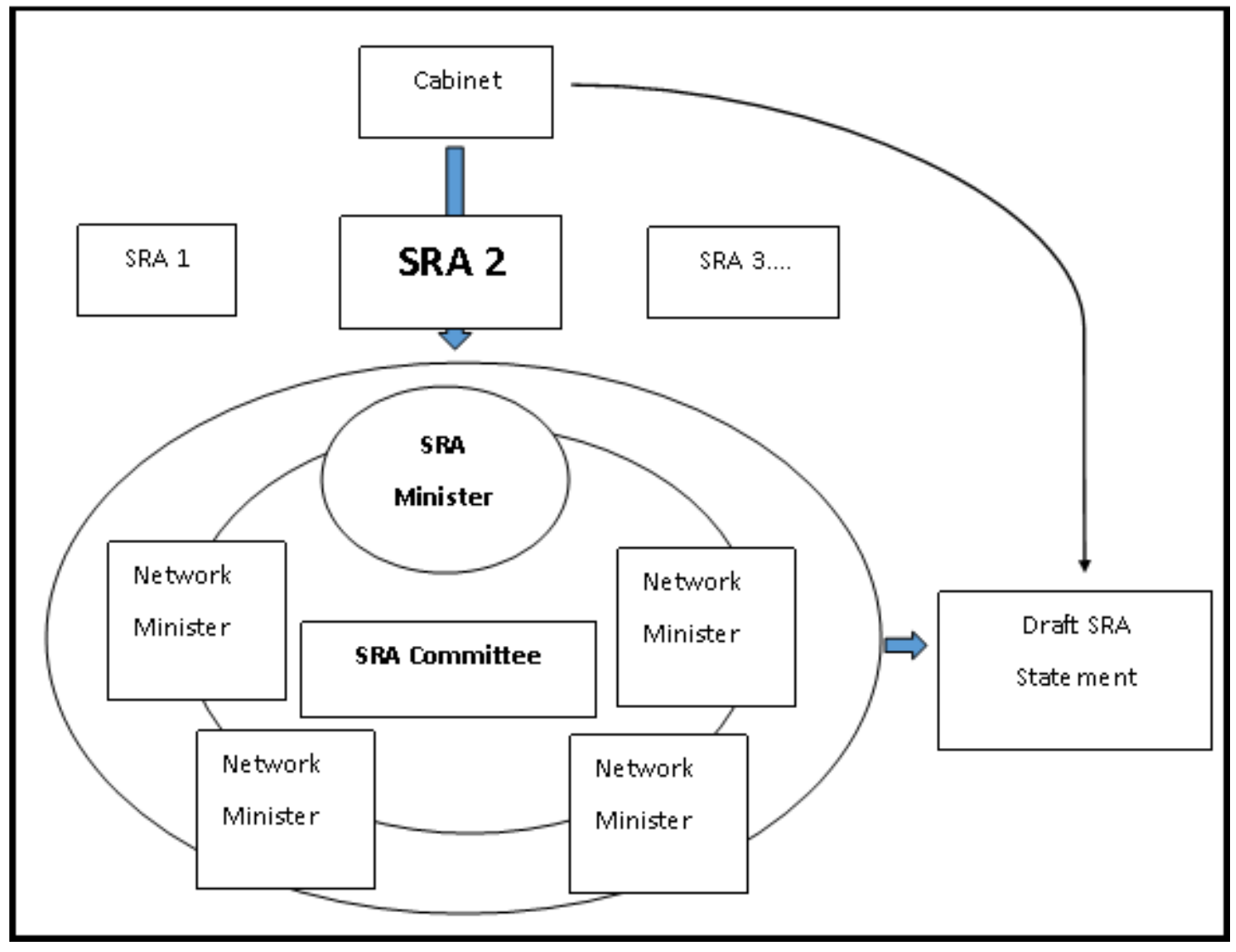

Source: (SSC, 1998, p. 8)

The success of SRA networks, however, was expected to be solely reliant on the departments producing policy outputs that would surely lead to the achievement of the intended policy outcomes. All policy advice implies a view on causality, and New Zealand has historically poor outcome specification (SSC, 1998), so the SSC suggested the challenges would be twofold: first, the departments might not have the capability to produce policy outputs leading to the desired outcomes; and second, over-emphasis on linking policy output to outcome rather than addressing a vital question 'is the right thing being made?' can be unduly costly and time-consuming (SSC, 1998, p. 5). 
Figure 4.3: The Relationships within Strategic Result Areas Cycle

Ex Post Evaluation

-Dece mber (Half Year) SRA Update (DSRAU) prepared reporting on progress towards the SRA

-SRA Report prepared at the end of the year reporting on progress towards the SRA
Vision to $S R A$

-Dece mber (Half Year) SRA Update (DSRAU) prepared reporting on progress towards the SRA

-SRA Report prepared at the end of the year reporting on progress towards the SRA

-Principles and budget parameters are established

Ex-Ante Docs

-SRA linked outputs approved in individual departments Budget

-SRA State ments fin alised

Allocation

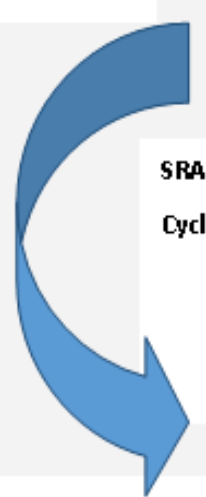

SRA

cle

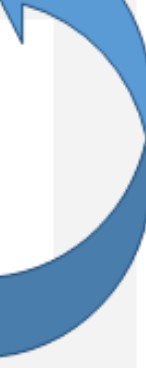

-Lead Minister \& Network Ministers (Network Committee) disaggre gate the SRA into SRA Outcomes.

- Ne twork Ministers ide ntify the interventions (outputs) to achieve each SRA Outcome

-Strate gic Re sult Indicators are established for evaluation purposes

Source: (SSC, 1998, p. 9)

The variation in leadership and performance of departmental policy units and underinvestment in capability development were seen as detrimental to policy capability. This was communicated by the State Services Commission (SSC) mainly through three working papers, Minds Over Matter: Human Resources Affecting the Quality of Policy Advice, 1999; High Fliers: Developing High Performing Policy Units, 1999; and Gaining through Training: Developing High Performing Policy Advisors, 2000.

The human resource requirements for high quality policy advice were expressed thus:

- 'sufficient numbers of 'high calibre' managers and staff (in terms of skills, knowledge, values and capability), i.e. quantity and quality; and 
- organisational systems, structure and processes that facilitate high performance within and across organisations over time (e.g. strategy and direction, planning systems, performance systems, information systems, organisational culture, EEO $\left.{ }^{11}\right)^{\prime}$. (SSC, 1999c, p. 6)

The SSC drew attention to both the 'quantity' and 'quality' of policy staff. The number of policy staff available in the whole public service was termed 'a mere drop in the bucket' (SSC, 1999c, p. 8).

Regarding the quality of policy staff and the core competences for policy analysts, the IQPA initiative mostly echoed the individual core competences identified by the PAI. However, the IQPA initiative project report also mentioned several important competences that could be expected to be exercised within a complex political environment: intellectual skills, relationship management skills, bicultural and treaty skills, public service ethics, technological skills, self-management skills, and contract management skills (SSC, 1999c). For policy managers, in addition to competence in policy advice, managing knowledge workers was identified as important. Managing knowledge workers involved leadership skills and promoting an organisational culture that would nurture and support the vision and eliminate the barriers such as lack of vital information, staff, and capital investment (SSC, 1999c, p. 7).

At the system level, a leadership style and organisational culture that stimulate diverse perspectives and experience and develop commitment were identified by the IQPA initiative as necessary to enable high-calibre policy staff to produce high-quality advice. Employee control over work decisions, challenging work, teamwork, shared gains, work culture, concern for people, technology and training and development are some of the factors in the level of commitment (SSC, 1999c, p. 7). Organisational reputation, systems and culture were found to be critical factors affecting the attractiveness of organisations for policy advisors and the quality of policy advice, as a result (SSC, 1999c).

${ }^{11}$ EEO stands for Equal Employment Opportunities 
Figure 4.4: The High-Performance Model

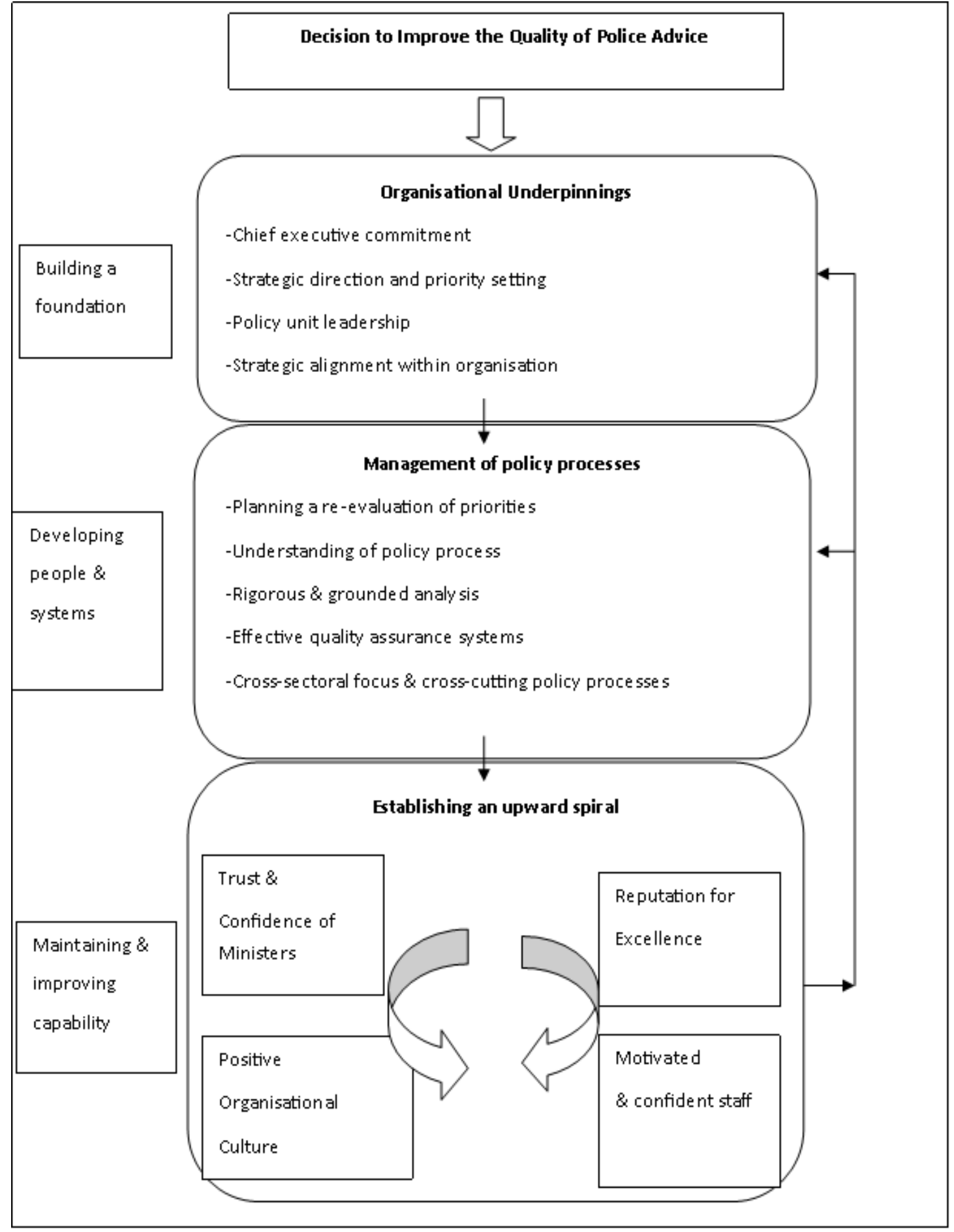

Source: (SSC, 1999b)

Professionalising policy analysis and advice involved developing capable policy units. The characteristics of a policy unit capable of consistently producing high-quality policy advice were identified and specified in a high-performance model (Figure 4.4). The model had three cumulative stages, each building on the characteristics established at 
an earlier stage. The model was essentially a model of good management. It addressed how the production unit (policy unit/shop) should work as a whole, and not simply the policy development process (SSC, 1999b).

This top-down management model represented developing policy advice not only as an analytical task but also as a managerial enterprise. The success of the model was reliant on the behavioural attributes of senior leaders of the organisations such as commitment, leadership and strategic capability. It also pointed out that achieving policy capability in a policy unit required building it first and then maintaining it by continuous improvement. Continuous improvement could be achieved when intangible factors such as trust, confidence, reputation, motivation, and cooperation across the system were present so as to establish an upward spiral. The dependence of the three stages, however, indicated that the failure of an earlier stage would hamper building the next stage in the model.

In general, the concern about significant variations in the leadership and performance of departmental policy units is addressed by this model by relying on a standardised topdown management model to build a capable policy unit. Nevertheless, when the very first stage of the model is reliant on the behaviour of the senior leaders, which would naturally vary, the success of the model in reducing the variation in leadership and the performance of the policy unit remains highly contingent upon the individual attributes of senior leaders.

The other concern of under-investment in capability development was to be managed via the value chain for training and development in policy advice (see Figure 4.5). The value chain set out the elements, roles and relationships of the delivery system for training and development, with the arrows depicting relationships of authority and influence (SSC, 2000). It was considered to have the ability to address market failure: insufficient numbers of skilled policy analysts and managers and a dearth of trainers and good quality training in policy analysis (SSC, 2000). 
Figure 4.5: The Value Chain for Training and Development in Policy Advice

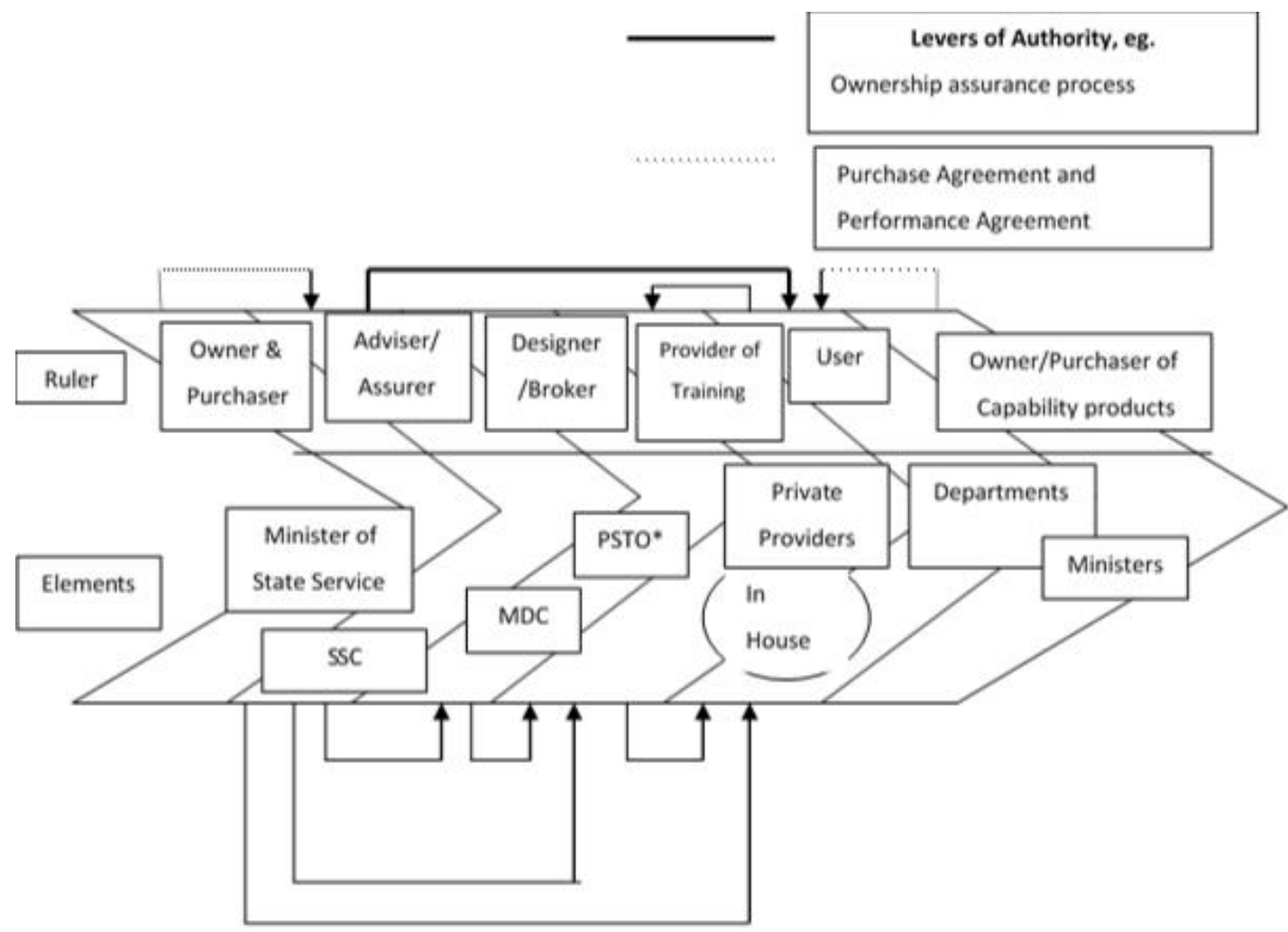

Levers of Influence e.g.
Knowledge
Experience
Reputation/credibility

*PSTO (Public Sector Training

Organisation) is hosted by the SSC

$\&$ functions as the Industry

Source: (SSC, 2000)

Training and development was considered one of the important ingredients in professionalising policy analysis and advice. It was suggested that it could be provided in the form of courses and conferences by the Public Sector Training Organisation (PSTO) and the Management Development Centre (MDC) - the brokers who were training providers to the public sector. But an equal emphasis was put on managers providing on-the-job-training for policy analysts through sound leadership, coaching, performance appraisal and modelling (SSC, 2000). 
The other concern identified by the IQPA initiative was the quality of policy inputs into policy development, and specifically the inadequate or ineffective use of information, research and evaluation and consultation techniques. The issue was addressed by Essential Ingredients: Improving the Quality of Policy Advice, Occasional Paper No. 9, 1999. The problems, factors influencing the problems and recognised solutions regarding the quality of policy inputs are set out in Table 4.8. The intention was to demonstrate the importance of the quality of policy inputs to policy development, and how to address the problems in that regard.

The five key messages were: a prevailing short-term focus in policy development; 'uneven demand for high-quality inputs to policy development' from clients and central agencies; 'uneven departmental capability', meaning only 'a few departments provide consistently high-quality policy advice and a few consistently weak advice'; 'persistent complexity in coordination'; and 'persistent short supply of highly competent policy managers and advisors' (SSC, 1999a, p. 15). This shows a continuation of the concerns with policy capability and high-quality policy advice that were addressed with despite the earlier initiatives. It also implies that policy capability of an agency is not limited to the ability of it to produce high-quality advice. Rather, the ability to engage with others, to strengthen the capability to produce long term research, to strengthen coordination with others, and to produce strategic policy advice became 'ingredients' of the improved policy capability of an agency. 
Table 4.8: Key Messages on the Quality of Policy Inputs, IQPA Initiative 1997-99

\begin{tabular}{|c|c|c|}
\hline Problem & $\begin{array}{l}\text { Influencing Factors behind the } \\
\text { Problem }\end{array}$ & Solutions Recognised \\
\hline $\begin{array}{l}\text { I Information and } \\
\text { research } \\
\text { Advice is not } \\
\text { underpinned by } \\
\text { robust information } \\
\text { and research. }\end{array}$ & $\begin{array}{l}\text {-very short time frames inhibit } \\
\text { in-depth research } \\
\text {-short-time incentives in the } \\
\text { public management system } \\
\text { encourage a focus on the } \\
\text { production of short term } \\
\text { outputs at the expense of } \\
\text { longer term capability } \\
\text {-a shortage of policy advisors } \\
\text { and managers } \\
\text {-information is typically } \\
\text { generated in departmental } \\
\text { silos } \\
\text {-lacking of the external think } \\
\text { tanks }\end{array}$ & $\begin{array}{l}\text { Strengthening the capability to produce long-term } \\
\text { research } \\
\text {-investing in long-term applied social science } \\
\text { research to generate evidence to underpin some } \\
\text { of the most challenging public policy issues } \\
\text {-making appropriate provision in performance and } \\
\text { purchase agreements for and use of research and } \\
\text { evaluation in support of policy advice and } \\
\text { programmes } \\
\text { Strengthening Coordination } \\
\text {-coordinating official statistics by Statistics New } \\
\text { Zealand } \\
\text {-collecting information from departments related } \\
\text { to outcomes identified in strategic priorities } \\
\text {-identifying limitations on knowledge inputs to the } \\
\text { development of policy advice across the } \\
\text { government }\end{array}$ \\
\hline $\begin{array}{l}\text { II Evaluation } \\
\text { Very little good } \\
\text { quality outcome } \\
\text { evaluation was } \\
\text { undertaken and } \\
\text { evaluation criteria } \\
\text { were typically not } \\
\text { built into policy } \\
\text { processes }\end{array}$ & $\begin{array}{l}\text {-low ministerial demand for } \\
\text { evaluation } \\
\text {-historically poor outcome } \\
\text { specification } \\
\text {-lack of any central-agency } \\
\text { champion for evaluation } \\
\text {-lack of demand for outcome } \\
\text { information in accountability } \\
\text { frameworks } \\
\text {-funding difficulties } \\
\text {-methodological hurdles } \\
\text {-poor evaluation capability in } \\
\text { departments }\end{array}$ & $\begin{array}{l}\text {-requiring good intervention logic prior to } \\
\text { implementing policy advice and ex post evaluation } \\
\text { results } \\
\text {-increasing demand for outcome information and } \\
\text { encouraging enhanced evaluation capability of } \\
\text { departments }\end{array}$ \\
\hline $\begin{array}{l}\text { III Consultation } \\
\text { Lack of } \\
\text { departmental } \\
\text { capability in } \\
\text { effective } \\
\text { consultation }\end{array}$ & not specifically mentioned & $\begin{array}{l}\text {-building into operational programmes the time to } \\
\text { conduct consultation, and the resources to meet } \\
\text {-providing for appropriate skills competency } \\
\text { development }\end{array}$ \\
\hline $\begin{array}{l}\text { IV Coordination } \\
\text {-mandatory } \\
\text { interdepartmental } \\
\text { consultation can } \\
\text { potentially dull the } \\
\text { freshness and } \\
\text { directness of } \\
\text { departmental advice } \\
\text {-'over-coordination' } \\
\text { can result in } \\
\text { synthesis that } \\
\text { overwhelms analysis }\end{array}$ & $\begin{array}{l}\text {-excessive focus on quality } \\
\text { control results in limited } \\
\text { lateral coordination to take in } \\
\text { 'big picture' and consultation } \\
\text { can become a substitute for } \\
\text { policy analysis rather than an } \\
\text { input to policy development } \\
\text {-relatively high turnover of } \\
\text { staff } \\
\text {-uneven competence at policy } \\
\text { manager levels } \\
\text {-lack of consolidated guidance } \\
\text { and advice } \\
\text {-absence of a solid service- } \\
\text { wide professional policy- } \\
\text { advice culture }\end{array}$ & $\begin{array}{l}\text {-improving the ways officials' committees are } \\
\text { constituted and operated } \\
\text {-encouraging better systems in departments to } \\
\text { manage and ensure high quality policy advice }\end{array}$ \\
\hline
\end{tabular}

Source: Adapted from Essential Ingredients: Improving the Quality of Policy Advice (SSC, 1999a) 
The IQPA initiative found problems associated with both the demand and the supply sides of the policy advice. The demand end was not hard enough on the effective use of evaluation, analysis, coordination and consultation. The supply end, on the other hand, was impulsive and responsive to the things that were 'most in demand' - reacting to major problems, formulating quick solutions to them, taking decisions, implementing them and then moving on to the next problems, and thus not accommodating inputs that required long lead-times such as longer-term research and evaluation (SSC, 1999a, p. 14).

The IQPA initiative 1997-99, overall, focused on policy management capabilities at individual, organisation and system levels. Nevertheless, it also showed how to improve the quality of policy analysis by improving the quality of policy inputs. Furthermore, it demonstrated an individual, a unit, an agency or the public sector required to consider more and more 'ingredients' in the development of policy analysis and advice to claim to be a policy capable individual, unit, organisation or sector.

\section{Policy Managers Network (PMN) 2000-2009}

The senior leaders of the New Zealand public sector realised the importance of building policy capabilities at system level by developing effective policy teams and a network of policy managers within the sector. With this in view, the Policy Managers Network (PMN) 2000-2009 initiative was designed not only to address the concerns identified, such as departmental patch-protection, but also to build a network of policy managers to facilitate policy work across departments in future. The objective was to establish a senior-level forum to promote a system-wide policy environment to foster collaboration across departments, reduce the costs of developing policy advice by avoiding duplication of policy work, and build policy capability by developing effective policy staff and teams. The PMN used a shared online workspace, ran policy manager meetings, and held workshops, policy forums and policy conferences to share information. It thus focused proactively on longer-term development of the intangible traits necessary for building policy capability across the system. 


\section{The Performance Improvement Framework (PIF) 2009}

Another initiative at the system level was the Performance Improvement Framework (PIF) (see Figure 4.6) which was introduced in 2009 to do quick reviews of agencies' overall capability and performance (SSC, 2012). It, however, was different from performance measures developed in other countries, such as Australia's Dynamic Fourtier Model for High Performance (Blackman et al., 2012); Canada's Management Accountability Framework (MAF) (Treasury Board of Canada Sectretariat, 2011); and European Union's Common Assessment Framework (CAF) (Europeam Institute of Public Administration, 2013). The PIF's relevance to building policy capability lies in its ex ante position, where the agencies are asked to show their strategies to meet future challenges, unlike other performance measures.

The PIF 2009 focused more on the overall capability of the agencies to deliver better results in each of the agency's core business areas through periodic performance assessment. However, the element Policy Advice under the Results component and the critical area People Development of the PIF model are more directly related to the development of policy advice and policy capability.

The PIF 2009 was developed to respond to wide concern that the New Zealand public sector was doing better in meeting current demand, but there was scope for improvement in meeting future demand for policy analysis and advice. It drew attention of the agencies' senior leaders to build agencies' policy capability to meet both current and future demand for policy analysis and advice. Agencies' achievement of improved policy capability required a deliberate attention to produce policy advice that was more strategic. Forward looking perspectives in the policy advice became an added component with which policy advice was judged for 'quality'. The use of a wider range of elements in efforts to improve policy capability reflects growing expectations from the clients. 
Figure 4.6: New Zealand's High-Level PIF Agency Model

\begin{tabular}{|c|c|c|c|}
\hline \multicolumn{4}{|c|}{$\begin{array}{l}\text { Delivery of Government Priorities } \\
\text { How well is the agency responding to government priorities? }\end{array}$} \\
\hline \multicolumn{4}{|c|}{$\begin{array}{l}\text { Delivery of Core Business } \\
\text { How effectively is the agency delivering each core business area? } \\
\text { How efficiently is the agency delivering each core business area? } \\
\text { How well does the agency's regulatory work achieve its required impact? }\end{array}$} \\
\hline \multicolumn{4}{|c|}{$\begin{array}{l}\text { Organisational Management } \\
\text { How well is the agency positioned to deliver now and in the future? }\end{array}$} \\
\hline $\begin{array}{l}\text { Leadership, Direction and } \\
\text { Delivery }\end{array}$ & External Relationships & $\begin{array}{l}\text { People } \\
\text { development }\end{array}$ & $\begin{array}{l}\text { Financial and Resource } \\
\text { Management }\end{array}$ \\
\hline $\begin{array}{l}\text { Purpose, vision and } \\
\text { strategy } \\
\text { - } \quad \text { Leadership and } \\
\text { Governance } \\
\text { - } \quad \text { Values, behaviour } \\
\text { and Culture } \\
\text { - Structure, roles and } \\
\text { responsibilities } \\
\text { - Review }\end{array}$ & 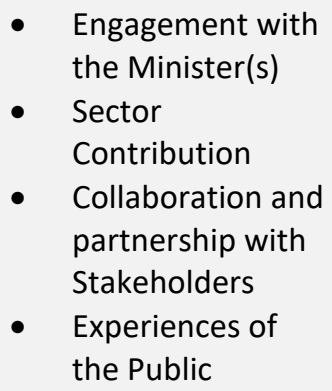 & $\begin{array}{l}\text { - Leadership } \\
\text { and } \\
\text { Workforce } \\
\text { Development } \\
\text { Management } \\
\text { of People } \\
\text { Performance } \\
\text { Engage with } \\
\text { Staff }\end{array}$ & $\begin{array}{ll}\text { - } & \text { Asset Management } \\
\text { - } & \text { Information } \\
\text { - } & \text { Imanagement } \\
\text { and Effectiveness } \\
\text { - } \quad \text { Financial } \\
\text { - Management } \\
\text { Risk management }\end{array}$ \\
\hline
\end{tabular}

Source: State Services Commission (SSC, 2012)

\section{The Review of Expenditure on Policy Advice (REPA) 2010}

In 2010, the New Zealand government was worried about rising expenditure under the appropriation for policy advice. Policy advice-related appropriations grew by more than 70\% between 2003/04 and 2009/10 (G. Scott et al., 2010, p. ii); but these appropriations included expenditure not related to policy advice. This indicated that agencies were still not clear about what expenditures could fall into policy-advice appropriation and the agencies included non-policy advice expenditure into policy advice-related appropriations, which even grew faster than the policy advice component (G. Scott et al., 2010, p. foreword). On one hand, expenditure on policy advice was increasing, and on the other hand, there was growing dissatisfaction about the quality of policy advice. The government responded to the situation by commissioning a committee chaired by Graham Scott with responsibility to enquire into the cost, alignment, efficiency and 
quality of spending under the appropriations for policy advice, and provide recommendations.

The REPA 2010, also known as the Scott Review, addressed the issues of ensuring high professional standards, cost-effectiveness, and alignment with government priorities. Specifically, it examined expenditure on policy advice, assessed the quality of policy advice and identified the opportunities for improvement. It showed most agencies devoted $70 \%$ of their policy advice work on average to ministerial portfolios and fewer than $12 \%$ of policy priorities were strategic and economic. This implied that policy work was mostly responsive although most of the time of policy analysts was spent on policy work compared to other functions relating to operations, administration, and ministerials, Official Information Acts (OIAs), Select Committee, Parliamentary Questions (PQs) and other non-policy (G. Scott et al., 2010).

Overall, the report from this review suggested professionalising policy analysis and advice to achieve high-quality policy advice. The recommendations covered four main areas: people, process, performance and prioritisation which are presented in Table 4.9. The REPA 2010 comprehensively demonstrated how to professionalise policy analysis and advice while keeping an eye on the cost of developing policy advice. Its emphasis was on suggesting what and how to change policy practices in the agencies to improve policy analytical and management capability at both individual and agency levels. Moreover, it showed the importance of meeting government priorities in order for an agency to demonstrate its policy capability. 
Table 4.9: The REPA 2010 Recommendations in Four Main Areas

\begin{tabular}{|c|c|}
\hline People & Process \\
\hline $\begin{array}{l}\text { - } \quad \text { Build analytical capability } \\
\text { - } \quad \text { Professionalise analytical capability } \\
\text { - } \quad \text { Improve management structures and capability } \\
\text { - } \quad \text { Strengthen policy-advice skills of CEs and } \\
\text { managers }\end{array}$ & 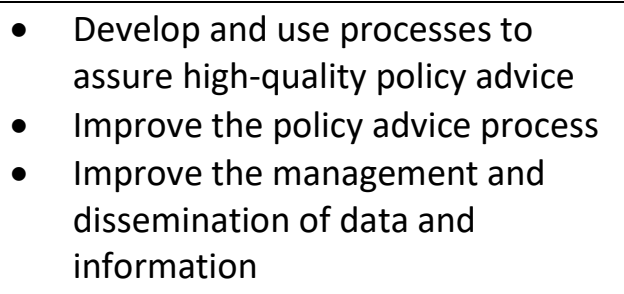 \\
\hline Performance & Prioritisation \\
\hline $\begin{array}{l}\text { - } \text { Reorganise policy-related appropriations } \\
\text { - Generate savings through review of } \\
\text { appropriations and expenditure } \\
\text { - } \text { senerate an efficiency dividend by reducing } \\
\text { - Develop and use management information } \\
\text { systems and tools to manage the policy work } \\
\text { programme } \\
\text { - Review the policy advice function of Crown } \\
\text { entities } \\
\text { Organise portfolios and agency policy functions } \\
\text { into clusters }\end{array}$ & $\begin{array}{l}\text { - Make government's overall goals } \\
\text { clear } \\
\text { - Agree explicit multi-year work } \\
\text { programme between ministers and } \\
\text { agencies } \\
\text { - Commission work on cross- } \\
\text { portfolio and/or long-term issues } \\
\text { and/or investment in capability }\end{array}$ \\
\hline
\end{tabular}

Source: Adapted from the Report of the REPA 2010

\section{The Policy Project 2016 (Initiated in 2014)}

The lack of collaboration between government departments was hindering their working as a part of the system, lack of policy people capability in terms of both quantity and quality, low level use of evidence in policy analysis and limited focus on meeting future challenges persisted. This persistent concern gave birth to another initiative, the Policy Project, established by the Department of Prime Minister and Cabinet (DPMC), it started to take shape in March, $2014^{12}$ and was inaugurated in 2016. The Policy Project was given a mandate to lead the 'policy system' and create pressure to improve policy capability and the quality of policy advice produced by departments and ministries.

The main features of the Policy Project drew lessons from previous initiatives and developed a co-production approach to fostering collaboration across the policy system. While the PAI 1991-1995 focused on promoting a certain standard of policy practice,

\footnotetext{
12 The timeframe for this thesis ended in 2015. Hence, the Policy Project is discussed briefly.
} 
the IQPA initiative 1997-1999 on the quality of policy inputs, and the REPA 2010 on the cost effectiveness and professionalising of policy advice, the Policy Project focused on system-wide policy improvement by bringing together policy capability, skills and quality frameworks (See Figure 4.7). Policy capability was considered to be the result of people capability, stewardship, policy quality systems and customer-centric engagement.

\section{Figure 4.7: Policy Improvement Frameworks of the Policy Project}

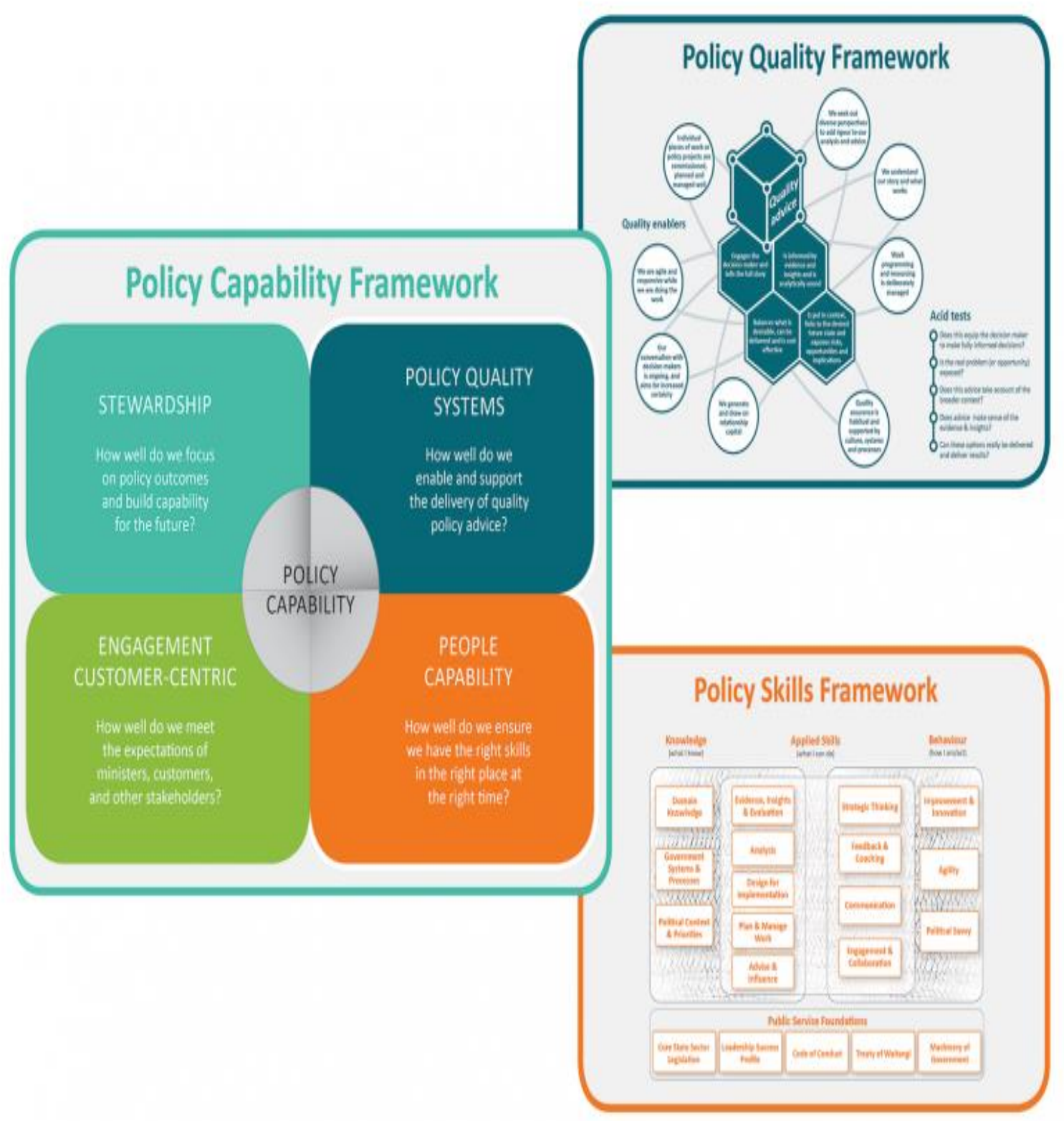

Source: Department of Minister and cabinet (DPMC, 2016b) 


\section{The Natural Resources Sector Framework (NRF) 2014}

The NRF 2014 initiative was developed to promote a collaborative style of policy analysis. The government recognised that policy analysis needed to develop beyond the jurisdiction of one agency and extend to the sector level so that policy issues would be comprehensively addressed and advice built on sectoral analysis which was more resilient and robust. Second, it aimed to promote collaboration in policy analysis and advice across agencies and break the silo approach when agencies produced policy outputs and outcomes to meet their own target objectives rather than supporting sectoral objectives of the government of the day. The development of the NRF was guided by the stewardship role. The overall purpose of the NRF 2014 was to build policy capability at the sector level to achieve the government's priority policy outcomes.

The NRF established a process for understanding the inter-relationships between people and natural resources that involves six key steps: Identify, Reveal, Establish, Integrate, Assess, and Advise where identifying an issue was the starting point that ensures mandate for analysis and Advise was the result that was consistent and linked with possible trade-offs. The steps Reveal, Establish, Integrate and Assess contribute to analysis which was guided by the concept of stewardship that was to improve the productivity of New Zealand's resource-reliant industries while reducing their environmental impact (MfE, 2014a). Thus, the NRF significantly altered the style of policy analysis in the NRS in which the partner agencies of the NRS remained vigilant on how to integrate the policy ideas emanating from partner agencies of the NRS relating to environmental matters. How to collaborate and integrate policy analysis became more prominent than the analysis itself.

The New Zealand public sector has developed various types of initiatives since public sector reforms, to guide how to professionalise policy practices. Professionalising policy practices is largely about how to change policy practices while keeping an eye on the expectations from policy analysis and advice. A comparison of central-agency-driven policy capability initiatives is outlined in Table 4.10 . 
Table 4.10: A Comparison of Central-agency Driven Policy Capability Initiatives

\begin{tabular}{|c|c|c|c|c|}
\hline Initiatives & $\begin{array}{l}\text { Specific Issues } \\
\text { Addressed }\end{array}$ & $\begin{array}{l}\text { Targeted } \\
\text { At }\end{array}$ & $\begin{array}{l}\text { Recommendations } \\
\text { Relate to }\end{array}$ & $\begin{array}{l}\text { Overall } \\
\text { Emphasis }\end{array}$ \\
\hline $\begin{array}{l}\text { PAl 1991- } \\
1995\end{array}$ & $\begin{array}{l}\text {-clarifying confusions by } \\
\text { providing the definition of } \\
\text { 'policy advice' } \\
\text {-analysing the meaning } \\
\text { of the 'quality' of policy } \\
\text { advice } \\
\text {-identifying competences } \\
\text { for policy analysts and } \\
\text { managers } \\
\text {-demonstrating the } \\
\text { characteristics of a 'good' } \\
\text { policy process; } \\
\text {-having the 'right' } \\
\text { people; and } \\
\text {-ensuring the 'right' } \\
\text { approach of consultation } \\
\text { and coordination }\end{array}$ & $\begin{array}{l}\text { mainly policy } \\
\text { analysts and } \\
\text { also policy } \\
\text { managers } \\
\text { (micro level) }\end{array}$ & $\begin{array}{l}\text {-policy inputs, process, } \\
\text { framework and output } \\
\text {-individual and team } \\
\text { competences } \\
\text {-consultation and } \\
\text { coordination as policy } \\
\text { inputs } \\
\text {-quality assurance } \\
\text { process }\end{array}$ & $\begin{array}{l}\text {-meeting clients' } \\
\text { expectations } \\
\text {-providing overall } \\
\text { guidance to policy } \\
\text { work } \\
\text {-demonstrating } \\
\text { policy } \\
\text { development as a } \\
\text { process for } \\
\text { meeting clients' } \\
\text { demands }\end{array}$ \\
\hline $\begin{array}{l}\text { IQPA } \\
\text { Initiative } \\
\text { 1997-1999 }\end{array}$ & $\begin{array}{l}\text {-lack of clarity in } \\
\text { ministers' statements } \\
\text { about desired outcomes } \\
\text { and policy directions } \\
\text {-insufficient incentives } \\
\text { for active co-operation by } \\
\text { departmental chief } \\
\text { executives on cross- } \\
\text { cutting policy issues } \\
\text {-significant variations in } \\
\text { leadership and } \\
\text { performance of } \\
\text { departmental policy units } \\
\text {-substantial under- } \\
\text { investment in capability } \\
\text { development resulting in } \\
\text { shortages of highly } \\
\text { capable policy managers } \\
\text { and advisors } \\
\text {-significantly inadequate } \\
\text { and/or ineffective use of } \\
\text { information, research, } \\
\text { evaluation and } \\
\text { consultation techniques } \\
\text { as inputs to policy } \\
\text { development }\end{array}$ & $\begin{array}{l}\text { producers of } \\
\text { policy advice, } \\
\text { users/clients, } \\
\text { policy units } \\
\text { and the } \\
\text { system (micro } \\
\text { and macro } \\
\text { levels) }\end{array}$ & $\begin{array}{l}\text {-quality of inputs } \\
\text {-human resources } \\
\text { management } \\
\text {-management of } \\
\text { development of policy } \\
\text { advice } \\
\text {-better consultation } \\
\text { and coordination } \\
\text {-training and } \\
\text { development } \\
\text {-leadership }\end{array}$ & $\begin{array}{l}\text {-exhibiting how } \\
\text { structures, } \\
\text { systems, human } \\
\text { resources and } \\
\text { management } \\
\text { practices impact } \\
\text { on the quality of } \\
\text { policy advice }\end{array}$ \\
\hline PIF 2009 & -ensuring results & $\begin{array}{l}\text { mainly } \\
\text { organisations } \\
\text { (meso level) }\end{array}$ & $\begin{array}{l}\text { Overall capability of } \\
\text { government } \\
\text { organisations }\end{array}$ & $\begin{array}{l}\text {-assessing } \\
\text { performance of } \\
\text { agencies to build } \\
\text { policy capability } \\
\text { in the future }\end{array}$ \\
\hline REPA 2010 & $\begin{array}{l}\text {-cost of developing } \\
\text { advice } \\
\text {-quality of advice } \\
\text {-strong alignment with } \\
\text { government priorities. }\end{array}$ & $\begin{array}{l}\text { mainly system } \\
\text { (macro level) } \\
\text { and } \\
\text { organisations } \\
\text { (meso level) }\end{array}$ & $\begin{array}{l}\text { Both policy analysis } \\
\text { and advice }\end{array}$ & $\begin{array}{l}\text {-professionalising } \\
\text { policy advice } \\
\text {-ensuring cost- } \\
\text { effectiveness in } \\
\text { developing advice } \\
\text {-achieving } \\
\text { government } \\
\text { priorities }\end{array}$ \\
\hline
\end{tabular}




\begin{tabular}{|l|l|l|l|l|}
\hline Initiatives & $\begin{array}{l}\text { Specific Issues } \\
\text { Addressed }\end{array}$ & $\begin{array}{l}\text { Targeted } \\
\text { At }\end{array}$ & $\begin{array}{l}\text { Recommendations } \\
\text { Relate to }\end{array}$ & $\begin{array}{l}\text { Overall } \\
\text { Emphasis }\end{array}$ \\
\hline $\begin{array}{l}\text { Policy Project } \\
\begin{array}{l}\text { (initiated in } \\
\text { 2014) }\end{array}\end{array}$ & $\begin{array}{l}\text {-Lacking an agency with a } \\
\text { mandate for leading the } \\
\text { New Zealand policy } \\
\text { system to increase } \\
\text { demand for better policy } \\
\text { advice }\end{array}$ & System level & $\begin{array}{l}\text { Policy capability, policy } \\
\text { skills, policy quality }\end{array}$ & $\begin{array}{l}\text { System-wide } \\
\text { policy } \\
\text { Improvement }\end{array}$ \\
\hline NRF 2014 & $\begin{array}{l}\text {-Doing policy analysis } \\
\text { going beyond agency's } \\
\text { jurisdiction }\end{array}$ & Sector level & $\begin{array}{l}\text { Policy Framework to } \\
\text { promote a } \\
\text { collaborative style of } \\
\text { policy analysis }\end{array}$ & $\begin{array}{l}\text { Sector-wide } \\
\text { policy } \\
\text { improvement }\end{array}$ \\
\hline
\end{tabular}

The form, design and purpose of the initiatives developed between 1990 and 2015 in the New Zealand public sector have shown the suggested changes in policy practices at different levels, individual, organisation and system levels. The following section shows the influences on policy analysis and advice.

\subsection{The Influences on Policy Analysis and Advice}

The developed initiatives, overall, were promulgating advice and instructions on how to professionalise policy practices. Professionalising policy practices was also driven by the contexts recognised by the initiators. However, the contexts continued to change due to changing priorities and policy agendas. These changed the concept of improved policy capability. Different types of policy capabilities became more or less significant in the changing contexts. The nature, form and design of the initiatives reflected the contexts. These initiatives were developed as responses to the concerns raised and wider policy influences, over time, in the New Zealand public sector. These contexts are outlined here.

The PAI 1991-1995 was developed to respond to the concerns recognised by the New Zealand public sector following the state sector reforms. The state sector reforms gave birth to a significant number of small agencies with a specific policy focus, and where policy practices were substantially different. The new way of doing business, predictably, created confusion about the roles, expectations and the policy output/outcome distinction. What 'policy advice' was, what activities would be considered directly related to the development of policy advice, how the 'quality' of policy advice would be assessed, the roles of public-service policy advisors and how to work together in a new 
environment were the essential questions. Some ministers were unsure about the value they were getting from public expenditure on developing policy advice; and not all ministers were clear about the time required to develop policy advice. There was a difference in understanding between the output category of 'policy advice' in the public accounts and the kind of activity which ministers considered to be 'policy advice' (Hawke, 1993, p. 1).

The reforms mandated a different approach to the production of policy analysis and advice from the way it was done in the pre-reform era. To professionalise policy analysis and advice, the PAI, therefore, aimed to set expectations of policy analysis and advice and clarify confusions about them. It comprehensively provided guidance relating to policy inputs, process, framework, tools and output and the quality of policy advice. The essence of the PAI was in providing guidance to improve policy analytical capability of policy staff and agencies.

The period from 1991 to 1995 in the New Zealand public sector has been characterised as focused on how departmental positions should be built into the way policy issues are presented to ministers and on fostering a sense of collegiality with other departments as components of a network rather than as antagonists (Hawke, 1993, p. 2). The post-New Public Management (NPM) era resulted in small policy-focused departments concerned with achieving efficiency and effectiveness and overlooking the objectives of the government of the day. The New Zealand public sector was quite fragmented and the PAI was an initiative intended to establish a standard set of policy practices across agencies. The PAI was developed as a response to the context that arose from the state sector reforms.

The context to adopt the IQPA initiative 1997-1999 was different than that of the PAI 1991-1995. The IQPA initiative was influenced by the idea of outcome-focused management in New Zealand. The intent of the state sector reforms was to shift the focus from how much was spent by the public sector, to what it was spent on and why (Kibblewhite \& Ussher, 2002, p. 85). To make it happen, the reforms made the policy output-outcome distinction explicit, with CEs 'directly responsible for the policy outputs 
produced by the departments, while the ministers [chose] which outputs should [were to be] produced and should therefore [had] to answer directly themselves for the outcomes' (G. Scott et al., 1990, p. 157). The ministers, therefore, needed to identify the policy outcomes that were required to achieve, and the agencies were required to produce the policy outputs that would lead to the identified policy outcomes.

Another factor that influenced the development of the IQPA initiative was shifting the focus of policy analysis and advice from short-term production of outputs to long-term policy outcomes planning as pointed out by Schick (1998a) report and the Logan report (SSC, 1991). These two influences resulted in producing the whole-of-government strategic setting in the New Zealand public sector in which the ministers were expected to work within the network of ministers to collectively contribute to achieve target policy outcomes.

While the PAI 1991-95 showed how to professionalise policy practices to improve policy analytical capability at individual and organisation levels, the IQPA initiative 1997-99 thus took a different approach to professionalise policy practices. It mainly focused on showing how to achieve policy management capability at all the three levels including the immediate client/minister at system level. A long term view on building policy capability was promoted by the IQPA initiative. It tried to shift the focus away from a short term view on policy capability in which the policy advice producers were concerned with meeting the immediate client's/minister's expectations from policy advice.

This long term view on policy capability influenced the design of the IQPA initiative 1997-1999. Training and development of policy staff to ensure adequate supply of 'quantity' and 'quality' of skilful policy staff then and in future became a crucial factor to professionalise policy practices. The characteristics of a high-performing policy unit developed by the IQPA initiative showed new and additional criteria that a policy capable unit or agency needed to achieve compared with those identified by the PAI 1991-1995. These included strategic direction, priority setting, policy leadership and intangible attributes such as trusts, motivation, reputation and culture. The need for 
consultation with stakeholders and mandatory interdepartmental coordination imply how an agency's efforts to improve policy capability became reliant on a wider context than before and hence, became more challenging.

Similar to the IQPA initiative 1997-1999, the PMN 2000-2009 also promoted professionalising policy practices in the public sector with the development of a network where the policy practices could work together as part of the whole-of-government strategy. While the ministers formed the SRA networks, it was the policy managers who formed the PMN. Thus, the idea of clients for policy advice widened from seeing the minister as the solely important client for policy advice. Also, the responsibility of ministers also became relatively explicit. Policy capability was no longer only a reflection of policy analytical capability. Achieving improved policy capability at any level, individual, organisation and system, became more challenging.

It was not only the New Zealand public sector which was viewing policy capability in a wider context. A similar idea was promoted by the United Kingdom (UK) Cabinet Office at the same time. In 2002, the UK Cabinet Office set out the relations between strategy (the overall process of reaching the desired future), policy (the means of moving towards that desired future) and delivery to reach the strategic outcomes, with a framework for strategic direction shown in Figure 4.8. This is an example of how policyrelated ideas reach beyond national boundaries to the public sectors of other countries. The sources and the directions of cross-boundary influences on policy practices are, sometimes, not possible to discern. 
Figure 4.8: A Framework for Strategic Direction

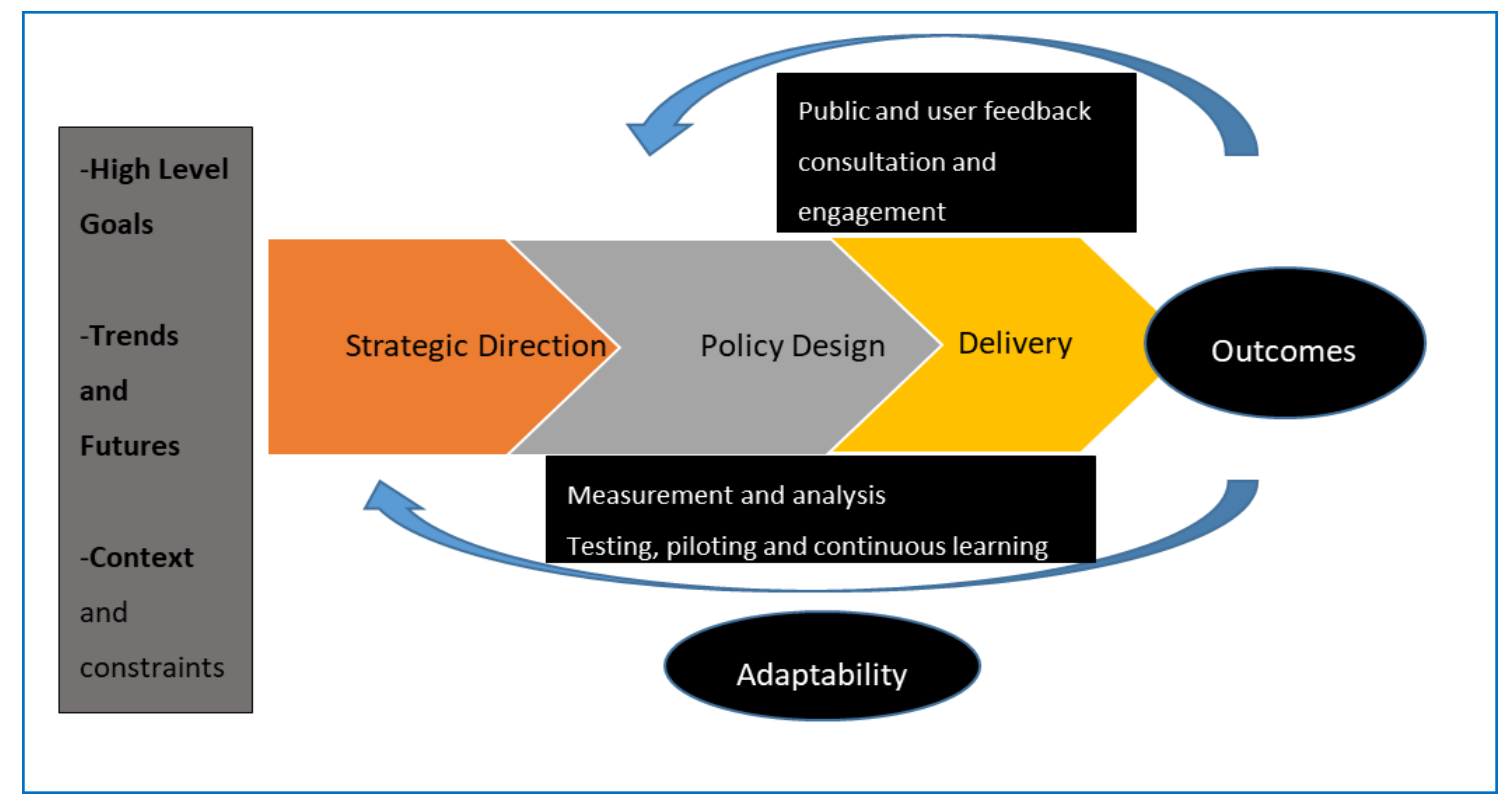

Source: UK Cabinet Office strategy survival guide (Cabinet Office UK, 2004)

Viewing policy capability in a wider context was further demonstrated with the development of the PIF 2009 in the New Zealand public sector. The PIF 2009 was influenced by learning from the best practices found in the UK but recognised the conditions applicable to New Zealand. The then State Services Commissioner mentioned specifically that the idea of the PIF originated from his visit to the UK. He wrote: The origins of the Performance Improvement Framework (PIF) lie in the United Kingdom's capability review programme. To create the PIF, New Zealand has taken the best of that work, combined it with the best of the organisational improvement model from the New Zealand private sector as well as methodologies from other jurisdictions, and adapted all of that to the New Zealand public management system. (Rennie, 2012, p. 8)

The forward-looking component made the PIF unique among other performance measures developed in different countries. The PIF 2009 mandated that the agencies take measures to invest in building long term capability, that also include policy capability, so that the agencies could meet both current and future demand from policy analysis and advice. The assessment of an agency's strengths and weaknesses by the PIF review supported the agency to identify areas needing intervention and to take 
appropriate measures. The PIF 2009 has the potential to work as a driver for agencies to adopt initiatives at agency level.

As policy problems are becoming increasingly complex and wicked, due to rapid changes in how people interact and expectations, many concepts are now merging with other similar concepts which were considered comprehensive and distinct. As an instance, the UK's revised model of capability (Figure 4.9) and the UK's framework for strategic direction (Figure 4.8) are built with some common elements. While 'capability' in the UK's model is the result of strategy, delivery and leadership, achieving strategic outcomes in the UK's framework for strategic direction is seen as the result of strategy, delivery and policy. Being influenced by the UK's revised model of capability, the elements of the PIF are not very different than that of the UK's revised model of capability and framework for strategic direction. This reinforces that the government organisations' achievement of improved policy capability, strategic outcomes and better performance are measured by similar elements. An agency's efforts to improve policy capability thus became increasingly challenging and complex.

\section{Figure 4.9: UK's Revised Model of Capability}

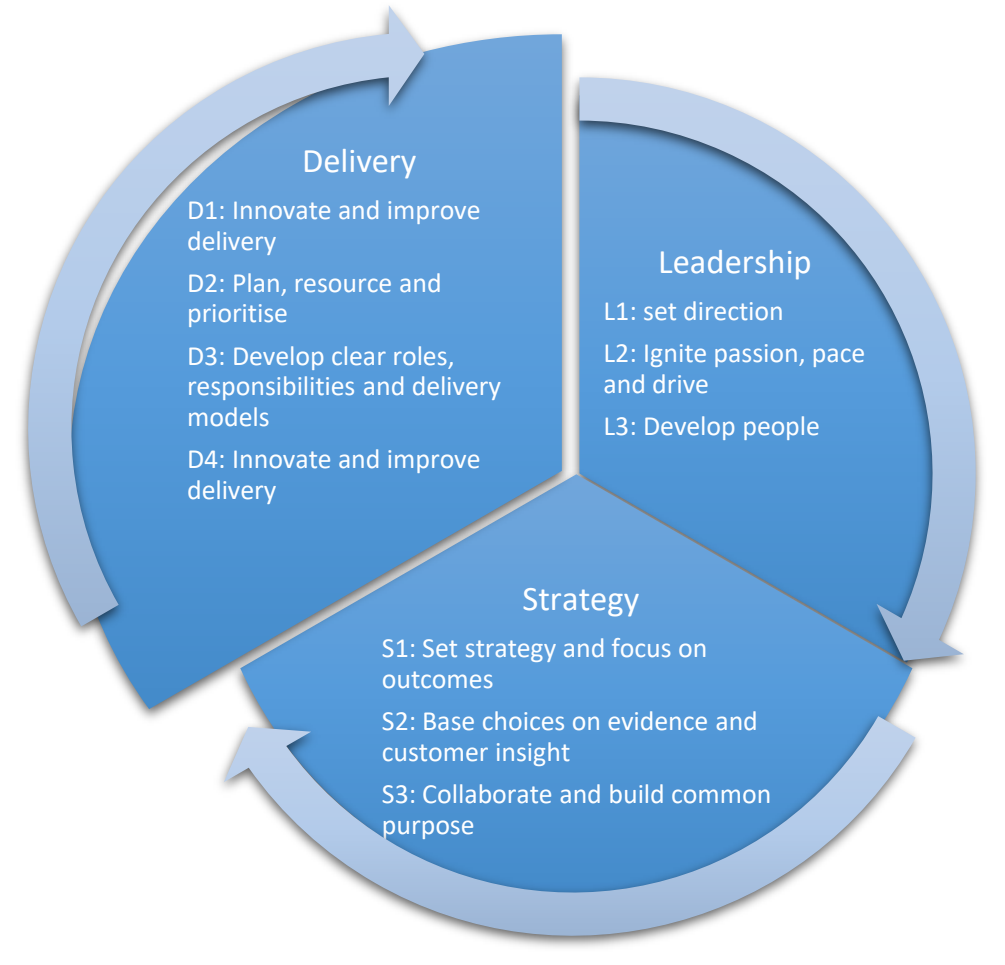

Source: (Service, 2009) 
The context for the development of the Policy Project 2016 (initiated in 2014) was the continuing concerns with lack of collaboration between the government departments hindering their working as a part of the system. The departmental patch protection that originated from the state sector reforms did not disappear. The Policy Project 2016 promoted the concept of stewardship, as a plan for solution, in which the CEs were considered the stewards whose roles must not be tied up only with the demand for policy advice from current government but for the successive governments. The Policy Project was also echoing the ideas of the Better Public Services (BPS) programme, an initiative in 2012 by the SSC to achieve 10 target results over the entire public sector. Both the BPS programme and the Policy Project focused on ensuring that the New Zealand public sector worked as a 'system', while the Policy Project was specifically about policy.

The Policy Project's focus on co-production approach to policy development and systemwide policy improvement involved bringing together policy capability, skills and quality frameworks to develop policy improvement framework (Figure 4.7). This, thus, showed the importance of improving policy analytical capability both at the individual and agency level to contribute to the improvement of policy capability at the system level. Policy capability was shown as something that improves by improving people capability, stewardship, policy quality systems and customer-centric engagement. The use of the stewardship concept in the Policy Project reminded the policy advisors in the public sector their role of producing free and frank advice under the Westminster policy advisory system.

The context for the NRF 2014 was quite similar to the context for the Policy Project, namely, the need for a whole-of-government approach to policy analysis and advice. While the Policy Project showed how an agency could contribute to achieve systemwide policy improvement, the NRF showed how some agencies could co-produce policy advice for a sector, the natural resources sector. This aimed to break agencies' silo approach to policy development influenced by the idea of stewardship role. This showed that policy outputs needed to be tied up with the outcome that the government sought 
for than with the department. Overall, the NRF was an instance of how to build policy capability at the sector level.

The objectives of the developed initiatives were to improve policy capability and the quality of policy advice. Both the PAI 1991-1995 and the IQPA initiative 1997-1999 tried to provide guidance on how to go about achieving the desired quality of policy advice, but it was clear from the findings of the REPA 2010 that there were still variations between the agencies' understanding of what counts as policy advice. The REPA 2010 noted that 'Agencies could not produce expenditure information before 2005/06 on our definition of policy advice' (G. Scott et al., 2010). The REPA 2010 was quite comprehensive and complete within the scope defined by the terms of reference agreed between the government and the review committee. It was, however, criticised for over-emphasising cost, measurement and audit rather than catalysing a system-wide improvement in capability (Davison, 2015, p. 1).

The suggestions of the PAI 1991-1995 and IQPA initiative 1997-1999 were found to be analytically compelling but lacked an implementation strategy, and therefore failed to attain the results the New Zealand public sector was seeking to attain (Davison, 2015, p. 1). The REPA 2010 was overly focused on the cost component of the policy advice, and put undue pressure on management and audit rather than promoting system-wide policy improvement (Davison, 2015, p. 1). The PIF 2009 was the driver of changes in organisations but not at the system level. It was also not easy to causally 'link the PIF to any particular changes as it gets embedded in strategy or disappears into the "ecosystem" of performance drivers' (Allen, 2017, p. vi). Thus, these developed initiatives were not perceived as completely successful in achieving the desired objectives. Concerns about policy capability and the quality of policy advice did not fade at all. The Policy Project 2016, the most recent initiative, itself is evidence of this.

With respect to the quality of policy advice, the clients remain an important consideration. As 'quality' will be perceived to vary from different perspectives, professionalising policy advice seems to be an option, so that the public-service policy advice producers focus on creating public value as envisioned by Moore (1995). It is 
particularly relevant when public-service policy advisors are required to produce free and frank policy advice because of the Westminster policy advisory system in which the advice is produced for the public based on information and evidence and without undue political influence but with awareness of the political context, often termed politically savvy or astute. High-quality policy advice is considered an essential element of effective government (Mintrom, 2011, p. 8).

\subsection{Summary Assessment of Central Agency Initiatives}

The development of a series of initiatives, however, does not necessarily indicate the failure of the previous initiatives. Neither must a common concern across initiatives indicate a presence of an ongoing identical concern. To illustrate, a concern with the quality of policy advice does not portray an identical concern because what characterises the 'quality' of policy advice varies under different contexts. The contexts under which policy analysis and advice is produced influence the yardstick with which policy capability and the quality of policy advice are assessed and valued. The contexts that influenced the choice and use of initiatives, shown above, demonstrate that the importance and relevance of policy analytical, management and political capability at individual, organisation and system level varies under different contexts.

Improving policy analytical capability, following the core public sector reforms, required a standard set of policy practices across departments. The PAI 1991-1995 therefore specified how to professionalise policy practices with special attention to quality expectations for policy inputs, framework, people capability and output. The ministers' satisfaction was considered to be one of the important yardsticks for measuring the quality of policy advice.

As time progressed, policy management capability at both organisation and system levels drew more attention, along with policy analytical capability. Many suggestions were put forward to manage the development of policy advice and develop a capable policy unit and/or organisation with appropriate training. 
The idea of the clients for policy advice broadened over time. The IQPA initiative 19971999 showed that the client for policy advice was not the minister only, it was the public sector that agencies needed to consider as the clients for policy advice. Therefore, agencies' ability to establish links between the policy advice they produced with the target policy outcomes of the government of the day became an important yardstick to assess an agency's policy capability and the quality of policy advice.

The scope of policy analysis and advice, consequentially, also widened from being tied up with the departmental policy output to the public sector's long term target policy outcomes. While the IQPA initiative 1997-1999 showed how the ministers could work together within the SRA networks, the PMN 2000-2009 showed how the policy mangers could work together to support the government of the day to achieve its target policy outcomes. This implied that policy analysis and advice was no longer an inside activity of an agency. Rather, policy analysis and advice in an agency was expected to be an activity contributing to the production of policy output that supported achieving government's target policy outcomes. An assessment of an agency's policy capability reflected the ability of an agency to meet the government objectives rather than to develop advice based on high-quality analysis. In other words, the rigour of policy analysis was not very relevant if the advice produced did not contribute to achieving target policy outcomes.

Considering the long term in policy analysis and advice became more significant over time. Agencies were urged to foresee and prepare for future challenges by the central agencies and to invest in building policy capability for that purpose. The PIF 2009 was used to communicate this message to the agencies. The PIF pointed to leadership, collaboration and managing resources as important factors in ensuring an agency is wellpositioned to deliver now and in the future. Thus, policy capability of an agency was viewed in a wider context.

Professionalising policy practices became more significant when the idea of clients widened and policy capability was also viewed in a wider context. The REPA 2010 comprehensively showed how to professionalise policy practices and suggested how to improve both policy analytical and management capability at both individual and agency 
levels. It also showed the importance of meeting government priorities in order for an agency to demonstrate its policy capability, while keeping an eye on the cost of developing policy advice.

The Policy Project showed how an agency could improve its policy capability and contribute to system-wide policy improvement. The NRF showed how to co-produce policy with other partner agencies. Both thus showed the need for the whole-ofgovernment approach to policy development. The ability of an agency to co-produce with other agencies with effective engagement and consultation are now more important than before to achieve improved policy capability.

The varying significance of different types of policy capability under different contexts implies that policy analysis styles also varied under different contexts. The public sector reforms and the change to the MMP (Mixed Member Proportional) electoral system meant that minsters along with their advisers could no longer rely on the unquestioned support of a disciplined parliamentary party. As there was no longer only one government policy agenda, negotiating on policy questions by the majority party with their coalition partners and managing political and policy conflicts with others gave rise to a more negotiated policy style in the New Zealand public sector (C. Scott, 2006).

The changes also meant that a two-tier public service would develop, consisting of 'partisans' in minsters office and 'career professionals' in agencies, as J. Martin (1996) predicted. This, along with the shift of policy agenda from economic to social policy problems between 1996-1999 (C. Scott, 2006), many more perspectives and government agencies provided inputs to the policy advice to make the negotiated policy style more prominent.

Between 1999 and 2005, policy analysis style became participatory and inclusive as the public expected to be engaged in policy processes (C. Scott, 2006). The policy analysis in this century is quite different than in mid-1980s. Policy advice producers in public sector have now less direct influence on policy design. Large numbers of organisations from inside and outside of the government are involved and considerable resources and time 
are spent in consultation. Central agencies play more of a 'followership' role than a 'leadership' role in policy development (C. Scott, 2006). Because 'Policy processes must allow time for the Prime Minister to secure political support from Coalition partners before matters are put before the Cabinet or legislation is introduced' (C. Scott, 2006). The Treasury sees itself as providing a 'second opinion' on social policy than being focused on economic problems; then the DPMC continues to play a coordination role and the SSC has developed a partnership model with departments, instead of playing an arms-length role as a monitor of departmental and CE performance (C. Scott, 2006). Policy advice producers in public sector, accordingly, responded to the changing policy setting by professionalising policy practices.

Overall, the demand for and supply of policy analysis, the nature of clients, the nature of problems, viewing policy capability in a wider context that includes incorporating long term and strategic views, and the changes in policy setting due to state sector reforms influenced the contexts. Although the contexts were different for each of the initiatives, a commonality across the initiatives is observed. Most initiatives were promoting the need to foster collaboration, coordination and coherence across agencies. The New Zealand public sector is now fragmented, and a lack of collaboration between the departments, ministries and units (R. O'Leary, 2014) is a feature of the post New Public Management (NPM) era. While small policy-focused ministries were built to produce effective policies following the reforms, their future is under threat as the public sector is promoting a joined-up approach to public policy by amalgamating departments. The formation of the Ministry of Business Innovation and Employment (MBIE) in 2012 and the reduction of the CEs in the public sector from 37 in 2008 to 28 in 2012 (Rennie, 2012 , p. 1) demonstrate this trend.

The examination of the central agency initiatives developed between 1990 and 2015 has shown how the New Zealand public sector was creating the demand for high-quality policy analysis and advice. The examination of the initiatives developed by three case organisations shows how agencies supplied policy analysis and advice to respond to the growing demand for high-quality policy analysis and advice. 
The next chapter presents an overview of the case organisations - their roles and functions, history, traditions, structure, people and policy practice - before the initiatives developed in case organisations are examined in depth in the subsequent chapter. 


\section{CHAPTER 5: The Overview of the Cases}

\subsection{Introduction}

The purpose of this chapter is to build an understanding of policy analysis and advising in three organisations, the Ministry of Transport (MoT), the Ministry for the Environment (MfE) and the Auckland Council (AC). The timeframe for the cases is from 2008 to 2015. Interviews and the organisations' publicly accessible databases, websites and publications were used to obtain information. Information regarding the purpose, role, structure, and history of the organisations is provided in the first section. Key information on policy work across the cases is presented in the second section. The similarities and differences between the cases are set out in the third section.

\subsection{The Information of the Cases}

\subsubsection{The Ministry of Transport (MoT)}

The MoT provides advice to the government on transport policy, regulation and investment. It delivers impartial and expert advice to the government to help it meet its objectives for transport. This includes advice on legislative, regulatory and policy settings; funding levels and priorities; and Crown ministry or council governance, performance and accountability. The Ministry represents the government's transport interests locally and internationally.

\section{Brief History of the MoT}

The MoT was established in 1968 with the merger of the Transport Department and the Civil Aviation Service. It was a large ministry, with 4,500 staff by the early 1970s. But when the State Sector Act 1988 and the Public Finance Act 1989 came into effect, the ministry was significantly restructured. Between 1988 and 2004, the functions of the MoT were divested to various government departments, State Owned Enterprises (SoEs) and private companies. During the 1980s, the MoT operated through divisions of other agencies, namely the Land Transport Division (including the Traffic Safety Service), the Meteorological Service, Air Transport, Maritime Transport, and Roading Divisions. The Roading Division became the separate Crown entity Transit New Zealand in 1989 (Ministry of Transport [MoT], 2015b). 
During the 1990s, the MoT was split up into SOEs and Crown entities and parts of it were sold to the private sector. To allocate resources to the roading system, Transfund New Zealand started operating as a Crown entity which was extracted from the MoT in 1996. During the 2000s, the MoT was further restructured. In 2004, Transfund New Zealand and the Land Transport Safety Authority combined to form Land Transport New Zealand. In 2008, Land Transport New Zealand and Transit New Zealand merged to form the New Zealand Transport Ministry. In the same year, the Ministry streamlined its services into four business units: Road and Rail; Aviation and Maritime; Financial and Economic Performance; and Business Services.

Currently, the MoT partners with the five transport Crown entities: the Civil Aviation Authority, Maritime New Zealand, the Medical Convenor, NZ Transport Agency and the Transport Accident Investigation Commission; with three State Owned Enterprises (SOEs): New Zealand Railways Corporation (KiwiRail), Airways Corporation of New Zealand Limited and Meteorological Service of New Zealand Limited (MetService); and with local government and the New Zealand Police (MoT, 2015c).

\section{Role, Goal and Function}

The primary roles of the MoT are to assist with the development of national policy and to coordinate work and regional matters that relate to transport. The stated purpose of the ministry is to ensure that the transport system in New Zealand 'helps New Zealand thrive'. The specific goals that the MoT aims to achieve are to: 'improve the overall performance of the transport system, improve the performance of transport Crown entities and achieve better value for money for the government from its investment in the transport system' (MoT, 2015a).

The main function of the MoT is to provide advice to the government on issues related to the New Zealand transport system, and support to ministers. Its specific functions include developing legislation, regulations and rules and managing and accounting for funds invested in transport (MoT, 2015c). 


\section{Organisational Structure}

The MoT has four policy groups: Aviation and Maritime; Road and Rail; Sector Performance; and Specialist Advice and Strategy. Each policy group has specific roles and functions to perform. The MoT is a relatively small organisation in terms of annual budget and staff. Its head office is in Wellington with an office in Auckland and a presence in Christchurch (MoT, 2015d).

\section{The Leadership Team}

The leadership team of the MoT consists of a Chief Executive (CE) with overall responsibility of the ministry and four General Managers who lead the four policy groups of the ministry. The responsibilities of the MoT's leadership team are shown in Figure 5.1. The transport sector overall is led by the Minister and Associate Minister. 
Figure 5.1: The Responsibilities of the MoT's Leadership Team

\begin{tabular}{|c|c|c|c|}
\hline & $\begin{array}{c}\text { CE } \\
\text { Overall } \\
\text { Responsibility } \\
\text { the MoT }\end{array}$ & & \\
\hline $\begin{array}{c}\text { General Manager, } \\
\text { Aviation and }\end{array}$ & $\begin{array}{l}\text { General Manager, } \\
\text { Road and Rail }\end{array}$ & $\begin{array}{l}\text { General Manager, } \\
\text { Sector Performance }\end{array}$ & $\begin{array}{l}\text { General Manager, } \\
\text { Specialist Advice } \\
\text { and Strategy Group }\end{array}$ \\
\hline $\begin{array}{l}\text { Responsibilities include: } \\
\text { a. developing policies in } \\
\text { aviation and maritime, } \\
\text { freight and logistics, } \\
\text { transport security, } \\
\text { technology and } \\
\text { transport systems } \\
\text { b. managing Crown's } \\
\text { interest in six joint- } \\
\text { venture airports } \\
\text { c. performing day to } \\
\text { day policy engagement } \\
\text { withCivil Aviation } \\
\text { Authority, Aviation } \\
\text { Security Service, } \\
\text { Maritime New Zealand } \\
\text { and Transport Accident } \\
\text { Investigation } \\
\text { Commission. }\end{array}$ & $\begin{array}{l}\text { Responsibilities include: } \\
\text { a. developing policies in } \\
\text { land transport access } \\
\text { and mobility; road and } \\
\text { rail safety; motor } \\
\text { vehicle, operator and } \\
\text { driver licensing; } \\
\text { b. transport planning, } \\
\text { and interacting with } \\
\text { local government and } \\
\text { resource management } \\
\text { frameworks; } \\
\text { c. Auckland transport } \\
\text { governance, strategy } \\
\text { and funding } \\
\text { d. engaging with rail } \\
\text { infrastructure project } \\
\text { appraisal and } \\
\text { coordinating policy } \\
\text { activity with the NZ } \\
\text { Transport Ministry or } \\
\text { council and the New } \\
\text { Zealand Railway } \\
\text { Corporation }\end{array}$ & \begin{tabular}{|l} 
Responsibilities \\
include: \\
a. managing Crown \\
entity governance and \\
accountability \\
b. managing the \\
revenue model \\
supporting land \\
transport funding \\
c. advising on \\
investment priorities \\
in transport \\
infrastructure \\
d. monitoring, \\
research and \\
evaluation \\
e.dealing with \\
strategic financial \\
management of \\
ministry and Crown \\
budgets
\end{tabular} & $\begin{array}{l}\text { Responsibilities } \\
\text { include: } \\
\text { a. analysing and } \\
\text { providing advice and } \\
\text { inputs on policy } \\
\text { development, } \\
\text { implementation and } \\
\text { legal issues } \\
\text { b. research and } \\
\text { evaluation } \\
\text { c. improving } \\
\text { management practices } \\
\text { that enhance policy } \\
\text { capability } \\
\text { d. developing overall } \\
\text { policy strategy, } \\
\text { ensuring the quality of } \\
\text { policy development, } \\
\text { prioritising work and } \\
\text { programmeming and } \\
\text { allocating resources to } \\
\text { key priorities }\end{array}$ \\
\hline
\end{tabular}

Source: Adapted from the Information from the MoT's Website 


\subsubsection{The Ministry for the Environment (MfE)}

The MfE is the New Zealand Government's principal adviser on the environment in New Zealand and on international environmental matters. It is not involved in day-to-day environmental management, but rather it provides environmental management systems including laws, regulations and environmental standards; sets national direction through national policy statements and strategies; offers guidance and training on best practice; and provides information about the health of the environment (MfE, 2018).

\section{Legislation}

The ministry was established in 1986 under the Environment Act 1986 with specific functions stated in Section 31 of the Act. These functions included providing advice to the Minister for the Environment on all aspects of environmental administration, collecting and disseminating information, resolving conflict and providing an environmental perspective on government proposals (MfE, 1986).

\section{Brief History}

The MfE has undergone significant changes since 2008. Departmental funding was reallocated following the re-scoping of its work. There was a reduction by 24 per cent of the Ministry's departmental baseline (it is 100 per cent Crown funded) from $\$ 68.4$ million in $2008 / 09$ to $\$ 52$ million by $2011 / 12$. This reduction was a result of discontinuing or scaling back of work programmes following a value for money review in 2008; completing several time-limited programmes; and establishing the Environmental Protection Authority in 2011/12 (MfE, 2015a, p. 25). The reduction of the ministry's baseline continued in 2012/13 and it faced significant delivery risk to its ambitious work programme. In 2015/16, the ministry's baseline funding was up again to $\$ 61.3$ million, but still less than it had been (MfE, 2015a, p. 25).

\section{Mission and Goals}

The mission of the MfE is 'environmental stewardship for a prosperous New Zealand'. The strategic plan of the MfE sets out its strategic priorities, target outcomes and the behaviours required to achieve them (see Table 5.1). The strategic plan takes a longterm view to 2045 , on the understanding that biophysical processes relating to the 
environment generally take place over a generation or more (MfE, 2015a, p. 12). The MfE has also set intermediate-term targets and outcomes towards attaining long-term targets and outcomes. These intermediate targets and outcomes are used to assess progress towards outcomes, which allows the modification of targets when required (MfE, 2015b, pp. 2-19).

\section{Table 5.1: The Strategic Plan in Action of the MfE}

\begin{tabular}{|l|l|}
\hline Mission: \\
Environmental stewardship for a prosperous New Zealand \\
\hline Strategic Priorities & Outcomes \\
Leadership: driving continuous improvement & The capacity of the environment to sustain \\
across the environmental management & itself is safeguarded. \\
system & The use of the environment and its natural \\
Information: collecting, broadening and & resources is optimised for the betterment of \\
communicating trusted information & society and the economy. \\
System Capability and Capacity: building & Risks to people and the environment are \\
capability and working within the system to & known, understood and well managed. \\
support better decision making & People are enabled to make and implement \\
Kaitiakitanga (Maóri world view): Ensuring & decisions that benefit society and the \\
analysis is based on iwi perspectives & environment. \\
\hline Behaviour: & \\
Shown by five-steps approach to work: Analyse, Engage, Learn, Validate and Collaborate \\
\hline
\end{tabular}

Source: The MfE's Four Year Plan 2016-2020 (MfE Report, 2015, p.3)

\section{Role and Functions}

The main function of the MfE is to provide advice to the government on the issues related to New Zealand environment and international matters that affect the environment. It provides expert advices to the Government on the system of institutions, laws, regulations, policies and economic incentives that form the framework for environmental management. It also monitors the performance of the system (MfE, 2015a, p. 7).

\section{Organisational Structure}

The MfE has four divisions: for natural resources policy, sector strategy, organisational performance and operations, and Treaty relationship and negotiations/kaahui taiao. Several directorates operate under each division, as shown in Figure 5.2. 


\section{Figure 5.2: The Organisational Structure of the MfE}

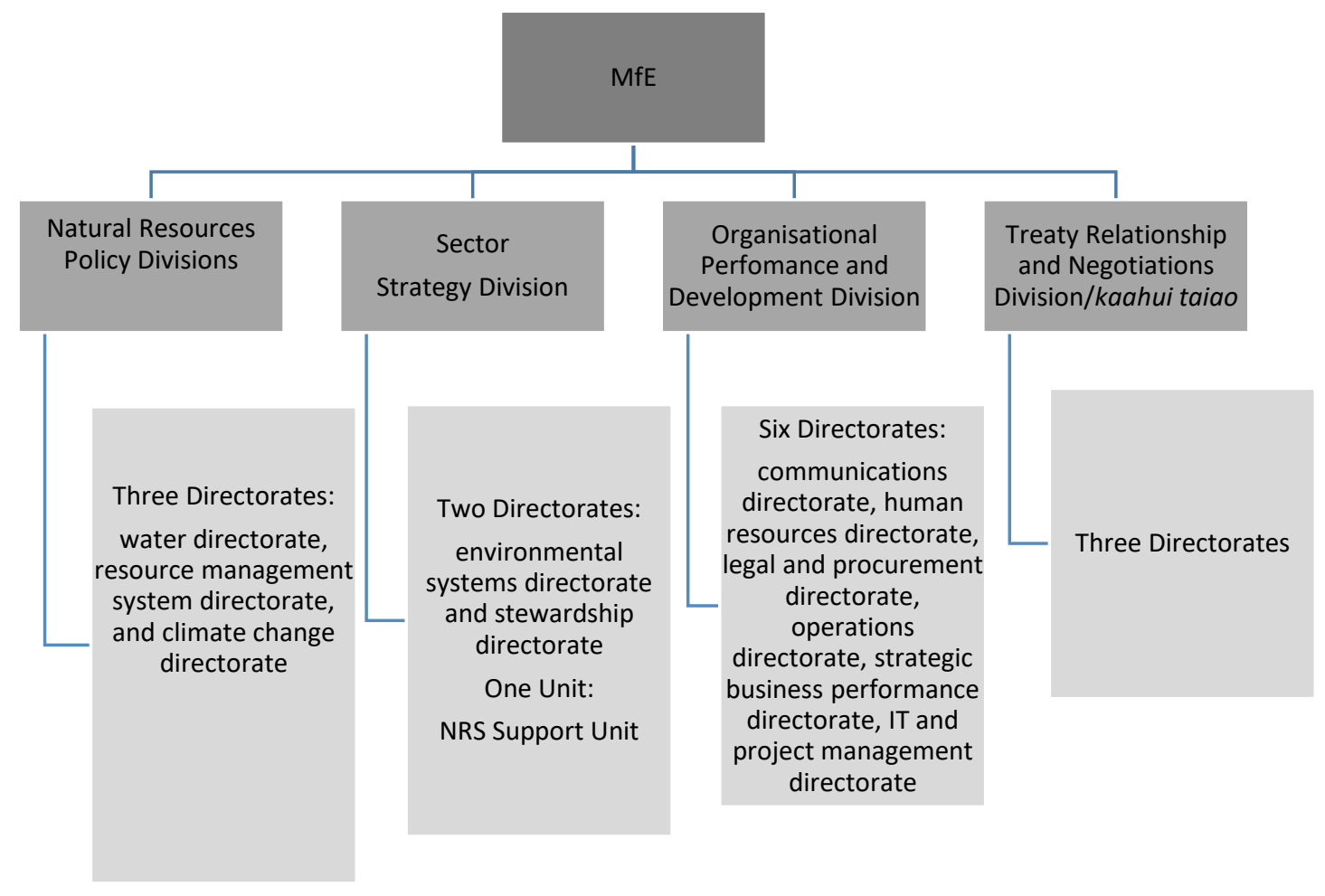

Source: Adapted from the Information from the MfE's Website

\section{Leadership Team}

The Environment Leadership Team (ELT) of the MfE consists of a Chief Executive (CE) with the overall responsibility of the ministry and four Deputy Secretaries who work under the guidance of the CE to lead their divisions. The ELT takes overall guidance from the Minister for the Environment, the Minister for Climate Change Issues and the Associate Minister for Climate Change Issues (MfE, 2015c). The responsibilities of the ELT are set out in Figure 5.3. 
Figure 5.3: The Responsibilities of the ELT

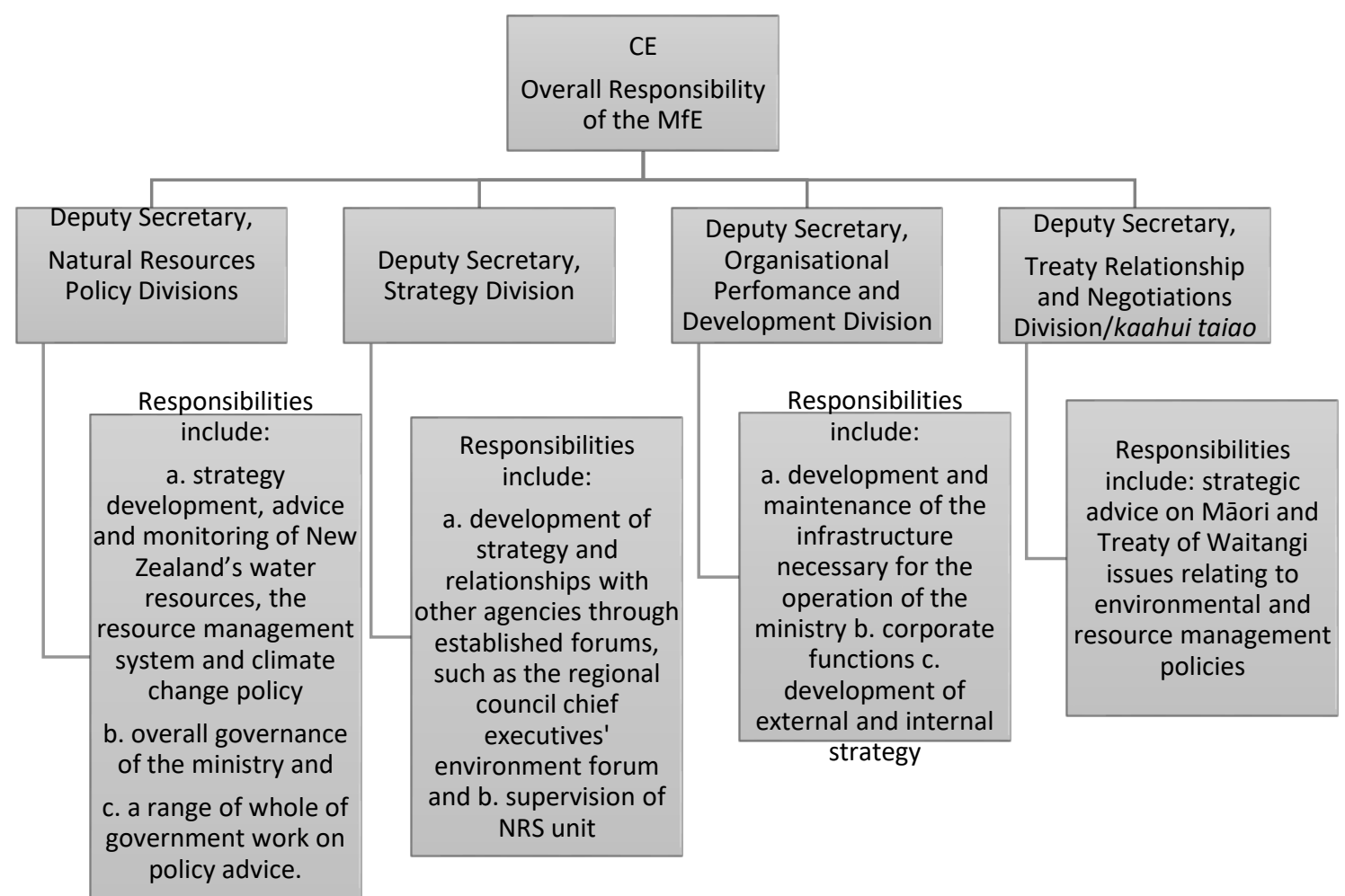

Source: Adapted from the MfE's website

\section{Partner Organisations}

The MfE partners with iwi/Māori under Te Tiriti o Waitangi, central government departments, Crown entities, local government, business, non-governmental organisations and the wider community (MfE, 2015a, p. 7). Within the public sector, it is a part of the Natural Resources Sector (NRS), a group of seven government ministries and departments that includes the Ministry for Primary Industries, the Ministry of Business, Innovation and Employment, the Department of Conservation, Land Information NZ, Te Puni Kókiri, and the Department of Internal Affairs. 


\subsubsection{The Auckland Council (AC)}

The $A C$ is one of the territorial authorities exercising local government in New Zealand. The local government sector in New Zealand consists of 78 local authorities positioned at two tiers: 11 regional councils and 67 territorial authorities (12 city councils, 54 district councils and the Auckland council). Six of the territorial authorities, (including Auckland, one City and four District Councils), also have the powers of a regional council

- these are sometimes referred to as unitary authorities (Auckland Council [AC], 2015).

\section{Brief History of the AC}

The AC was the Auckland City Council until 1 November 2010, when it took over the functions of the Auckland Regional Council and the region's seven city and district councils: Auckland City Council, Manukau City Council, Waitakere City Council, North Shore City Council, Papakura District Council, Rodney District Council and most of Franklin District Council.

In the late 2000s, the New Zealand public sector considered that the seven city and district councils were too many to work collaboratively, and determined that the Auckland Regional Council had limited powers to formulate and implement policy. Overall, the lack of strong regional government was identified as a factor hindering Auckland's progress. A form of stronger regional government, or an amalgamation under a single local council was thought to be potentially beneficial for Aucklanders. In 2007, a royal commission on Auckland governance was established to report on what restructuring could be done to establish a strong regional government. The report came out in March 2009 and the government subsequently announced that a 'super city' would be set up to include the full metropolitan area under an Auckland Council with a single mayor. Eventually the AC was formed in 2010.

\section{Legislation}

The Council was set up by three pieces of legislation, the Local Government (Tamaki Makaurau Reorganisation) Act 2009, the Local Government (Auckland Council) Act 2009, and the Local Government (Auckland Transitional Provisions) Act 2010. The instruments that set up the governance structure of the AC are the Local Government Act, 2002 
sections 39 to 48 and Schedule 7, and the Local Government (Auckland Council) Act, 2009 Section 7.

\section{Governance Structure}

The AC consists of the governing body, local boards, the staff of the council organisation, and council-controlled organisations (CCOs). The Local Government (Auckland Council) Act 2009 also created the Independent Māori Statutory Board which is independent of council. The governing body and local boards provide the governance of Auckland Council (AC, 2017). The governance structure of the $A C$ at a glance is shown in Figure 5.4 .

Figure 5.4: The Governance Structure of $A C$ at a Glance

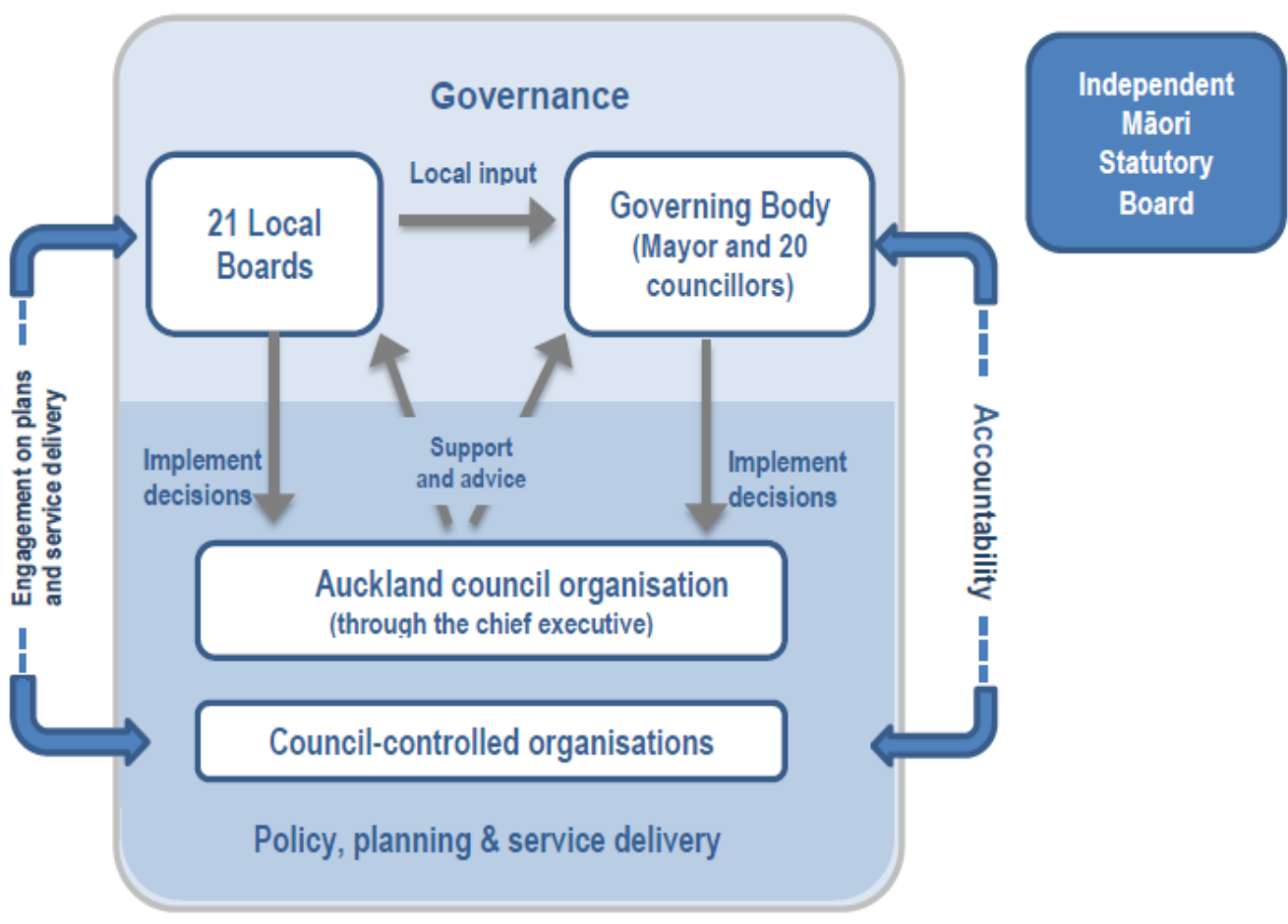

Source: The Auckland Council Report (AC, 2017, p. 8)

The governance structure of the Auckland Council consists of a governing body, comprising the mayor and 20 elected members, with regional and regulatory 
responsibilities; and 21 local boards, who each elect their chairperson from among their members, with local responsibilities (AC, 2017, p. 14).

\section{Key Difference from Other Local Authorities}

There is a key difference between the $A C$ and other local authorities in respect of decision-making responsibilities. Unlike other local authorities, the governing body and the local boards of the AC share decision-making responsibilities. While the focus on region-wide strategic decisions and services is with the governing body, the local boards represent their local communities and make decisions on local issues, activities and facilities.

The following section compares the case-study policy teams in terms of clients, work style, size, and decision-making process.

\subsection{Key Information on Policy Analysis and Advice across the Cases Immediate Clients for/Consumers for Policy Advice}

The responsible ministers for the ministries, including associate ministers, are the immediate clients for both the MoT and the MfE. But the MfE co-produces policy advice with other ministries and departments in the natural resources sector (NRS) group and needs to respond to the multiple ministers responsible for them. For the $A C$, the immediate client is the governing body (the mayor and 20 councillors).

\section{Policy Team/Producers of Policy Advice}

Policy advice is developed by a team of policy experts, and never single-handedly, in these three organisations. The leadership team of the organisation usually forms a policy team by matching the skills of people within the organisation to the nature and scope of the policy problem. The policy team usually has four to five members.

The leadership team's principal responsibility is to oversee the production of policy advice. However, it also actively engages with planning to improve policy capability of 
the organisation, changes the structure of the organisation when deemed necessary, and manages resources to work towards achieving its mission.

A policy team is often made up of people with different backgrounds and disciplines who are broadly categorised either as 'generalists' or 'specialists'. The 'generalists' in a policy team are professionals who do policy analysis and advise, using skills developed by learning by doing, on-job-training, coaching, and mentoring. They usually have formal qualifications in disciplines such as law, economics, sociology, or psychology. Those with degrees in public policy, the discipline specifically about how to do policy, are also classed as 'generalists'.

The 'specialists' in a policy team are those who have formal education in disciplines such as biology, chemistry, environmental science, urban design, law or any disciplines that provide subject-specific knowledge; they bring technical expertise to policy analysis. Interestingly, when a policy professional who has a degree in Law takes part in policy analysis $s /$ he are called a generalist. But when the same person provides technical support to policy analysis in the form of legal information, $\mathrm{s} /$ he is considered a specialist. What determines whether a policy staff member is a generalist or specialist depends on what $\mathrm{s} /$ he contributes to policy analysis rather than his or her formal qualifications.

A policy team often formed includes experts in economic analysis, who apply techniques to policy issues. Such professionals will be acquainted with a range of analytical approaches learned from a multidisciplinary academic programme, and with specific policy areas learned on the job. It is not uncommon to include overseas recruits in the policy team for a specified time who are experts in specific policy areas. Frequently, policy staff move around between different departments, from central to line agencies, from the public service to local governments, non-government organisations and government organisations in the sector.

The members of policy teams have various job titles, some of which are set out in Table 5.2. For example, the designations for team members in the MfE are Principal Policy Analyst, Senior Policy Analyst, Policy Analyst and Entry Level Policy Analyst. 
Table 5.2: A Selection of Typical Job Titles for Policy Staff

\begin{tabular}{|l|l|l|l|l|}
\hline Analyst & Policy Adviser & Policy Analyst & $\begin{array}{l}\text { Senior Policy } \\
\text { Analyst }\end{array}$ & $\begin{array}{l}\text { Principal Policy } \\
\text { Analyst }\end{array}$ \\
\hline Planner & Policy Adviser & $\begin{array}{l}\text { Manager } \\
\text { Strategy and } \\
\text { Planning }\end{array}$ & $\begin{array}{l}\text { Operational } \\
\text { Policy Adviser }\end{array}$ & $\begin{array}{l}\text { Policy and } \\
\text { Development } \\
\text { Manager }\end{array}$ \\
\hline $\begin{array}{l}\text { Policy } \\
\text { Researcher }\end{array}$ & $\begin{array}{l}\text { Policy } \\
\text { Research } \\
\text { Manager }\end{array}$ & $\begin{array}{l}\text { Programme or } \\
\text { Project } \\
\text { Manager }\end{array}$ & $\begin{array}{l}\text { Regulatory } \\
\text { Adviser }\end{array}$ & $\begin{array}{l}\text { Public sector } \\
\text { Manager }\end{array}$ \\
\hline $\begin{array}{l}\text { Research } \\
\text { Advisor }\end{array}$ & Researcher & $\begin{array}{l}\text { Strategy and } \\
\text { Planning } \\
\text { Manager }\end{array}$ & $\begin{array}{l}\text { Business } \\
\text { Analyst }\end{array}$ & $\begin{array}{l}\text { Policy } \\
\text { Advocate }\end{array}$ \\
\hline
\end{tabular}

Source: Adapted from the information from job sites, job advertisements and government documents

\section{Roles of Team Members}

The team members belong to different tiers in the organisational hierarchy and each have specific tasks to carry out. In both the MfE and MoT, the members on the lowest tier do more routine, lower-risk or less sensitive policy tasks, and support the work of others in the policy team, for example by preparing draft ministerial replies and reports.

On the lower tiers, team members carry out medium-complexity policy tasks with limited risks and sensitivity and work independently (MfE, 2011). On the medium tier, policy tasks involve large and contentious issues involving considerable risks, conflicts, sensitivity and intellectual complexity. The team members at this level manage complex projects, provide written and oral briefings to Ministers, Cabinet and Parliamentary committees, represent ministry or council in engagement with policy stakeholders, and develop networks within their own organisation and with other agencies (MfE, 2011). Their responsibilities also include coaching and mentoring, and guiding and supervising other team members' work.

The top tier consists of the expert practitioners who may be either general policy leaders or the specialist leaders. They deal with policy tasks that involve significant sensitivity, conflicts and risks. They are expected to deliver high-quality policy advice and provide professional policy leadership and guidance to other team members to uplift the policy capability of the ministry or council by coaching and mentoring others. They bring in 
considerations of the strategic position of the ministry or council, the government's priorities and perspectives, and the whole of government approach into their policy advice (MfE, 2011).

Policy advice is, thus, a result or accumulation of the contributions from team members, while each member has specific tasks to carry out. Policy advice is usually presented to the clients in the form of policy papers, strategic papers, policy briefs and regulatory impact statements.

\subsection{Similarities and Differences across the Cases}

This section shows similarities and differences across the cases with respect to the clients for policy advice, structures, expectations, and challenges. Since I explain the initiators' and users' choice and use of initiatives, it is, therefore, important to establish how these three case organisations are similar and different. The similarities and differences below amplify the information set out in Chapter 3 to justify the choice of these organisations as case studies.

\subsubsection{Similarities across the Cases}

\section{Notable Changes in the Organisations}

The brief history of the MfE, MoT and AC shows that these organisations went through structural changes over time. The significant changes in these three organisations were the responses of these organisations to inevitable changes in the public sphere.

Since the inception of the MfE in 1986, the notable change that took place in the MfE was in 2008. The reputation of the MfE was poor and publicly known (Interview 17). As a response, it realigned the purpose of the ministry and restructured the organisation and shifted its focus to policy. The significant changes also involved bringing a new team of senior leaders for the MfE. The MfE witnessed high staff turnover in the early stage of restructuring. The creation of NRS in 2014 also brought about changes in the way the MfE dealt with policy problems that involved partners from the natural resources sector. 
The MoT has turned into a small policy ministry from being a large organisation in 1970s and 1980s. It is not engaged with service delivery. Its budget and size of staff have significantly reduced over time. But its role of making policies to meet present and future demand in transport has increased. It restructured the organisation over time to respond to the government's priorities related to transport.

The AC also underwent remarkable changes in 2010. It was essentially an entirely new organisation, formed by the amalgamation of one regional authority, the Auckland Regional Council, and seven city or district authorities. A Royal Commission in 2007 recommended that a stronger Auckland Council with a single mayor would be better able to take quick decisions when necessary. This restructure conferred on the Mayor's Office bigger responsibilities and more powers to make quick decisions.

\section{Pressure to Improve Policy Capability and Advice}

A similarity across the three case organisations was that all were challenged to improve their policy capabilities. The challenge to the MoT originated from the Minister and the report of the Performance Improvement Framework (PIF) review; the challenge to MfE came from the clients at sector level through the NRS; and that to the AC resulted from public expectation following its formation by amalgamation. The challenge to the MoT, the MfE and the AC to improve policy capability and the quality of policy advice happened in 2008, 2009 and 2010 respectively. To some degree, they all experienced harm to their reputation when external assessments of their capability and performance were made public.

\section{Meeting the Expectations}

Another challenge to these organisations was to meet the expectations of the New Zealand public sector and the general public. A ministry needs to be vigilant about changes in central government agencies' focus, and respond accordingly. Having the responsibility of overseeing the New Zealand public sector, the central agencies draw the attention of line agencies to issues pertinent to ensuring that performance of the overall public sector improves. 
The recent priorities of the central government agencies have been developing an understanding of the 'stewardship' role of the agencies, so the agencies do not exclusively seek to meet the current needs of citizens, but also focus on developing strategies to gain capability for the future. Thus, these central agencies encourage the other agencies to focus on developing strategic policy.

These central agencies also promote collaboration between departments to avoid the overlapping of efforts in developing policy advice on similar issues. The State Services Commission (SSC) focuses on better public services with a collaborative culture of working across sectors (Rennie, 2013). The Natural Resources Framework (NRF) is an instance of how the central government agencies are seeking policy advice from the line agencies (MfE, 2013a) that are collaborative in style.

The central agencies put emphasis on establishing protocols, promulgated by the DPMC, for seeking scientific advice and incorporating it into the policy process (Gluckman, 2011, 2013). A number of ministries and departments now have a Science Adviser who ensures that evidence is used adequately and appropriately in policy analysis.

The central agencies seek to refocus or reduce total government expenditure on policy advice, while ensuring that policy advice is aligned with government priorities and is of a quality that reflects the high professional standards of policy teams (G. Scott et al., 2010). The Treasury demands that policy advice meets the quality expectation but with minimal use of resources.

The central agencies are also charged with assessing whether agencies are 'fit for purpose for today' and 'fit for the future' by means of the PIF Reviews (Rennie, 2012, p. 8). The PIF reviews call for an agency to take measures to improve its policy capability of the ministry and thus perform better now and for the future. The line ministries aim to achieve a better score in the PIF review, demonstrating their seriousness and commitment to improving capability. These reviews give a ministry the opportunity to demonstrate its investment in improving capability. 
The central government agencies keep renewing their expectations from an agency, and agencies continue responding to central agencies. An agency demonstrates the seriousness of its efforts to play a stewardship role; that it promotes and takes part in collaboration; that it is increasing its performance score in the PIF reviews; takes initiatives to improve its policy capability; upgrades the quality of policy advice by using appropriate and sufficient evidence; and aims for high- quality policy advice that meets the expected standard.

\subsubsection{Differences across the Cases}

\section{Nature of Clients}

The nature of clients is different across the cases. The MoT has only one minister and two associate ministers as its immediate clients. The MfE serves two ministers, one for the environment and one for the climate change, as its immediate clients for policy advice which also include two associate ministers for the environment. Besides, as a partner organisation of the Natural Resources Framework (NRF), the MfE also serves to a group of several ministers as its clients for policy advice. The AC's immediate client for its policy work is the Mayor of Auckland and the City Councillors.

While the MoT and the MfE are both overseen by central government, the $\mathrm{AC}$ is a council exercising local government. The AC has its mayor and the councillors as its immediate clients who are elected. The nature of the clients for the AC brings in different considerations to policy analysis and advice than in the MoT and MfE.

\section{Nature of Policy Roles}

The MoT is a dedicated sector policy ministry, developing policy advice relating to transport matters. The New Zealand Transport Agency (NZTA) does the major work of delivering roads and maintenance. The MoT mainly produces regulatory policies and deals with policies for the current and future needs of the transport sector.

The MfE is a policy ministry which has a mixture of roles. It is involved with regulatory roles and has responsibility for making sectoral policy from an environmental 
perspective. It deals with often challenging and 'wicked' problems relating to environment. It co-produces policy with other partner organisations in the sector, and interfaces with local governments too. Both the MoT and the MfE have very limited operational responsibilities.

The AC, in contrast, is a service-delivery organisation with many more operational roles than the other two cases. The focus of the AC has traditionally been on developing locally focused and operational policies and undertaking traditional urban planning, guided by engineers and other technical professionals.

\section{Structure of the Organisations}

The MfE and MoT have similar organisational structures, both being public service departments within the state sector. There are four divisions in each agency, under the overall guidance of the CE. Then there are directorates within the divisions. While the division leaders in the MfE are known as Directors, they are called General Managers in the MoT. The AC, being a local government, has a significantly different structure. The governing body, consisting of the Mayor and 20 Councillors, shares the power to make decisions with the local boards. The Mayor's Office has its own staff and it plays a key role in developing policies. The Mayor of the $\mathrm{AC}$ has been given significant power to make policies and implement them under a newly introduced strong Mayor Model (Shirley et al., 2016) developed by the council.

The following chapter demonstrates how these agencies address their responsibilities and expectations with the initiatives developed within the agencies, so that their policy capability is improved, and the advice produced is of a high quality. 


\section{CHAPTER 6: The Agency Driven Initiatives}

\subsection{Introduction}

The initiatives developed by three public-sector organisations, the Ministry of Transport (MoT), the Ministry for the Environment (MfE) and the Auckland Council (AC), to improve policy capability and quality are the focus of this chapter. The overall purpose is to establish the findings from the case studies, in order to provide answers to the research questions: what initiatives have been developed in the three cases, why were they developed, and what are the consequences of the initiatives.

The drivers for the initiatives, as understood by the interviewees particularly at senior roles, are discussed in the first section. The second section describes each agency's initiatives. The forms, designs and approaches of the initiatives are described using information from interviews and analysis of documents. The approach followed in presenting the cases is to first set out the internally and externally identified policy capability issues of the organisations, and then to consider the agencies' actions as solutions to the identified issues. This structure helps draw out the similarities and differences between the policy capability issues raised and the solutions applied. The third section shows the consequences of the initiatives on policy capability and the quality of policy advice. A summary of the cases is presented in section four. This chapter, thus, captures the changes in policy practices followed by the developed initiatives in these three case organisations. The following chapter identifies what influenced the choice and use of initiatives before drawing conclusions.

\subsection{Initiatives and the Drivers behind them}

\section{Initiatives}

Initiatives developed by the MoT, MfE and AC involved efforts to hire the 'right' policy staff, to upgrade the skills and talents of current and newly recruited policy staff, to develop and expand policy tools and frameworks to increase the policy capability of staff and the organisations, and thus to improve the quality of policy analysis and advice. Initiatives involved changes in the approaches to recruiting and selecting policy staff; offering formal training, coaching and mentoring; supplying policy tools and 
frameworks; and ensuring feedback was obtained on the quality of policy analysis and

advice. The initiatives developed in these cases are summarised in Table 6.1.

Table 6.1: Selected Initiatives Developed by the MoT, MfE and AC

\begin{tabular}{|c|c|c|c|c|}
\hline Purpose & $\begin{array}{l}\text { Interventions } \\
\text { Areas }\end{array}$ & МоТ & MfE & $A C$ \\
\hline $\begin{array}{l}\text { Improving } \\
\text { Organisational } \\
\text { Performance }\end{array}$ & $\begin{array}{l}\text { Restructuring } \\
\text { of the } \\
\text { Organisation }\end{array}$ & $\begin{array}{l}\text { Some restructuring } \\
\text { but major change in } \\
\text { the work-style; } \\
\text { introducing the } \\
\text { professional services } \\
\text { model; }\end{array}$ & $\begin{array}{l}\text { Major changes to put } \\
\text { more focus on the } \\
\text { policy function with } \\
\text { stronger leadership and } \\
\text { direction from the } \\
\text { Senior Leadership Team }\end{array}$ & $\begin{array}{l}\text { Major changes } \\
\text { to form the AC } \\
\text { in } 2010\end{array}$ \\
\hline $\begin{array}{l}\text { Changing the } \\
\text { attributes and } \\
\text { skills of new } \\
\text { staff }\end{array}$ & $\begin{array}{l}\text { Changes to } \\
\text { selection and } \\
\text { recruitment of } \\
\text { policy staff }\end{array}$ & $\begin{array}{l}\text { Less hierarchy in the } \\
\text { organisation } \\
\text { Improved multi- } \\
\text { method recruitment } \\
\text { approach involving a } \\
\text { combination of } \\
\text { testing, interview, } \\
\text { group activity and } \\
\text { role playing }\end{array}$ & $\begin{array}{l}\text { Recruiting a cohort of } \\
\text { thought leaders; } \\
\text { changing interview } \\
\text { processes to } \\
\text { understand both the } \\
\text { ability and behaviour of } \\
\text { the applicants; hiring } \\
\text { through the best } \\
\text { recruiting firm }\end{array}$ & \multirow{5}{*}{$\begin{array}{l}\text { Quality of } \\
\text { Policy Advice } \\
\text { Initiative (QPAI) } \\
\text { Programme } \\
\text { QPAl with } \\
\text { several built-in- } \\
\text { it components } \\
\text { relating to } \\
\text { policy tools, } \\
\text { guidance, } \\
\text { framework. } \\
\text { Aspirations to } \\
\text { improve NZIER } \\
\text { ranking } \\
\text { Auckland Policy } \\
\text { Guide } \\
\text { More hands-on } \\
\text { direction of } \\
\text { policy } \\
\text { managers over } \\
\text { policy work }\end{array}$} \\
\hline \multirow[t]{3}{*}{$\begin{array}{l}\text { Upgrading skills } \\
\text { and talents }\end{array}$} & $\begin{array}{l}\text { Formal } \\
\text { Training }\end{array}$ & $\begin{array}{l}\text { Professional courses } \\
\text { with the School of } \\
\text { Government (SOG) } \\
\text { of the Victoria } \\
\text { University of } \\
\text { Wellington (VUW); } \\
\text { a-PAD programme } \\
\text { for new graduates } \\
\text { taking up policy } \\
\text { positions }\end{array}$ & $\begin{array}{l}\text { Professional courses } \\
\text { with the School of } \\
\text { Government (SOG) of } \\
\text { the Victoria University } \\
\text { of Wellington (VUW); } \\
\text { Building Capable } \\
\text { Managers Programme; } \\
\text { In-House Formal } \\
\text { Training programme, In- } \\
\text { house training } \\
\text { programme, running } \\
\text { policy courses internally }\end{array}$ & \\
\hline & $\begin{array}{l}\text { Coaching, } \\
\text { mentoring and } \\
\text { peer review }\end{array}$ & $\begin{array}{l}\text { One-to-one } \\
\text { coaching and } \\
\text { mentoring: buddy } \\
\text { roles of policy } \\
\text { advisers and policy } \\
\text { managers }\end{array}$ & $\begin{array}{l}\text { Support from the policy } \\
\text { manager }\end{array}$ & \\
\hline & $\begin{array}{l}\text { Policy tools \& } \\
\text { frameworks }\end{array}$ & $\begin{array}{l}\text { Analytical } \\
\text { Framework }\end{array}$ & $\begin{array}{l}\text { COBRA policy guide, } \\
\text { PANDA framework }\end{array}$ & \\
\hline $\begin{array}{l}\text { Quality } \\
\text { Assurance } \\
\text { Process }\end{array}$ & $\begin{array}{l}\text { Monitoring } \\
\text { performance \& } \\
\text { Providing } \\
\text { Feedback } \\
\text { Internal Review } \\
\text { for Quality } \\
\text { Assurance }\end{array}$ & $\begin{array}{l}\text { Internal Panel for } \\
\text { Quality Assurance, } \\
\text { Peer Review }\end{array}$ & $\begin{array}{l}\text { Internal Panel for } \\
\text { Quality Assurance, Peer } \\
\text { Review, Feedback loop, } \\
\text { Feedback from } \\
\text { Managers }\end{array}$ & \\
\hline
\end{tabular}




\section{Drivers behind the Initiatives}

'Drivers' is broader in meaning than 'reasons' or 'rationale' for adopting any initiative. In addition to reasons for adopting initiatives, drivers include the conditions in the wider policy environment that influence the direct reasons for adopting initiatives.

Unlike central agency initiatives, agencies' own initiatives typically lack any explicit articulation of the rationale for their development. Central agency initiatives such as the Policy Advice Initiative (PAI) 1991-1995, Improving the Quality of Policy Advice (IQPA) Initiative 1997-1999, Performance Improvement Framework (PIF) 2009, Review of Expenditure on Policy Advice (REPA) 2010 and Policy Project 2016 clearly identified the areas for improvement and explained how these initiatives were likely to address the identified issues.

Most of the initiatives developed in the MfE, MoT and AC did not declare the area of weaknesses which was required to be addressed. But the forms and designs of the initiatives suggest that they were developed to influence the policy practices. In all three agencies, the purpose for developing initiatives was either to build, to improve or to maintain policy capability. The need to improve the policy capability in each agency, however, derived from different circumstances and specific contexts.

\section{The Ministry of Transport}

The MoT initiatives reflected an aspiration to enhance the agency's reputation as a policy-capable agency in the public sector. Referring to providing formal training and having an appropriate recruiting strategy to hire the best policy staff in the market, one senior leader commented,

Even if we had been the best organisation in the whole country, I would have still want[ed] those two things going. (Interview 9)

The interviewees from the MoT attached specific reasons to various initiatives. The initiators were influenced by their personal experiences gained overseas to improve formal training of policy team members and screening and recruiting strategies (Interview 9). Referring to the introduction of one-to-one coaching, the interviewee 
mentioned that it was driven by a 'review'. For initiatives such as 'peer review and feedback', the driver identified was ensuring that the impacts of all the changes that the MoT introduced through initiatives were monitored.

'Value for money' was also identified as a driver. One respondent explained that there had been no increase in budget for the MoT since 2008, but the operating costs went up in that time, noting,

We've had eight years of no budget increase, but of course, the costs of building go up, the cost of IT goes up, the cost of catering goes up, and you have to give your staff a small increase of salary to recognise the increase in costs of living which means you can't have the same structure that you used to have. You have to change the structure and find a way to make it deliver work of at least the same quality, so that was about the value for money. (Interview 9)

A senior leader at the MoT was asked if the initiatives of the MoT were affected by its reputation as assessed in the PIF Reviews and NZIER rating. The respondent replied that the 'quality' of policy advice produced by the MoT was assessed as 'pretty good' by the PIF Reviews. Its rating by the NZIER improved from among the bottom four in 2012 to the top four among the participants by May 2016. The interviewee expressed the view that the main driver behind the MoT's initiatives was gaining the capability to maintain what it was delivering, with a reduced budget:

If you've cut your resource effectively by 30 percent, the question is can you maintain what you deliver at a 30 percent cut. (Interview 9)

\section{The Ministry for the Environment}

The reason given for the MfE's initiatives was to fix its poor policy capability. Asked why the MfE developed several initiatives between 2008 and 2015, one interviewee responded with, 'Its policy capability was at zero (in 2008) and we had to fix it' (Interview 17). Another interviewee, reflecting on the need to focus on how effectively natural resources could be utilised for wellbeing of New Zealanders, with the understanding that humans would need to continue using natural resources said, 
The real driver was actually a notion that said that the MfE had a really important role, a role that it was not fulfilling ... So you end up in a situation, where the big driver was actually the outcomes. A different set of outcomes that are a different way of thinking about it than what would occur in a ministry at that point, which was simply about the environmental protection. (Interview 1)

Another interviewee, with reference to the newly hired CE, appointed in 2008, noted: There were a lot of issues with the MfE that he needed to fix really quickly, and one of the first things he did was to sort out the management capability. So, that happened. Once that has been settled, then the next question was how do we raise policy capability. (Interview 4)

All the interviewees, who worked at different policy tiers in the MfE between 2008 and 2015 , consistently agreed that policy capability of the MfE was below standard and its poor reputation was publicly known. Taking initiatives to build policy capability was a clear priority for the MfE.

\section{The Auckland Council}

The $A C^{\prime}$ s initiatives were driven by two factors, according to the interviewees. The first was becoming an effective organisation that could significantly affect the economy of New Zealand. One senior leader stated,

The decisions made in the AC affect not only the 1.5 million people in Auckland, they do affect the whole of New Zealand. The quality of policy advice has a huge potential impact on overall wellbeing of New Zealand. (Interview 2)

The interviewee mentioned that the local government did not have quite the same tradition of high-quality policy advice as did the central government, further stating that policy advice developed in the AC relating to economic development was the area where an uplifting of quality was realised the most.

Poor policy capability was identified as an issue by the New Zealand Institute of Economic Research (NZIER) rating, and was the second driver behind the initiatives developed by the AC. One interviewee, appointed in 2010 after the establishment of the 
AC to lead the Quality of Policy Advice Initiative (QPAI), said that the NZIER did a survey of 18 organisations in 2012. In that survey, the NZIER assessed the quality of approximately 40 policy papers from each organisation. The AC's policy papers were rated lowest among the 18 . Asked if the low NZIER rating was the driver of the initiatives in the $A C$, the interviewee suggested that the $A C$ considered that the low rating reinforced, rather than drove, steps to consider the quality of policy advice more thoroughly and comprehensively.

Across all the cases, a common driver was the questionable reputation of the agencies. The reputation of all three agencies was unsatisfactory and publicly known. The MfE had a seriously poor reputation in 2008. Indications were the resignation of the CE in that year and the reassignment of the ministerial portfolio (Interviews 1, 17). For the MoT and the AC, poor reputation was reflected in NZIER ratings in 2012, the MoT being in the bottom four (Interview 9) and the AC being the last of 18 in that year's assessment cohort (Interview 2). The reputation factor represented a similar driver for these three agencies to develop initiatives. These agencies were challenged to build policy capability and improve the production of 'quality' policy analysis and advice. 


\subsection{Agencies' Initiatives for Policy Capability and Quality Assurance}

\subsubsection{The MoT's Initiatives for Policy Capability and Quality Assurance} Initiatives for Policy Capability

Initiatives in the MoT were challenge-driven. Significant continuous structural changes in the Ministry since its establishment in 1968 reduced it to a small policy agency ${ }^{13}$ focused on developing effective transport policies. The size of the MoT was further reduced in 2014 from its 2008 size. The full-time equivalent (FTE) staff was 182 in 2008, whereas it had fallen to only 155 in 2014 . The annual budget was also slashed to 30 million dollars in 2014 (MoT, 2014b), from 48 million dollars ${ }^{14}$ (approximately) in 2008 (MoT, 2009, p. 38). The scope for the ministry, however, was not diminished. It faced growing expectations that it should develop effective policies. On the one hand, its resources were slashed and on the other hand, the demand for performance as a policy agency increased.

Another challenge was to respond to continual changes in global circumstances affecting the New Zealand transport system, and the expectation of policy responses. For instance, changes in infrastructure were necessary to accommodate new technology (such as electric vehicles). Another challenge identified by a newly appointed senior leader in September 2008 was the likely changes in different views on policy goals and objectives from a new government: 'the change of government in November 2008 brought with it a different view of the priorities for the transport sector, and the ministry has worked hard to review programmes and policy to support these priorities' (MoT, 2009, p. 1)

A further challenge was to develop effective policies to address foreseeable transport issues by focusing on strategic and long-term policy thinking (MoT, 2013). Facing these

\footnotetext{
${ }^{13}$ It is, however, responsible for some operational functions that include contracting the NZ Transport Agency to collect licensing fees, road user charges and fuel excise duty; licensing all international airlines operating to and from New Zealand; managing the Milford sound aerodrome; overseeing the Crown's interest in joint venture airports; and administering a contract with the Meteorological Service of New Zealand Limited (MoT, 2009, p. 2).

${ }^{14}$ Cash flow from Crown
} 
challenges, the MoT's senior leadership team (which had remained mostly unchanged from 2008 to 2015) focused on maintaining and developing strategic policy capability and to contribute to the transport sector by providing new methods and approaches to their analysis with a view to delivering more strategic and high-quality policy advice.

\section{Overall Solution Considered}

The overall solution proposed to tackle the challenges was to put efforts into building a more 'policy capable' and 'responsive' ministry. The MoT leaders set three success factors for the agency: to be more responsive to the highest priority policy issues of the government; to improve productivity; and to ensure more flexibility in allocating resources in delivering its annual programme. These factors were reflected in its change programme, Shaping our Future (MoT, 2010, p. 10).

\section{Diagnosis One: Unchanged strategy is fallible in changing circumstances}

The leadership team of the MoT recognised that the same level of performance, let alone its enhancement, could not be achieved with the same or very similar strategy to that followed before resources were reduced. When the challenges increased, the MoT considered that the existing structure of the organisation would become incompatible with catering for the additional need.

Strategy: Changes in operational style to accommodate flexibility

On 1 September 2009, the MoT undertook to restructure itself to operate in a new way as a professional services ministry, by implementing its change programme Shaping Our Future. The programme was underpinned by six development goals. Each goal was approached with specific strategies, as shown in Table 6.2. 
Table 6.2: Goals and Strategies of the MoT towards a Professional Services Ministry

\begin{tabular}{|c|c|}
\hline Development Goals & Strategies \\
\hline \multirow[t]{2}{*}{$\begin{array}{l}\text { Goal One } \\
\text { Identifying key issues, } \\
\text { developing views on those } \\
\text { using good practice and } \\
\text { communicating clearly }\end{array}$} & $\begin{array}{l}\text { Strategy One } \\
\text { Developing sector expertise and strategy by seven sector teams } \\
\text { responsible for policy development, centres of knowledge, key } \\
\text { relationship management with stakeholders and longer term strategic } \\
\text { thinking on transport issues }\end{array}$ \\
\hline & $\begin{array}{l}\text { Strategy Two } \\
\text { Strengthening financial and economic capability by establishing a } \\
\text { Financial and Economic Analysis Team led by a General Manager, } \\
\text { Financial and Economic Performance }\end{array}$ \\
\hline \multirow[t]{3}{*}{$\begin{array}{l}\text { Goal Two } \\
\text { Prioritising work and } \\
\text { delivering effectively and } \\
\text { efficiently by allocating } \\
\text { resources flexibly towards } \\
\text { those priorities }\end{array}$} & $\begin{array}{l}\text { Strategy One } \\
\text { Establishing Transport Managers' Group (TMG) to allocate resources } \\
\text { flexibly within the ministry, a task considered central to the } \\
\text { professional services model responsible for ensuring the right skills } \\
\text { are deployed to the most critical parts at the right time }\end{array}$ \\
\hline & $\begin{array}{l}\text { Strategy Two } \\
\text { Focusing on leadership of policy projects by appointing Policy Projects } \\
\text { Managers to lead the ministry's most significant policy initiatives. }\end{array}$ \\
\hline & $\begin{array}{l}\text { Strategy Three } \\
\text { Managing reduction of FTE staff positions within the ministry by } \\
\text { selective non-replacement }\end{array}$ \\
\hline \multirow{2}{*}{$\begin{array}{l}\text { Goal Three } \\
\text { Building working } \\
\text { partnerships with } \\
\text { stakeholders }\end{array}$} & $\begin{array}{l}\text { Strategy One } \\
\text { Ensuring policy is well informed by stakeholder interest by } \\
\text { Stakeholder Engagement Strategy }\end{array}$ \\
\hline & $\begin{array}{l}\text { Strategy Two } \\
\text { Building collaborative relationships with key stakeholders by } \\
\text { establishing Key Relationship Manager roles to improve the ministry's } \\
\text { effectiveness and reputation as a trusted and impartial adviser }\end{array}$ \\
\hline \multirow{2}{*}{$\begin{array}{l}\text { Goal Four } \\
\text { Challenging and supporting } \\
\text { people to fulfil the potential } \\
\text { of people resource }\end{array}$} & $\begin{array}{l}\text { Strategy One } \\
\text { Ensuring flexible deployment of staff to high priority work by } \\
\text { matching skills and expertise with New Principles of Staffing }\end{array}$ \\
\hline & $\begin{array}{l}\text { Strategy Two } \\
\text { Ensuring consistent level of skills in core competencies by establishing } \\
\text { a structured professional development programme for managers, all } \\
\text { advisers, and business services staff to ensure high quality policy } \\
\text { advice }\end{array}$ \\
\hline \multirow{2}{*}{$\begin{array}{l}\text { Goal Five } \\
\text { Having supportive business } \\
\text { systems enabling the } \\
\text { potential use of people and } \\
\text { their time and ensuring the } \\
\text { systems focus on the } \\
\text { achievement of the role }\end{array}$} & $\begin{array}{l}\text { Strategy One } \\
\text { Developing a knowledge-based culture at the ministry by establishing } \\
\text { an Information Group responsible to ensure easy access to, and } \\
\text { appropriate training on business systems }\end{array}$ \\
\hline & $\begin{array}{l}\text { Strategy Two } \\
\text { Establishing a Programme Management Office that serves as the hub } \\
\text { for designing, implementing and embedding sound project } \\
\text { management methodologies for the delivery of policy projects }\end{array}$ \\
\hline \multirow[t]{2}{*}{$\begin{array}{l}\text { Goal Six } \\
\text { Lifting leadership and } \\
\text { managerial Performance }\end{array}$} & $\begin{array}{l}\text { Strategy One } \\
\text { Enhancing management capability of leaders and managers with } \\
\text { specific initiatives which were then considered the next critical stage }\end{array}$ \\
\hline & $\begin{array}{l}\text { Strategy Two } \\
\text { Improving the ministry's strategic capability to meet the current and } \\
\text { future transport policy challenges }\end{array}$ \\
\hline
\end{tabular}

Source: Adapted from the information available in annual report 2009-2010 (MoT, 2010) 


\section{Professional Services Model}

The professional services model, also termed a matrix approach or matrix model by the interviewees, was a new way of doing business in the MoT. It allowed resources to be drawn flexibly for assigned tasks. Policy staff, under this work style, were rotated into different projects and departments within the organisation, rather than attached solely to one department (Interview 15). The purpose of the model was to respond to policy problems flexibly, in a timely manner, and with appropriate policy staff from among those available within the organisation (Interview 9). The interviewee remarked, Under the matrix approach, when a new project comes up, we try and find the people [within the Ministry] with both the right experience but who are not open or haven't been exposed to that subject matter or to that person to work for. (Interview 9)

The deployment of policy staff to a policy team was influenced by two factors: matching the skills and expertise of policy staff (subject-specific experts) with the problems to be addressed, and promoting learning opportunities for staff who were relatively inexperienced with that policy issue (generalists). The team, therefore, contained both technical experts and generalists to have an opportunity to learn from peers. The MoT, thus, aimed to transform inexperienced into more expert policy staff through the matrix approach.

The ability of the professional services model to perform its catalytic role with respect to growing experienced staff hinged on some key design features. Frequent or rapid changes of policy staff in this work style raise questions as to whether staff had reasonable time for expertise to grow. In addition, policy problems are often unique, and addressing them requires different policy approaches, tools, and skills. Encountering similar enough policy problems to support the logic of this model was not very likely (although various problems all related to the transport sector may have significant similarities). This concern was raised in the 2014 PIF review: '- like any matrix management model - expertise can be diluted as people move around' (MoT, 2014a, p. 11). The relatively high staff turnover, 17-18\% in 2015 at the MoT (Interview 9), could be considered an additional factor detrimental to the growth of expertise. 
The interviews did not support the argument that the model's design was flawed. No concerns were raised about a possible trade-off between speedy allocation of resources and people and the dilution of knowledge under the professional services model. On the contrary, one interviewee explicitly rejected the idea that there was such a trade-off. The same interviewee commented that the policy teams were often formed from regular policy people, whom he called a 'home team', and subject-specific experts. So, when a policy task was allocated to a new policy team, the home team could share its accumulated expertise and knowledge with the others (Interview 5). The PIF Review of the MoT in 2013 also found the professional services model in the MoT to be an appropriate choice, as it provided flexibility and speed in allocating resources to projects, although it also pointed out the possible dilution of knowledge (MoT, 2013).

So while, on balance, the PIF reviewers considered that the gains outweighed the losses, it is possible that the inherent trade-off could have resulted in employing less than the optimum resources to address any policy problem, depending on the allocation of experienced policy staff and relatively inexperienced staff to policy teams. Perhaps teams were over- or under-weighted with experienced staff.

\section{Diagnosis Two: Need to improve productivity/increase efficiency}

The need to improve the ability of the available resources to meet increased expectations was seen as essential if the quality of policy advice was to be maintained with reduced resources. This presented as a matter of efficiency, understood as producing the same level of output (maintaining the quality of policy advice in this case) with reduced resources or producing more output (better quality policy advice) with the same level of resources.

Several strategies were considered as potential ways to increase the productivity or efficiency of available resources. The MoT could not afford to get rid of 'not-so-fit-forpurpose' staff as it was already facing challenges from reduced resources. Instead of identifying and replacing these staff, it focused on developing initiatives to help extend the quality of existing policy staff. The assumptions behind these strategies were 
expressed this way: 'the quality of the Ministry's advice and the effectiveness of its operations will largely be determined by the quality of its staff' (MoT, 2010, p. 10). The MoT, therefore, put an emphasis on upgrading policy skills with a range of initiatives. It also, however, improved its selection mechanism in an effort to select the best applicants, particularly for new policy graduate intakes.

Strategy One: Selecting the 'right' policy staff with better selection mechanism The MoT continued to have regular graduate intakes of 6 to 10 graduates (Interview 15) using an improved selection mechanism intended to enhance the overall skill level of policy teams. A top leader said,

You've got to have a very good selection mechanism. So, you start right from the beginning, so you have formal assessments process for graduates coming in, so you've got good stock of people coming in. (Interview 9)

A policy graduate, newly recruited at the time of interview, shared the experience of being selected using the MoT's new selection mechanism. The selection process involved an assessment for about half a day, in which the applicants took part in a simulation of a problem situation, and were required to come up with solutions under time pressure (in 30-45 minutes). The simulation was designed to test how the applicants reacted to the problem situation, communicated with others in the team, challenged others and responded to being challenged by others, influenced others on whether to buy in to proposed advice; and articulated the advice (Interview 15).

The applicants were also required to complete a questionnaire about problem solving and thinking, which tested analytical rigour. The next stage involved a writing exercise, where the applicants had to write advice on some specific questions asked by the Minister, which tested their written communication skills. Then, there was a quiz which included a why me? exercise. The applicants were given five minutes to prepare, and then had to deliver a one-minute speech on why they should get the job. The selection panel then conversed with the applicants, asking about the rationale of their actions, behaviour and judgement. The interviewee said: 
So, I guess, they look at what are the skills you already have, what are the skills you need to be trained on ... and the skills that will come with time. (Interview 15)

A senior manager confirmed that the Ministry implemented a multi-method recruitment approach, with a combination of testing, interviews, group activity and role playing. With this approach, the MoT looked for role-related ability, some capacity to function effectively with others, and the ability to construct and deliver arguments (Interview 3 ).

To attract skilful and experienced policy staff to apply, one interviewee commented that the MoT relied on 'word of mouth' and 'personal networks'; the respondent thought the market for skilled policy staff was 'tight' (Interview 3). The respondent continued, The present scenario in the market for policy advisers is that there is a gap in the middle. Experienced advisers, new to middle-experienced senior advisers are very thin on the ground. So, when we are recruiting, at the moment [in 2015] we tend to be overrecruiting well-established and experienced people of fairly specific skills or graduates. (Interview 3)

\section{Strategy Two: Upgrading policy skills}

The MoT put emphasis on upgrading policy skills by means of a range of initiatives. The observations suggest that the MoT emphasised the learning of policy staff from all possible sources. The learning sources included formal training in theory; formal on-thejob-training; informal interactions; peer reviews; mentoring; structured and unstructured intensive learning sessions; and in-house coaching. If learning is to contribute to improving policy capability, however, it requires an understanding of what policy skills are required to deliver high-quality policy advice.

Understanding policy skills is a prerequisite to upgrading them. Interviewees from the MoT indicated what skills, talents, competences, general and subject-specific knowledge and expertise were important for policy analysts to develop policy advice. Their comments and understandings are set out in Table 6.3. 
Table 6.3: MoT Interviewees' Views on Policy Skills and Attributes in Policy Staff

\begin{tabular}{|c|c|}
\hline Int. \# & Comment \\
\hline 5 & $\begin{array}{l}\text { Good analytical skill, good questioning and listening skills, being able to think } \\
\text { strategically, ability to consider big picture, maintaining good stakeholder } \\
\text { relationship, being politically savvy, being able to break down a problem into its } \\
\text { constituent parts, being able to assemble information and making sure that it is } \\
\text { coherent and logical, being able to work with others and function in the team and } \\
\text { having good leadership skills. Working with others was considered as the most } \\
\text { critical. }\end{array}$ \\
\hline 3 & $\begin{array}{l}\text { 'Combination of basic skills and the specialist ones. Obviously, specialist ones fill in } \\
\text { different specialisations, excellence for everything. These ones are not really the } \\
\text { skills so much as a state of mind, I think, which is that you need a certain element of } \\
\text { faith, and you need a certain element of curiosity and you need a big element of self- } \\
\text { discipline'. 'You have got to have that kind of instinct to explore, push-in to think, ask } \\
\text { different questions, look at them from different angles, but again you got to be } \\
\text { disciplined, (as) you can't spend all your time exploring, and you can't spend all your } \\
\text { time just mixing things up which can change while you are experimenting, you got to } \\
\text { deliver certain things. Then, it comes back to faith and trust which you have been } \\
\text { told that this is the line, you've got to accept it for there's good reasons for calling a } \\
\text { halt to your exploring and curiosity, just getting on and doing it. I would say, those } \\
\text { three things: faith or trust, curiosity and discipline, they are, three key person } \\
\text { characteristics'. }\end{array}$ \\
\hline 15 & $\begin{array}{l}\text { A good knowledge of different frameworks, being able to use good policy tools and } \\
\text { being able to know when to use the various tools and when to adapt them, being } \\
\text { able to have a sense of what the actual underlying cause of the problem are, being } \\
\text { able to articulate clearly and show reasoning. The policy process, problem } \\
\text { identification, criteria to evaluate policy options, policy options, recommendations } \\
\text { and implementation, evaluation are considered. For each of those, there are specific } \\
\text { frameworks or ways of going about work to complete that part of the process and so } \\
\text { being able to know what those are and to develop your own. Also, being dynamic } \\
\text { and flexible as the process is, sometimes, not completed very scientifically. Being } \\
\text { comprehensive to capture the various perspectives, the multiple actors, and the } \\
\text { impacts on stakeholders and making sure that no stones were left unturned. }\end{array}$ \\
\hline
\end{tabular}

The interview information suggested that policy advice was considered a two-step process. The first stage involved analysis: dissecting and analysing a problem with appropriate tools and frameworks in developing advice; applying behavioural norms that assured the ability to work constructively in a team; knowing when to rein in curiosity under time pressure; drawing conclusions; and then bringing together the constituent parts logically and coherently to conclude the analysis meaningfully.

The second stage involved communicating the analysis in the form of advice. It required appreciating the importance of the stakeholders' views, multiple actors' views, political 
considerations, and the bigger picture (how advice was going to contribute to the New Zealand public sector), and delivering the advice on time within approved or estimated costs so that it could be implemented.

The many considerations in these two stages imply that policy development was neither a pure scientific process relying on evidence alone to draw conclusions, nor just a common-sense activity based on multiple views, perspectives, trust and faith.

\section{Emphasis on Learning}

A feature of the MoT's initiatives is an emphasis on learning from various sources. The MoT ran formal external and in-house training courses for their policy staff in the theories underpinning policy analysis. The courses showed policy staff how to use policy tools and frameworks and their applicability under different scenarios. Another source of learning for policy staff was interaction with the experienced policy staff within the organisation, who also played the role of mentors and provided feedback to junior policy staff.

\section{Formal Training}

The MoT partnered with Victoria University of Wellington (VUW) in 2013 to provide structured formal training for new-entrant graduate policy advisors, and co-designed the Applied Policy Adviser Development (a-PAD) programme with four modules: Institutions: How the State Works; How Parliament Works; Policy Methods and Practice; and Policy Analysis and Advising. ${ }^{15}$ It was set up as a one-year course of study and the successful attendees get a Post-Graduate Certificate in Public Policy (Interview 5). The course provides an opportunity for attendees to learn theories and academic views on policy work and then match them with practice.

\footnotetext{
${ }^{15}$ The modules were tailored each year to fit the requirements. This programme is an ongoing initiative.
} 
Induction Course

The new entrant policy graduates had to undergo an eight-week course inducting them into the Ministry. They were introduced to the Ministry's key people, with one-to-one meetings with each member of the senior leadership team; to the electronic systems they needed to work with; to the legal aspects of policy work; and to the parliamentary processes governing their communications with the Parliamentary Counsel Office. The course was intensive in nature. One interviewee said, 'For the first two weeks involving the whole day meetings and/or training sessions, and then from third and fourth week onwards, it starts to get less because you start to get more work' (Interview 15).

In-House Formal Training

The MoT also provided scope to learn from senior policy staff or managers, with an inhouse formal training programme. The programme included modules such as Finance, the Machinery of Government, and Presentation Skills: 'it [was] not only about good policy analysis, not only about writing, but also delivering' (Interview 5).

\section{Buddy system}

The MoT used the preceding cohort of policy graduates to provide a pool of 'buddies' for the new policy graduate intake. The buddy role helped 'find their feet in their shoes' (Interview 3) for the new graduates, and tested the ability of members of the earlier cohort to disseminate knowledge and experience to the new intake. A buddy relationship was also formed between a policy manager and policy graduate. Each policy graduate was deployed with a policy manager to deliver assigned tasks and learn through feedback under the close supervision of senior experienced managers. This 'challenge and support' (Interview 3) strategy provided some room for graduates to try things, make mistakes, receive feedback and learn.

\section{Knowledge Team}

The MoT established a knowledge team to support policy analysts by supplying them policy inputs such as information, data and evidence related to policy work in the MoT. The policy inputs were supplied in two ways. Policy staff sometimes asked for support 
from the knowledge team. The knowledge team also collected and stored information related to transport for policy staff to explore.

The purpose of the knowledge team was to ensure that the policy team was up-to-date with the available evidence and data, so that innovative ideas and practice applied elsewhere could be adapted for New Zealand. The knowledge team set up news alerts for policy staff via the internet, and met individual requests from policy staff. One interviewee described it this way:

We have got a knowledge team in the Ministry who help us to set up those alerts and they sort of keep us posted on sort of research in our field and they have lists of documents that we can then request to have a read of, if we are interested. So, like when I was at Aviation, one of the things I requested was 50 years' forecast for passengers' cargo, ... and what the trend might be, so that was quite interesting. (Interview 15)

Training for Senior Policy Managers

The MoT was a part of the Leadership Development Centre (LDC), a central government organisation for training managers at the second and third tiers in leadership. An interviewee also mentioned Victoria University's Senior Advisory Programme, (interview 5) 'Lifting our leadership' (the PIF 2013, p.5). Such training supported senior policy managers to become policy leaders who not only oversee the production of policy analysis and advice but build and manage teams of policy capable staff.

\section{Commissioning Conversations}

An approach to requesting policy work called 'commissioning conversations' was introduced in the MoT. These two-way conversations took place between the client (the Minister) and policy staff (usually the CE), and were aided by templates (Interview 5). The process helped to set out and clarify in written form the expectations and demands of the clients regarding a policy issue. Then, depending on the commissioning conversations, a team was formed using the professional services model, pulling in people from across the organisation. One respondent said, 
This outlines exactly what this [the policy issue] is about, what is expected to ensue, clarifies the job assigned. If there is clarity in the beginning that helps to get along. (Interview 5)

Commissioning conversations also had a broader use. In addition to describing and clarifying a required policy task, it was an opportunity for policy team members to test their understanding of the policy task. It was also about fitting the task into the other policy work already under way, which helped efficient allocation of resources. The commissioning of the policy work set the tone of the work (Interview 3) and 'Commissioning [was] quite fluid' (Interview 3).

Use of Frameworks

Policy staff at different layers of the organisations repeatedly mentioned several frameworks they found useful in delivering policy work. The understanding of framework, however, did not seem to be the same among policy staff. One respondent, who was directly engaged with developing policy advice, appreciated frameworks as follows:

The structure that you apply in thinking about an issue; it is the process that you set up for how you are going to, when someone presents you with an issue, how are you going to actually analyse it and work through it and come up with a solution that meets their needs. (Interview 15)

A policy staff member in a senior role described learning the basics of policy work from the VUW as learning from formal frameworks. The interviewee commented:

So, I've talked about the formal frameworks here that they learn from Victoria University. But those will tend to be on ... the basic ways which you think about policy. (Interview 9)

The same interviewee also talked about interconnectedness of relationships within and across the sectors as 'frameworks':

But there are also frameworks in transport, so there's a framework of what's the relationship between transport and economic activity, what's the framework of 
the way you think about, health outcomes and transport, social outcomes in transport, environmental outcomes in transport.

The interviewee continued, 'How does that fit in the system? How does that fit with regulation, responsive enforcement, advocacy etc.' (Interview 9). Despite the differences in usage of the term framework, commonality was seen in understanding frameworks as things that aid a systematic approach to policy analysis.

\section{Overseas Experts}

The MoT also employed foreign experts on a temporary basis when they were required. One interviewee said,

Some people [the MoT] brought in from the UK, for instance. They flew in for a week, worked full time and then they would be there, and sort of working around on a part-time basis [referring to need-basis]. (Interview 15)

\section{In-House Experts as Mentors}

Internal strategy directors, with 30-40 years' experience of dealing with transport policy issues in different countries, played the role of in-house experts to diffuse their experience and expertise among policy staff in a non-confrontational manner. One interviewee said, regarding one internal strategy director,

[Name] has this wonderful ability to share wisdom in a way that isn't confrontational, and the value is that everybody [policy staff of the MoT] wants him to help them, because they know [name] adds value, but he will never do it in a difficult way. (Interview 9)

Another interviewee expressed a similar impression.

[Name] is quite good in that space. He won't impose a view, but he will question, and he will test. (Interview 15)

Policy experts with good interpersonal skills helped the organisation not only to find solutions to specific transport issues, but also promoted learning within the organisation. Other policy staff could develop learning relationships with the experts by asking questions (Interview 9). 


\section{Diagnosis Three: Need to improve future-focus}

The PIF Review (2013) pointed out that the MoT needed to 'lift [its] focus on strategic and long-term policy thinking for the transport system' (MoT, 2013, p. 4). The need to become more strategic was also reflected in the interviewees' comments (Interviews 5, $9,15)$. One interviewee commented:

[The MoT had] a good vision for the transport system and how we [the MoT] wanted to make an impact, but we did not necessarily have a clear plan of how we wanted to get there and sort of a clear strategy, I guess. (Interview 15) The MoT focused on becoming more strategic to address foreseeable transport-related policy issues.

\section{Strategy One: Creation of Strategic Direction and Performance Team}

Considering the challenge described in one of the interviewee's comments, 'Given what little we have to work within our discretion, what can we actually make the most of those resources' (Interview 15), a strategic and performance team was formed to spend time thinking about the priority areas where the MoT could best make a difference in the transport sector. The strategic capability of the team was strengthened by engaging two thought leaders on strategic policy projects, who were Director-level policy staff (PIF 2013, p.4). The team used the PIF Review's four-year excellence horizon as a mechanism to prioritise thinking about the future in the organisation. The team helped the MoT think in the longer term and on a bigger scale, (Interview 5) and it worked as a thinktank for the organisation (Interview 15).

The roles of the Strategic Directors are clearly described by one of the directors: I have an unusual job, I'm called strategy director and it's not part of the hierarchy or advisor to the whole of the ministry, issues that have strategic content, which means real issues that are long term or ... complex, and I move around different parts of the ministry, depending on where the pressures are, either I get asked to help with something that's challenging, or I notice something that could do with extra help, above the normal. So, I'm full time doing that, I don't manage a team or anything like that. [I provide advice] to everybody, everyone from a junior recruit up to chief executive depending on the issues, 
sometimes it'll be a small team, who I join for a while to help them through the difficult time, or it could be one individual, it's quite flexible. I got known and I got more that sort of work with these different parts of the place. And then sometimes people just came to see me, and I feel almost like a GP, general practitioner doctor, sitting there and suddenly, suddenly somebody politely comes up and says hello [Name], we've got a problem with this or that. (Interview 6)

\section{Strategy Two: The Use of a New Policy Tool}

The Scenario Planning Exercise tool introduced a new way of thinking and built policy capability, as confirmed by interviewee 5 . The tool helped the agency to learn how the New Zealand transport system could work to ensure mobility in the future. As an initial exercise with the tool, the MoT produced three strategy projects, looking at transport demand up to 2042, the relationship of transport to economics and the future funding of the transport system. The MoT was working on two more future-focused projects in 2015: Regulation 2025 and Public Transport 2025.

\section{Strategy Three: Use of External Expertise}

To support its strategic work, the MoT brought in three external people from academia: an expert in economics from Lincoln University, a specialist from the University of Auckland who was running the transport research centre, and a third-the youngest ever professor of transport-from the United Kingdom. They worked with the MoT's policy team two days a week on a short-term, secondment-style basis, so that the team could learn from their expertise. They came up with the three initial future-focused projects

The MoT valued academics' and specialists' years of contemplation of specific transport issues, and saw engagement with them as a way to leap-frog (Interview 9) by learning from the leading thinkers. One of the senior leaders said,

The benefit was, the teams then had the chance to work closely with leading thinkers so that the skill came back into the ministry rather than just go away, not like a consulting piece of work. (Interview 9)

The respondent also said, 
Part of the idea is, we wanted to plug in as far as possible to the academic community. There are people who had lots of time spent looking into these issues, why are we not taking advantage of it? (Interview 9)

\section{The MoT Initiatives for Quality Assurance}

Internal Panel

An internal panel, formed in 2012 (Interview 3), assessed the quality of all the papers developed in the MoT using the NZIER's methodology. It assigned scores, gave feedback and classified the papers in terms of quality after the papers went out (Interview 5). This was 'essentially a structured peer review' (Interview 3), where the ex-post evaluation of the papers helped managers and senior managers to find out if any team was falling behind the others. One interviewee argued that the evaluation might not help improve the quality of the policy advice at the time it was produced, under the time constraints, but it signified what 'good' and 'bad' policy advice looked like and developed a shared view of those standards.

The review panel had ten managers and principal managers. One of the members acted as the permanent chair. The panel had two groups of five advisers attached to it. Every three months, half the group was replaced by new members from the same pool of positions. Each manager or principal manager worked with one of the more junior advisers to review two or three papers together each fortnight. Each person gave a score and comments to explain the score. The score was then communicated to the managers responsible for the papers. The managers then communicated the feedback to the authors of the paper. If both the teams wanted, they could discuss the papers together.

Rotating people between teams and giving an opportunity for everyone to take part in the review panel facilitated a common understanding and built up a common language. Being both a recipient of the feedback and the generator of the feedback gave a chance for everyone in the panel to apply different ways of considering the same thing. 
Peer Review and Feedback

Another initiative was peer review, known as 'level four internal review' as the policy manager was at level four (Interview 5). This was real-time feedback (Interview 9) from the managers while working under close supervision, or from a colleague. Feedback was both informal and formal.

\section{The Overall Approach of the MoT to Policy Capability and Quality Assurance}

Overall, a whole-system approach was applied, influencing several components of policy capability. It put emphasis, however, on the learning of policy staff from a range of different initiatives. This was reflected in the comments from one interviewee in a very senior role:

So, it's a whole system approach, you've got a good stock of people coming in, you've got the formal frameworks, when people start to work in the organisations they have a good base knowledge and then you create a structure where the more senior staff, their role is not to write the policy papers, it is to coach and develop these people in order to be good at producing policy. (Interview 9)

The interviewee continued:

We changed the structure, we changed the role of these people, we provided the formal frameworks, we enhanced the selection process, and the other thing we did was to broaden the experience of these people in two ways [referring to secondments out of the organisations, and rotation within the organisation under the MoT's professional services model]. (Interview 9) 


\subsubsection{The MfE's Initiatives for Policy Capability and Quality Assurance}

\section{Initiatives for Policy Capability}

Initiatives in the MfE were reform driven. A new team, known as the Environment Leadership Team (ELT), was given responsibilities for the agency in 2008, following the replacement of both the Minister for the Environment and CE of the MfE. The ELT first diagnosed what had gone wrong in order to decide on the appropriate actions. It then focused on building policy capability so that the agency could perform its expected role and contribute to a more prosperous New Zealand.

\section{Diagnosis One: Lack of Fitness of the Mission of the MfE}

The diagnosis suggested that the previous leaders' understanding of 'environment' was overly focused on environmental protection and ensuring sustainability over generations (Interview 1). Their approach to the environment could be compared with the role of environmental activists or advocates, one senior leader commented (Interview 1). In contrast, the ELT favoured a re-balancing with economic principles. They accepted that economic policies were linked with environment policies, and economic strategies made use of core natural resources. The team also recognised that the continuing reliance of people on using natural resources was inescapable. The ELT's revised understanding of environment acknowledged the need for the effective use of natural resources for economic wellbeing while maintaining them for future generations (Interview 1 ). This led to its setting out the mission of the MfE as 'environmental stewardship for a prosperous New Zealand' in 2010 (MfE, 2013b, p. 76).

\section{Strategy One: Restructuring the Organisation}

Building policy capability in the MfE involved major restructuring of the agency from 2008 to 2015, in several stages. (The organisational charts of the MfE for the years 2008 to 2015 are available in the MfE's annual reports, accessible at the MfE's website).

In 2008, when the ELT took over responsibility for the MfE, the agency had seven divisions, three of which pertained to policy functions classified according to the clients of the policy advice: central government, local government and businesses. Strategic direction was provided by one unit in a division led by a deputy chief executive. 
Organisational capability was intended to be built by a unit under the Corporate and Community division (MfE, 2008, p. 118). Building policy capability did not appear initially as a priority for the agency.

In 2009, the MfE's focus on its policy functions increased. The ELT introduced a considerable restructuring of the organisation and reduced its divisions from seven to three: Policy; Programme; and Strategy and Corporate. This structure clearly demonstrated the agency's increased attention to policy functions, effective implementation and building strategy. Accordingly, new directorates under each division and units under each directorate were created (MfE, 2009). The new organisational structure's distribution of divisions and directorates indicated their relative importance for the achievement of the MfE's mission.

The 2010 restructuring maintained an important connection between the Policy and Programme divisions by keeping the directorates under joint supervision. This may have reflected an understanding of the relationship between developing policy advice and implementing it. The functions located in the Policy division were policy thinking, problem definition scoping, options development and analysis, and regulatory impact analysis. The services that the Programme division took part in were the technical design for the delivery and review of the national instruments, tools and operational functions that gave effect to the policies and legislation. The Strategy and Corporate division was given the responsibility of overseeing the NRS network secretariat (MfE, 2010).

A further restructuring in 2011, interestingly, returned to the structure of 2009, restoring a distinction between policy analysis and advice and policy implementation under separate supervision. While the roles expected of the Policy division did not change, the Programme division took on the additional responsibility of providing environmental data. Changes were also made in the Strategy and Corporate division. The number of directorates was reduced from six to three by demoting some directorates to units. A minor readjustment took place in 2012, when Treaty of Waitangi negotiations became part of the Operations directorate under the Programme division. 
The Natural Resources Sector (NRS) network secretariat became a unit directly supervised by the programme division.

Next, in 2013, the MfE's functions were re-scoped into four newly created divisions: Organisational Performance, Treaty Relationship and Negotiations, Policy, and Sector Strategy (MfE, 2013b, p. 142). The policy division was expanded and reorganised with new directorates for water reform, environmental regulation, reform policy, and climate risk. The Programme division was abolished. This suggests that the MfE put emphasis more on widening the scope of policy analysis and advice on implementation was relocated to Policy. The functions of the Policy division were redesigned accordingly to include strategic policy issues, strengthening policy relationships across economic and social policy networks, and making connections across different sectors. The objective of the division was to achieve economic, social and environmental benefits from effective and integrated environmental management (MfE, 2013b, p. 141).

The creation of a separate Organisational Performance division in 2013 is an indication that internal and external organisational performance functions became an important focus of the agency. It seemed to be a response by the MfE to the central agencies' focus on improving performance with the introduction of the PIF in 2010 (the first PIF review of the MfE was done in 2012). The Sector Strategy division was created to monitor and evaluate environmental outcomes, and thus the effectiveness of the Ministry's interventions. It also implies a sectoral focus for policy analysis and advice relating to the environment, along with a longer-term perspective on achieving policy outcomes. The creation of a Sector Strategy division seemed to be another response to the central agencies' call for a sectoral focus.

The restructuring continued in 2014. The Organisation Performance division became the Organisational Performance and Operations division with six directorates instead of five, with the addition of an IT and project management directorate and its two units for information management and project management (both of which were previously under the strategic business performance directorate) (MfE, 2014b, p. 153). The Policy division became the Natural Resources Policy division and the number of directorates 
were reduced from four to three (water, resource management system, and climate change). The Sector Strategy division was expanded from one to three directorates (environmental systems, stewardship, and NRS support). The NRS support unit replaced the NRS network secretariat unit. The restructuring in 2014 streamlined policy functions, merged performance and operational divisions and expanded the Sector Strategy division. These changes suggest that the emphasis on enhancing performance and incorporating a wider sector view in policy work carried over from the previous year with renewed emphasis in 2014.

Yet a further restructuring in 2015 redesigned all four divisions. The three directorates under the Organisational Performance and Operations division were merged to create two directorates. The Policy division remained essentially unchanged, with just a minor change in the resource management unit's title. The MfE created a post of science advisor to the $\mathrm{CE}$, who reports directly to the $\mathrm{CE}$; the directorate for the science advisor was located in the Sector Strategy division (MfE, 2015d). The creation of posts such as science advisor implies that the scientific approach to analysis and the use of evidence had become important, as these roles were intended to ensure the use of evidence in policy analysis and advice as suggested by the DPMC. The Kaahui Taiao unit under Treaty Relationship and Negotiations division was upgraded to a directorate, suggesting that the MfE elevated the importance of incorporating Treaty relationships into analysis.

The restructuring of the organisation from 2008 to 2015 suggests several general observations. First, changes in the organisational structure were mostly a response to the changes in settings both external and internal to the agency. The agency seemed to have undertaken a whole-of-government approach and responded to the central government agencies' initiatives by making necessary changes in the structure accordingly. For example, the MfE responded to the central agencies' PIF review initiative by creating an Organisational Performance division. Besides, the Review of Expenditure on Policy Advice (REPA) 2010 and four-year excellence of the PIF review conveyed messages to the agencies that policy advice should be fit-for-purpose and fitfor-future. The MfE, hence, responded with a continuing emphasis on the Strategy division, by expanding its scope. The inclusion in the Sector Strategy division of an 
environmental systems directorate and a stewardship directorate indicate that the MfE sought the development of strategies taking a longer-term view of environmental stewardship.

Another instance of a response to external circumstances was the agency's upgrading the NRS support unit to directorate level, in accordance with the whole-of-government approach of extending policy work beyond the agency's jurisdiction to the sector level. Responses to circumstances internal to the agency were also observed. For instance, the Policy and Programme divisions' supervision was merged then reversed, in response to what seemed to work best for the agency. Similarly, the streamlining of functions within and across divisions and directorates was intended to sort out the effective way of doing business.

The significant changes in the policy division between 2008 and 2015 imply that the agency had been continually trying to understand how to do policy work effectively. The structural changes indicate that the MfE effected continual changes in the organisation to respond to both external and internal circumstances. These changes included the distribution of policy functions according to their clients in 2008, the redistribution of policy functions into the policy and programme areas in 2009, the merging of the two under joint supervision in 2010 , followed by separation in 2011 , and the expansion of the boundary of policy work to sector level by creating the NRS network secretariat in 2010 and NRS support unit in 2011. The continual responses of the MfE to circumstances imply that either it remained unsure about how to carry out policy work most effectively, or it kept upgrading the policy functions with the knowledge gained in light of experience.

The creation of an IT and Project Management directorate indicates that the support services were recognised as important for the successful completion of policy projects. The restructuring of the MfE spanned four areas: policy, strategy, sector focus, and performance. These four areas singled out by the agency for intervention were not coincidental; they were chosen on the basis of central agencies' requirements from line agencies. Concern over the quality of policy advice, failure to take a long-term view in 
policy work, lack of collaboration between ministries and sectors, and a need to diagnose capability issues and measure performance were reasons for changing the structure of the MfE between 2008 and 2015.

\section{Diagnosis Two: Lack of Clarity about Policy Work and Functions}

A lack of clarity about expectations from the agency and the roles of policy staff was reflected in the interview information. The MfE, in 2008, showed low understanding of how central government worked, and struggled to understand its roles and accordingly failed to deliver the expected results (Interview 1). Policy staff spent a significant amount of time on activities that were not considered to be policy work as per the Treasury definition. Policy staff spent about 50 percent of their time on 'reactive' work such as drafting ministry correspondence on complaints to ministers, supplying information under the Official Information Act, and writing briefings for ministers to respond to issues of the day and so on (Interview 4). There was a lack of clarity about and diverging views among policy staff on exactly what activities constituted policy analysis and advising.

\section{Strategy: Guiding policy work by developing policy guides}

In addition to setting the MfE's mission statement, creating Policy and Programme divisions and streamlining functions within the divisions, in 2011 the ELT considered developing guides for policy staff in order to standardise policy analysis and advising The Cost Opportunity Benefit Risk Analysis (COBRA) policy guide clarified the MfE's approach to policy analysis not only for the agency's own staff but also for the entire New Zealand public sector, and Professionalising Policy: A Guide for Developing the Craft of Policy Analysis (Minitry of the Environment, 2011) showed how to develop professional skills in policy analysis. The Professionalising Policy: A Guide for Developing the Craft of Policy Analysis is a companion piece to the COBRA policy guide. The guides were intended to be used together to understand the behaviours and skills required to be a policy specialist (MfE, 2011, p. 12).

Despite a healthy debate on whether the COBRA could be treated as a framework or model, the agency considered it simply as valuable in its aim to achieve some specific 
objectives. First, the guide standardised policy work with a nine-phase policy cycle (see Figure 6.1). Second, it set out the behaviours that policy staff were required to exhibit: analyse, engage, learn, collaborate and validate (MfE, 2011, p. 10). Third, it clarified the measures by which the quality of policy advice could be assessed.

\section{Figure 6.1: The MfE's Nine-Phase Policy Cycle}

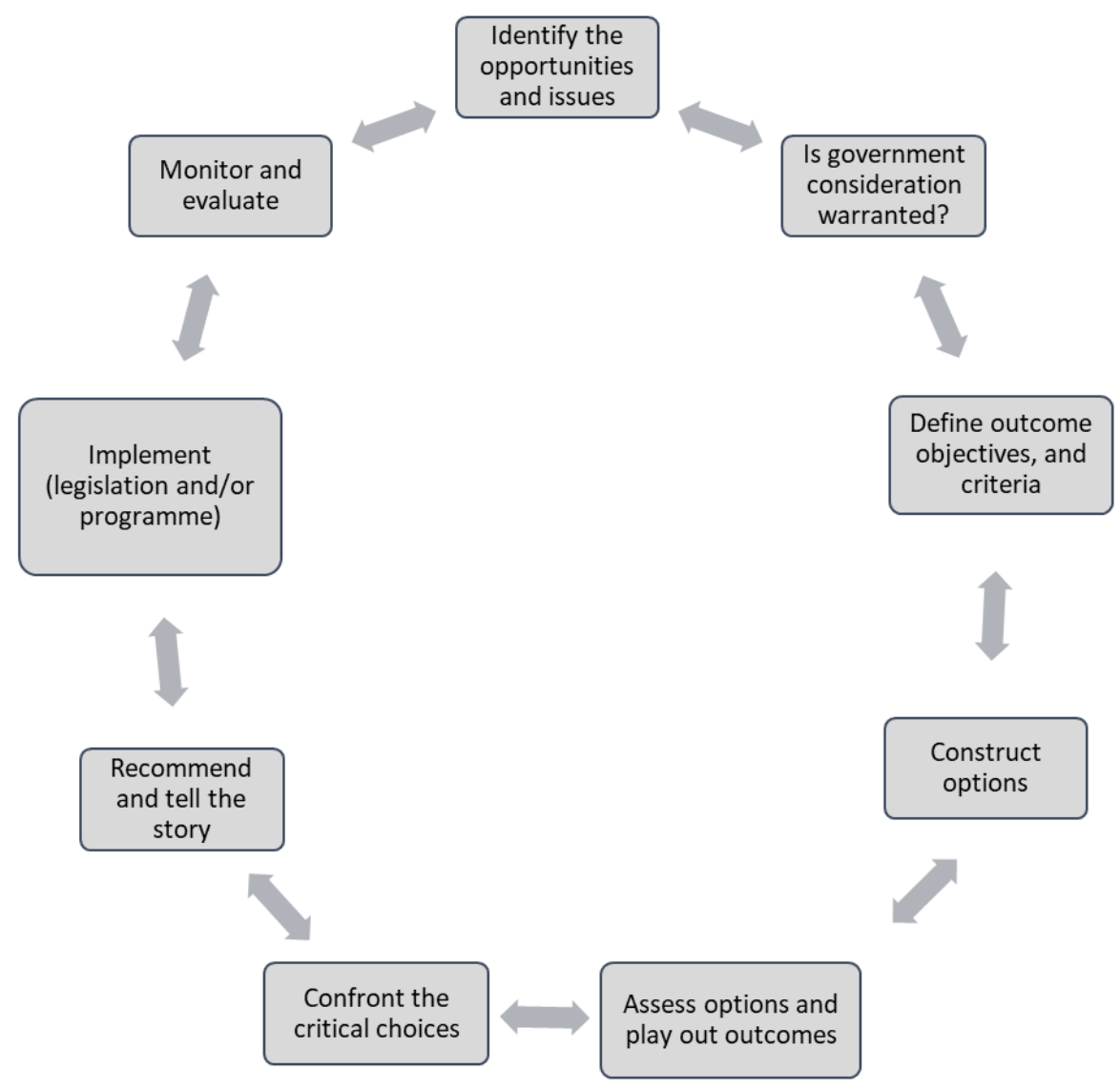

Source: COBRA Policy Guide (MfE, 2011, p. 13)

The purpose of the Professionalising Policy guide was to demonstrate to policy staff at different levels (Entry Level Policy Analyst, Policy Analyst, Senior Policy Analyst and Principal Policy Analyst) how to develop the craft of policy analysis. It set out the expected roles and accountabilities; defined a scope for self-assessment in terms of acquiring policy skills and expertise; helped identify the areas for improvement for policy staff in the short, medium and longer term; described how to plan professional development and career progression; and provided basic sources for information, data 
and evidence. One interviewee said, 'It's a great framework; it does, it helps frame your thinking and your advice...' (Interview 13).

With these two guides, the MfE clarified its expectations of policy staff in terms of policy analysis and advice, provided guidance, conveyed the required quality standard for advice and explained how to develop in the craft of policy analysis. It, thus created the demand for high-quality policy analysis and advice. These standardised guides provided a common language for policy staff (Interview 4) and showed how people of different cultural norms and behaviours could work together (Interview 17). They aimed to send a message to central government that the ELT was addressing the issue of underperformance by the MfE as an agency. The guides also had the effect of demonstrating to the entire New Zealand public sector the MfE's sincere efforts to create the demand for high-quality policy analysis and advice and meet the expected standard of policy advice, regardless of how the clients might assess the resultant advice.

\section{Diagnosis Three: Lack of Policy Skills}

One interviewee expressed a strong opinion, suggesting a serious perceived deficiency in the quality of policy staff:

When I first joined the Ministry, ...[I thought] who are these people? I would fire them, I honestly would fire them, I honestly would fire the manager, if it was the case. (Interview 4)

There were 20 vacancies in the policy function at some point during the change project, as the organisation kept only the 'right' people for the current policy tasks (Interview 4). The lack of policy skills in staff was associated with poor understanding of policy work. The interviewee continued,

Before any of these [initiatives], there was no understanding of what it meant to be a policy person. There was no professionalism around what was done. It was just, I know a lot about this area and I am an advisor. But it wasn't actually about following a systematic approach or providing advice that was actually balanced and useful to decision makers in terms of helping to take an issue forward. (Interview 4) 


\section{Strategy One: Hiring the 'Right' Policy Staff}

The agency used three strategies: terminating staff considered less suitable; hiring the 'right' policy staff; and upgrading the skills of existing staff with a range of initiatives. This, however, required understanding the 'right' skills in a policy expert, and an appropriate selection and recruitment process to attract and appoint suitable policy staff.

Almost all the interviewees, regardless of their tier, were asked an identical question: What skills, talents, competences, general and subject specific knowledge and expertise were the most important for a policy analyst to be successful in developing policy advice? The answers provided a list of attributes, knowledge and skills as set out in Table 6.4. The skills said to be required varied between the different levels or tiers of the interviewees' positions. They also varied according to the nature of particular policy work.

Table 6.4: Interviewers' Views on Policy Skills and Attributes in Policy Staff

\begin{tabular}{|l|l|}
\hline Int. \# & Comment \\
\hline 1 & $\begin{array}{l}\text { First, ability to solve problems with intellect. Second, knowing where to search for } \\
\text { resources and support for policy analysis. Third, ability to work with others and build } \\
\text { relationships; to lead, work, and influence others in the team. }\end{array}$ \\
\hline 17 & $\begin{array}{l}\text { First, analytical skills. Second, working with others, as policy development is a social } \\
\text { process. }\end{array}$ \\
\hline 13 & $\begin{array}{l}\text { Ability to develop an argument and tell a story. Understanding when to let go or } \\
\text { move into the next stage. Ability to critique something, ability to break down a } \\
\text { problem into component parts. Understanding clients, approving authority. Being } \\
\text { politically savvy. }\end{array}$ \\
\hline 7 & $\begin{array}{l}\text { First, having diverse range of experiences in order to deal with policy problems in } \\
\text { different areas with different sets of skills and knowledge. People who can stay in } \\
\text { those various domains and work with different people are likely to be successful. } \\
\text { Diversity of thinking and world view; and then you need something in common. } \\
\text { Second, ability to appreciate context and timeframe under which the advice is to be } \\
\text { delivered. Third, ability to engage with other policy practitioners. }\end{array}$ \\
\hline $\begin{array}{l}\text { Two completely different sets of things: one set for analysis and one for } \\
\text { communicating results. They must reflect each other but they can be quite different. } \\
\text { The ability to carry out fundamental analysis; and then there is a whole mixture of } \\
\text { bringing subject-specific expertise to the fundamental analysis. Communicating } \\
\text { advice to different stakeholders is essential. A good analysis that cannot be } \\
\text { communicated well is a waste of time. }\end{array}$ \\
\hline
\end{tabular}

Source: Adapted from interview information 
The interview information suggested that policy advice was a social process where people with different sets of skills, behaviours, knowledge, and competencies needed to come together to develop policy options on an issue. Policy staff needed a common platform to integrate the resulting ideas, while respecting and nourishing the diversity of views. They needed to exercise basic analytic skills independently and be open to be tested in a team. And they had to be able to synthesise information, data and evidence to demonstrate how the conclusions were reached; to convince others that the wider policy view was well considered; and to forecast reasonably accurately the consequences of policy options and judge which ones were implementable. The next skill which was given significant emphasis by all the interviewees was communication. Another skill that the MfE informants found significant in senior policy staff was the ability to influence others and lead policy work. Senior policy staff must have the ability to train, coach and mentor junior policy staff.

Understanding policy skills, thus, required taking into consideration not only analytical ability and knowledge but also competencies that supported analytical ability with appropriate behaviours. The behaviour of policy staff was considered an important component of policy capability. An appropriate mix of generalists and specialists in the policy team and a favourable ratio of senior policy analyst to less experienced analysts in the organisation were considered to be factors in improving policy capability.

\section{Strategy Two: Attracting the 'Right' Policy Staff}

The interviewees were asked whether and if so how the radical reduction and changes in people resources following the Policy Review led by the then Deputy Secretary were helpful in building the policy capability of the MfE. Also, they were asked how these changes were helping to attract new policy staff with the 'right' skills.

In terms of attracting 'suitable staff from the market, the radical change was said to be conveying a message that working in the MfE would now be challenging and rewarding. People who loved to take on challenges would be attracted to the agency. The salary was also increased by a reasonable amount. Thus, the radical reform was a deliberate action to get rid of the less 'fit-for-purpose' staff and convey a message to the policy 
market that work in the MfE would be challenging but rewarding. One interviewee commented,

We give you a whole bunch of real and interesting work, heavy duty issues to work on, we would through that provide the underpinnings and support so that you can develop your policy capability. (Interview 1 )

The ELT considered the ability to face and handle challenges as one of the skills that a policy specialist should have.

\section{Strategy Three: Terminating less suitable staff}

The MfE made significant changes to its policy staff under its change project. ${ }^{16}$ The existing staff were interviewed by the ELT about their views on policy work. Only a few survived. This conveyed a message to current staff to reassess their fitness to survive and perhaps to seek a more appropriate role elsewhere. The MfE had more senior analysts and fewer analysts. But by the time of the change project in 2015 Senior Policy Analyst positions had been reduced from 45 to 25 and Policy Analyst positions increased from 20 to 40 . The purpose was to achieve a ratio of 3 senior policy analysts to 4 policy analysts (Interview 1). The MfE challenged policy staff to sort out the survivors, who had enough understanding of policy roles and were ready for the challenges.

\section{Strategy Four: Identifying the 'Right' Policy Staff}

The MfE made changes to the selection and recruitment process. The skills and behaviours sought in policy analysts and managers were fed into the ministry's recruitment process. The applicants were given a test asking them to demonstrate their skills in producing a structured piece of advice convincingly, clearly and quickly. It helped the employer to determine whether the candidates had the thinking skills and analytical ability to demonstrate logical flows and so to develop policy options quickly. The tests were designed to find the skills sought in a policy analyst. To spot appropriate behaviours, a psycho-type profile (Interview 17) of candidates was created by putting

\footnotetext{
${ }^{16}$ An informal term widely used by the MfE interviewees to represent a series of work programme that brought in changes in the MfE relating to people and policy process. It was also termed as Policy Review, the review done in 2008-09 by Deputy Secretary approved by the then CE.
} 
the applicants in role-play situations in the presence of psychologists, which was said to be 'unique' in the New Zealand public sector (Interview 17).

The recruitment strategy was to wait, and employ 'thought leaders' who could lead teams, rather than hastening to fill the roles from candidates with less than the desired skills and behaviours. The thought leaders were not only the champions of analytical thinking, but also had to have good people skills (Interview 17). The recruitment of policy staff took place only after the thought leaders were recruited. A senior leader explained,

We regarded that cohort as being our thought leaders ... We wanted them to be the champions for analytical thinking, we wanted them to be the post of excellence that people would cluster around. So, what that meant was that not only did they need to be of being genuine principal analysts. We also wanted them to have good people skills. And it took us a while to find because there aren't many around. But we did manage to get a cohort of people together and my view is they made a profound impact [in building policy capability of the MfE]. (Interview 17)

Another recruitment strategy was to ensure an appropriate mix of specialist and generalist policy staff (Interview 10).

\section{Strategy Five: Upgrading of Skills}

The MfE introduced a wide range of initiatives to enhance policy capability. Its emphasis was on providing coaching, mentoring, training and feedback. The overall approach was not to rely on learning from one source only but to draw on all the sources: formal training to delve into theory; in-house training by academic policy experts who connect theory and practice; on-the-job learning from coaching and mentoring by senior policy staff; reflecting on skills in internal workshops and seminars; and self-learning from being challenged by peer review.

\section{Formal Training}

Formal training was provided by internal and external courses. The MfE and the School of Government (SoG) of VUW had an arrangement to run policy courses in the MfE. The 
courses were to provide an opportunity for policy staff to learn about the theories and see how theories and policy practices can be bridged. Another in-house policy course provided a general understanding of policy work particularly for new recruits. The course was run by a former academic from Lincoln University, hired by the strategic policy unit of the MfE, so policy staff could learn from an in-house expert with an academic point of view.

The ministry also enrolled employees in the School of Government's Applied Policy Adviser Development (a-PAD) programme. Policy staff from the MfE, MoT (as mentioned above) and several other agencies in the New Zealand public sector participated to understand the theories underpinning policy development. The Building Capable Managers Programme was a course initiated by the MfE to run internally. The programme was designed to build the capability of managers and leaders in the NRS. However, it subsequently became an external programme, run by the NRS and led by the MfE.

\section{Coaching and Mentoring}

The ministry introduced both formal and informal coaching. The objective was to build a coaching relationship to support building skills among the policy staff. The formal coaching sessions, each lasting two days, were run a couple of times each year (Interview 10). In the formal sessions, the team contained a mixture of new recruits and experienced staff. The approach was to raise questions about policy issues rather than informing, and to encourage brainstorming and two-way learning. Informal coaching ensured that policy staff learned from each other while working in a team through sharing, collaborating and providing feedback.

\section{MfE's Initiatives for Quality Assurance}

Translating Skills into Results

Having people with right skills is one aspect of improving policy performance. Another aspect is achieving results from those skills. The MfE created a quality assurance process that monitored the work in progress of policy staff, provided timely support and suggestions, assessed the outputs and provided feedback for future work. The MfE did 
this with the help of an internal panel for quality checking and a regulatory impact assessment panel.

Internal Check for Quality

The MfE had an internal panel of senior staff, with rotating membership and an independent chair, who was a policy expert external to the organisation. The panel assessed a sample of the ministry's policy advice against its own quality measures two or three times each quarter and produced a numeric rating for external reporting purposes; feedback to policy staff to foster organisational learning and continuous improvement; and overall messages on areas for improvement for communication throughout the organisation (MfE, 2014c, p. 27).

Internal Measures for Quality

The internal panel used an internally developed quality measure to assess the quality of policy advice (see table 6.5). The MfE used ten dimensions to measure the quality of policy advice. The standard for assessing the quality of policy advice is presented in Appendix 2 of the COBRA model. The quality of policy advice is measured in terms of recognizing the needs of the customer of the policy advice, a Cabinet Committee or the Minister; presenting advice in terms of the wider context, forward and outward looking; defining a problem clearly; identifying risks; giving importance to consultation and collaboration; developing a range of practical policy options; recommending policy options without ambiguity and presenting in a structured way (see Table 6.5). 
Table 6.5: COBRA Quality Standards for Policy Advice

\begin{tabular}{|c|c|}
\hline \multicolumn{2}{|l|}{ Criteria } \\
\hline Customer focus & $\begin{array}{l}\text { Policy advice is pitched to the needs of the audience, a Cabinet } \\
\text { committee or minister and makes clear the position of advice in } \\
\text { relation to time and process. }\end{array}$ \\
\hline Context & $\begin{array}{l}\text { Policy advice is presented within the big picture ensuring that it is } \\
\text { both forward looking and outward looking. }\end{array}$ \\
\hline $\begin{array}{l}\text { Problems and } \\
\text { opportunities }\end{array}$ & Problem is clearly defined and indicates the size of the problem. \\
\hline Analysis and argument & $\begin{array}{l}\text { Analysis is complete, transparent and analytical framework is fit for } \\
\text { purpose. }\end{array}$ \\
\hline Risks & $\begin{array}{l}\text { Policy analysis identifies economic, environmental and delivery risks. } \\
\text { It also identifies both adverse and favourable events amongst } \\
\text { stakeholders. }\end{array}$ \\
\hline $\begin{array}{l}\text { Consultation and } \\
\text { collaboration }\end{array}$ & $\begin{array}{l}\text { Advice should be developed based on appropriate collaboration } \\
\text { within ministry and external collaboration and consultation to } \\
\text { ensure that subject experts have been consulted and they are fit for } \\
\text { purpose and realistic. }\end{array}$ \\
\hline Options & $\begin{array}{l}\text { Policy advices should come as number of options to show that } \\
\text { selection is transparent, and options can be chosen from a } \\
\text { comparative study on the options. }\end{array}$ \\
\hline $\begin{array}{l}\text { Conclusions and } \\
\text { Recommendations }\end{array}$ & $\begin{array}{l}\text { Recommendations should be short, unambiguous, complete and } \\
\text { realistic. Advice is free and frank and astute. }\end{array}$ \\
\hline Presentation & $\begin{array}{l}\text { Format is correct and free from errors, well-structured and free from } \\
\text { unexplained jargon and acronyms. }\end{array}$ \\
\hline
\end{tabular}

Source: Adapted from Appendix 2 Quality of Policy Advice, COBRA policy guide (MfE, 2011, p. 75)

Regulatory Impact Analysis Panel

The MfE also had a regulatory impact analysis panel that assessed the quality of regulatory impact statements in terms of government requirements which meant assessing the likely benefits, costs and effects of new or changed legislation and regulations. The panel also supported policy staff in conducting their analyses (MfE, 2014c, pp. 27-28).

Feedback

Informal feedback on policy advice was provided by both peers and policy staff in managerial roles. It was generally provided in the course of working in a team. 


\section{Overall Approach to Policy Capability and Quality Assurance}

The design and approach of the initiatives indicate that the MfE used a crisis in the organisation as an impetus to bring in the changes considered necessary by the ELT. A very senior leader expressed this belief clearly:

So, actually what happened was, we had a crisis, and I poured petrol on the fire and flames made it burn harder and used the crisis to drive the change. Classic management. (Interview 17)

The initiatives' designs indicate that the MfE emphasised learning from various possible sources:

So, we ran policy courses internally by a guy who came from Lincoln University who worked in the ministry in the strategic policy unit. We are linked up with the SOG [Victoria's School of Government] to do programmes here. What we all were interested in doing was putting into people's hands skills that they could get on the job and on the job learn and deliver... We focused very strongly on building capable managers in the organisation. So, we used an external agency to help us deliver it internally, there was a combination of, kind of, people meeting in groups and e-learnings, so we were looking for again the ways that managers could upskill themselves on the job and use the experiences we were having in real time, to actually then be applied in a systematic way to increase their skill levels. So, we really focused on doing that and then we also ran leadership programmes ... So, Building Capable Mangers Programme started inside the MfE and became the natural resources sector offering ... But very much the focus was on lifting skills and lifting the game in all the dimensions inside the place, doing it in a real time because we, we simply had to have people learning on the job. (Interview 17)

The emphasis on learning was focused on senior leaders rather than the policy staff at junior levels who were directly engaged with policy analysis. The rationale for doing so lay in the recruitment strategy, which employed a cohort of thought leaders before recruiting the policy staff who would be directly engaging into policy analysis. The cohort of thought leaders was considered the 'post of excellence that other policy staff would cluster around' (Interview 17). 


\subsubsection{The AC's Initiatives for Policy Capability and Quality Assurance}

\section{Initiatives for Policy Capability}

The transformation of the AC into a unitary council ${ }^{17}$ in late 2010 significantly widened its scope, conferred bigger responsibilities on it, and delegated more power and duties to the Mayoral Office to execute the council's decisions. The rationale for the AC as a unitary council was to respond to two significant matters. The first was the importance of Auckland, reflected in its population base in terms of density, diversity and potential, and its role as a junction or portal for both the national and global economies (Shirley et al., 2016, pp. 10-18). The second factor was the recognition by a Royal Commission of two broad systemic problems: weak and fragmented regional government; and poor community engagement (Salmon, Bazley, \& Shand, 2009, p. 4; Shirley et al., 2016, pp. 10-18).

The nature of initiatives in the AC was expected to stem from two factors: the preexisting problems, conditions and constraints that necessitated the birth of the AC as a unitary council; and the policy capability of the council at the time of development of the initiatives. Since the second factor arose from the first, the focus was put on the second factor in efforts to understand what influenced the designs and forms of the initiatives.

\section{Pre-Initiative Policy Capability}

There was no universally agreed way to measure or assess policy capability of the council, but this capability at the time of amalgamation was crucial to understanding the drivers, designs and forms of the initiatives developed. Hence, a broad assessment was made of the council's policy capability at the time the initiatives were developed, using two sources: the policy capability issues and concerns of the council as they were documented; and the interviewees' comments.

\footnotetext{
${ }^{17}$ Two foundation reports for the formation of the AC were: Royal Commission on Auckland's Governance, 2009, it represented a comprehensive assessment of governance in the region, and Making Auckland Greater, the Government's response to the Royal Commission Report.
} 
The AC's policy capability issue was reflected in 2012, when it asked the Head of its Policy and Planning Division to focus on how to enhance the council's policy capability to meet the growing expectations. As a first step towards improving its policy capability, the Head of the Policy and Planning Division wanted to assess the quality of its policy papers against those of government departments by taking part in the NZIER survey in 2012. The NZIER surveyed 18 different organisations, assessed 40 policy papers from each organisation, and rated the organisations in terms of the quality of the papers. The AC came last out of the 18 organisations (Interview 2).

The policy capability of the AC was evidently in need of improvement. For example, the AC's Chief Operating Officer (COO) approached the Head of the School of Government at Victoria University of Wellington to provide staff for a tailored policy analysis programme for the AC's Executive Leadership Team. Academic staff were also involved in reviewing material developed to support policy work.

One comment from an interviewee on the success of one initiative elucidates the preinitiative policy capability of the council. The interviewee pointed out that the mere numbering of paragraphs of reports was a big improvement.

Imagine that, that you had reports literally in their 100s going to 21 Local Boards and all these Committees, they didn't have their paragraphs numbered and people would sit there in a meeting and they would be trying to say ... Where is that? Page 93, paragraph at the bottom, sort of. So, pretty rudimentary really. Certainly, improved a lot. (Interview 19)

\section{Not Enough Policy People}

The AC's concerns regarding the policy capability of the organisation were reflected in interviewees' comments, which pointed out that there were not enough policy practitioners in the council for the size of the organisation and its impact on a large population (Interview 19). Another interviewee expressed a similar concern, pointing out that there was only one economist on the council staff (Interview 16). However, the senior leader of the AC pointed out there were 400 people in the council organisation 
who developed policy advice (Interview 2) but emphasised the need for them to be trained, mentored and supported with peer review (Interview 2).

Lack of Clarity about Policy Practices and Processes

Policy development practices and processes were not clearly understood by policy staff, even at a senior level. Interviewees mentioned the ignorance of policy staff about policy work. There was no practice of peer review or of seeking advice from the appropriate departments regarding the legal and financial implications of advice before tendering it to the decision-makers. Policy development methodology was also not well understood. These views were expressed in various comments by the interviewees:

They don't know what policy is. They don't have any understanding of it. So, to them it's some kind of abstract thing. (Interview 16)

We already knew that things had to improve ... So, those kind of pretty basic things [referring to some of the fundamentals of good practices such as formalised peer review of policy papers] weren't happening and policy development methodology wasn't really well understood. (Interview 19)

Most of the people who provided the advice didn't know why they were doing it. They didn't have the training to know why they were doing it, even the managers, some very senior people really didn't understand the advice in governance. (Interview 16)

The different parts of Auckland Council have engineers, planners, community development people who have their day jobs to do, and then they would write these reports to committees, and they didn't see that was the core part of their work. They saw it as bit of a nuisance. They didn't really have much idea about what [and] when they should to do it. (Interview 16)

Focus on Operational Policies rather than Strategic Policies The policy work in the Council was mostly operational. Its focus was on land use planning, developing 'small p' policies using a rules-based approach. It followed a basic 
traditional process of writing a rule book, going through a consultative process with the public, and making all the decisions public, which were then contested. One respondent said,

Local government policy has been actually land-use planning and about probably what you would say small 'p' policies, we need a policy on such and such, and we would write a rule book, and it will go through a consultative process with the public about this rule book and we would make some changes and we would adopt that policy and it might be about have they made grants? or have they controlled weeds? Often, it's quite operational things. And in my experience, it's a great deal of examination of the sort of bigger policy questions about how we shape our law or what sort of interventions are appropriate to use to address particular problems that we have identified, and that's probably the biggest difference. (Interview 19)

The AC's potential impacts on Aucklanders then and in the future was being overlooked by the council; the interviewees found the council was overly-focused on developing 'small p' policies in response to specific issues, rather than strategic policies.

\section{Poor Policy Analysis}

The quality of policy analysis was poor. There was an absence of rigorous policy analysis to underpin the advice forwarded to councillors. Policy options were not linked with the analysis of benefits and associated risks. One interviewee shared councillors' impressions on the rigor of policy analysis:

I remember interviewing a bunch of councillors at one point on what their views were, and a lot of them were saying we feel like we are expected to rubberstamp things. We are not given the full range of options, you are presenting your preferred option and we are not seeing the analysis behind that. (Interview 19)

They [councillors] say they want to hear more about risks and the negative impact of things and they are not getting that information because officers in local authorities have pressure not to do that. They're trying to tell a good news story. (Interview 16) 
Lack of Accountability/No Setting of Expectation

Interviewees thought there was no serious commitment from senior management of the council. The senior management did not communicate their expectations of the policy work, but commented on policy advice from their own understandings of quality (Interviews 16, 19). One interviewee remarked:

Probably two things. I guess the culture of excellence and pride in your work, and I'm not saying the people aren't, don't take pride in their work, but the expectation, setting the expectations, and I think a lot of that comes from the top and I think a lot of Auckland Council's problem is that the Management, Senior Management who sign out the policy papers are not, for whatever reason, not giving their full attention, they are not pushing back... A lot of the times papers are being authorised by Senior Management and they are not even reading them. (Interview 19)

Asked why this was so, the interviewee replied, 'I think people [Senior management] get very busy in meetings and don't prioritise'. (Interview 19)

\section{Size and Structure of Policy Team}

The policy team in the AC consisted of more senior policy advisors (Principal Advisers and Policy Mangers) than junior policy staff. There were not enough policy staff immediately below the senior staff to support their work. There was less scope in the roles of Policy Analyst and Senior Policy Analyst in policy work of the council than would be found in government departments. As an informant expressed it,

We also have got a very, very flat structure, and I don't think that helps, ... so if you look to the Organisational Chart and the Policy Division, you will see Policy Manager, 10 Principal Advisors, no Senior Advisors, no straight Policy Analysts, and ... there is no space there for them. I think these graduates coming in here because we do have a graduate programme, but for someone who is Policy Analyst or Senior Policy Analyst, there is no way for them to slot in, so you tend to have a fairly static [structure]. (Interview 19)

The flat structure was found not helpful to analysis, because policy development ideally required incorporating different policy inputs, views, perspectives from policy staff at 
different levels. It also did not support growing policy people within the organisation who would be aware of the organisational culture and the expectations of the clients, and ultimately contribute to develop institutional knowledge.

We have got an organisational structure that drew people from the previous councils ... So, you are not bringing people in and developing them in the culture and expectations you want to have in your organisation. You have got the people that you inherited, and then you bring in new people either at graduate level or at that very senior level. You are not really growing people. (Interview 19)

\section{Poor Collaboration}

Broadening the perspectives and using different lenses were critical to developing and running a large complex city, but poor collaboration between teams meant they could not review each other's work and learn. One of the interviewees said,

Another thing that I would really expect to see in an agency of this size is crossteam working. So, we need a bunch of senior analysts or junior analysts from across the various parts of the policy division to work together on a common problem. Just this kind of vertical, social policy we do, environmental policy we do, transport policy we do, so there is not a lot of connection across. (Interview 19)

\section{Lack of Trust and Ownership}

There was serious need to improve the level of trust between policy staff and councillors. One interviewee remarked emphatically:

I think this is an inherent issue about trust, trust between elected representatives and officials, the perennial issues of capture and bureaucratic agendas and especially when there are changes in government. You certainly see when the government changed in 2008, Ministers will go out and seek independent external advice. They don't trust the previous administration and we certainly have some councillors who just do not trust staff at all and I could not be shy about saying so. Yeah, but we do have a couple of councillors would just in public say that they don't trust the advice provided by staff, they believe that staff have 
agendas, or they are incompetent or lie or worse. So, I don't think those questions get openly addressed often, the trust relationship. (Interview 19)

Lack of Leadership

A serious concern regarding lack of leadership was expressed. The interviewee commented that even the senior leaders of the council did not clearly know what policy was:

In my view, there's hardly any leaders in Auckland Council who know what policy is, so even on the management team, only a few of them know what policy is and they can't provide that leadership. (Interview 16)

\section{Poor Organisation of Policy Work}

Some of the interviewees clearly indicated that there were elements of unproductive policy practice in the organisation. Many policy documents were prepared repeatedly for presentation to the clients. The purpose of the documents was not clear to the clients and they were often rejected. The repetitive production of policy documents by policy staff was indicative of poor collaboration across the organisation. The interviewee said:

One of the things I found was the huge amount of paper being generated, going up to these committees and get rejected quite often and having to be repeated. There's this huge amount of work, and for me, it was very difficult to get quality improvements, and a system that was drowning in quantity, and completely misdirected quantities. (Interview 16)

A lot of the papers ... just nothing happened with them or a waste of time. A waste of everyone's time, the people writing them and ... people who are sitting around the table talking about them. (Interview 16)

\section{Lack of Guidance}

The lack of guidance in policy development was evidently the result of the senior management's ignorance of the policy practices and processes, and of the nature of the relationship with councillors. One interviewee remarked: 
In local government is just completely random, there's not really much guidance.

The people are giving advice in that system by trial and error. They find out where they might make mistakes, and there aren't codified practices. (Interview 16)

\section{Role Confusions and Lack of Professionalism}

Policy advisors' lack of clarity on their roles signified that the practice of policy work was unprofessional. Some advisors were found to be undertaking overlapping roles, both developing advice and making decisions. The policy staff considered the councillors to be lay people (Interview 16), and failed to detach themselves from their own views in presenting advice to them. Policy staff could not view themselves clearly as the producers only of the policy advice and the councillors as the sole decision makers. One interviewee expressed this without hesitation:

I've really noticed with some people in some parts of local government they [referring to Policy Advisers in the AC] don't quite understand, they think they are the decision makers. They are not entirely sure about why they are giving information to the councillors. They think that's kind of a matter of courtesy or something just getting annoying in the way. (Interview 16)

\section{Quality of Policy Advice Initiative}

The policy capability of the AC needed to be rebuilt. The AC introduced four work streams: Capability and Performance; Guidelines; Tools and Techniques; and Quality Control. Asked how the council was coordinating the four work streams, the senior leader of the council replied that the AC pulled together nine to ten people from different departments of the $\mathrm{AC}$ who were keen, passionate and ambitious to lift the game of the AC, and they acted as the lead drivers of the Quality of Policy Advice Initiative (QPAI) (Interview 2).

The AC developed the QPAI in 2013, under the leadership of the Head of Policy and Planning Division. The QPAI produced the Guide to Providing Quality Policy Advice at 
Auckland Council ${ }^{18}$ in 2013 which provided general guidance to policy staff by setting expectations for policy analysis and advice; clarifying the commissioning process; and establishing a quality-check process. Other initiatives included the training of policy staff; changing the recruitment process to recruit more suitable policy people to the council; and focusing on developing strategic policy looking to the future.

\section{Expectations for Policy Analysis and Advice}

The QPAI, as a first step, defined policy advice for the AC as a policy output: 'material that is presented to political decision-makers that offers guidance about future decisions or actions. It clearly sets out problem definitions, relevant evidence, criteria for assessment of options and recommendations' (AC, 2013, p. 7). It conveyed a message to advisers or analysts, team leaders, peer reviewers, and senior managers that policy advice needed to reflect on the context and analytical and political inputs, but to be premised on evidence, and the analysis of the consequences and risks of recommended policy options (AC, 2013, p. 7). It clarified and emphasised the role of policy staff as merely the producers and presenters of policy options to the decision-makers, so they should not be overly attached to the options they recommend.

\section{Characteristics of High-Quality Policy Advice}

The ten characteristics of high quality policy advice (Table 6.6) set by the QPAI were treated as targets to achieve high quality policy advice. The quality standard sets the expectations for policy advice developed in the AC.

\section{Expectations for Policy Analysis and Presenting Advice}

The AC developed a nine-step schematic representation of its policy cycle (Figure 6.2) with three broad stages: the commissioning process; the policy analysis and advice process; and implementation and monitoring. It is seen through five 'lenses': Engagement, Implementation, Māori representatives, Local and regional, and Evidencebased.

\footnotetext{
${ }^{18}$ Often referred to as the Auckland Council Policy Guide
} 
Table 6.6: The AC's Quality Standards for Policy Analysis and Advice

\begin{tabular}{|c|c|}
\hline Standard & Description \\
\hline Purpose & Has a clearly stated purpose \\
\hline Significance & Reflects the significance of the issue \\
\hline Context & Recognises and presents the wider context \\
\hline $\begin{array}{l}\text { Opportunity/Problem } \\
\text { Definition }\end{array}$ & Clearly defines the problem or opportunity \\
\hline Evidence and Analysis & $\begin{array}{l}\text { Based on evidence, states assumptions, uses robust analytical tools } \\
\text { and is objective }\end{array}$ \\
\hline $\begin{array}{l}\text { Consultation and } \\
\text { Collaboration }\end{array}$ & Informed by consultation and collaboration \\
\hline $\begin{array}{l}\text { Developing and } \\
\text { Analysing Options }\end{array}$ & $\begin{array}{l}\text { incudes a range of practical options and uses appropriate criteria } \\
\text { to evaluate these, including consistency with the council's } \\
\text { statutory purpose }\end{array}$ \\
\hline Recommendations & Includes appropriate recommendations \\
\hline Timeliness & Prepared in a timely way \\
\hline Presentation & $\begin{array}{l}\text { Structured and presented logically and in a way that is appropriate } \\
\text { to the audience }\end{array}$ \\
\hline
\end{tabular}

Source: Adapted from the information from Guide to Providing Quality Policy Advice at Auckland Council, (AC, 2013, pp. 7-9)

\section{Figure 6.2: The AC's Policy Cycle}

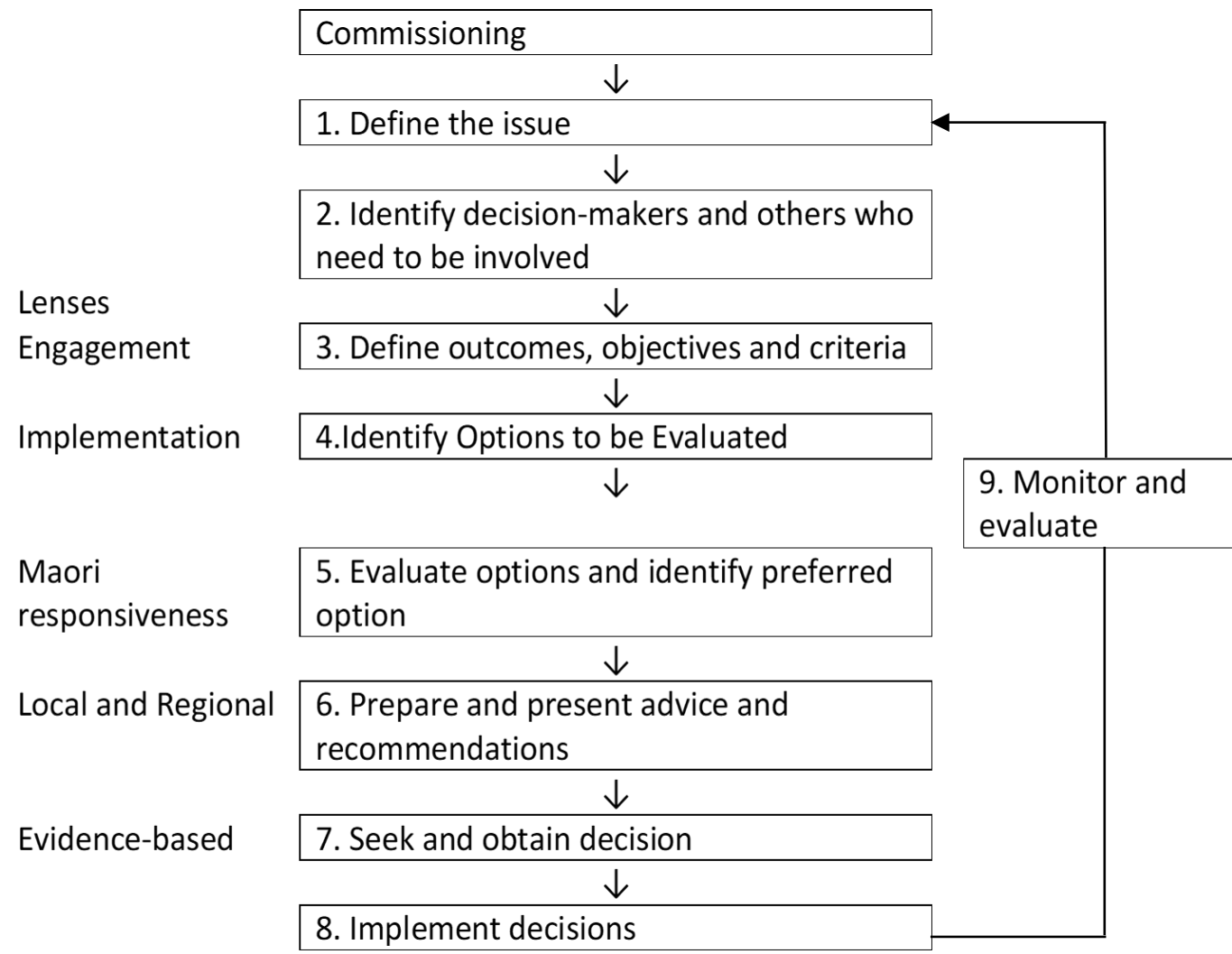

Source: Guide to Providing Quality Policy Advice at Auckland Council (AC, 2013, p. 10) 
This stepwise linear approach to policy analysis and advice attempted to standardise the policy process and practice in the council. The five lenses were intended to draw into the analysis the necessary considerations, some internal and some external to the council. The policy cycle treated scoping of the problem, identifying the actors involved, and maintaining a feedback loop as important aspects of policy development.

\section{Streamlining of the Commissioning Process}

Since requests for policy advice could come from a variety of sources such as local boards and governing bodies, and executive and senior leadership teams (AC, 2013, p. 10), the commissioning process was considered very important for the AC to prioritise policy work and to avoid duplication. There was a need to be aware of existing policies on the related issues, and exploit potential synergies (Interview 2). The eight-step commissioning process developed is shown in Figure 6.3. The AC's approach to providing overall guidance on developing policy advice was centred on setting expectations, standardising policy practices, and promoting collaboration between departments.

\section{Ensuring Availability of Resources}

The AC understood that the quality of policy analysis and advice was reliant on the quality of the inputs used. This is reflected in its initiative to develop to the Quality Policy Hub and Policy Register, and ensure policy staff had access to them. The Quality Policy Hub was established on the AC's intranet for easy one-step access to information. It included the Guide to Providing Quality Policy Advice at Auckland Council, templates, case studies, sample analyses, links to external groups involved in policy work, and links to other documents and tools for policy staff.

The Policy Register was a centralised database developed to help determine at an early stage the scale and scope of a policy issue or opportunity before committing significant resources to it. The onus was on all the advisers to update the database on their own work. It was also their responsibility to check for any similar policy work done previously, to avoid duplication of work. 
Figure 6.3: The AC's Eight-Steps Commissioning Process

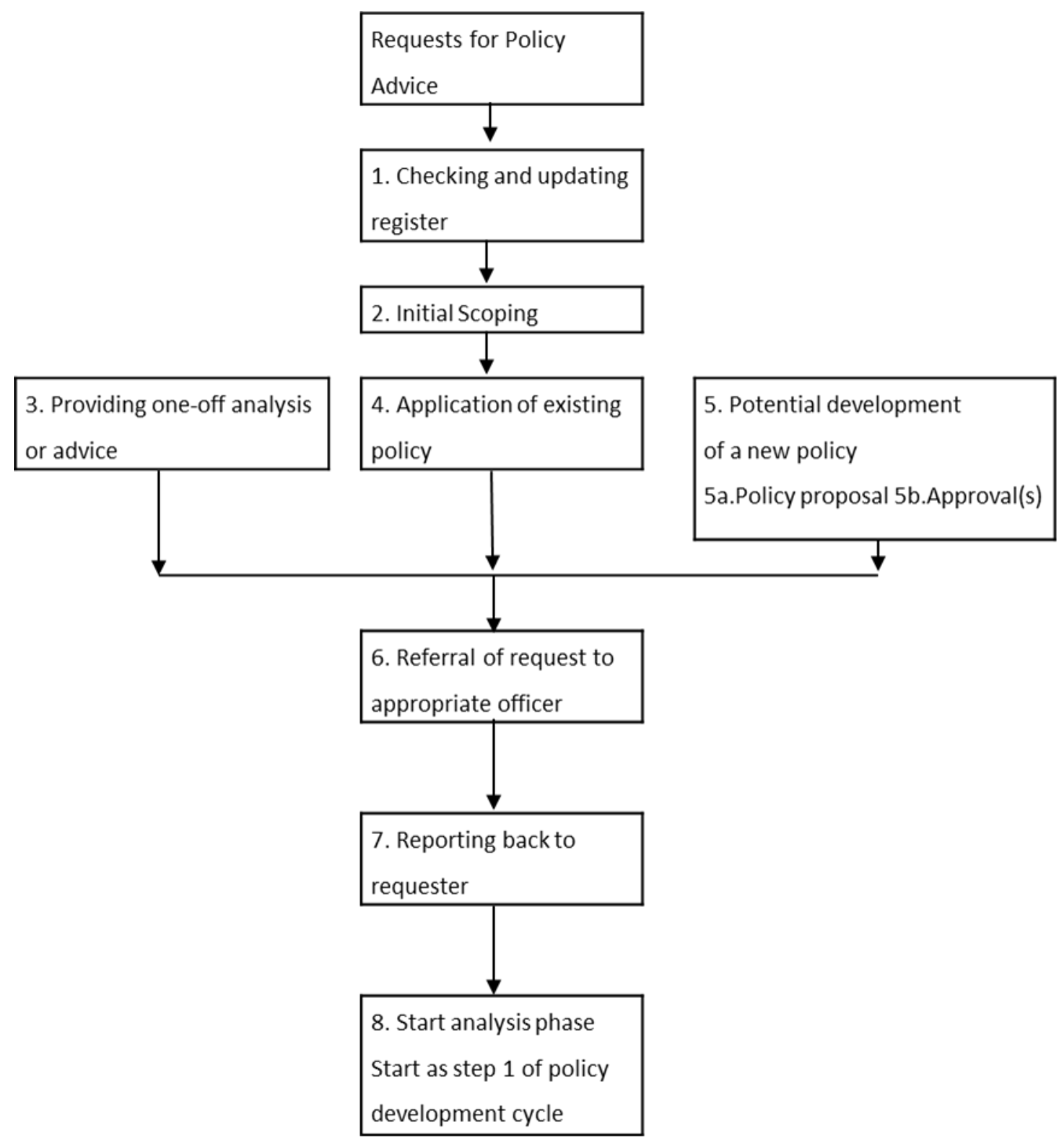

Source: Guide to Providing Quality Policy Advice at Auckland Council (AC, 2013, p. 16)

The senior leader of the AC said that the Policy Register was introduced because it was realised that the council did not have a proper record of what policy advice had developed or had in process. It helped sharing information; gave better control over what advice was being developed or in process; and helped prioritise areas of work (Interview 2). The Policy Hub and the Policy Register were developed to solve the issue of lack of collaboration across the council. 


\section{Peer Review}

Peer reviewing was introduced in the Council to cast extra eyes over the policy advice to get feedback from additional perspectives. This is expressed in the Guide to Providing Quality Policy Advice at Auckland Council as follows:

Peer reviewing involves sharing a draft piece of work with an identified peer reviewer who will offer feedback and suggestions for improvement. Peer reviewing is not proofreading; it is focused on the paper as a whole and represents a debate with the author, focused on improving the advice. (AC, 2013, p. 35).

\section{Recruitment and Selection}

An interviewee in a senior role commented that the council considered the whole issue of recruitment and selection. The $\mathrm{AC}$ developed a set of competencies with which to specify the skills required of recruits for policy advisory roles, testing for example their critical analytical ability and exercise of judgment (Interview 2). The interviewee also mentioned a need to improve both general and specific skills that the council sought for in the applicants (Interview 2).

\section{Work Streams}

The AC had four work streams: Capability and Performance; Guidelines; Tools \& Techniques; and Quality Control. Under the Capability and Performance stream, issues such as defining competencies, recruitment and selection processes, training and development, and performance management roles were addressed. Mentoring of new recruits by experienced policy staff and policy advice networks fell into this stream too. The Guideline stream involved the development of the Guide to Providing Quality Policy Advice at Auckland Council. Under the Tools \& Techniques stream, the AC worked on improving tools and how they were used. The tools included cost benefit analysis and intervention logic. Members of the QPAI team took the lead in this area. Another team was assigned to ensure quality standards under the Quality Control stream (Interview 2). 


\section{Training}

Training was designed for policy staff who were giving advice, and a lot of them needed basic training. The AC set up a new two-day programme on critical thinking. One interviewee, who was the trainer for the programme, said,

We got this consultation. How people think about different issues in the way when we normally think about them, that [could] provide quite pure logic, so they [the $\mathrm{AC}$ ] ran quite creative courses, really teaching policy thinking, but ... not using policy jargon. (Interview 16)

The training was specifically for policy staff, who

... never had that kind of training before and whose professional training was often quite technical in different directions, and to get them to unlock some of their ways of thinking about things and teach them some new ways. (Interview 16)

\section{The Auckland Plan}

The development of the Auckland Plan, a single comprehensive 30-year strategic plan to achieve the 'world's most liveable city', was a response to the need for the Council to focus on the future and strategic matters. In 2012 the AC developed the Auckland Plan, in which it considered six transformational shifts: focusing on the prospects of Auckland's children and young people; committing to environmental action and green growth; bringing public transport within one system; improving the quality of urban living; raising living standards for all Aucklanders, with special focus on those who needed it most; and significantly lifting Maori social and economic wellbeing.

Two big initiatives were The City Centre, a blueprint for a 20-year transformation of the city centre, and the Southern Initiative, which set immediate (five-year), short term (within 10 years), medium term (within 20 years) and long term (within 30 years) action plans addressing high social needs in South Auckland. The development of the Auckland Plan was regarded as a move from planning to action (AC, 2012, p. 16). 


\section{Auckland Unitary Plan}

A key tool, the Auckland Unitary Plan, was developed to implement the Auckland Plan, replacing the district plans and regional policies of the eight former councils. It was seen as 'a rule book for how the AC managed and developed its natural and built environment, outlined where houses and businesses could be built and conditions that applied to certain areas' (AC, 2012, p. 16).

The second section of this thesis has covered the initiatives developed in the three organisations. Why these initiatives were developed has also been examined by showing the drivers behind the initiatives and the expectations of them for contributing to building, improving or maintaining the policy capability of the organisations. The question of why initiatives were developed is discussed further in the following section, along with the consequences of the initiatives.

\subsection{Consequences of the Initiatives}

The understanding of consequences can be nuanced in terms of the interpretation of consequences, results, effects, outputs, outcomes and impacts. Consequences, for this thesis, were understood as the extent of changes in policy practices that took place after the initiatives had been developed, and if and how those changes contributed to building or improving or maintaining the policy capability of the organisations.

The changes covered what information, data and evidence to use and how; the approach to policy analysis; the style of policy work; and guidance and similar factors that influenced the development of policy advice in the three organisations. Improvement in policy capability was gauged by the perceptions of the organisations, internal and external measures of the quality of policy advice, and any available external measures of policy capability.

However, each initiative's contribution to improvement in policy capability could not be separated from their collective contributions. The influence of the initiatives on policy capability was found to be more fluid than discrete. Interviewees identified the 
initiatives as complementary in their effects on their ability to carry out their policy tasks. For instance, training and mentoring were found to complement each other in upgrading individual skills. Overall, building or improving or maintaining policy capability clearly involved learning by policy staff, which might have happened with or without the initiatives and deliberation as such that the contributions of initiatives to policy capability were collective in nature.

To clarify what is meant by consequences in this thesis, when initiatives are considered successful it is the view of the organisation, reflecting its internal and external measures of policy capability and the quality of policy advice that all the initiatives collectively contributed. When a specific initiative is said to be successful, it is the view of the interviewee/s from the specific organisation that the initiatives produced the expected change in policy practice, which was considered important ultimately for policy capability and the quality of policy advice.

The thesis neither attempted to establish any causal relation between the initiatives and the improvement of policy capability or the quality of policy advice, nor did it try to establish the importance of the initiatives from their contribution to policy capability and the quality of policy advice. Rather, it focused on identifying the influential factors and conditions in building or improving policy capability and the quality of policy advice and their complementarity. This established a basis for interpretations in the following chapter in light of the existing literature that bears on the nature of policy analysis and advice in the cases.

The consequences of the initiatives are discussed in the two following sub-sections: changes recognised after the initiatives had been developed, and the contribution of those changes to policy capability and the quality of policy advice. 


\subsubsection{Changes in Policy Practice}

Changes found were related to the process and work style of developing policy advice, change in the behaviour of policy staff towards policy work, standardising of policy work, and greater use of policy guides, frameworks and tools. Changes were also found in the style of leadership in the case organisations.

\section{The MoT}

Following the initiatives, there was more emphasis on feedback and conversations about the quality of policy papers among policy staff (Interviews 3, 9, 6). One interviewee said, 'the feedback is the key piece ... there is feedback, and then there is conversation about the feedback, then there is participation, and then the review panel' (Interview 3). The initiatives were perceived as successful in clarifying expectations and promoting sharing behaviour. Interviewees pointed out that post evaluation of policy papers might not have helped improve the quality of advice at the time it was developed, but it had signalled what 'good' and 'bad' policy advice looked like and developed a shared view of those standards (Interview 3). Sharing and collaboration within the policy team were promoted by rotating members of the internal review panel, which facilitated common understanding and language. One of the interviewees, who was both a recipient and generator of feedback, said,

We seem to have seen quite a marked improvement and certainly spotting and removing errors before it goes and, in some cases, a deliberate course of more evaluative types of features in people's work. (Interview 3)

Changes were also observed by the interviewees in the focus of the agencies, which became more future-oriented. The MoT produced three strategy projects that were focused on the future: Future Demand for Transport (which looks at transport up to 2042), Regulation 2025 and Public Transport 2025 (Interview 5). New policy tools were introduced and used, such as scenario planning exercise methodology which proposed a new way of thinking and helped building policy capability (Interview 5). Although the MoT traditionally had a good reputation for using data (Interview 3), one interviewee thought that the skills of policy staff had improved (Interview 5). 
The initiatives considered to have been successful in the MoT were about improving the skills of policy staff, bringing about changes in the use of policy tools and evidence, promoting collaborative behaviours, and improving quality assurance processes.

\section{The MfE}

Interviewees observed an overall change in the attitude of policy staff towards their work following the initiatives. It seemed expectations from and standard to meet for policy staff became clearer after the introduction of the initiatives. An interviewee commented,

After the policy change project [referring to all the initiatives collectively as a 'change project'], there were clear expectations, clear standards of what good policy advice looked like and so that was most systematic, like an approach (Interview 4).

The behavioural change observed by the interviewees involved fostering collaboration across the directorates. Openness to challenge and sharing ideas were also considered to have been influenced by the initiatives:

We are seeing a more similar cross-ministry approach, more sharing across different directorates. Definite improvement. Compared to a few years ago, there's far more openness to challenge across different areas, just general communications and keep people in the loop, testing ideas with other parts of the building, the ones that haven't been deeply involved in development which is a good way of improving the quality. (Interview 7)

Behavioural changes following the initiatives were also seen across the organisation in the weekly improvement meetings. One interviewee said, We've also seen, through the weekly quality improvement panels, the upfront ones around commissioning, more of different parts of the building being aware of what's going on, what's coming up, and much more people seeking peer review from outside their own area, that sort of things. (Interview 7) 
The culture change was believed to have been driven by five behaviours of the organisations toward its work: Analyse, Engage, Learn, Validate and Collaborate. These five behaviours were outlined in its behavioural framework (Interview 17).

Changes occurred relating to using new policy tools/frameworks. The COBRA and Professionalising Policy guides were developed to standardise the policy work of the agency so that policy staff would excel in producing high-quality policy advice and progress in their careers. Professionalising Policy guides distinguished the knowledge, skills and competencies of positions at different levels of the organisation. More use of evidence in policy analysis was also witnessed by the interviewees. One interviewee said,

We've certainly had a stronger evidence basis for policy, that's being supported by the environmental reporting work and by the information being gathered in the water area [mentioned as an example], so the stronger scientific and stronger evidence basis for the policy. (Interview 7)

\section{The AC}

Regarding changes following the initiatives, one of the interviewees commented that the AC had significantly improved in the use of policy tools and methods to find policy options. In particular, there had been an increase in the use of policy tools such as intervention logic, systematic processes for evaluating options, and cost-benefit analysis. The AC also introduced significant changes into a traditional way of developing policy advice. Training on policy writing was also found quite successful in raising the communication skills of policy staff (Interview 2).

Sharing information across the AC was promoted by the introduction of a Policy Advice Register. The register ensured proper documentation and better control of the advice being developed, what was in the loop or in the process, and the important areas to work on (Interview 2). Resource allocation within the AC had been facilitated by the Policy Commissioning Process. The Policy Hub was termed the most successful initiative because the policy community can go to the hub to understand the policy process, standards and measures (Interviews 2, 19). 
Behavioural change in policy staff was witnessed by these interviewees. One remarked that policy staff in the $\mathrm{AC}$ realised the importance of raising the quality of policy advice, and it was picked up by other staff of the AC (Interview 2). The inclusion of raising the quality of policy advice as a key performance deliverable in the performance agreement between the $A C$ and its $C E$ indicates the emphasis placed on this improvement by the organisation (Interviews 2, 19).

\subsubsection{Contribution of Changes to Policy Capability}

\section{The MoT}

A senior leader of the MoT considered the initiatives successful in improving the overall quality of policy advice:

The organisation over this time has increased its perceived score. So, we had NZIER score which were relatively low and I think we've gone from bottom four to top four over four years [referring to 2012-2015]. (Interview 9)

A similar view was expressed by another interviewee:

We got 7.6 and we were ranked in the top four in the public sector by the NZIER, so it was quite a journey from being in the middle of the class to be near the top and it was from a deliberate approach of upping up our game. (Interview 15)

The responses from the MoT interviewees indicated overall that the MoT's initiatives were perceived as successful in improving the policy capability of the agency and the quality of the policy advice produced.

\section{The MfE}

A senior leader from the MfE responded, I think they [the initiatives taken in the MfE] did ... if you look at the reforms once and what the departments actually produced, I think, it was successful. (Interview 17) 
The interviewee, however, mentioned that the results were achieved at a slower pace than expected. Another interviewee explained that the bar was raised and the quality of advice also improved:

I really think the bar [for the quality of policy advice] got higher rather than lower, that's one bit. The second bit was seeing the growth and improving in the quality scores. (Interview 1)

Another interviewee opined,

I think the results that were successful are probably for two main reasons: setting clear expectations [from policy analysis and advice] and standard [for the quality of policy advice]. (Interview 4)

The responses were consistent enough to imply that the MfE's initiatives were perceived as successful in improving the policy capability of the agency and the quality of the policy advice it produced. Specifically, the initiatives were considered successful in bringing about supportive changes in the process of developing policy advice, promoting behaviours to drive cultural change within the organisation, and improving policy analytical capability by the use of policy tools and evidence.

\section{The AC}

The overall impression of the consequences of the initiatives was called 'underwhelming' by the senior leader who was responsible for raising the quality of policy advice produced in the AC. This leader pointed out that the NZIER score raised the organisation only to $17^{\text {th }}$ out of 19 organisations from $18^{\text {th, }}$ even after several initiatives had taken place. The point was reinforced by restating a comment from the NZIER evaluator, 'What the NZIER said is that they thought that we [The AC] have improved and we fixed the spelling mistakes' (Interview 2). That is, the NZIER did not see much difference the second time round compared with what they found previously in assessing the quality of policy papers (Interview 2).

The overall responses from the $A C^{\prime}$ 's interviewees indicated that the $A C^{\prime}$ 's initiatives were not perceived to be as successful as expected in improving the policy capability of the agency and the quality of its policy advice. However, some of the initiatives were 
considered successful in demonstrating the importance that the organisation was placing on raising policy capability and the quality of policy advice. Initiatives had helped bring about changes in the use of policy tools and evidence in policy analysis, and promoted collaborative behaviours and better resource allocation.

While the interviewees from the MoT and MfE were found to be confident, the interviewees from the $\mathrm{AC}$ seemed unsure about the consequences of the initiatives for policy capability and the quality of policy advice.

\subsection{Summary of the Cases}

The MoT's initiatives were mainly challenge driven. The MoT had been restructuring and reshaping itself to become a policy-focused ministry over time. Although this resulted in less financial and people resources being available to it, the policy performance expectations from the MoT grew over time. Along with this challenge, the Ministry needed to continue responding to the changing environment of the transport sector due to innovation in technology and other such factors. The ministry, therefore, invested in ensuring efficiency in delivering policy advice to the client.

The initiatives were also influenced by the ministry's public reputation. The PIF Review suggested that the organisation needed to focus more on the future demand from the transport sector and create strategies to meet them. This required adopting strategic initiatives to build maintainable policy capability in the organisation. Reflecting on the PIF review, a senior leader summarised:

We [the MoT] need to take a more strategic look because if [we] are here to deliver the best thing in New Zealand, [we] could have been looking ahead and understand what the issues are and what the opportunities are. So, out of the PIF review, we started a strategic programme. (Interview 9)

Another interviewee from the MoT mentioned that the creation of a strategic directorate was a result of the PIF review in 2012 (Interview 5). 
The widely known poor NZIER rating in 2012 for its policy papers was another influence for adopting initiatives, although a senior leader mentioned that the PIF Review in 2012 concluded that the MoT was 'pretty good' at developing policy advice. Portraying the higher NZIER rating in 2015 as the consequence of the initiatives developed and a measure of improvement in quality of policy advice implied that it was logical to see the poor NZIER rating in 2012 as an influencer for taking initiatives.

As a response to the challenges and to improve its reputation, the Ministry focused on improving and/or maintaining the policy capability of the organisation by introducing changes. The changes were catalysed by the new leadership team. The senior leaders promoted changes, developing a whole-system approach in the organisation with a range of initiatives. The changes introduced a new professional services model to respond quickly and flexibly to the government's policy requirements; created a dedicated team responsible for strategic direction and performance; upgraded the skills of policy staff by improving selection processes, training, coaching and mentoring; introduced new policy tools; developed frameworks to guide policy work; promoted collaboration and the use of evidence in policy analysis; and improved the policy advice assurance process.

The focus of the initiatives, however, was on promoting learning by policy staff from all the possible sources, which included experienced internal, external, local and international policy experts, formal education and training in theories of policy development and practice, peer review, feedback, knowledge management, and buddy systems. The senior leaders played a vital role in promoting the changes in the organisation that they considered important. The consequences of the initiatives were perceived as successful. The organisation judged success by the higher NZIER rating after the initiatives had been developed, the production of several future-focused policy outputs and strategic documents, and the replication from the UK of one of the MoT's policy tools, a scenario planning exercise.

Thus, the drivers, forms, design and approach of the MoT's initiatives to improve policy capability and policy advice were influenced by the challenges it faced, the reputation it 
had, the changes it drove in the organisation, and the role of the senior leaders in responding to expectations.

\section{The MfE}

Initiatives in the MfE were mainly reform driven. When the new ELT took over responsibility in 2008, it found the MfE's mission was not aligned with the government's expectations of the organisation. There was lack of clarity about the expectations from policy work, and a lack of policy skills among policy staff. The ELT rebuilt the organisation by changing the mission, structure and people of the organisation to meet the expected stewardship role for the environment.

The initiatives were also influenced by the organisation's reputation. Most of the interviewees, without hesitation, recognised that the reputation of the MfE as a ministry was quite poor when the new ELT took over in 2008. They mentioned the resignations of the minister and the CE as the evidences of this. A very senior leader commented: The organisation was going through a very hard time. So, it was actually a very bad time, and I came into it because it lost its chief executive. He had to resign, his minister had resigned, and its budget had just been slashed by $25 \%$. Its people were in state of chaos and the analytical competency of the organisation was very, very low. (Interview 17)

Asked whether the reputation of the MfE as described in the PIF review influenced the initiatives, most of the interviewees gave negative responses. One of the senior leaders from the MfE said,

No, not much. Because I was probably ahead of the curve to be honest with you. In fact, I think some of the things we did in Environment probably influenced what happened there [referring to the central agencies which introduced the PIF] to be quite honest. (Interview 17)

The same interviewee drew attention of the timeline of the PIF and MfE's initiatives to indicate that the most of the MfE's initiatives were initiated in 2008 and 2009, before the introduction of the PIF in $2009 / 10$. Initiatives such as the policy guides, however, 
were developed in 2012. The timeline makes it clear that some of the MfE's initiatives were not influenced by the PIF review.

Nevertheless, some of the initiatives introduced after the PIF Review were likely to be influenced by the PIF Review's comments and suggestions. One interviewee expressed a strong opinion in favour of the PIF as an influencer:

Strong but indirect. The last PIF review for example for the MfE led directly to something like the appointment of the principal analyst cohort, for example, as thought leaders, and bringing more expertise to the ministry. It also, and was reinforced by the internal review, led directly to the development of the Outcomes Framework. And the analytical framework that preceded it. So, that's just a couple of examples on how we [the MfE] have directly responded to that. I think also the restructuring of the organisation a few years ago more around, end-to-end delivery. So, for example, Water Directorate includes everything from the science through to the policy development. The implementation with the council and monitoring review are in one directorate. So, that was a new operating model that we applied in several parts of the organisation. So the operating model, the analytical framework, the Outcomes Framework, the principal analyst group all those could be directly tied back to the PIF review. (Interview 7)

As a response to identified weaknesses, challenges and reputation, the Ministry brought in massive changes in the organisation. The ELT focused on building the policy capability of the organisation with a range of initiatives. It continuously restructured the organisation; replaced policy staff with new recruits with the skills that the MfE was seeking, using an improved selection and recruitment process; upgraded the skills of policy staff by training, coaching and mentoring; provided guidance for policy work; displayed the behaviours required to craft policy analysis; and ensured the quality of policy advice assurance process with an internal panel for quality checking, peer review and feedback. 
The role of the senior leaders in designing and shaping the initiatives and responding to expectations were the main features of the MfE's initiatives. The MfE recognised the importance of the leadership role in improving the quality of policy advice. It, therefore, allowed sufficient time to recruit a cohort of thought leaders. The cohort of thought leaders aimed to convey the demand for high-quality policy analysis and advice to the junior staff. The cohort clarified the roles of policy staff at different levels, provided guidance to standardise policy work, and showed how to craft policy analysis. It also emphasised communicating the behaviours required to become successful in policy work. The continuous restructuring of the organisation to meet its own needs and those of the central agency and sector indicated the MfE's responsiveness to the expectations.

The consequences of the initiatives were perceived to be successful. The organisation judged success by the appreciation of the public sector of the policy guides it produced, the comments from its client about its policy work and the leading role of the NRS.

The drivers, forms, designs and approach of the MfE's initiatives to build policy capability and the quality of policy advice were influenced by the challenges it faced, the reputation it had while adopting the initiatives, the weaknesses it identified, the use of crisis to drive the necessary changes in the organisation, and the significant role of the senior leaders to respond to the expectations.

\section{The AC}

The initiatives in the $A C$ were reform and reputation driven. The creation of the $A C$ as a unitary council challenged the newly formed organisation to respond to increased expectations. The expectations were not about effective service delivery but about big policy issues focused on the future of Auckland as a liveable city. This necessitated a stocktake of the policy capability of the Council to identify areas for intervention. The AC sent its policy papers to the NZIER to understand its relative position in the public sector and came at the bottom of the ratings. This motivated the $A C$ to consider the quality of policy advice more thoroughly and comprehensively. 
In response to the challenges and to improve its reputation, the AC focused on building the policy capability of the newly formed council. The QPAI was launched to set up the expectations for policy analysis and advice, and for its presentation. It tried to streamline the commissioning process, ensure the availability of resources through the Policy Hub and Policy Register, and facilitate receiving feedback from peer review of policy advice. It also emphasised improving the selection and recruitment process to draw skilled policy staff into the organisation, and training to raise the skills of current and new policy staff.

The overall purpose of the initiatives was to promote a new culture and work style. The focus of the initiatives was to introduce in the council the policy practices that are seen in government agencies. The emphasis was on setting up expectations of policy work, clarifying the roles of policy staff, establishing protocols in the organisation, and quality assurance processes for policy advice. The consequences of the initiatives were perceived as unsuccessful. The organisation judged this failure by the unchanged NZIER rating after the initiatives had been developed.

The drivers, forms, design and approach of the AC's initiatives to build policy capability and the quality of policy advice were influenced by the challenges it faced, the reputation it had while adopting the initiatives, the known policy capability issues and the changes it wanted to see in the organisation. A mapping of different issues across the cases is shown in Table 6.7.

Table 6.7: Mapping of Different Issues across the Cases

\begin{tabular}{|l|l|l|l|}
\hline & MoT & MfE & AC \\
\hline $\begin{array}{l}\text { Type of } \\
\text { Organisation }\end{array}$ & $\begin{array}{l}\text { A small policy ministry } \\
\text { responsible for providing } \\
\text { advice on transport } \\
\text { matters with minimal } \\
\text { operational duties }\end{array}$ & $\begin{array}{l}\text { A large ministry responsible } \\
\text { for providing expert advice } \\
\text { on environmental matters, } \\
\text { often co-producing advice } \\
\text { with other ministries in the } \\
\text { sector }\end{array}$ & $\begin{array}{l}\text { A local government } \\
\text { unitary council mostly } \\
\text { focused on service- } \\
\text { delivery and limited } \\
\text { strategic policies, with } \\
\text { semi-skilled policy } \\
\text { advisors }\end{array}$ \\
\hline Client/Audience & $\begin{array}{l}\text { One powerful minister } \\
\text { enabling quick decisions }\end{array}$ & $\begin{array}{l}\text { Several ministers/clients } \\
\text { having different expectations }\end{array}$ & $\begin{array}{l}\text { The mayor and the } \\
\text { councillors }\end{array}$ \\
\hline
\end{tabular}




\begin{tabular}{|c|c|c|c|}
\hline & MoT & MfE & AC \\
\hline $\begin{array}{l}\text { Crucial Success } \\
\text { Factors for the } \\
\text { Organisation }\end{array}$ & $\begin{array}{l}\text { Being responsive to the } \\
\text { changing environment in } \\
\text { transport sector, and } \\
\text { preparing to meet } \\
\text { foreseeable future } \\
\text { demand }\end{array}$ & $\begin{array}{l}\text { Being able to address wicked } \\
\text { environmental issues and } \\
\text { managing collaborative work } \\
\text { with other ministries in the } \\
\text { sector }\end{array}$ & $\begin{array}{l}\text { Being able to make } \\
\text { and implement } \\
\text { decisions that are } \\
\text { future focused and } \\
\text { strategic along with } \\
\text { effective delivery of } \\
\text { services }\end{array}$ \\
\hline $\begin{array}{l}\text { Policy Capability } \\
\text { Before initiatives }\end{array}$ & $\begin{array}{l}\text { 'Good' in providing high } \\
\text { quality policy advice but } \\
\text { not future-focused } \\
\text { (comments from the PIF } \\
\text { review) }\end{array}$ & $\begin{array}{l}\text { Lack of understanding of } \\
\text { policy staff regarding their } \\
\text { own role and policy practices } \\
\text { which led to an inappropriate } \\
\text { focus for the organisation }\end{array}$ & $\begin{array}{l}\text { Lack of understanding } \\
\text { of policy advice, } \\
\text { practices and } \\
\text { processes, along with } \\
\text { role confusion }\end{array}$ \\
\hline $\begin{array}{l}\text { Policy Capability } \\
\text { After initiatives }\end{array}$ & $\begin{array}{l}\text { Improved. } \\
\text { Judged by the move } \\
\text { towards a higher NZIER } \\
\text { rating }\end{array}$ & $\begin{array}{l}\text { Improved. } \\
\text { Judged by the enhanced } \\
\text { reputation in the policy } \\
\text { market mirrored from } \\
\text { leading the NRS sector and } \\
\text { attracting the approval of the } \\
\text { New Zealand public sector } \\
\text { and academics with its policy } \\
\text { guide }\end{array}$ & $\begin{array}{l}\text { Unchanged. } \\
\text { Judged by the nearly } \\
\text { unchanged NZIER } \\
\text { rating. }\end{array}$ \\
\hline $\begin{array}{l}\text { Constraints/ } \\
\text { Challenges }\end{array}$ & $\begin{array}{l}\text { Two challenges: resource } \\
\text { cuts and increased } \\
\text { expectations of } \\
\text { deliverables }\end{array}$ & $\begin{array}{l}\text { Three challenges: dealing } \\
\text { with wicked problems; } \\
\text { meeting diverse expectations } \\
\text { from several } \\
\text { ministers/clients; and the } \\
\text { influence of historically poor } \\
\text { collaboration }\end{array}$ & $\begin{array}{l}\text { A mix of challenges: } \\
\text { poor policy } \\
\text { understanding and } \\
\text { practices; diverse } \\
\text { interest groups } \\
\text { influencing the } \\
\text { decisions; and the } \\
\text { tensions among these } \\
\text { parties }\end{array}$ \\
\hline $\begin{array}{l}\text { Main Drivers of } \\
\text { the Initiatives }\end{array}$ & $\begin{array}{l}\text { Publicly expressed } \\
\text { (NZIER rating) low } \\
\text { reputation along with } \\
\text { increased demand and } \\
\text { resource cuts. Overall, } \\
\text { Initiatives were } \\
\text { challenge driven }\end{array}$ & $\begin{array}{l}\text { Known poor policy capability, } \\
\text { resulting in the organisation } \\
\text { failing to meet expectations. } \\
\text { Overall, initiatives were } \\
\text { reform driven }\end{array}$ & $\begin{array}{l}\text { Very poor reputation } \\
\text { (the lowest NZIER } \\
\text { rating) and } \\
\text { responding to new } \\
\text { expectations from a } \\
\text { newly formed unitary } \\
\text { council. Overall, } \\
\text { reform driven }\end{array}$ \\
\hline $\begin{array}{l}\text { Forms and } \\
\text { Designs of the } \\
\text { Initiatives }\end{array}$ & \multicolumn{3}{|c|}{ Discussed in detail in this chapter } \\
\hline $\begin{array}{l}\text { Approach of } \\
\text { The Initiatives }\end{array}$ & $\begin{array}{l}\text { Enhancing efficiency with } \\
\text { emphasis on learning } \\
\text { from initiatives including } \\
\text { learning from different } \\
\text { sources, personnel, } \\
\text { linking with academics. } \\
\text { Also, a new flexible and } \\
\text { responsive work style }\end{array}$ & $\begin{array}{l}\text { Focusing on guidance from } \\
\text { senior leaders to change the } \\
\text { inherited organisational } \\
\text { culture by introducing policy } \\
\text { guides, coaching and } \\
\text { mentoring. }\end{array}$ & $\begin{array}{l}\text { Borrowing initiatives } \\
\text { from the central } \\
\text { agencies to rebuild } \\
\text { the policy capability in } \\
\text { the Council }\end{array}$ \\
\hline
\end{tabular}

Source: Adapted from the three Case Studies 


\subsection{Summary of the Findings}

There was a pattern in the drivers for the initiatives across the cases. All three organisations were challenged to either build or improve policy capability so that the policy advice could meet the quality expectations of the clients. The MoT was required to improve policy capability under resource constraints, the MfE to reform due to poor policy capability, and the AC to build policy capability because of its absence in the agency. The reputation of all the three organisations was questionable and publicly known either from NZIER ratings or PIF reviews or perceptions in the policy market.

But the purpose of the initiatives varied across the cases. The purpose of the initiatives of the MoT was to improve or maintain policy capability, the MfE to rebuild it and the AC to build it up. The initiatives, however, were similar in their forms and intervention areas. The initiators intended to create the demand for high-quality policy analysis and advice in the organisations by setting high-expectations from policy analysis and advice. They focused on improving policy inputs that included the development and use of new and innovative policy tools; providing explicit guidance; and upgrading the skill level of policy staff by recruiting the best from the market, training, coaching and mentoring. The initiatives such as peer review, feedback and a quality assurance process across the cases were considered important means to improve the quality of policy analysis and advice. The initiatives were introduced to each agency as a package, a combination of different initiatives that sought to influence the constituents of policy capability and the quality of policy advice.

Despite the similarities of the initiatives in their forms, the approaches of the initiatives varied as to how the organisations designed the initiatives and their areas of emphasis. The MoT put emphasis on learning with a range of initiatives design to promote learning; the MfE on starting afresh by altering, replacing and upgrading the constituents of policy capability with special attention to behaviour, communication and consultation; and the AC on intervening to address the identified policy capability issues of the Council by borrowing initiatives from other government agencies to fix its reputation as expressed in its NZIER rating. 
All the approaches used change as a means of either building or rebuilding or maintaining or improving the policy capability of the organisations. But how the change was applied varied according to the role of the senior leaders. The role of the senior leaders was an important factor in shaping the initiatives and achieving perceived success.

The perceived consequences of the initiatives on policy capability were different. While the initiatives in the MfE and MoT were perceived as successful, the perceived consequences of the AC's initiatives did not meet its expectations.

A similar but wide range of initiatives to improve, maintain or build policy capability with different approaches implies two things. The agencies' efforts to improve policy capability were based on similar understanding on how to improve the quality of policy analysis and advice as their efforts did not vary much either to build or maintain or improve policy capability. Second, the differences in the initiators' approaches are attributable to the initiators' appreciation of contextual conditions. The contextual influences are outlined in the following chapter.

The focus in this chapter was on the initiatives: the forms, design, and approach of the initiatives. It has also shown the drivers behind and the consequences of the initiatives, as perceived by the interviewees. The discussion of the initiatives, overall, has shown how the MoT, MfE and AC tried to change policy practices to professionalise policy analysis and advice. Since the discussion of why connects the discussion of the organisations' actions, expectations, and the consequences of the actions, it is continued in the following chapter, which explains the choice and use of these three agencies' initiatives, followed by conclusions. 


\section{CHAPTER 7: The Choice and Use of Agency Driven Initiatives}

\subsection{Introduction}

This chapter explores the choices and use of the agency initiatives. The guiding question is: why did the initiators choose initiatives in a specific way or, in other words, what influenced their choices of initiatives? The three case study agencies, the Ministry of Transport (MoT), the Ministry for the Environment (MfE) and the Auckland Council (AC), developed a range of initiatives to professionalise policy analysis and advice. The choice of initiatives and related organisational changes are part of an organisational strategy which reflects the organisational and management capability of the three agencies.

Chapter 7 has three sections, designed to explain the purpose, design and forms of the initiatives and their uses (as set out in Chapter 6) in light of the literature on policy analysis and policy capability. The agencies' efforts to professionalise policy analytical capability is shown in the first section, with attention to the four constituents: knowledge, skills, competencies, and behaviours. Policy management capability efforts of the three case organisations at individual and organisation levels are presented in the second section. The influences on policy practices in the three case organisations are outlined and analysed to consider how the different contexts influenced the three agencies' strategies to professionalise policy analytical and management capability and including explanations as to why the initiators designed initiatives in a specific way.

Initiators were the leadership teams of the MoT and the MfE (comprising chief executives and senior policy managers) and at the AC, the senior leaders and the Mayor. In addition, some agency initiatives were developed to respond to central agency initiatives, such as the Performance Improvement Framework (PIF). In such instances, the initiatives implemented by senior managers were influenced by the guidance and suggestions provided by external sources.

\subsection{Policy Analytical Capability}

The three agencies' use of concepts and strategies to improve policy analytical capability is similar to those presented in both academic and practitioner literature, which have 
been reflected in central agencies' initiatives. Some of concepts and 'good practice' principles can be sourced to both academic and practitioner literature that are widely promulgated by both academic and practitioner literature, as summarized in Chapter 2 . Some examples include: 'Good process is likely to produce good quality policy output'; 'the quality of policy inputs is essential in improving the quality of policy advice'; 'the solution to policy problems requires a systematic approach'; 'crafting skills requires the use of appropriate tools and methods from a policy toolbox'; and 'knowledge of policy substance is important'. These concepts are reflected in the initiatives developed to improve policy analytical capability of policy staff. A strongly held view used is that: the quality of policy analysis underpins high-quality policy advice.

The three case organisations supported policy staff to acquire further knowledge and skills of policy substance from both formal and informal training and guidance. Training, guidance, and peer review showed how to select and apply appropriate models, tools and frameworks and analytical techniques. These activities helped policy staff to gain the competencies needed to successfully acquire and apply knowledge and skills to their tasks by using appropriate tools and frameworks. Behavioural frameworks and/or high expectations of policy analysis and advice encouraged the policy producers to practice the behaviours that improve the rigour of analysis and promote collaboration within and across agencies. Summarised case findings on policy analytical capability efforts in the three cases are presented in Table 7.1.

Existing guidelines, as well as academic recommendations, cannot fully inform the efforts of policy staff to achieve policy analytical capability. To identify how recommendations to improve policy analytical capability in the literature are similar or different from the efforts undertaken in these three case agencies, agency activities, centred on the development and use of the initiatives, need to be mapped against the literature. 
Table 7.1: Policy Analytical Capability Efforts in the Three Cases

\begin{tabular}{|c|c|c|c|c|}
\hline \multicolumn{5}{|c|}{ Policy Analytical Capability } \\
\hline & $\begin{array}{l}\text { Acquiring } \\
\text { knowledge }\end{array}$ & $\begin{array}{l}\text { Improving skills } \\
\text { by learning }\end{array}$ & $\begin{array}{l}\text { Gaining } \\
\text { Competences }\end{array}$ & $\begin{array}{l}\text { Practicing } \\
\text { required } \\
\text { behaviours }\end{array}$ \\
\hline 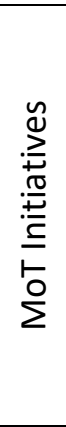 & $\begin{array}{l}\text { Formal training with } \\
\text { the a-PAD } \\
\text { programme; } \\
\text { Formal in-house } \\
\text { training; } \\
\text { Induction course }\end{array}$ & $\begin{array}{l}\text { Buddies; } \\
\text { Mentoring and } \\
\text { coaching; } \\
\text { Feedback and } \\
\text { peer reviews }\end{array}$ & $\begin{array}{l}\text { Use of external } \\
\text { Expertise; } \\
\text { Use of internal } \\
\text { expertise; } \\
\text { Use of knowledge } \\
\text { team; } \\
\text { Use of evidence, tool, } \\
\text { frameworks, and best } \\
\text { practices }\end{array}$ & $\begin{array}{l}\text { Working within } \\
\text { the expected } \\
\text { behavioural } \\
\text { framework; } \\
\text { Maintaining good } \\
\text { working relations }\end{array}$ \\
\hline 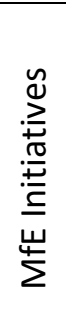 & $\begin{array}{l}\text { Formal professional } \\
\text { course with the } \\
\text { SOG; In-house } \\
\text { formal training } \\
\text { programme; In- } \\
\text { house policy } \\
\text { courses }\end{array}$ & $\begin{array}{l}\text { Mentoring and } \\
\text { coaching; } \\
\text { Feedback; } \\
\text { peer review; } \\
\text { support from } \\
\text { policy manager }\end{array}$ & $\begin{array}{l}\text { Use of Internal and } \\
\text { external expertise; } \\
\text { Use of policy guides, } \\
\text { frameworks. }\end{array}$ & $\begin{array}{l}\text { Working within } \\
\text { the expected } \\
\text { behavioural } \\
\text { framework }\end{array}$ \\
\hline 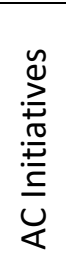 & $\begin{array}{l}\text { Training and } \\
\text { Development }\end{array}$ & Mentoring & Use of policy tools & $\begin{array}{l}\text { Promoting } \\
\text { behaviours for } \\
\text { collaboration and } \\
\text { engagement }\end{array}$ \\
\hline
\end{tabular}

Source: Adapted from the three Case Studies

\subsubsection{Acquiring Knowledge}

The literature clearly indicates that knowledge of policy substance is essential for policy analysis and advising (Colebatch, 2002; Dunn, 2004; Knoepfel, Larrue, Varone, \& Hill, 2007; Parsons, 1995; Thissen \& Walker, 2013). Policy analysts need to know about theories of policy process (Birkland, 2001; Hill, 2005; Sabatier, 2007), how to do policy analysis (Bardach, 2012; Mintrom, 2012), what to include as policy inputs, how to use policy tools and frameworks and how to ensure the use and quality of evidence in policy analysis (Head, 2008; S. Nutley, Walter, \& Davies, 2009) and related factors. Overall, knowledge of policy substance answers the question: what needs to be known to 'effectively' produce policy analysis and advice? 
However, it is difficult to pre-determine the type of knowledge that policy analysts require to do policy analysis. In practice, knowledge on policy substance is developed as individuals improve their knowledge through experience as practitioners working on particular substantive issues. Thus, although there is a vast amount of academic and practitioner literature that proffers guidance on policy knowledge (key examples include Bardach (2012) and other such process-based heuristic models), some practical considerations of doing policy analysis are poorly captured. These omissions include bringing government, political and clients' priorities and requirements into consideration.

There are many reasons. First, policy analysis is a field of practice that draws on knowledge from different disciplines which make it difficult to clearly define the boundary for knowledge of policy substance. Second, unlike some other professions, doing policy analysis and advice is not usually an independent individual activity. Rather, it is common to find teams comprising staff with various levels of proficiency and expertise, generalists, subject-specialists, scientists, economists, advocates, statisticians, political scientists with different backgrounds who bring in multiple perspectives and views in producing policy analysis. All these factors make it complicated to identify in advance the kinds of knowledge that will be crucial for policy analysis and advice.

Moreover, the focus of policy knowledge and the role of analysis in the policy process in theory are also different from what is required in practice. The academic literature places heavy emphasis on policy stages and processes (Althaus et al., 2007; Bardach, 2012; Mintrom, 2003), even though these writers acknowledge that stages are simply a device for presenting what is in practice a messier, more iterative process. The literature presents characterisations of policy institutions, policy actors and actors' use of policy tools, policy models and frameworks, and evidence that generalise across many cases, and hence match none in actual practice.

Furthermore, organisation leaders recognise policy development as a social process, which involves intangible factors that derive in part from the personality of policy staff. Several relational interfaces have significant roles to play in developing policy analysis 
and advice. How generalists and subject-specialists/technocrats/scientists interact and integrate their similar or differing views has significant influence on policy analysis and advice. Yet the literature is concentrated on aiding 'generalists' only, and less focused on how personnel with technical know-how can be more 'effectively' engaged in policy analysis and advice.

Despite the generic treatment of the acquisition of substantive policy knowledge featured in the literature, the three agencies relied significantly on learning from theory, academic curricula and formal in-house training. The MoT provided formal training to new recruits with the applied Policy Advisor Development (a-PAD) programme, formal in-house training and induction course. The MfE ran formal professional course with the School of Government (SOG); in-house formal training programme and in-house policy courses, while the $\mathrm{AC}$ provided in-house training and development.

However, the three agencies demonstrated, by their choices and approach to designing formal training, that there was always a need for customising the academic programmes to suit the agency's context and requirements. Both the MoT and MfE made special arrangements with the academic institution, the VUW, to run tailored professional courses for their policy staff in which agency-specific capabilities and skills were taken into considerations to design the programme. The MoT's formal in-house training and induction course and the MfE's in-house formal training programme and policy courses (run by the experts external to the agencies) were also tailored to suit the needs of each agency. The AC also customised its training modules to develop the core capabilities required to lift policy performance and in some cases specialist knowledge and a more strategic outlook on their work programmes was introduced.

The demand for type and application of policy knowledge varied across the cases and hence agencies tailored the academic programme and formal in-house training to suit their needs. The MoT focused on developing strategic policies using forecasts of future demand from the transport sector. Activities included looking at the future of electric cars and appointing a strategic director. This futures attention was MoT's response to the comments made in the PIF review. The MoT tailored the programme to include 
further learning about policy tools and frameworks to develop forecasting skills. The agency was expected to develop and communicate with other actors and institutions in the transport sector. This led to seminars and presentations with key sector leaders. The PIF also makes an assessment about how agencies engage and communicate with key stakeholders and important actors and institutions in the transport sector. The MfE deals with environmental problems which are complex and wicked in nature. Developing knowledge and skills to deal with wicked problems was of more interest to the MfE than to the other agencies. The AC was at the stage of introducing policy practices in the Council for the first time and their training programme, therefore, presented the fundamental principles of policy process, including such fundamentals as the nature of policy advice.

The commonality in interest to learn from theory and practice and the similarity in approaches with tailored programmes to gain value from academic and practitioner knowledge imply that these agencies considered formal academic programmes and training as an important avenue to learning. But the learning was most effective when it was tailored to meet agency-specific requirements.

\subsubsection{Improving Skills by Learning}

The specification of policy skills is sufficiently clear in the literature and in practice. The skills sought in policy staff are reflected in job advertisements, recruiting agencies' websites, and public-sector organisations' career pages. The identified skills can be broadly categorised into two groups: the ability to ensure the rigour of policy analysis to develop policy advice for clients and the ability to effectively communicate the advice to the clients, as also pointed out by theories related to policy analysis. The case studies also identified a similar set of in-demand policy skills for policy staff, shown in Chapter 6 .

Improving the skills of policy staff in these organisations involved both formal and informal training, guidance from experienced to less-experienced policy staff through sharing work experience, learning-by-doing, coaching, mentoring, providing feedback and peer reviews. Overall, the organisations supported staff so that they could gain an 
understanding of basic policy skills from formal academic programme and training and then tailor their skills to suit the organisational requirements through in-house activities. The senior leaders of the organisations also paid attention not only to support improving individual analytic skills but also to utilizing the skills to yield expected results rather than their mere presence in policy staff.

Several factors influenced the use and application of policy skills. The demand for and supply of policy skills played significant roles in this regard. In the perspective of a supply and demand approach to policy analysis, the level of policy analysis depends on 'the extent to which policy analysis is demanded by state actors as well as on the degree to which the elements needed to supply it are present' (Mendez \& Laguna-Dussauge, 2017, p. 73). Mendez and Laguna-Dussauge (2017), following Howlett (2015) and Weimer (2015), developed a supply-demand matrix of governmental policy analysis which showed that a higher level of analysis is associated with high-levels of both the demand for and supply of policy analysis. These experts have classified most Western European nations, the United States and Canada, Australia and New Zealand and some East Asian countries as developing high-level policy analysis.

\section{The Demand for Policy Skills}

The demand for policy analysis at system level is referred to as the requirement for research (Riddell, 1998) by state actors in which it 'emphasises the issue of the quality of the research demanded and not just its quantity' (Howlett, 2015, p. 176). The demandside factors identified by scholars are the type of political regime, the level of bureaucratic development (Mendez \& Laguna-Dussauge, 2017) and a culture in which openness is encouraged and risk-taking is acceptable (Riddell, 1998).

Similarly, the demand for policy skills at the organisation level in these cases is recognised by the senior leaders' quality expectations from policy analysis and advice, rather than by the quantity or research or the work culture in which research is practised. Openness and risk-taking are accepted and promoted, particularly in the MoT and MfE. 
The MoT's internal panel for 'quality' conveyed the demand for policy skills. The internal panel assessed the quality of policy papers produced, post-evaluated the policy papers, provided feedback on those and demonstrated the shared views on the examples of 'good' and 'bad' policy advice. Thus, the internal panel tried to ensure less variation regarding the quality of policy advice across policy teams within the organisation. The panel aimed for a particular standard for policy analysis and advice that the MoT staff were required to attain. The involvement of policy staff at senior level to teach, train, coach and guide the less-experienced policy staff was implemented so as to communicate the high demand for the use and application of specific skills.

The MfE had a similar approach with its internal panel for quality assurance and the Regulatory Impact Statement panel which provided feedback. These initiatives, in addition to achieving the target objectives, clearly communicated to policy staff that high-level skills were required and must be applied when undertaking policy analysis and advice. The termination of 'not so fit for purpose' policy staff was a clear indicator that only those with high policy skills would survive in the organisation.

In contrast, the AC suffered from the lack of demand for policy skills. It was partly because there was little focus on the policy advisory functions. The other reason was the culture and tradition of the council was to undertake planning, not to make policies. For these reasons, the top management could not generate a high demand for policy skills (see section 6.2.3). The low demand for policy skills in the AC did not seem supportive of the optimal utilisation of the skills, whereas the high demand was supportive of the application and use of skills in the MoT and MfE.

\section{The Supply of Policy Skills}

Mendez and Laguna-Dussauge (2017) considered the availability of quality data and information and the existence of study programmes on public policy as well as in related disciplines such as economics, public administration and political science as two supply side factors at system level. At the organisation level, the supply of policy skills in these cases is recognised by the availability of skilful policy staff equipped with academic 
education and formal and informal training to make use of available quality data and information and not by the mere presence of resources.

There is a limited supply of skilful policy staff both by 'quantity' and 'quality'. The limited supply of people with desired policy skills influenced how these three organisations made choices to improve policy analytical capability. There was a small talent pool which agencies were competing for and the agencies preferred not to fill up vacancies with semi-skilled policy staff. The MoT and MfE took two strategies to address this shortage. First, they sought to attract the best from the market with the help of improved selection and recruitment process. Second, they focussed on upgrading the skill level by ensuring a continuous learning process aided by formal and in-formal training, guidance, feedback, mentoring, and coaching.

In attracting the 'best' from the market, the MfE used 'challenge' and 'reward' as the attractive factors. Its radical change and downsize of policy people and then offering significantly higher remuneration for those positions conveyed to the job market that there was reward for challenging work in the MfE. There was no such deliberate strategy observed in the MoT to attract the 'best', perhaps due to shrunk resources over the years, but they focused on recruiting young professionals and upgrading their skills in a strategy of 'build [their] own' (see section 6.2.2). No such strategy to respond to the limited supply of policy skills was found in the AC, although it improved the recruitment and selection process.

The limited supply of skills raised several issues that the three organisations had to deal with such as relatively high turnover of policy staff, managing secondments, deciding between filling the positions with less than desirable candidates and waiting to find the desirable candidate. This also resulted in having a high ratio of experienced staff at policy manager or senior/principal policy analyst level, to less-experienced policy staff (analysts and junior analysts) than a desirable ratio. Also, more senior policy staff were also involved in activities ideally designated for junior policy staff. The 'build their own' strategy with new or junior policy analysts was intended to both facilitate the senior policy staff to perform their designated roles and to 'groom' new staff with the 
institutional knowledge relevant to policy analysis and advice. Thus, the limited supply of skills influenced the choices of the organisations in achieving improved policy analytical capability.

\section{Policy Skills Vary across Organisations, Levels and Nature of Problem}

The skills required were also significantly influenced by the role of the three agencies and the nature of policy problems they dealt with. The MoT as a dedicated sector policy ministry was involved in a regulatory role and in future planning relating to transport but had a limited operational role. The relevant skills found (as described in Chapter 6) were to know how to use data and forecast futures; predict and link consequences with policy options; use up-to-date policy tools and framework to respond to a changing environment characterised by continual innovations in transport; and follow, adapt and appreciate the world's best practices affecting transport sector to serve one immediate client, the Minister of Transport.

The case studies found that the need for such skills was influenced by a range of factors. For example, the MoT had a reputation for using data, and recognised the importance of thinking strategically, exploring and experimenting with curiosity and discipline, and adapting and applying different frameworks and tools. The initiatives such as creating Strategic Direction and Performance Team, the use of new policy tools and different frameworks, and the use of international and external experts were found compatible with the skills in demand for the MoT.

The MfE, in contrast, being a policy ministry with responsibility for making sectoral regulatory policies from an environmental perspective, interfaces with local governments and many other departments and Ministries. It has a mixture of roles regulation and broad policy design but limited operational roles. Its involvement with and leadership of the NRS showed that the environmental issues needed to be dealt with by going beyond the jurisdiction of the departments' and ministries' portfolios and approved by multiple ministers. The environmental policy issues were wicked in nature and the policy work in the MfE involved successful integration of the work of generalists and scientists. These factors determined the skills required by the MfE. 
The interviewees from the MfE identified an ability to do analysis, work with others within the organisation and sector, and effectively communicate to multiple clients as some important skills. The COBRA policy approach also clearly displayed the specific importance to evidence and engagement.

The skills needed for the AC were found different because of differences in its role, client for policy advice, tradition and culture from that of the MoT and MfE. The AC, traditionally being a service-delivery organisation, was engaged in developing small plans and operational policies which involved more engineers, planners and customer services than policy staff. The AC had to contend with the lack of policy people and common understanding on how to develop policies. The skills such as the ability to work with diverse cultures seemed significantly relevant to the organisation.

The set of skills also varied across policy staff within the same organisation. Since developing policy advice is a team effort where policy staff at different levels contribute to the parts of whole, skills at one level are different from skills at another level. The MfE's Professionalising Policy: A Guide for Developing the Craft of Policy Analysis clearly classified the expectations and skill sets for policy staff depending on where they belonged in the process of developing policy analysis and advice (MfE, 2011). The MoT also promulgated job specifications and outlined expectations differently for policy staff at different levels.

Some skills were also influenced by how they were acquired. For example, leadership skills could hardly be learnt; these were rather acquired over a lifetime of experiences. The recruitment process of the MfE, therefore, looked at the other occupational roles and the personal achievements of the candidate to reflect on the candidate's leadership ability.

The skills required were also determined by the nature of the problems: strategic, conceptual, analytical, process, and coordination and delivery. The MoT dealt with strategic and future-focused analytic problems, the MfE dealt with strategic, 
coordination and process problems working within the NRS, while the AC dealt with conceptual, strategic, analytical, process and coordination problems. The skill sets in demand by the three agencies varied accordingly, which were reflected by the interviewees identifying the policy skills differently across the cases.

The above discussion on the specification, application, demand for and supply of policy skills suggests that the policy skills relevant for an agency is rather context specific. The nature of the problem and clients, the availability of skills, how the skills are sought by the senior leaders, and the role of the organisation are some factors that determine the nature, relevance and applicability of the skills. There was no evidence that organisations developed a generic approach, understood as a one-size-fits-all approach.

\subsubsection{Gaining Competences}

Staff gained competencies in the three agencies through agency-specific learning and guidance. These organisations did not develop any competency framework such as the Treasury Competency Framework (The Treasury of New Zealand, 2008) or Organisation for Economic Co-operation and Development (OECD) Competency Framework (OECD, 2014). Rather, the strategy was to utilise the experiences of internal and external, local and international experts, either by employing them short- term to permit staff to gain hands-on experience working with them or by arranging seminars and in-house training. One-to-one coaching, mentoring, buddy support and peer review facilitated learning from experienced policy staff within the agency. The learning was more interactive in nature that could not be obtained from the literature.

Guidance for policy work was also found as a means for policy staff to gain agencyspecific competencies. The MfE's Professionalising Policy: Cost Opportunity Benefit Risk Analysis (COBRA), the policy guide, demonstrated evidence, engagement and context as some important considerations in developing policy advice in the MfE, because it needed to deal with other agencies within the natural resources sector, in addition to ensuring the rigour of policy analysis. The Professionalising Policy: A Guide for Developing the Craft of Policy Analysis showed how to do craft in policy analysis and 
advice. These two together supported gaining competences in the MfE and showed how 'generalists' and 'scientists' could contribute together within a COBRA policy approach.

Gaining competencies involved the use of policy frameworks and tools in the MoT to increase the ability of policy staff to accomplish policy tasks. As described in Chapter 6 (section 6.2.1), the MoT had numerous frameworks to aid policy development, such as a framework for the relationship between transport and economic activity.

Along with these frameworks, the MoT developed policy tools, such as scenario analysis, to predict consequences associated with policy options. The policy frameworks and tools, reflecting the organisation-specific competencies, gave policy staff a structure to employ their skills and knowledge to accomplish their tasks. In a similar fashion, intervention logic and cost-benefit analysis helped policy staff of the AC to build their analytical competencies.

\subsubsection{Practicing Required Behaviours}

Only the most recent literature has pointed out the importance of the 'social characteristics of individuals and their qualities' in predicting high performance over time and organisational success by focussing more on 'deeper competencies' such as motivation and commitment, values, self-esteem and self-image than on technical skills (Tiernan \& Wanna, 2006, p. 5). In achieving improved policy capability, the three agencies identified a different set of 'behaviours' relevant to policy analysis and advice and showed balanced attention to both technical skills and the behaviours of policy staff.

The required behaviours, as expressed by the interviewees, varied at different levels: individual level while doing policy analysis; team level while contributing to policy analysis and advice; and both organisation and system levels in managing relationships with clients and stakeholders. Behaviours such as self-discipline, faith or trust, curiosity and discipline were directly associated with policy analysis at an individual level. As 
further set out in Chapter 6, the abilities to work with others in a team; lead, work, and influence others in a team; and to work with others and build relationships were related to performing functions within a team environment. Having good leadership skills and maintaining good stakeholder relationship, and being politically savvy were some behaviours in demand at organisation and system levels.

The expected set of behaviours varied across the agencies too. For example, the MfE's behavioural framework includes analyse, engage, learn, validate and collaborate. MfE interviewees identified an increase on similar practices across the ministry and more sharing across different directorates as a positive result of the initiatives. This provides evidence that the MfE needed to promote those behaviours that supported coproduction of policy advice with other ministries and departments within the NRS.

In contrast, the MoT promoted sharing behaviours and collaboration within the organisation through feedback, commissioning conversations and rotating members in the internal review panel to build common language and understanding, because the MoT needed to focus on analysing and forecasting the future with data to meet the expectations of only one immediate client/minister, unlike in the MfE where multiple immediate clients and ministers determined the quality of policy analysis and advice.

The initiatives such as the Policy Hub and Policy Register by the AC (see section 6.3) clearly indicated the need for avoiding duplication of work in the AC. These promoted collaborations across departments within the organisation. The senior leader considered these two as the most influential initiatives in influencing the necessary cultural changes for the organisation.

The commonality of the identified behaviours was in emphasising horizontal collaboration and engagement over vertical. This echoes the findings of the literature that there has been a tradition and history of lack of collaboration across than vertical in the New Zealand public sector (R. O'Leary, 2014). This also justifies the inseparable influences from wider policy environment or system into policy analysis and advice at organisation level. 
The discussion above has shown that policy knowledge, competencies, skills, and behaviours are agency- and context-specific. Second, the three organisations' sincere attention to learning from the literature implies that the literature served basic, yet essential, support to improving policy analytical capability. Third, achieving individual policy analytical capability involves gaining capabilities in all the four constituents: knowledge, competencies, skills and behaviours which can be improved by learning from a range of different sources. Fourth, policy organisational analytical capability is about supporting the better use of individual analytical capability by providing support services and creating a culture of learning where policy analysis is innovatively produced by continuously changing policy practices relating to the policy process and inputs used.

Fifth, the use of different types or forms and designs of initiatives, tailoring the academic programmes and training to suit organisational needs, the use of experiences from different sources, promoting capability of innate nature, and the use of different tools and frameworks together demonstrate a comprehensive effort to support learning of policy staff to do policy analysis. This comprehensive strategy seems to correspond to the rationalist assumption of improving policy analysis and advice by enhancing professional policy knowledge and analytical techniques when policy-making is uncertain and dynamic (Parsons, 2004; Tiernan \& Wanna, 2006).

Policy analytical capability, in theory, is the means for the analyst to work as an 'objective technician' (Weimer \& Vining, 2017) who will find the solutions for the policy problems as if 'analysis' has produced the 'advice' with a state-of-the-art mechanistic process based on appropriate policy inputs, facts and evidences, not the 'analyst'. The case studies suggest that policy analytical capability refers to the ability to use knowledge, skills, competencies, and behaviours in policy analysis having regard for the specific issue, context and complexity.

The following section shows what is involved in improving policy management capability at both individual and organisation levels. These three agencies' efforts to managing policy capability show that the rigour of policy analysis is only one side of it. 


\subsection{Policy Management Capability}

Nicely crafted and well-developed policy advice underpinned by high-quality policy analysis is of no use if it is not welcomed by the client. This draws attention to the indistinct line between the responsibility of policy practitioners' and the intervention of the client. A mixed picture was found in the cases. The policy professionals directly engaged in policy analysis and advice and junior policy analysts considered developing policy options and advice for clients as the end of their responsibilities. They had no involvement in what happened next with their advice. But, the senior policy staff expressed a broader view. Pursuing the reasoning of advice with multiple clients was considered as their responsibility, confirmed as successful if the advice was accepted by the client.

Junior policy analysts' views match the profile of an objective technician. However, policy managers add a number of practical considerations into policy analysis and advice, consistent with a 'craft' interpretation provided by Majone (1989), A Wolf (2014), Bromell (2017), Tiernan (2015) and Irwin (2003). Thus, an objective view on developing policy analysis and advice is augmented by policy managers' inclusion of practical considerations such as political and implementation feasibility, cost, timeliness, the public sector's overall forecasted target outcomes, community interests, values, culture and history and more into the production of policy analysis and advice, as suggested by scholars such as Hogwood and Gunn (1984), Hallsworth (2011).

The New Zealand Westminster system sets expectations on how senior policy staff produce and communicate policy advice. Specifically, Westminster requires senior policy staff to maintain a neutral stance, not to engage in counter-productive activities, and to offer free and frank advice. This broader role of senior policy staff was clearly found in the cases, which went beyond ensuring policy analytical capability. This broader role can be matched with the analytical integrity of a client's advocate as sketched by Weimer and Vining (2017).

Policy management capability at the individual level refers to this broader role of senior policy staff, outlined above, in addition to the capabilities identified by theory such as 
expertise in planning, staffing, budgeting, delegating, directing and coordinating as policy individual operation capabilities (Wu et al., 2018, pp. 4-14). The three agencies' use of concepts and strategies to improve policy management capability at the individual level is somewhat different from those used in academic literature.

The senior leaders' understanding of policy management capability at organisation level is also found to be slightly different from those identified in theory. Policy management capability at organisation level, in theory, refers to the organisational commitment to achieving goals, availability of fiscal and personnel resources, coordination of internal processes, performance management, and administrative accountability (Wu et al., 2018, pp. 4-14). Policy management capability at organisation level, in practice, in addition to the elements identified by theory, is seen as the strategies to ensure supply of quality policy inputs; improve and upgrade the policy capabilities repertoire; and maintain policy capability by responding to dynamic influences on policy practices. Improving policy management capability at organisation level, thus, includes a time horizon unlike in theory.

The difference between theory and practice is explained by an expectation-response relation between the clients for and producers of policy advice. This relation mandates that the initiators include a time horizon in their efforts to improving policy management capability. Second, they take efforts to respond to the clients' expectations and the dynamic influences on policy analysis and advice. These are shown below.

\section{Understanding an Expectation-Response Relation}

'Advice giving and advice seeking [are] hardly new' (Radin, 2013, p. 13) and 'The practice of policy advising is as old as government' (C. Scott \& Baehler, 2010, p. 1). But how policy advice is given and sought has changed over time, especially since policy analysis and advice emerged as a new profession in the 1960s (Radin, 2013). But the inherent relation between the producers of and clients for policy advice seems unchanged and not unique to any era. Since the inception of this relation, policy producers are supposedly the experts on policy analysis and advice and the clients are the non-experts, generally, be they rulers or politicians. 
Despite ministers, councillors, other politician and being non-expert in the competencies of policy analysis, they have their own expertise about policies, and expectations about policy analysis and advice from their own standpoints. Central agencies, charged overseeing the public sector agencies have expertise suited to these roles, including an ability to review the analytic qualities of advice. These actors' expectations are reflected in their comments and feedback on the quality of policy advice, either communicated internally or publicly. Client satisfaction, therefore, has remained an important element of several measures to determine the quality of policy advice such as in the Policy Advice Initiative (PAI) and Quality of Policy Advice Initiative (QPAI). The clients' feedback on the quality of policy advice can be publicly known and this can create an image of the agency's policy capability.

The initiators and producers of policy advice regard this expectation-response relation with care. The policy managers and the senior leaders work as client's advocates but with different fundamental values than as outlined by Weimer and Vining (2017). The analysts appreciate the expectation of their role under the Westminster advisory system which requires policy analysts to produce free and frank policy advice and to focus on creating public value because the public is the ultimate client for the policy advice. To satisfy multiple clients, analysts produce policy advice that is analytically strong, cost effective, timely, robust, implementable and linked with the possible consequences and values so that the ministers can make informed decisions.

The following section outlines the policy organisational management capability. The three agencies' efforts to improve policy management capability, correspond with the State Services Commission's (SSC) understanding of policy capability at organisational level, which is 'what an agency needs in order to deliver its outcome now and in the future in a high quality, efficient and timely manner' (SSC, 2008).

Policy management capability at organisation level involved three things. First, agencies responded to internal influences by taking initiatives to improve and maintain policy capability. Second, they responded to external influences on the production of policy 
analysis and advice in their agencies. Third, they contributed to meeting their clients' quality expectations from policy advice by establishing standards for monitoring and evaluating policy work and outputs internally, and taking part in external quality assessment exercises. The agencies' efforts to ensure skilful policy staff, improve skills repertoire and maintain policy capability are outlined in Table 7.2. 
Table 7.2: Policy Management Capability Efforts in the Three Cases

\begin{tabular}{|c|c|c|c|}
\hline \multicolumn{4}{|c|}{ Ensuring Skilful Policy Staff ${ }^{19}$} \\
\hline & $\begin{array}{l}\text { 1. Identifying the } \\
\text { skilful applicants }\end{array}$ & $\begin{array}{l}\text { 2. Terminating the } \\
\text { unfitting ones }\end{array}$ & $\begin{array}{l}\text { 3. Attracting the } \\
\text { skilful } \\
\text { to the agency }\end{array}$ \\
\hline $\begin{array}{l}\text { MoT } \\
\text { Initiatives }\end{array}$ & $\begin{array}{l}\text { Improved selection and } \\
\text { recruitment process }\end{array}$ & - & - \\
\hline $\begin{array}{l}\text { MfE } \\
\text { Initiatives }\end{array}$ & $\begin{array}{l}\text { Improved selection and } \\
\text { recruitment process }\end{array}$ & $\begin{array}{l}\text { Drastic screening- } \\
\text { out of unfitting } \\
\text { policy staff }\end{array}$ & $\begin{array}{l}\text { High rise of } \\
\text { remuneration with } \\
\text { increased } \\
\text { challenges for the } \\
\text { fittest to survive }\end{array}$ \\
\hline $\begin{array}{l}\text { AC } \\
\text { Initiatives }\end{array}$ & $\begin{array}{l}\text { Improved selection and } \\
\text { recruitment process }\end{array}$ & - & - \\
\hline \multicolumn{4}{|c|}{ Improving Skills Repertoire } \\
\hline & 4. Upgrading skills of policy staff & \multicolumn{2}{|c|}{ 5. Improving policy practices } \\
\hline $\begin{array}{l}\text { MoT } \\
\text { Initiatives }\end{array}$ & $\begin{array}{l}\text { Training, coaching and } \\
\text { mentoring; feedback; peer } \\
\text { review; buddy support; formal } \\
\text { and informal training; sharing } \\
\text { experience with internal and } \\
\text { external policy experts; working } \\
\text { under supervision }\end{array}$ & \multicolumn{2}{|c|}{$\begin{array}{l}\text { Professional services model; } \\
\text { commissioning conversations; } \\
\text { use of new policy tool; } \\
\text { use of evidence and best practices }\end{array}$} \\
\hline $\begin{array}{l}\text { MfE } \\
\text { Initiatives }\end{array}$ & $\begin{array}{l}\text { Training, coaching and } \\
\text { mentoring; feedback; peer } \\
\text { review; }\end{array}$ & \multicolumn{2}{|c|}{$\begin{array}{l}\text { Policy process/framework expressed in } \\
\text { the policy guides; behavioural framework }\end{array}$} \\
\hline $\begin{array}{l}\text { AC } \\
\text { Initiatives }\end{array}$ & Training; peer review & \multicolumn{2}{|c|}{$\begin{array}{l}\text { The commissioning process; the quality } \\
\text { policy hub; the policy register; the AC's } \\
\text { policy cycle }\end{array}$} \\
\hline \multicolumn{4}{|c|}{ Maintaining Policy Capability } \\
\hline & $\begin{array}{l}\text { 6. Responding to the } \\
\text { Dynamic influences }\end{array}$ & \multicolumn{2}{|c|}{ 7. Future focus/Strategic } \\
\hline $\begin{array}{l}\text { MoT } \\
\text { Initiatives }\end{array}$ & $\begin{array}{l}\text { Restructuring the organisation } \\
\text { (creation of performance team); } \\
\text { taking initiatives to respond to } \\
\text { the reputation and challenges }\end{array}$ & \multicolumn{2}{|c|}{$\begin{array}{l}\text { Developing strategic papers; creation of } \\
\text { strategic direction team }\end{array}$} \\
\hline $\begin{array}{l}\text { MfE } \\
\text { Initiatives }\end{array}$ & $\begin{array}{l}\text { Restructuring the organisation; } \\
\text { re-scoping the roles; taking } \\
\text { initiatives to respond to the } \\
\text { reputation and challenges }\end{array}$ & \multicolumn{2}{|l|}{-} \\
\hline $\begin{array}{l}\text { AC } \\
\text { Initiatives }\end{array}$ & $\begin{array}{l}\text { Responding to the reputation } \\
\text { and challenges with the QPAI }\end{array}$ & \multicolumn{2}{|c|}{ Developing strategic papers } \\
\hline
\end{tabular}

\footnotetext{
${ }^{19}$ Skilful policy staff refers to the policy staff with required skills, knowledge, competences and behaviours and not skills only
} 


\subsubsection{Responding to Internal Influences}

Policy management capability involved taking initiatives to respond to the internal policy capability issues. The agency-specific internal policy capability issues influenced the design and approach of the initiatives. The MfE, because of its poor and publicly known reputation as a policy ministry in 2008 , considered rebuilding its policy capability as a better strategy instead of trying to repair it by some sporadic fixes. The initiatives developed, therefore, were of a drastic nature to expedite changes considered important for building policy capability.

The severity was reflected in the changes in people resources by excluding 'not so fit for purpose' policy staff, not found in the other two cases; introducing new policy tools and frameworks; articulating a new policy approach with the developed COBRA policy guide; and setting expectations from policy analysis and advice by the quality measure of policy advice. The cohort of thought leaders set examples to guide these changes. Continual restructuring of the organisation in the MfE between 2008 and 2015 also demonstrated how the MfE responded to the internal influences to sort out what worked from what did not work. All these initiatives, collectively, brought changes in policy practices in the MfE.

In contrast, in the AC the initiators, representing a small part of the Council, could not opt for a strategy of drastic changes for building policy capability. The overall approach of the initiatives was influenced by the tradition and culture of the council which was accustomed to developing small plans and not big policies. The AC, therefore, took an approach to establish a good set of policy practices first and then to gradually bring about a cultural change in the organisation to enable policy analysis to be innovatively practised. Cultural change takes time and hence, the initiators desired changes fell short.

The design and approach of the initiatives of the MoT were influenced by internal policy capability issues. Its capability issues were different from that of the MfE and AC. It needed to increase the 'efficiency' of policy staff under resource cuts and increased expectations from its policy analysis and advice. Hence, relatively more and a wider range of initiatives promoting 'learning' were observed in the MoT. 
Overall, initiatives were considered as a means by the senior leaders of the agencies to convey to policy staff the high-demand for policy analysis and guide the supply of quality policy analysis under increased expectations. A wide range of policy capability initiatives communicated to policy staff the need for improvement and how to improve in policy analysis and advice; what support services, rewards, resources, policy tools and policy guidance were available; and how to achieve the quality expectations from policy advice.

To clients, initiatives communicated the seriousness and efforts of the organisations in achieving improved policy capability. This was particularly seen in the MfE and AC. The MfE's Professionalising Policy: Cost Opportunity Benefit Risk Analysis (COBRA) Policy Guide and Professionalising Policy: How to Do Craft in Policy Analysis and the AC's Quality of Policy Advice Initiative had relatively more demonstration value than the initiatives of the MoT.

In contrast, the MoT's was dedicated to more internal processes to promote learning and sharing work experiences, using various internal and external sources and experiences, and hands-on guidance by policy mentors. However, the MoT's scenario planning tool and strategic papers relating to future demand have drawn external attention.

The publicness of the initiatives was more relevant for the MfE and the AC than for the MoT. The MfE and AC had more than one immediate client. This made it relatively difficult for advisors, as they had to address multiple immediate clients with different viewpoints, perspectives and quality expectations of policy advice. Logically, this required expanding the scope of considerations compared with the scope needed to address only one immediate client, as was the case for the MoT. Senior leaders' adoption of externally accessible initiatives met another purpose, namely, the need to demonstrate organisational efforts to achieve improved policy capability. If the organisation fails to satisfy the quality expectations of policy advice from multiple clients, these initiatives may safeguard the agency because there were efforts to 
improve policy analytical capability and the quality of policy advice. The failure may be explained by the factors beyond analysis.

\subsubsection{Responding to External Influences}

Policy management capability involved taking initiatives to respond to the policy capability issues of the agencies identified by the external measures and publicly known reputation. Some initiatives were developed in these three agencies to respond to the policy capability concerns identified by external measures such as the PIF reviews and the New Zealand Institute of Economic Research (NZIER) ratings on the quality of policy advice. These external influences shaped how the initiatives were designed and approached.

The main and common driver for beginning to adopt initiatives across the cases was the questionable and publicly known reputation of the agencies, which challenged and demanded that the agencies build and improve on policy capability. But the publicly known reputation of the three agencies came from different external sources. The MoT's reputation was expressed in the PIF, based on a need for improvement in its policy capability, particularly being more strategic with a future focus. In addition, the NZIER rated the quality of policy advice it produced in the bottom four among the participating departments in 2012. The MfE's poor reputation in 2008 was publicly known in the media, as was the resignation of the Minister for the Environment and CE of the MfE. The AC's poor reputation was expressed in the NZIER rating in 2012, where it came last among 18 other participating organisations. All the three agencies developed several initiatives to respond.

The MoT's initiatives were significantly influenced by the PIF review which drew the MoT's attention to the need to be more strategic and future focused. Activities included creating a strategic direction and performance team, developing a scenario planning exercise tool, producing strategic papers such as Future Demand for Transport, Future Funding as a Transport System, and the future-focused projects Regulation 2025 and Public Transport 2025. These show how the MoT planned to achieve its vision, which 
followed from the PIF review comment that the agency had a good vision for the transport system but did not have a clear strategy to achieve it.

The NZIER rating on the quality of policy advice produced by the MoT had some limited influences on the agency's adopting of quality assurance initiatives. A senior leader from the MoT did not see the poor NZIER rating in 2012 as a driver behind the initiatives but considered the better NZIER rating as a reflection of improvement in 2016. The leader acknowledged that the NZIER rating was somehow an indirect influence.

The seriousness of policy capability concerns in the MfE in 2008 influenced the Environment Leadership Team (ELT) to start afresh to build policy capability. The ELT brought massive structural changes in the organisation and people resources, and replaced numerous policy staff with the new recruits. It renewed the mission of the agency, introduced new policy guides to craft policy analysis and advice and frequently restructured the organisation to promote innovative policy practices. The rationale for massive changes was in expediting the necessary changes because the behaviour and culture change were associated with habits practiced over a long time and difficult to alter otherwise.

The MfE also responded to the PIF reviews, although some initiatives were developed before the first PIF review. However, the PIF subsequently influenced policy analysis and advice in the MfE which was reflected in an interviewee's clear comments.

The AC's initiative was significantly influenced by the continuing poor NZIER rating. The strong and direct response by the AC was to uplift the quality of policy advice with the QPAI. But the QPAI did not produce the expected rating and the NZIER did not think that the AC managed to dramatically lift the areas like problem definition, intervention logic, systematic process of evaluating options, and cost-benefit analysis. The AC's concern with the NZIER rating was also reflected in the comment from another interviewee who conducted in-house training for policy staff. The interviewee, who was a trainer too, expressed that the $A C$ was more fixated on its rating and ranking with other departments than with being focused on the comments provided by the NZIER. The 
concern with the NZIER rating seemed a strong influence on policy analysis and advice in the AC.

\subsubsection{Meeting the Client's Quality Expectations from Policy Advice}

The case organisations relied on similar forms of initiatives to improve the quality of policy advice. The initiatives to improve the quality of policy advice, in the three cases, are shown in Table 7.3. The initiators first developed internal measures for quality checks to set and clarify the expectations regarding the quality of policy advice. As a second step, the initiators wanted to gain an assessment of the quality of policy advice produced in the organisations by the internal panels who periodically provided ratings of and feedback on the advice. They also participated in the NZIER rating to have a relative assessment of the advice. As a final step, they followed up with the comments provided by the internal panel, PIF reviews, peer reviews and feedback from managers.

Table 7.3: The Quality of Policy Advice Assurance Efforts in the Three Cases

\begin{tabular}{|l|l|l|l|}
\hline & $\begin{array}{l}\text { Setting and clarifying } \\
\text { Expectations } \\
\text { of the Quality of Advice } \\
\text { (Internal Measures for } \\
\text { Quality) }\end{array}$ & $\begin{array}{l}\text { Quality Check } \\
\text { (Internal and External) }\end{array}$ & $\begin{array}{l}\text { Following up with the } \\
\text { comments }\end{array}$ \\
\hline $\begin{array}{l}\text { MoT } \\
\text { Initiatives }\end{array}$ & $\begin{array}{l}\text { Internal measures for } \\
\text { the Quality of Policy } \\
\text { Advice }\end{array}$ & $\begin{array}{l}\text { Internal panel for quality } \\
\text { check; RIS Quality } \\
\text { Assurance Panel; } \\
\text { participating in the NZIER } \\
\text { rating; Peer Review }\end{array}$ & $\begin{array}{l}\text { Post evaluation of policy } \\
\text { reports; feedback from } \\
\text { managers; PIF Review }\end{array}$ \\
\hline $\begin{array}{l}\text { MfE } \\
\text { Initiatives }\end{array}$ & $\begin{array}{l}\text { Internal measures for } \\
\text { the Quality of Policy } \\
\text { Advice }\end{array}$ & $\begin{array}{l}\text { Internal panel for quality } \\
\text { check; Regulatory Impact } \\
\text { Analysis Panel; Peer } \\
\text { Review }\end{array}$ & $\begin{array}{l}\text { Feedback loop; PIF } \\
\text { Review; guidance from } \\
\text { policy staff at senior } \\
\text { roles }\end{array}$ \\
\hline $\begin{array}{l}\text { AC } \\
\text { Initiatives }\end{array}$ & $\begin{array}{l}\text { Internal measures for } \\
\text { the Quality of Policy } \\
\text { Advice }\end{array}$ & $\begin{array}{l}\text { Participating in the NZIER } \\
\text { rating; Peer Review }\end{array}$ & \begin{tabular}{l} 
- \\
\hline
\end{tabular}
\end{tabular}

Source: Adapted from the information from interviews and documents

These efforts, however, were not original. The policy advice 'quality' measures shown in the PAI 1991-1995, IQPA 1997-1999, Review of Expenditure on Policy Advice (REPA) 2010, Cost Opportunity Benefit Risk Analysis (COBRA) policy guide by the MfE and the QPAI by the AC are, fundamentally, based on similar ideas. All these showed the 
ingredients for the rigor of policy analysis, applied policy analysis, and how to communicate the advice effectively.

The commonality in these measures indicate that the quality of policy advice was broadly reliant on the quality of inputs, ensuring a quality assurance process, and understanding the wider policy environment that influenced policy analysis and advice of the organisations. All these measures recognised clients' satisfaction as one of the important yardsticks in determining 'quality'.

The traditional measures of the quality of policy advice have the potential to increase contestability, learnings and positive engagement with policy analysis and advice. In an opposite direction, measure can increase compliance behaviour, client-centric engagement and, as a result, may lead to less focus on the rigour of policy analysis.

However, since some quality measures were already available, it can be asked what the need was for the organisations to adopt an internally developed quality measures. Three reasons seem plausible. First, agencies needed to reflect on the quality criteria that are particularly relevant for the organisations. Second, they wished to ensure that policy advice producers bring changes in policy practices in doing policy analysis in which quality consideration is given serious attention. Having their own measure for quality was considered a way to demonstrate seriousness. Third, there is value in relying on more than one measure to reflect on the quality of policy advice. In portraying an allinclusive assessment of the quality of policy advice, the senior leaders of the organisation considered the comments in the PIF reviews, NZIER ratings and feedback, clients' comments and feedback from peers, managers, and internal and external panels.

This approach of the three organisations, with degrees of variation and emphasis, is different from the earlier central agencies' initiatives. While the earlier central agency initiative such as the PAI 1991-1995 might have promoted compliance behaviour with its mechanistic approach, strict pre-defined guidelines and the criteria outlined in the developed quality measures, the initiatives in these organisations designed to improve the quality of policy advice were about going beyond compliance behaviour. Care was 
given to the quality of policy inputs, quality assurance process and the comments from multiples sources, both internal and external to the organisations. The overall approach to ensure the quality of policy analysis and advice in these organisations seems relatively more comprehensive than the previously developed quality measures such as the Treasury measure, the PAI measure or the NZIER measure for quality.

Three agencies' efforts to improve policy analytical and policy management capability at both individual and organisational levels showed that improving policy capability is reliant on both improving the quality of policy analysis and managing the expectationresponse relation between the policy advice consumers or clients and producers of policy advice. The policy analysts in the agencies act as objective technicians but pay attention to the contextual influences on policy analysis and the policy managers act as client's advocates to create public value guided by the requirement of the policy advisory system. The specific policy capabilities at individual, organisation and system levels are outlined in Table 7.4

However, the contributions to policy development by some elements such as learning were less separable as this was more implicit. Although the individual policy political capability and the system levels were out of the scope of the research, still some elements, shown in upper right corner of Table 7.4, were observed which are categorised as individual political capability. Taking initiatives to meet the quality expectation of the clients for policy advice shows the ability of the agency to appreciate policy political capability at organisation level. This aligns with the theory that the system level resources (or expectation) affect the resources (capability efforts) at the organisational level (Wu et al., 2015).

The clear separation between policy analytical and management capability efforts in these cases also confirms that gaining adequate analytical capability or management capability at individual or organisation level was not a guarantor either for effective performance of the others or for the consequences of improved policy capability, as also argued by (Wu et al., 2018). The improved capability is determined not by analysis only 
but by many other influences that are context specific, which are discussed further in the following section.

Table 7.4: Different Types of Policy Capabilities at Different Levels

\begin{tabular}{|c|c|c|c|}
\hline $\begin{array}{l}\overline{\frac{\pi}{2}} \\
\frac{0}{2} \\
\frac{0}{2} \\
\text { ㄷ }\end{array}$ & $\begin{array}{l}\text { Individual } \\
\text { Analytical Capability } \\
\text {-ability to use } \\
\text { knowledge, skills, } \\
\text { competencies, and } \\
\text { behaviours in policy } \\
\text { analysis having regard } \\
\text { for the specific issue, } \\
\text { context and complexity }\end{array}$ & $\begin{array}{l}\text { Individual } \\
\text { Management Capability } \\
\text {-ability to incorporate } \\
\text { practical considerations } \\
\text { in policy analysis } \\
\text {-managing policy } \\
\text { development in a team, } \\
\text { planning, staffing and } \\
\text { leading } \\
\text {-learning, building and } \\
\text { improving }\end{array}$ & $\begin{array}{l}\text { Individual } \\
\text { Political Capability } \\
\text {-having knowledge about } \\
\text { how to design a policy } \\
\text { process and stakeholders' } \\
\text { position } \\
\text {-understanding the } \\
\text { expectation-response } \\
\text { relation among the clients } \\
\text { and implementers of policy } \\
\text { analysis and advice }\end{array}$ \\
\hline 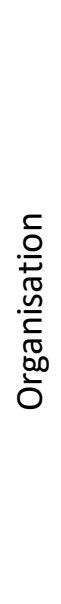 & $\begin{array}{l}\text { Organisational } \\
\text { Analytical Capability } \\
\text {-availability of } \\
\text { individuals with policy } \\
\text { analytical capability } \\
\text {-upgrading policy skills } \\
\text { by providing scope for } \\
\text { learning } \\
\text {-organisational } \\
\text { commitment to } \\
\text { improve the quality of } \\
\text { policy inputs }\end{array}$ & $\begin{array}{l}\text { Organisational } \\
\text { Management Capability } \\
\text {-organisational } \\
\text { commitment to achieving } \\
\text { goals } \\
\text {-adopting innovative } \\
\text { initiatives to build culture } \\
\text { of learning } \\
\text {-coordination of internal } \\
\text { processes } \\
\text {-performance } \\
\text { management }\end{array}$ & $\begin{array}{l}\text { Organisational } \\
\text { Political Capability } \\
\text {-Taking initiatives to meet } \\
\text { the quality expectation of } \\
\text { the clients for policy advice }\end{array}$ \\
\hline
\end{tabular}

Source: Adapted from the Information in Three Cases

The examination of policy analytical and management capability initiatives across the three agencies demonstrated that improving policy capability at the organisation level is premised on two central ideas. First, the organisational policy capability is an important dimension and is given insufficient attention when assessing the quality of policy analysis and advice. The current academic literature on policy capability has given undue emphasis to individual knowledge, skills and competencies. However, the increasing set of knowledge, skills and competencies which are being identified as relevant to address the more complex and wicked nature of policy issues means that the art and craft of doing policy analysis relate to the importance of high skills of option analysis (Weimer \& Vining, 2017) and the difficult but important skill of projecting outcomes. The greater 
use of contingent recommendations may also be an important skill for communicating the strengths and weaknesses of different options to the various client(s) for policy analysis and advice. The three case studies have policy issues require awareness and the need to take into account systemic influences.

To ensure a capable policy team, the agencies identified and recruited policy staff with the help of improved selection and recruitment mechanisms. Then staff were trained, coached, mentored, guided, and supplied with tools and frameworks. The expected behaviours were also outlined. With all these, the organisations provided them the institutional knowledge and expectation so that the capabilities could be contextualised.

Second, policy capability was not about only achieving it, but also about maintaining it over time. None of the initiatives was limited to any specific policy issue or timeframe or specific policy problems. Rather, the initiatives collectively were focused on demonstrating how to approach different policy problems with applicable tools and frameworks, identify the capabilities required, and gain the capabilities to ensure that policy capabilities do not fall short in accomplishing policy analysis and advice in future issues and generations.

Overall, the agencies did not build policy capability in a generic, context-free way, but used the dynamic, context-specific influences to direct capability-building efforts. The external and internal initiators considered several ideas and options, reflected in the design and approach of the wide range of initiatives, as part of improving policy analysis and advising with a view to increasing quality and performance of their agency, the sector and the broader policy system. They relied on learning from academic and practitioner literature, looked at the local and international practices considered effective in other public-sector organisations; responded to the circumstances specific to the organisation and to the internal and external influences on policy capability; and focused on meeting the clients' quality expectations regarding policy advice. 


\subsection{Influences on Policy Practices in the Cases}

'Professionalising' policy analysis and advice did not introduce identical initiatives across the cases, as argued in the literature (see 2.2.1). Each case agency was different in its role, policy, priorities and stakeholder groups and in its governance and accountability arrangements. These differences influenced the design and approach of the initiatives. The initiators tailored each of the initiatives, be that for improving policy analytical or management or political capability, to respond to agencies' specific roles, activities and requirements. The initiators' choice and use of initiatives were influenced by the nature of clients, the demand for and supply of policy analysis, the nature of the agencies' roles and functions, the governance and accountability arrangements, the tradition and culture of the organisation, and the policies and priorities of the government of the day.

These influences were inseparable and these collectively contributed to changes in practices in these three agencies to professionalise policy analysis and advice. As an example, the quality of policy analysis will be influenced not only by the extent of demand for high-quality policy advice, but also by the source of demand and the type of policy problem/s. The source of demand (if the demand was coming from a single client or a group of clients) and the type of problem (if analysis was done to solve a simple problem such as determining the location of a community swimming pool, or a complex or wicked such as climate change, as an instance), will influence the quality and style of policy analysis. The discussion of influences, as follows, hence, does not present each influence separately, but presents them collectively.

In theory, the high demand for and supply of policy analysis are important factors to improve policy analytical capability at country level. Recently, Mendez and LagunaDussauge (2017) described four demand-side elements: the type of political regime, level of bureaucratic development, work culture and professionalism (with formal training as the measure), which together indicate that the demand originates from and is affected by multiple sources.

The three case studies, albeit at the level of organisation, also show that the level of policy analysis is strongly influenced by the demand for policy analysis from multiple 
sources. Here, however, a different set of demand elements are noted. These are: the type of agency (either central or local government); the level of professionalisation and standardisation of policy analysis and advice; the traditions, roles and cultures of the organisation; and the feedback mechanism. These demand-side elements are discussed below with respect to the different ways demand affected efforts to further professionalise policy analysis and advice in these three case agencies.

Professionalising policy analysis and advice took different forms in the AC than in the MoT and the MfE due to different tradition and work culture. Both the MoT and the MfE have long traditions and rich cultures of doing policy as mainstream central government agencies. The AC, in contrast, has the long tradition and culture of planning or developing small ' $p$ ', operational policies. Therefore, while the MoT and the MfE built on existing foundations to improve policy inputs, processes, and tools and put strategies in place to meet current and future demand for advice to governments, the AC was at an earlier stage of introducing policy practices and initiating a work culture. The AC was following the central agencies' policy practices and seeing their diffusion in the Council.

The different traditions, roles and work cultures and the nature of policy problems together influenced the style of policy analysis in these agencies. The MoT is expected to produce analytically strong and timely information for clients when demanded; forecast future demand from transport; and demonstrate strategies to meet foreseen future demand. It is also expected to be proficient in developing regulatory policies as its policy advice often takes the form of rules and regulations.

The MoT's style to policy analysis was influenced by applying policy and economic frameworks, such as market failure and government failure. The nature of policy problem in the MoT was often complex, but rarely wicked. Solutions to the problems mainly relied on the technical and effective use of data and evidence relating to transport matters and the use of technology. The activities that made up policy analysis in the MoT were: Research and analyse and Design and recommend. Has the number of road accidents increased due to lowering the minimum-age-restriction to consume alcohol? Has the number of accidents increased due to lower the warranty-of-fitness 
requirement for vehicle from twice a year to once a year? Such questions were relevant to analysts in the MoT which were about facts, causes and effects that required scientific research. But questions such as: 'what will be the future demand from transport sector?' and 'what measures the MoT can take to meet the future demand?' are mainly design and solution oriented. Its policy analysis style correspond to the rational style as outlined in the Mayer et al. (2013) model, a single conceptual model to (re)structure policy analysis discipline.

Professionalising policy practices in the MoT, hence, was focused on developing innovative and future-focussed policy methods, tools and recruiting more fresh graduates than the senior level policy staff and training them in a wide range of ways to better ensure that policy analysis would be conducted with objectivity and technical rigour.

The MoT's initiatives were often associated with changes to how staff were organised and managed and how policy work was developed and delivered. It brought about management change which removed the segmentation of different forms of transport (road, rail, sea and air) and did not assign staff to a specific manager. Instead, the CE organised the policy work of the agency according to a professional services model by setting up teams as needed (and within 24 hours), making the agency more responsive and efficient in starting and completing projects. This accommodated speedy and flexible allocation of resources to increase its responsiveness to government priorities.

Professionalising policy analysis and advice took a different approach in the MfE. The MfE changed in 2008 from an agency oriented by environmental protection to one serving as an environmental steward overseeing the efficient use of natural resources over generations. The role change dictated a new work culture in the MfE.

The MfE renewed its work culture by making changes in policy inputs and processes, communicating the behaviour that was expected from policy staff when undertaking policy analysis and advice, and creating a common platform where scientists and technical experts and generalists could collectively contribute to the MfE's policy work. 
The MfE made considerable changes in altering the skills repertoire of policy staff by hiring, training and sanctioning. It also used COBRA policy guide and Professionalising Policy: A Guide for Developing the Craft of Policy Analysis, and an internally developed behavioural framework to standardise policy practices within the agency. The other strategy it used to promote work culture towards its role of environmental stewardship was developing role models within the agency which others could follow. Hence, its strategy focused on recruiting a cohort of thought leaders before recruiting the junior level policy staff.

The initiators designed policy tools and frameworks suited to the role of the agency. The MfE's COBRA approach to policy showed how the MfE needed to consider a variety of factors when producing policy analysis and advice. These included evidence and engagement, culture, context, history, government coalition agreement, output plan, Treaty of Waitangi and strategic direction (MfE, 2011). The breath and scope of these requirements helps explain the MfE's focus on recruiting more senior level generic policy staff than new graduates, because it was the responsibility of policy staff at senior level to incorporate these wider policy considerations in policy analysis and advice (MfE, 2011). While the focus on evidence and engagement implies that the MfE recognised the importance of rigorous policy analysis, this emphasis was also tailored to incorporate practical considerations by senior level policy staff.

The MfE dealt with wicked policy problems which required analysing the policy problem from different perspectives. Different perspectives came from technical experts, including biologists, environmental specialists, and other scientists, as well as from generalists. It, therefore, aimed to develop a common platform with its policy guides to make sure that this diversity of expertise could be effectively synthesised towards achieving policy goals rather than developing scientific and objective solutions only. Across the NRS, different perspectives came from experts, analysts, clients, stakeholders and target groups having differing views of the same thing. The Natural Resources Framework (NRF) served as a platform across the sector to take on board the different perspectives to environment matters from participating agencies and their stakeholders. 
The MfE's style of policy analysis, therefore, was interactive as featured in the Mayer et al. (2013) model. The challenges posed by climate change or global warming, for example, are never fully solved or free from disputes. Besides, these policy issues are not value-free. Experts, citizens and other stakeholders actively engage with their own views about the policy problem. From Mayer at al. model (2013) the activities that made policy analysis in the MfE were: Democratise to consider different perspectives and Mediate to resolve policy issues where analysts consulted and negotiated with different stakeholders and participants in the NRS.

The AC's efforts to professionalising policy practices were also influenced by its tradition and work culture. The Auckland City Council was a service delivery organisation with many departments providing different services to Aucklanders. When the AC was formed in 2010, it needed to shift its focus from operational policies to developing strategic policies to positively affect Aucklanders' public life then and in the future. This required change in the work culture in the $\mathrm{AC}$ and building a common understanding of how to approach a policy problem.

The AC had to develop policies to govern a much larger authority which could serve the diversity of policy settings. A very large and new organisation inherited staff from previous councils (one regional council and seven local councils), who brought with them knowledge and experiences with policies associated with smaller and more diverse policy settings. Larger councils had more staff and during the period of transition, there was often debate about the merits and demerits of the policies of such councils. The previous councils had also struggled to build consensus among the councillors because of governance arrangements that created divisiveness. The non-collaborative culture among departments of the $A C$ also produced duplication of policy work. This required the $A C$ to develop new policies which could cater for the much greater diversity across the council. The councillors' struggle to make timely decisions tended to strengthen the power of the Mayor's Office, with the mayor increasingly empowered with resources to make quick decisions. 
The tradition and work culture, accordingly, influenced how to design initiatives to professionalise policy practices in the AC. The AC, therefore, developed its eight-step policy commissioning process to streamline and standardise policy work in the Council and an eight-step policy cycle to convey the idea of how and who could contribute to the AC's policy process. The Policy Hub and Policy Register were designed to enhance collaboration across the departments within the Council and avoid duplication of policy work.

The AC's style of policy analysis corresponded to the features of a Client Advice style. A client advice style, as described by Mayer et al. (2013) model. A client advice style is observed when 'policymaking occurs in a complex and rather chaotic arena. There are numerous players, with different interests and strategies' (Mayer et al., 2013, p. 180). The councillors were at times divided according to differing opinions and decision making was not easy and quick. The $A C^{\prime}$ 's forward looking view, reflected in making future plans, shows its policy analysis activities were: Design and recommend and Strategic as sketched in the Mayer et al. (2013) model.

Although policy analysis styles observed were rational and interactive in the MoT and the MfE respectively, the policy analysis styles in these two agencies also corresponded to a client advice style. The client advice style is the one which 'involves a more designoriented approach or a strategic, process driven approach' (Mayer et al., 2013, p. 180). As envisaged in the model, the senior leaders in these agencies performed as the designers who gained insight in the various objectives, means and interests of the actors involved. Policy analysis also involved politico-strategic insight and skills including clientanalyst communication. The findings confirm the claim of Mayer et al. (2013, p. 169) that in practice, policy analysis consists of creatively combining these activities and styles' and 'when more activities are combined, a policy analysis project will become richer and more comprehensive, but also more complex' (Mayer et al., 2013, p. 173).

The different nature of clients across the cases also influenced how these agencies professionalised policy practices. There were significant differences in the institutional context. The councillors in the AC were not necessarily on the same side when making 
decisions. In contrast, when government made decisions in the matters related to transport or environment, either in cabinet or cabinet committee, decision makers were all from the same party. The AC operated more like a parliament. They debated, often broke rank, went to the media, and tried to engender support for the next election for themselves personally, as confirmed by the interviewees. In the AC, there was no authority, such as a minister in the central agencies, who took ownership of the analysts' advice to take a decision. The analysts owned the advice more than the councillors whereas, in the central agencies, the cabinet potentially owned the advice more than the analysts. These different contexts influenced the level of professionalising.

The level of professionalising policy analysis and advice is also significantly affected by demand stemming from PIF reviews, senior leader's role, the NZIER ratings and the feedback mechanism, although the specific sources varied across the cases. The demand for high-quality analysis, primarily, in the MoT was created by the PIF reviews, in the MfE by the Environment Leadership Team's (ELT) role and in the AC by the NZIER ratings. The feedback mechanism in the cases, with degrees of variation, included internally developed quality measures for policy analysis and advice, peer review, regulatory impact statement panel, internal review panel for quality check, and informal feedback from policy managers. Each was meant to show policy staff how to achieve the quality standard for policy analysis and advice, while also creating high expectations for the work of policy staff. Thus, the demand for high-quality policy analysis originated both internally and by some externally developed measures or reports of reviews.

The sources of demand, whether originated internally and/or imposed externally, for high-quality policy analysis and advice also shaped the nature of professionalising policy practices. The nature of policy capability deficit, perceived skill levels and confidence of senior managers in the agencies influenced the degree to which policy initiatives were designed and implemented by the agency. If the influence and nature of initiatives were determined by the authors of a PIF report or performance assessment, the agency had less flexibility in how it invested to improve policy capability, as seen in the MoT. Where there were concerns about performance, the PIF review could trigger further reviews which would put pressure on the organisation to demonstrate improvements. Some 
information regarding the specific design and choice of initiatives was outlined in a PIF report and in some cases, initiatives were specifically defined by the PIF report which was signed by the three central agencies.

In cases of internally developed demand for high-quality policy analysis, the CE and senior managers had the scope to design various initiatives which were decided primarily by the specific public sector agencies, as found in the MfE. In the AC, the demand was created mainly by the external measures and it responded to the NZIER ratings by adopting initiatives to improve policy capability and the quality of policy advice. The AC's efforts to professionalise policy practices were significantly affected by the lack of demand from its clients and senior leaders of the Council.

The two supply-side elements identified in theory were the availability of quality data and information and the existence of study programmes on public policy (Mendez \& Laguna-Dussauge, 2017). These three agencies' efforts to ensure the supply of highquality policy analysis with a wide range of initiatives show a clear appreciation of available knowledge in academic and practitioner literature. The supply side elements were not limited to the availability of quality data and information and the existence of study programmes but included a range of ways and means to promote learning and innovations in producing policy analysis and advice (shown in detail in Chapter 6).

The initiatives developed by the three agencies, to improve both policy analytical and management capability, led to a wide range of similar forms of initiatives. What varied was how the chief executives and senior managers designed and implemented similar approaches but had regard for the scope and nature of their policy advice and various contextual conditions and influences. The managers who developed and implemented the initiatives were sometimes required to design an approach which was tailored for more successful implementation. To illuminate, two agencies with very similar capability deficits may adopt different strategies: one may seek to recruit and build capability skills for junior policy staff, as did the MoT, whereas other agencies may invest in hiring senior staff, as did the MfE, to help the organisation lift the quality of its policy analysis and 
advice. Professionalising policy analysis and advice across the cases, consequently, took different approaches.

In brief, the findings suggest that initiatives are developed and designed according to influences and circumstances specific to the agencies (internal influences) as well as an expectation-response relationship between the producers of and clients for policy advice (external influences). Second, the initiators' regard for internal and external influences, across the cases, shows that the relevance and significance of different types of policy capability at individual and organisation levels have varied under different contexts.

The summary and conclusions of are set out in Chapter 8. 


\section{CHAPTER 8: Conclusion}

In this thesis, the central agency initiatives developed between 1990 and 2015 to improve policy capability and the quality of policy analysis and advice were examined longitudinally to explain the initiators' choice and use of initiatives over a long time period. The initiatives in three case agencies developed between the shorter time period, 2008 and 2015, were examined to explain the initiators' choice and use of initiatives. Analysis of the central agencies' initiatives has shown how the initiators persistently created high expectations from policy analysis and advice, whereas in the case of agencies' initiatives, analysis has shown responses to expectations.

More specifically, the examination of central agency initiatives demonstrated how the significance of policy analytical, management and political capability at individual, organisational and system levels varied over time under different contexts, due to changing priorities and policy agendas. The guidelines to professionalising policy analysis and advice, reflected in the nature, form and design of the initiatives, changed accordingly. The initiators' focus was on improving the rigour of policy analysis and satisfying the immediate client following the reforms in the 1990s. The focus then shifted to improving policy management capability and meeting the expectations of the public sector instead of being overly focussed on immediate clients. Since the beginning of this century, policy analysis and advice is now required to be more free and frank under the Westminster policy advisory system, strategic, future-focussed and prepared not only for the government of the day but for successive governments and the public. The New Zealand government has called for a 'whole of government' approach to promote horizontal and vertical dimensions of collaboration in the public sector while producing policy analysis and advice, and mandated that policy staff in senior roles will act not only as policy leaders but also as policy stewards to be prepared for future governments. With these changing priorities, the style of policy analysis has become more collaborative, inclusive and participatory over time.

Turning to the examination of agency initiatives, the analysis demonstrated how the significance of policy analytical, management and political capability at individual and 
organisation levels varied across the cases and under different contexts pertinent to the agencies. The different contexts related to the nature of clients, the demand for and supply of policy analysis, the nature of the agencies' roles and functions, the governance and accountability arrangements, the tradition and culture of the organisation, and the policies and priorities of the government of the day. The efforts to professionalise policy analysis and advice therefore have taken different approaches in the three cases and the style of policy analysis also varied accordingly across the cases.

The common factors found in the examination of both central and agency initiatives are the role of 'change' and the role of 'context' in influencing the production of policy analysis and advice. The changes have taken place in policy priorities and agendas, and as a response to that, in policy inputs (policy staff, tools, methods, models and frameworks and guides), in the approaches to professionalising policy practices and in the clients' views on the quality of policy output (policy advice). The context has played a significant role in shaping the approaches to professionalising policy analysis and advice, over time and across the cases, and producing different styles to policy analysis.

The research has found that the overall purpose of the initiators' actions, centred on the development and use of initiatives, was to professionalise policy practices. According to this purpose, the agencies sought to build, improve and maintain policy capability so that policy analytical, management and political capability at all levels, individual, organisation and system, would become and remain refined and polished to meet the ever-changing nature of demand for policy analysis and advice.

The key factors found to achieve and maintain improved policy capability are the policy leaders' ability to understand government priorities and relevant contexts and thus, to choose and apply a policy analysis style ensuring the production of fit-for-purpose and fit-for-future policy advice. Second, in their role as the designers of initiatives in which they incorporate contextual information, leaders seek to ensure that their choices in professionalising policy analysis and advice are relevant to the agency, and flexible and responsiveness to the changing nature of demand for policy analysis and advice. 
The dynamic influences on the production of policy analysis and advice show that the concept of improved policy capability and the assessment of the quality of policy analysis and advice are also dynamic. These cannot be gauged against static presketched views of policy capability and the quality of policy advice.

Policy capability in practice differs from that in theory. Policy capability, in theory, is identified by its constituents: knowledge, skills, competencies and behaviours at three levels, individual, organisation and system. Theories specify what knowledge, skills, competencies and behaviours are required to achieve improved policy capability. However, policy capability, found in practice, treats the suggestions, guidance, and recommendations available from theory somewhat differently to reflect the importance of context-specific conditions.

Theory is centred on improving the policy process, the quality of policy inputs and outputs, the quality and appropriateness of policy tools, and other such factors to improve policy analytical capability. The assumption is that any dissatisfaction with the quality of policy advice is due to poor policy analytical capability. Looking from the findings of this research back to theory, it is evident that there is less focus in theory on the dynamic influences under which policy analysis and advice is developed. Policy capability, in practice, puts significant emphasis on responding to influences, both internal and external to the agencies.

Policy capability cannot be ascertained by looking only at whether policy analysis and advice includes some stated attributes in some 'right' mix. Correspondingly, policy capability at the organisation level is not the sum of individual policy capability, although policy capability at the organisation level is reflected by the ability of its policy staff. Policy capability cannot be said ever to have been achieved once and for all.

Rather, whether improved policy capability has been achieved was found to be strongly relative to the contextual conditions. Thus, a view that achieving improved policy capability by gaining some set of capabilities, perhaps guided by generic initiatives, must be rejected. From practice examples, it is clear that improved policy capability can only 
be assessed through reflection on the use of policy analytical, management and political capability at individual, organisation and system levels to be able to produce fit-forpurpose policy advice.

The delivery of fit-for-purpose policy advice today, however, does not guarantee further such success in the next policy assignment or task from the same policy producers. The next policy assignment or task will require adapting different considerations and integrating capabilities in new ways, leading to more fit-for-purpose insights. However, a fresh approach to a new policy enterprise each time must not be misconstrued as some adventurous activities without any logical structure and boundaries. Rather, policy processes, frameworks, tools, methods, guidance, as suggested in theory, help policy analysts and advisors to navigate and structure their work and their insights are effectively channelled.

The assessment of policy capability cannot be captured by the quality of policy advice. Multiple clients at different levels, including the public, may judge the quality of policy advice. However, in New Zealand practice, quality judgements have been dominated by those made through the Performance Improvement Framework (PIF) and New Zealand Institute of Economic Research (NZIER) ratings. These privilege judgements by clients at a system level. On this basis, no linear relation can be claimed between improved policy capability and the quality of policy advice. In other words, while there is no universal stance on how to gauge improved policy capability and measure high-quality policy advice, assuming a linear relation between them must be rejected. Therefore, it is futile to attempt to correlate achieving improved policy capability and producing high-quality policy analysis and advice.

The political leaders' concern with the declining policy capability of policy advice producers in the public sector needs revisiting. Since policy capabilities are separable as policy analytical, management and political capability but they also are inter-connected and governed by different considerations (Wu et al., 2015). Even if it is true (which is not certain) that policy capability is declining, policy advice producers' poor policy analytical capability cannot be the sole cause. The consumers' policy capability at system level also 
influences how policy analysis and advice is produced and used. Improving policy capability of the policy actors at system level is likely to be interpreted as an increase in policy capability.

Approaching policy analysis as a design exercise is promising. A design-approach may be contrasted with rationalist/formalist; positivist; and post-positivist approaches. The policy mangers' role as designers fits with the context-relevance emphasis found in the cases examined in this research. In designing the initiatives, the initiators acted as the designers, with penetrating insight into the context, an element of the policy-design approach to policy analysis and advice. This element guided the designers to clearly 'differentiate between those things that must be accepted as given preconditions or constraints on the design activity and those that could be changed by their own talents and efforts' (Adachi, 2017, p. 33). The internal and external influences on shaping the design and form of the initiatives implied that the constraints were first considered as preconditions, then treated with the appropriate initiatives and efforts as the initiators applied their insights to the context-specific conditions.

These conclusions emphasize the role of policy staff at senior roles as vital to produce fit-for-purpose and fit-for-future policy advice. Their roles were found crucial in adopting and applying insights through initiatives. Future research can focus on identifying what attributes senior policy managers should have to best apply insights. Other questions concern whether policy managers can be trained how to better apply insights in design pre-conditions or whether this ability is naturally developed in the 'right' environment, over time and in different policy roles. These issues and related ones can be examined to make good use of policy managers' insights.

\section{Epilogue}

Policy analysis and advice is done in dynamic environment. Policy people change, resources change, tools change. Along with these, the ideas and concepts change or vice versa. Initiatives also come and go as the personnel across the organisations change or as change of priorities comes along. Priorities fade to accommodate another new priority. Just to reinforce the diversity and changing policy environment under which 
policy analysis and advice is produced, it is noted that many of the policy professionals interviewed for this thesis are no longer serving for the same employers or the same profession even. Some ideas and initiatives developed by the senior leaders were discontinued after 2015 , beyond the time frame for this thesis, and replaced by the ideas of the new senior leaders in the organisations. The exquisiteness of policy work, perhaps, lies in this diversity. 


\section{References}

Adachi, Y. (2017). The policy analysis profession. In Routledge handbook of comparative policy analysis (pp. 27-42). London: Taylor \& Francis Group.

AGRAGA. (2010). Ahead of the Game: Blueprint for the Reform of Australian Government Administration. Retrieved from

Allen, B. (2017). Independent Review of the Performance Improvement Framework. Retrieved from New Zealand:

Althaus, C., Bridgman, P., \& Davis, G. (2007). The Australian policy handbook (4th ed. ed.). Crows Nest, N.S.W.: A\&U Academic.

ANZSOG. (2002). Australia and New Zealand School of Government, EMPA programme. Retrieved from https://www.anzsog.edu.au/

Auckland Council. (2012). The Auckland plan. Retrieved from New Zealand:

Auckland Council. (2013). Guide to providing quality policy advice at Auckland Council. Retrieved from New Zealand:

Auckland Council. (2015). About local government. Retrieved from http://www.localcouncils.govt.nz/lgip.nsf/wpg_url/about-local-government-index

Auckland Council. (2017). Auckland Council governace statement 2017. Retrieved from https://www.aucklandcouncil.govt.nz/about-auckland-council/how-aucklandcouncil-works/Documents/local-governance-statement.pdf

Baimyrzaeva, M. (2013). Policy analysis as a profession in government: Who does what and how. University of Central Asia, Institute of Public and Administration, 2, 32.

Bale, M., \& Dale, T. (1998a). Public Sector Reform In New Zealand And Its Relevance To Developing Countries. World Bank Research Observer, 13(1), 103-121. doi:10.1093/wbro/13.1.103

Bale, M., \& Dale, T. (1998b). Public sector reform in New Zealand and its relevance to developing countries. The World Bank Research Observer, 13(1), 103-121.

Bardach, E. (2012). A practical guide for policy analysis: The eightfold path to more effective problem solving (4th ed.). Los Angeles, CA: CQ Press.

Barney, J. (1991). Firm Resources and Sustained Competitive Advantage. Journal of Management, 17(1), 99-120. doi:10.1177/014920639101700108

Birkland, T. A. (2001). An introduction to the policy process: theories, concepts, and models of public policy making. New York: Routledge.

Blackman, D. A., Buick, F., O'Donnell, M., O'Flynn, J., \& West, D. (2012). Developing high performance: Performance management in the australian public services. Crawford School Research Paper.

Boston, J. (1994). Purchasing policy advice: the limits to contracting out. Governance, 7, $1-30$.

Boston, J., \& Eichbaum, C. (2014). New Zealand's Neoliberal Reforms: Half a Revolution. Governance, 27(3), 373-376. doi:10.1111/gove.12092

Bromell, D. (2010a). The public servant as analyst, adviser, and advocate. Public policy: Why ethics matters, 55-78.

Bromell, D. (2010b). The public servant as analyst, adviser, and advocate. In J. Boston, A. Bradstock, \& D. Eng (Eds.), Public policy: Why ethics matters. Wellington: New Zealand: ANU E Press.

Bromell, D. (2017). The Art and craft of policy advising: A practical guide. Cham: Switzerland: Springer International Publishing.

Brown, T. (2008). Design thinking. Harvard Business Review, 86(6), 84. 
Cabinet Office UK. (2004). Strategy survival guide. Retrieved from http://webarchive.nationalarchives.gov.uk/20060214033713/http://www.strategy.g ov.uk/downloads/survivalguide/downloads/ssg_v2.1.pdf

Cairney, P., \& Geyer, R. (2015). Handbook on Complexity and Public Policy. Cheltenham: Edward Elgar Publishing.

Civil Service. (2013). Twelve actions to professionalise policy making. Retrieved from UK:

Civil Service. (2017). Policy Profession Standards. Retrieved from UK:

Civil Service. (2019). Policy lab. Retrieved from https://openpolicy.blog.gov.uk/about/

Civil Service UK. (2018). Twelve actions to professionalise policy making. Retrieved from https://civilservicelearning.civilservice.gov.uk/sites/default/files/twelve_actions_r eport_web_accessible.pdf

Colebatch, H. K. (2002). Policy (2nd ed.). Buckingham ; Philadelphia, PA.: Open University Press.

Colebatch, H. K. (2006). Beyond the policy cycle : the policy process in Australia Crows Nest, N.S.W.: Allen \& Unwin.

Considine, M. (1994). Public policy: A critical approach. Melbourne: Australia: Macmillan Education Australia.

Craft, J., \& Halligan, J. (2017). Assessing 30 years of Westminster policy advisory system experience. Integrating Knowledge and Practice to Advance Human Dignity, 50(1), 47-62. doi:10.1007/s11077-016-9256-y

Craft, J., \& Howlett, M. (2012). Policy formulation, governance shifts and policy influence: location and content in policy advisory systems. Journal of Public Policy, 32(2), 79-98. doi:10.1017/S0143814X12000049

Creswell, J. W. (2009). Research design: qualitative, quantitative, and mixed methods approaches (3rd ed.). Thousand Oaks, California: SAGE Publications Inc.

Davison, N. (2015). Lifting the policy game across the system: the case of the policy project. Retrieved from New Zealand:

Department of Prime Minister and Cabinet. (2016a). Launch of Policy Project frameworks [Press release]. Retrieved from https://www.beehive.govt.nz/speech/launch-policy-project-frameworks

Department of Prime Minister and Cabinet. (2016b). The Policy Project. Retrieved from https://www.dpmc.govt.nz/our-programmes/policy-project/policy-improvementframeworks

Department of Prime Minister and Cabinet. (2017). The Policy Project. Retrieved from https://www.dpmc.govt.nz/our-programmes/policy-project

Dror, Y. (1967). Policy analysts: A new professional role in government service. Public Administration Review, 27(3), 197-203. doi:10.2307/973282

Dunn, W. N. (2004). Public policy analysis: an introduction (3rd ed.). Upper Saddle River, N.J. : Pearson Prentice Hall.

Eichbaum, C. (2017, 8 August). Free and frank advice fast disappearing. Stuff. Retrieved from https://www.stuff.co.nz/national/politics/95499693/chris-eichbaum--freeand-frank-advice-fast-disappearing

Eisenhardt, K., \& Martin, J. (2000). Dynamic Capabilities: What Are They? Strategic Management Journal, 21, 1105-1121.

Europeam Institute of Public Administration. (2013). CAF - Common Assessment Framework. Retrieved from Canada:

Flyvbjerg, B. (2006a). Five misunderstandings about case-study research. Qualitative Inquiry, 12(2), 219-245. doi:10.1177/1077800405284363 
Flyvbjerg, B. (2006b). Five Misunderstandings About Case Study Research Qualitative Inquiry, SAGE Publications Inc., 12(2), 219-245.

Franks, T. (1999). Capacity building and institutional development: reflections on water. Public Administration and Development, 19(1), 51-61. doi:doi:10.1002/(SICI)1099-162X(199902)19:1<51::AID-PAD54>3.0.CO;2-N

Geva-May, I. (2005). Thinking like a policy analyst: policy analysis as a clinical profession (1st ed.). New York, USA: Palgrave Macmillan.

Geyer, R., \& Rihani, S. (2010). Complexity and public policy : a new approach to twentyfirst century politics, policy and society. London ; New York: Routledge.

Gillham, B. (2000). Case study research methods. New York : London: Continuum International Publishing Group.

Gluckman, P. (2011). Towards better use of evidence in policy formation: An address to the institute of public administration New Zealand Retrieved from New Zealand

http://www.pmcsa.org.nz/wp-content/uploads/Towards-better-use-of-evidence-inpolicy-formation.pdf

Gluckman, P. (2013). The role of evidence in policy formation and implementation. Retrieved from http://www.pmcsa.org.nz/wp-content/uploads/The-role-ofevidence-in-policy-formation-and-implementation-report.pdf

Gluckman, P. (2014). The art of science advice to government. Nature International Weekly Journal of Science, 507(7491), 163-165.

Hallsworth, M. (2011). Policy-making in the real world. Political Insight, 2(1), 10-12.

Hawke, G. R. (1993). Improving policy advice. Wellington, NZ: Institute of Policy Studies, Victoria University of Wellington.

Head, B. W. (2008). Three lenses of evidence-based policy. Australian Journal of Public Administration, 67(1), 1-11.

Head, B. W., \& Alford, J. (2015). Wicked Problems: Implications for Public Policy and Management. Administration \& Society, 47(6), 711.

Hill, M. J. (2005). The public policy process (4th ed.). Harlow, England ; New York: Pearson Longman.

Hogwood, B. W., \& Gunn, L. A. (1984). Policy analysis for the real world Oxford, U.K: New York Oxford University Press Inc. .

Howlett, M. (2009). Policy analytical capacity and evidence-based policy-making: Lessons from Canada. Canadian Public Administration, 52(2), 153-175. doi:10.1111/j.1754-7121.2009.00070_1.x

Howlett, M. (2010). Designing public policies: Principles and instruments. London: Routledge.

Howlett, M. (2015). Policy analytical capacity: The supply and demand for policy analysis in government. Policy and Society, 34(3-4), 173-182. doi:10.1016/j.polsoc.2015.09.002

Howlett, M., Ramesh, M., \& Perl, A. (2009). Studying public policy : policy cycles \& policy subsystems (3rd ed.. ed.). Don Mills, Ont. ; New York: Oxford University Press.

Howlett, M., Ramesh, M., \& Perl, A. (2009). Studying Public Policy: Policy Cycles \& Policy Subsystems (3rd ed.). Canada: Oxford University Press.

Huxham, C. (2003). Theorizing collaboration practice. Public management review, 5(3), 401-423.

Irwin, L. G. (2003). The Policy Analyst's Handbook: Rational Problem Solving in a Political World. Oxfordshire, England; New York: Routledge

Jenkins-Smith, H. (1990). Democratic politics and policy analysis Pacific Grove, California Brooks/Cole. 
John, P. (2012). Analyzing public policy (2nd ed.). Abingdon, Oxon ; New York: Routledge.

Kettl, D. F. (2005). The global public management revolution (2nd ed.). Washington D.C.: Brookings Institution.

Kibblewhite, A., \& Boshier, P. (2018). Free and Frank Advice and the Official Information Act: Balancing competing principles of good government. Policy Quarterly, 14(2), 3-9.

Kibblewhite, A., \& Ussher, C. (2002). Outcome-focused management in New Zealand. OECD Journal on Budgeting, 1(4), 85-109. doi:https://doi.org/10.1787/16812336

Knoepfel, P., Larrue, C., Varone, F., \& Hill, M. (2007). Public policy analysis. Bristol, UK: The Policy Press at the University of Bristol.

Krauss, S. E. (2005). Research paradigms and meaning making: a primer. The Qualitative Report, 10(4), 758-770.

Laking, R. (2000). Introduction: a strategic approach to policy organisation. School of Government. Victoria University of Wellington. New Zealand.

Lijphart, A. (1984). Democracies: Patterns of majoritarian and consensus government in twenty-one countries. New Haven, Connecticut: Yale University Press.

Lodge, M., \& Hood, C. (2003). Competency and bureaucracy: Diffusion, application and appropriate response? West European Politics, 26(3), 131-152. doi:10.1080/01402380312331280618

Lundin, M., \& Öberg, P. (2017). Policy analysis at the local level. In M. Brans, I. GevaMay, \& M. Howlett (Eds.), Routledge handbook of comparative policy analysis (pp. 131-142). New York, NY: Taylor \& Francis.

MacIntyre, A. (1985). After virtue: A study in moral theory. London: Duckworth.

Majone, G. (1989). Evidence, argument, and persuasion in the policy process. New Haven, Connecticut: Yale University Press.

Martin, J. (1996). The impact of MMP on policy development and advice. Public Sector, $19(2), 17-22$.

Martin, J. R. (2012). Round table on 'Free and frank advice': Summary of discussion. Policy quarterly (Victoria University of Wellington. Institute for Governance and Policy Studies : Online), 8(4), 11-15.

Matthews, P. (2013). Capability. Training Journal. Retrieved from https://www.peoplealchemy.co.uk/capability-2/

Mayer, I. S., van Daalen, C. E., \& Bots, P. W. (2013). Perspectives on policy analysis: a framework for understanding and design. In W. A. H. Thissen \& W. E. Walker (Eds.), Public Policy Analysis (Vol. 179, pp. 41-64). New York; London: Springer New York; Heigelberg Dordrecht London.

McConnell, A. (2010). Understanding Policy Success: Rethinking Public Policy. New York: Palgrave Macmillan.

Meltsner, A. (1979). Creating a policy analysis profession. Social Science and Modern, 16(6), 45-51. doi:10.1007/BF02694522

Mendez, J.-L., \& Laguna-Dussauge, M. I. (2017). Policy analysis and bureaucratic capacity. In Routledge Handbook Comparative Policy Analysis (pp. 70-84). London: Taylor \& Francis Group.

MfE. (2011). Professionalising Policy: A Guide for Developing the Craft of Policy Analysis Retrieved from Wellington, New Zealand: https://www.mfe.govt.nz/about/docs/panda-mfe-policy.pdf

Millerson, G. (1964). The qualifying associations : a study in professionalization. London: Routledge \& Kegan Paul. 
Ministry for the Environment. (1986). Environment Act 1986. Retrieved from http://www.legislation.govt.nz/act/public/1986/0127/22.0/DLM98975.html

Ministry for the Environment. (2008). Report of the Ministry for the Enviroment for the year ended 30 June 2008. Retrieved from http://www.mfe.govt.nz/sites/default/files/annual-report-2007-2008_0.pdf

Ministry for the Environment. (2009). Report of the Ministry for the Enviroment for the year ended 30 June 2009. Retrieved from https://www.mfe.govt.nz/sites/default/files/report.pdf

Ministry for the Environment. (2010). Report of the Ministry for the Enviroment for the year ended 30 June 2010. Retrieved from http://www.mfe.govt.nz/sites/default/files/mfe-annualreport2009-2010.pdf

Ministry for the Environment. (2011). Professional policy: Cost opportunity benefit risk analysis. Retrieved from Wellington, New Zealand: https://www.mfe.govt.nz/about/docs/cobra-mfe-policy.pdf

Ministry for the Environment. (2013a). Natural Resources Framework: Guidance for users. Retrieved from New Zealand:

Ministry for the Environment. (2013b). Report of the Ministry for the Enviroment for the year ended 30 June 2013. Retrieved from https://www.parliament.nz/resource/miNZ/50DBHOH_PAP25442_1/d9160019646bf8662d2fd00bdef7cf5d252d2cb4

Ministry for the Environment. (2014a). Natural resources sector. Retrieved from

Ministry for the Environment. (2014b). Report of the Ministry for the Enviroment for the year ended 30 June 2014. Retrieved from http://www.mfe.govt.nz/sites/default/files/media/About/annual-report-2014.pdf

Ministry for the Environment. (2014c). Statement of intent 2014-2018. Retrieved from http://www.mfe.govt.nz/sites/default/files/statement-of-intent-2014.pdf

Ministry for the Environment. (2015a). Four Year Plan 2016-2020. Retrieved from https://www.mfe.govt.nz/sites/default/files/media/About/four-year-plan-2016.pdf

Ministry for the Environment. (2015b). A generation from now: Our long-term goals. Retrieved from http://www.mfe.govt.nz/sites/default/files/media/About/generation-from-nowoutcomes.pdf

Ministry for the Environment. (2015c). Leadership team. Retrieved from http://www.mfe.govt.nz/about-us/leadership-team

Ministry for the Environment. (2015d). Report of the Ministry for the Enviroment for the year ended 30 June 2015. Retrieved from http://www.mfe.govt.nz/sites/default/files/media/About/annual-report-2015.pdf

Ministry for the Environment. (2018). About the Ministry for the Environment. Retrieved from http://www.mfe.govt.nz/about-us/about-ministry

Ministry of Transport. (2009). Annual report 2008-2009. Retrieved from https://www.transport.govt.nz/assets/Uploads/About/Documents/Annual-Report2008-09.pdf

Ministry of Transport. (2010). Annual report 2009-2010. Retrieved from https://www.transport.govt.nz/assets/Import/Documents/MOT-Annual-Report2009-10-web.pdf

Ministry of Transport. (2013). Performance Improvement Framework: Review of the Ministry of Transport (the Ministry) 2013. Retrieved from http://www.ssc.govt.nz/sites/all/files/pif-mot-review-august2013.PDF

Ministry of Transport. (2014a). Performance Improvement Framework: Follow-up review of the Ministry of Transport 2014. Retrieved from 
https://www.transport.govt.nz/assets/Uploads/News/Documents/PIF-MOTfollowup-FINAL.PDF

Ministry of Transport. (2014b). Transport sector briefing to the incoming minister: Introduction to transport. Retrieved from https://www.transport.govt.nz/assets/Uploads/About/Documents/TransportSector-BIM-2014.pdf

Ministry of Transport. (2015a). About the Ministry of Transport. Retrieved from https://www.transport.govt.nz/about/

Ministry of Transport. (2015b). History of the Ministry. Retrieved from https://www.transport.govt.nz/about/history/

Ministry of Transport. (2015c). Our functions. Retrieved from https://www.transport.govt.nz/about/functions/

Ministry of Transport. (2015d). Policy groups. Retrieved from https://www.transport.govt.nz/about/our-people/policy-groups/

Minitry of the Environment. (2011). Professionalising Policy: A guide for developing the craft of policy analysis. Retrieved from Wellington, New Zealand: https://www.mfe.govt.nz/about/docs/panda-mfe-policy.pdf

Mintrom, M. (2003). People skills for policy analysts Washington D.C.: Georgetown University Press.

Mintrom, M. (2011). Policy advice and the pursuit of public value. Policy quarterly (The Institute of Policy Studies, School of Government at Victoria University of Wellington), 7(3), 8-12.

Mintrom, M. (2012). Contemporary policy analysis New York, USA: Oxford University Press, Inc.

Mintrom, M., \& Luetjens, J. (2016). Design Thinking in Policymaking Processes: Opportunities and Challenges. Australian Journal of Public Administration, 75(3), 391-402. doi:10.1111/1467-8500.12211

Mintrom, M., \& Thomas, M. (2018). Improving commissioning through design thinking. Policy Design and Practice, 1(4), 310-322. doi:10.1080/25741292.2018.1551756

Moore, M. H. (1995). Creating public value: Strategic management in government. Cambridge Harvard University Press.

Morrison, V. (2013). Wicked problems and public policy. Retrieved from https://www.inspq.qc.ca/pdf/publications/1841_Wicked_Problems_Policy.pdf

Moses, J. W., \& Knutsen, T. L. (2012). Ways of knowing: Competing methodologies in social and political research (2nd ed.). New York, NY: Palgrave Macmillan.

Mulgan, R. (2012). What future for free and frank advice? Policy quarterly (Victoria University of Wellington. Institute for Governance and Policy Studies : Online), 8(4), 3-10.

Mulgan, R. G. (1997). Politics in New Zealand (2nd ed.). Auckland, New Zealand: Auckland University Press.

Nagel, S. S. (2002). Handbook of Public Policy Evaluation: SAGE Publications, Inc.

Nutley, S., Walter, I., \& Davies, H. (2009). Past, present, and possible futures of evidence-based policy. In G. Agryous (Ed.), Evidence for policy and decisionmaking: a practical guide. Sydney: University of New South Wales Press Ltd.

Nutley, S. M., Walter, I., \& Davies, H. T. O. (2007). Using evidence: How research can inform public services. Bristol: Policy Press at the University of Bristol.

NZIER. (2012). Policy Advice Quality Review 2012. Retrieved from Wellington, New Zealand: http://www.parliament.nz/resource/0002154478

O'Leary, R. (2014). Collaborative governance in New Zealand : important choices ahead / prepared by Rosemary O'Leary. In i. b. Fulbright New Zealand \& b. Ian Axford 
Fellowships in Public Policy. sponsoring (Eds.): Wellington, New Zealand : Fulbright New Zealand.

O'Leary, Z. (2017). The essential guide to doing your research project (3rd edition.. ed.). London; Thousand Oaks, California Sage Publications Ltd.

OECD. (2014). Competency framework. Retrieved from https://www.oecd.org/careers/competency_framework_en.pdf

Painter, M., \& Pierre, J. (2005). Unpacking policy capacity: Issues and themes. In Challenges to State Policy Capacity: Global Trends and Comparative Perspectives. New York, NY: Palgrave Macmillan.

Parkhurst, J. (2017). The Politics of Evidence. United Kingdom: Taylor \& Francis.

Parsons, D. W. (1995). Public policy: An introduction to the theory and practice of policy analysis. Aldershot, England: Edward Elgar.

Parsons, D. W. (2004). Not just steering but weaving: Relevant knowledge and the craft of building policy capacity and coherence. Aust J Public Adm, 63. doi:10.1111/j.1467-8500.2004.00358.x

Patton. (2001). Qualitative research \& evaluation methods.

Patton, C., \& Sawicki, D. (1993). Basic Methods of Policy Analysis and Planning (2nd ed.). New Jersey, USA: Prentice Hall Inc.

Pratt, M., \& Horn, M. (2014). Leadership and capability development and deployment in the New Zealand state service. Policy quarterly (Victoria University of Wellington. Institute for Governance and Policy Studies : Online), 10(1), 45-53.

Radin, B. (2000). Policy analysis comes of age. Canberra Bulletin of Public Administration(97), 73-77.

Radin, B. (2013). Beyond Machiavelli: policy analysis reaches midlife.

Radin, B. (2017). Refrlection on a half century of policy analysis. In M. Brans, I. GevaMay, \& M. Howlett (Eds.), Routledge Handbook of Comparative Policy Analysis (pp. 85-99). London: Taylor \& Francis Group.

Rennie, I. (2012). Changing the culture to build better public services: It's not only what we do but how we do it that will make us great. Policy quarterly (Victoria University of Wellington. Institute for Governance and Policy Studies : Online), 8(3), 4-10.

Rennie, I. (2013). Speech of Head of State Services and State Services Commissioner Iain Rennie at the Institute of Public Administration New Zealand (IPANZ) State sector legislation launch. Retrieved from http://www.ssc.govt.nz/sscer-speechipanz-30july13

Rhodes, R. A., Wanna, J., \& Weller, P. (2008). Reinventing Westminster: how public executives reframe their world. Policy \& Politics, 36(4), 461-479.

Rhodes, R. A. W., \& Weller, P. (2005). Westminster transplanted and Westminster implanted: Exploring political change. In H. Patapan, J. Wanna, \& P. Weller (Eds.), Westminster legacies: Democracy and responsible government in Asia and the Pacific (pp. 1-13). Sydney, Australia: University of New South Wales Press Ltd.

Riddell, N. (1998). Policy research capacity in the federal government. In. Ottawa, Canada: Policy research initiative.

Roberts, N. (2000). Wicked problems and network approaches to resolution. International public management review, 1(1), 1-19.

Rowley, J. (2002). Using case studies in research. Management research news, 25(1), 1627.

Sabatier, P. A. (2007). Theories of the policy process (2nd edition.. ed.). Boulder, Colo.: Westview Press. 
Salmon, P., Bazley, M. C., \& Shand, D. A. (2009). Royal Commission on Auckland Governance. Retrieved from http://www.royalcommission.govt.nz/

Schick, A. (1998a). The Spirit of Reform: Managing the New Zealand State Sector in a Time of Change. Australian Journal of Public Administration, 57(3), 139.

Schick, A. (1998b). Why Most Developing Countries Should Not Try New Zealand's Reforms. World Bank Research Observer, 13(1), 123-131. doi:10.1093/wbro/13.1.123

Scott, C. (2006). Policy work and public sector reform in New Zealand. In H. K. Colebatch (Ed.), The work of policy: An international survey (pp. 133-145). Lanham, Maryland: Lexington Books.

Scott, C. (2008a). Enhancing the quality and capability in the public sector advisory system. In Futuremakers lecture series. Wellington, New Zealand: Institute of Policy Studies.

Scott, C. (2008b). Enhancing the quality and capability in the public sector advisory system. Paper presented at the Futuremakers lecture series, Wellington, New Zealand.

Scott, C. (2017). The Choice of Formal Policy Analysis Methods. In Routledge Handbook of Comparative Policy Analysis (pp. 57-69): Routledge.

Scott, C., \& Baehler, K. (2010). Adding value to policy analysis and advice Sydney University of New South Wales Press Ltd.

Scott, G. (2001). Public sector management in New Zealand : lessons and challenges Canberra ; Wellington, N.Z.: Centre for Law and Economics, Australian National University.

Scott, G., Bushnell, P., \& Sallee, N. (1990). Reform of the Core Public Sector: New Zealand Experience. Governance, 3(2), 138-167. doi:10.1111/j.14680491.1990.tb00112.x

Scott, G., Duignan, P., \& Faulkner, P. (2010). Improving the Quality and Value of Policy Advice: Findings of the committee appointed by the government to review expenditure on policy advice. Retrieved from https://treasury.govt.nz/sites/default/files/2011-04/report-repa-dec10.pdf

Service, C. (2009). Capability reviews: Refreshing the model of capability. Retrieved from U.K.: http://www.civilservice.gov.uk/about/improving/capability/model

Shaw, R., \& Eichbaum, C. (2011). Public policy in New Zealand: Institutions, processes and outcomes (3rd ed.). Auckland, New Zealand: Pearson Education New Zealand.

Shirley, I., Molineaux, J., Shand, D., Jackson, N., Duncan, G., \& Lewis, N. (2016). The governance of Auckland: 5 years on. Retrieved from file:///C:/Users/jahanaf/OneDrive\%20$\% 20$ Victoria\%20University\%20of\%20Wellington\%20$\%$ 20STAFF/Reference/The_Governance_of_Auckland_5_Years_On__Full_Report\%20(1).pdf

Simon, H. A. (1996). The sciences of the artificial (1st ed.). Cambridge, MA: MIT Press.

State Services Commision. (2012). Core guide 1: Understanding the performance improvement framework agency model. Retrieved from New Zealand:

State Services Commission. (1991). Review of the purchase of policy advice from government departments. In L. Dan Long Memorial (Ed.). Wellington, N.Z.]: Wellington, N.Z. : State Services Commission.

State Services Commission. (1992). The policy advice initiative: Opportunities for management. Retrieved from http://www.ssc.govt.nz/node/4707. 
State Services Commission. (1998). A better focus on outcomes through SRA networks. Occasional Paper(3).

State Services Commission. (1999a). Essential ingredients: Improving the quality of policy advice. Occasional Paper, 9.

State Services Commission. (1999b). High Fliers: Developing High Performing Policy Units. Occasional Paper(22).

State Services Commission. (1999c). Minds Over Matter: Human Resource Issues Affecting the Quality of Policy Advice. Occasional Paper, 8.

State Services Commission. (2000). Gaining through training: Developing high performing policy advisors. Retrieved from https://www.ssc.govt.nz/wp2

State Services Commission. (2008). The capability toolkit: A tool to promote and inform capability management. Retrieved from http://www.ssc.govt.nz/upload/downloadable_files/Capability-Toolkit-December2008.pdf

State Services Commission. (2013). Speech of Head of State Services and State Services Commissioner [Press release]. Retrieved from http://www.ssc.govt.nz/sscerspeech-ipanz-30july13

Teasey, S., \& Forword, P. (2012). Capability Reviews: Central Pilar in a High Performing Public Sector. Capability Reviews, June 2012, 1-14.

Teece, D. J., Pisano, G., \& Shuen, A. (1997). Dynamic capabilities and strategic management. Strategic Management Journal, 18(7), 509-533. doi:doi:10.1002/(SICI)1097-0266(199708)18:7<509::AID-SMJ882>3.0.CO;2-Z

The Treasury of New Zealand. (2008). Competency Framework. Retrieved from New Zealand:

The Treasury of New Zealand. (2012-2013). The Treasury Annual Report. Retrieved from Wellington, New Zealand:

http://www.treasury.govt.nz/publications/abouttreasury/annualreport/12-13/ar12$13 . \mathrm{pdf}$

Thissen, W. A. H., \& Walker, W. E. (2013). Introduction In W. A. H. Thissen \& W. E. Walker (Eds.), Public Policy Analysis: New Developments. New York Springer US : Imprint: Springer.

Thomas, G. (2010). How to do your case study : a guide for students / by Gary Thomas. London: London : Sage Publications Ltd.

Thomas, G. (2011). A Typology for the Case Study in Social Science Following a Review of Definition, Discourse, and Structure. Qualitative Inquiry, 17(6), 511521. doi:10.1177/1077800411409884

Tiernan, A. (2015). Craft and Capacity in the Public Service. Australian Journal of Public Administration, 74(1), 53-62. doi:10.1111/1467-8500.12134

Tiernan, A., \& Wanna, J. (2006). Competence, capacity, capability: Towards conceptual clarity in the discourse of declining policy skills. Paper presented at the Govnet International Conference, Australian National University, Canberra, Australia.

TMP Worldwide. (2018). An equal opportunity employer. Retrieved from https://www.tmp.com/

Tong, R. (1986). Ethics in policy analysis. N.J.: Prentice-Hall.

Treasury Board of Canada Sectretariat. (2011). What are MAF's objectives?

Veselý, A. (2013). Policy analysis in the central government. In M. Brans, I. Geva-May, \& M. Howlett (Eds.), Routledge handbook of comparative policy analysis (Vol. 32, pp. 199-209). New York: Taylor \& Francis.

Voyce, E. (1997). Providing free and frank advice to government: Fact or fiction. Public Sector, 20(1), 9-17. 
Wanna, J. (2005). New Zealand's Westminster trajectory: Archetypal transplant to maverick outlier. In H. Patapan, J. Wanna, \& P. Weller (Eds.), Westminster legacies: Democracy and responsible government in Asia and the Pacific (pp. 153-185). Sydney, Australia: University of New South Wales.

Washington, S., \& Mintrom, M. (2018). Strengthening policy capability: New Zealand's Policy Project (Vol. 1).

Weimer, D. L. (1998). Policy analysis and evidence: A craft perspective. Policy Studies Journal, 26(1), 114-128. doi:10.1111/j.1541-0072.1998.tb01928.x

Weimer, D. L. (2015). The Evolution of Policy Analysis in the United States: Four Sources of Demand. Foro Internacional, $55(2$ (220)), 540-575. doi:10.24201/fi.v0i0.2250

Weimer, D. L., \& Vining, A. R. (2005). Policy Analysis: Concepts and Practice (4th ed.). New Jersey, USA: Pearson Prentice Hall.

Weimer, D. L., \& Vining, A. R. (2017). Policy analysis: Concepts and practice (6th ed.). New York: Routledge, Taylor \& Francis Group.

Wesselink, A., Colebatch, H., \& Pearce, W. (2014). Evidence and policy: Discourses, meanings and practices. Integrating Knowledge and Practice to Advance Human Dignity, 47(4), 339-344. doi:10.1007/s11077-014-9209-2

Winer, M. D. (1983). Quick analysis for busy decision makers, by Robert D. Behn and James W. Vaupel. New York: Basic Books, 1982, 415 pp. Price: \$18.95. In (Vol. 3, pp. 151-151). New York.

Wolf, A. (2000). Building advice: The craft of the policy professional.

Wolf, A. (2014). Middle-range theory: A note for DGov candidates, course convenors and supervisors.

World Population Review. (2018). Auckland population 2018. Retrieved from http://worldpopulationreview.com/world-cities/auckland-population/

Wu, X., Ramesh, M., \& Howlett, M. (2015). Policy capacity: A conceptual framework for understanding policy competences and capabilities. Policy and Society, 34(3-4), 165-171. doi:10.1016/j.polsoc.2015.09.001

Wu, X., Ramesh, M., \& Howlett, M. (2018). Policy capacity: Conceptual framework and essential components In X. Wu, M. Ramesh, \& M. Howlett (Eds.), Policy capacity and governance (Vol. 34, pp. 165-171): Taylor \& Francis.

Yin, R. K. (1994). Case study research design and method (2nd ed.). Los Angeles, CA: SAGE Publications Inc.

Yin, R. K. (2014). Case Study Research Design and Method (5th ed. Vol. 30). Los Angeles Sage. 


\section{Appendices}

\section{Appendix 1 The New Zealand Government's Other Principal Economic Reforms}

A list, not exhaustive, of the main changes until March, 1989 is as follows:

- the deregulation in part or in full of banking and finance, transport, energy, telecommunications, broadcasting and a number of smaller sectors

- the lowering of the fiscal deficit from around 9\% of GDP in 1983-84 to an expected $2 \%$ in the current year

- the imposition of relatively tight monetary policy

- the removal of controls on international capital movements and the encouragement of foreign investment

- the floating of the exchange rate

- the reform of personal and company tax, including a shift towards indirect tax, a broader tax base and lower marginal tax rates for companies and individuals

- the lowering of fiscal assistance to industry

- the lowering of border protection, including moves in the direction of a common market with Australia under the CER agreement

- the transformation of a number of government trading activities into stateowned corporations, and the partial privatisation of some government assets

- the reform of local government

- the reform of social services such as health, education and welfare

- the privatisation of many state-owned assets, partly as means of reducing the government's debt

- the reform of the central bank's role and status, requiring it to concentrate on achieving price stability within legislative guidelines

- the review of property rights to the Maori people in formal recognition of certain obligations under the Treaty of Waitangi

Source: Scott \& Gorringe, 1989, Appendix 1 


\section{Appendix 2 Interview Consent Form, Information Sheet and Guide \\ TE WHARE WĀNANGA O TE OFOKO O TE TKA A MĀU

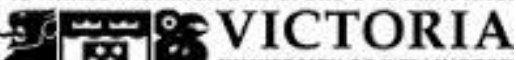 \\ c. $\div$ UNI}

Consent to Participate in Research: Interviews

\section{Policy Capability Initiatives in the New Zealand Public Sector}

This consent form outlines my rights as a participant in the research on Policy Capability Initiatives in the New Zealand Public Sector by Khandaker Aftab Jahan, PhD Candidate, School of Government, Victoria University of Wellington.

- I agree to take part in this research. I have been given and have understood an explanation of this research project. I have had an opportunity to ask questions and have them answered to my satisfaction.

I understand that:

- I may withdraw myself (or my interview data) from this project at any time before the analysis of data $\left(31^{\text {st }}\right.$ December, 2016) without having to give reasons. Withdrawn data will be immediately destroyed and not used in any subsequent analysis;

- The interview will be audio-recorded, on the understanding that Khandaker Aftab Jahan will make detailed notes, transcribe and then delete the recording;

- Any information I provide will be kept confidential to the researcher and supervisors;

- The information I provide will not be used for any purpose not disclosed on the information sheet, nor will it be released to others, without my written consent;

- The published results will not use my name, but, where necessary for the thesis aims, opinions may be attributed to me by role;

- Five years after the completion of the doctoral project, all raw data will be destroyed.

Signed:

Name of the participant:

Organization/Address: Date:

$\square$ I would like to receive a summary of the interview.

$\square$ I would like to have the link to the e-version of the thesis.

I can be contacted at the following email address

You may scan and email a signed, completed form to aftab.jahan@vuw.ac.nz or sign at the time of the interview. 


\section{Information Sheet: Interviews}

\section{Policy Capability Initiatives in the New Zealand Public Sector}

\section{Researcher: Khandaker Aftab Jahan, School of Government, Victoria University of Wellington}

I am a PhD student in School of Government, Victoria University of Wellington. As part of this degree, I am undertaking a research project leading to a thesis. The project I am undertaking is examining how central government and agency-led initiatives have influenced agency practice in developing policy advice and efforts to enhance policy capability in the New Zealand public sector. I work as a mid-level government official in Bangladesh. As a researcher and a practitioner from another country, I am interested in where practice and theory meet and I want to explore and understand the consequences of the policy capability initiatives in New Zealand.

This research project has already received approval from the Victoria University Human Ethics Committee.

This information sheet is designed to help you decide if you wish to take part in the study. It is to be read in conjunction with the attached consent form.

1. What is the purpose of the study?

Both central government agencies and line agencies have taken policy capability enhancing initiatives to develop high quality policy advice. The purpose of my research is to explore how these initiatives have influenced agency practice in developing policy advice and efforts to enhance policy capability. The specific objectives of my research are: understanding how different initiatives have influenced the process of developing policy advice; identifying how these initiatives have affected the quality of policy advice and revealing the perceived consequences of these initiatives in building policy capability.

2. Why have you been invited to participate in this study?

To achieve the specific objectives of the study, I seek views from relevant experts and practitioners with experience or knowledge on policy capability enhancing initiatives. You have been identified or nominated as someone with a suitable level of experience and standing who could contribute valuable insights to this project.

3. What does this study involve?

This study involves a face-to-face meeting of about one hour, during which you will take part in a semi-structured and open-ended interview intended to explore your views on the following themes: 
- Policy capability enhancing initiatives, policy process and the wider environment and actors involved in developing policy advice.

- The current process of developing policy advice and the quality of policy advice.

- The consequences of the policy capability enhancing initiatives on further improving policy capability of agencies.

The interview will be audio-recorded. It is important that you understand that your involvement in this study is voluntary. You are not required to answer a question if you do not want to. You may stop an interview, at any time, without providing an explanation. You may also withdraw data from the study anytime until the analysis is completed ( $30^{\text {th }}$ June, 2016).

4. How will your confidentiality be protected?

The final report will focus on the responses to themes. I will not use your name. No information on your personal characteristics (age, gender etc.) will be collected or used in any way (unless you refer to such details in the interview). I will, however, report some information attributable to your role, where this is necessary for meeting my study objectives. If your role is unique, although I will not use your name, you will be identifiable by your role. In all other cases, care will be taken in such reporting so that a reader will be unlikely to identify you, even though some informed readers may be able to guess your identity. You will be offered a summary of your interview.

All of the data will be kept securely in my office or in password-protected computers until the conclusion of the doctoral dissertation and only available to me and my supervisors. The information will then be securely stored for an additional 5 years, in accordance with standard practices to ensure the integrity of subsequently published research.

6. How will the results be used?

The findings will contribute to a PhD dissertation. Subsequently, this information may be used for published articles and other academic purposes.

Participants will be offered a summary and a link to the final PhD dissertation.

\section{What next?}

If, after reading this information, you wish to participate, you can let me know by email: aftab.jahan@vuw.ac.nz. I will then arrange a time and venue convenient to you. The consent form can be completed now or at the interview.

If you have any further questions or would like to receive further information about the project, please contact me at 4639591 or aftab.jahan@vuw.ac.nz or my supervisors Professor Claudia Scott, at 463 5377, claudia.scott@vuw.ac.nz and Dr. Amanda Wolf at 463 5712, amanda.wolf@vuw.ac.nz of School of Government, Victoria University of Wellington. 


\section{Interview Guide}

The following questions* are prepared for my own guidance to make the engagement with the interviewees more effective. The semi-structured open-ended face-to-face interviews will be conducted in a less-structured way. I have attempted to classify the interview questions into different themes relevant for my research. The sub-questions for each theme are examples only. The following questions listed below are for policy professionals involved in policy development. Similar questions on the same themes but from different perspectives will be asked to the interviewees who have different roles such as the Minister and Chief Executives and professions such as the independent consultants.

\section{Guide questions for Professionals Involved in Policy Process}

\section{Process for Policy Development}

1. What is the current process for policy development?

a. What is the current process for managing the development of policy analysis and the delivery of policy advice?

b. What practices do you use to identify and manage risks in the development and delivery of policy analysis and advice? c. How do you come to know about the issue of interest?

Quality Assurance for Policy Advice

2. How do you ensure high quality of policy analysis and advice? a. What is it meant by 'quality' in your opinion? Who should value it?

b. What does it mean to the Minister?

c. How do you come to know how the Minister assesses the quality of policy advice?

d. How do you incorporate evidence in your policy analysis?

\section{Policy Capability Enhancing Initiatives}

3. How do policy capability enhancing initiatives have further enhanced your skill in developing high quality policy advice?

\begin{tabular}{l}
\hline \\
\hline
\end{tabular}

d.th

a. How do policy capability enhancing initiatives have influenced your practice of developing policy advice?

b. How effective these initiatives were to alter or develop or improve your process of developing policy advice?

c. Which initiatives, in your opinion, worked well and which did not and why?

$d$. What else in your opinion should be introduced that would enhance the policy capability of the policy professionals?

*The interview guide is influenced by the questionnaire of Review of Expenditure on Policy Advice (G. Scott et al., 2010, p. 75) 